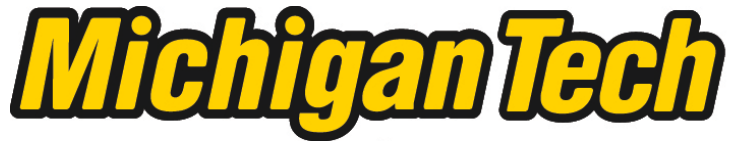 \\ Michigan Technological University Create the Future Digital Commons @ Michigan Tech
}

Dissertations, Master's Theses and Master's Reports - Open

Dissertations, Master's Theses and Master's

Reports

2013

Development of Vapor Deposited Silica Sol-Gel Particles for a

Bioactive Materials System to Direct Osteoblast Behavior

Katherine Lynn Snyder

Michigan Technological University

Follow this and additional works at: https://digitalcommons.mtu.edu/etds

Part of the Biomedical Engineering and Bioengineering Commons

Copyright 2013 Katherine Lynn Snyder

\section{Recommended Citation}

Snyder, Katherine Lynn, "Development of Vapor Deposited Silica Sol-Gel Particles for a Bioactive Materials System to Direct Osteoblast Behavior", Dissertation, Michigan Technological University, 2013.

https://doi.org/10.37099/mtu.dc.etds/624

Follow this and additional works at: https://digitalcommons.mtu.edu/etds

Part of the Biomedical Engineering and Bioengineering Commons 


\title{
DEVELOPMENT OF VAPOR DEPOSITED SILICA SOL-GEL PARTICLES FOR A BIOACTIVE MATERIALS SYSTEM TO DIRECT OSTEOBLAST BEHAVIOR
}

\author{
By \\ Katherine Lynn Snyder \\ A DISSERTATION \\ Submitted in partial fulfillment of the requirements for the degree of \\ DOCTOR OF PHILOSOPHY \\ In Biomedical Engineering \\ MICHIGAN TECHNOLOGICAL UNIVERSITY \\ 2013 \\ (C) 2013 Katherine L. Snyder
}


This dissertation has been approved in partial fulfillment of the requirements for the Degree of DOCTOR OF PHILOSOPHY in Biomedical Engineering.

Department of Biomedical Engineering

Dissertation Advisor: $\quad$ Rupak Rajachar, PhD

Committee Member: $\quad$ Seth Donahue, $P h D$

Committee Member: $\quad$ Ryan Gilbert, PhD

Committee Member: Chang K. Choi, PhD

Department Chair: $\quad$ Sean Kirkpatrick, PhD 
TABLE OF CONTENTS .........................................................................................ii

LIST OF FIGURES .................................................................................................

LIST OF TABLES .............................................................................................................. vii

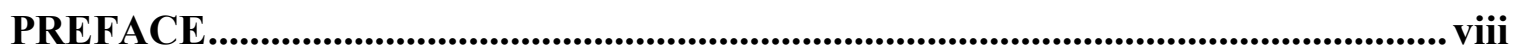

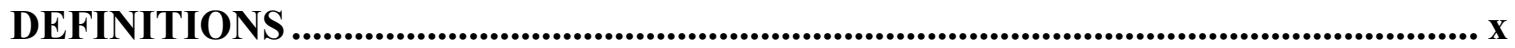

ABBREVIATIONS .......................................................................................................... xii

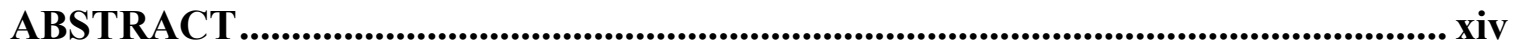

CHAPTER ONE: INTRODUCTION ............................................................... 1

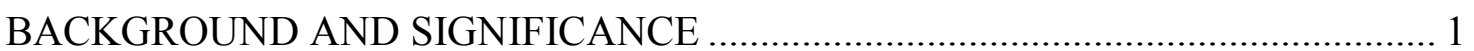

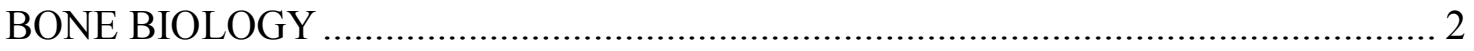

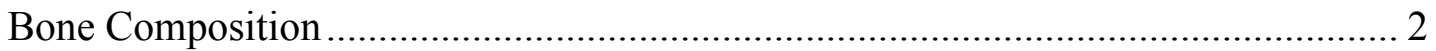

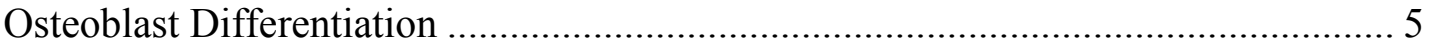

TREATMENT OF DAMAGED TISSUES ………….......................................... 7

Biologic and Synthetic Grafts ...................................................................... 7

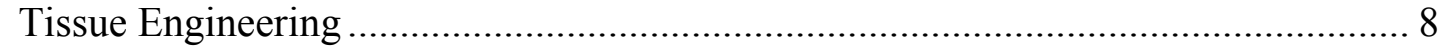

MATERIAL PROPERTIES INFLUENCE CELL BEHAVIOR ................................. 8

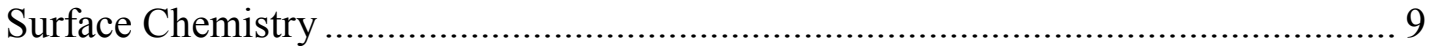

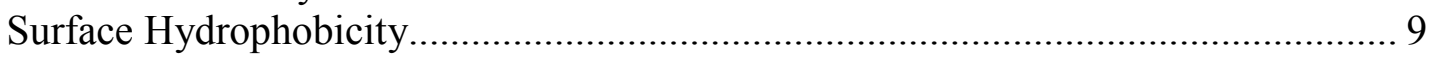

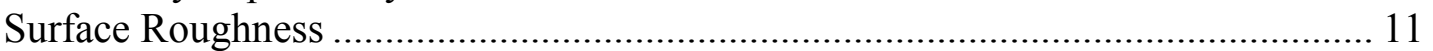

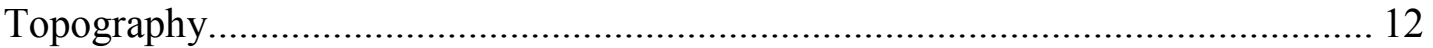

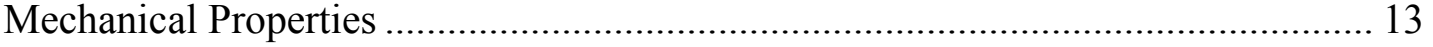

SOL-GEL METHODS FOR GENERATING BIOACTIVE GLASSES …………...... 13

Silica Sol-Gel Bioactivity and Mineralization ........................................................ 16

ION INFLUENCE ON OSTEOBLAST BEHAVIOR …………................................ 19

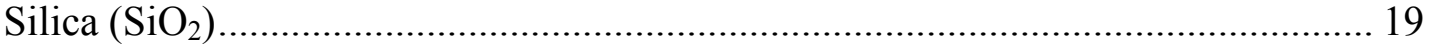

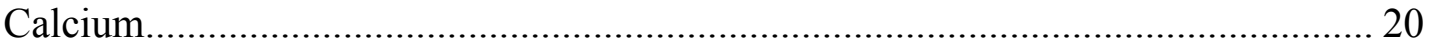

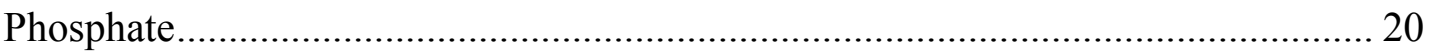

NEBULIZER BASED SOL DEPOSITION OF SOL PARTICLES ………………..... 21

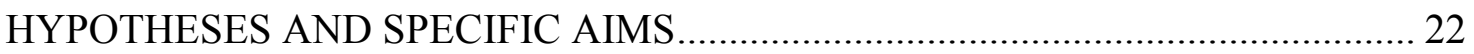

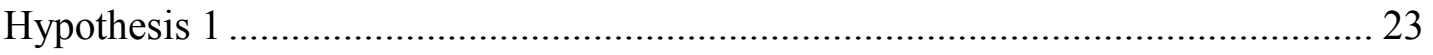

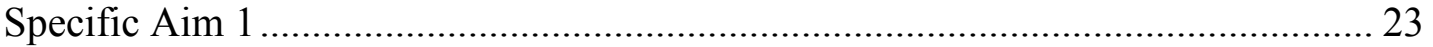

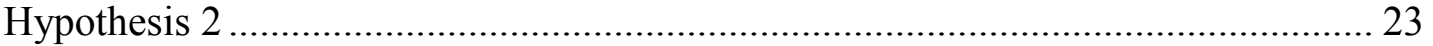

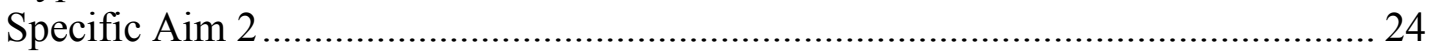

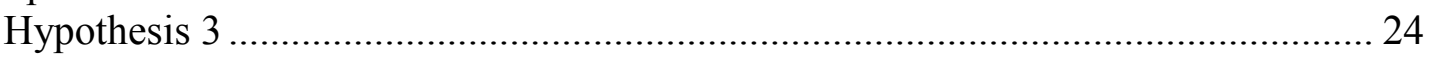

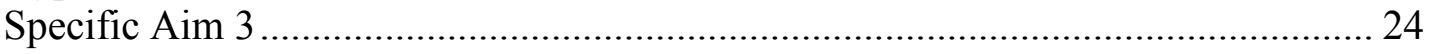

Summary of Dissertation Chapters................................................................... 24

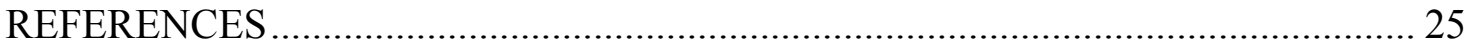




\section{CHAPTER TWO: DEVEOLOPMENT OF VAPOR DEPOSITED SOL-GEL}

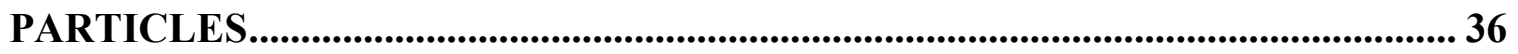

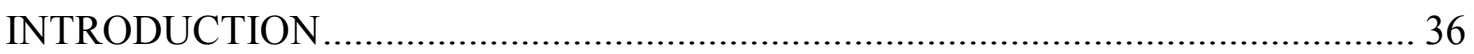

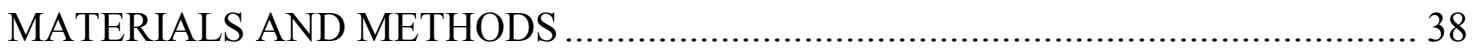

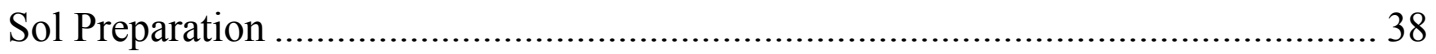

Vaporization System and Deposition .................................................................... 39

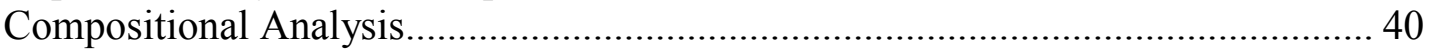

Sol Formulation and Manufacturing Parameters..................................................... 40

Morphology and Size Distribution ..................................................................... 40

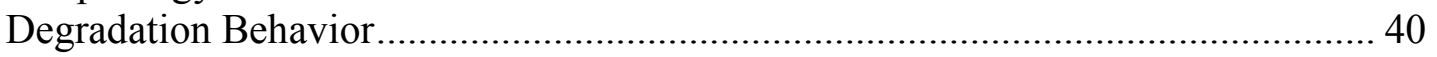

Surface Hydrophobicity and Roughness ................................................................ 41

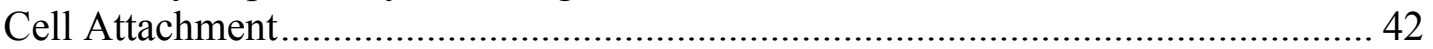

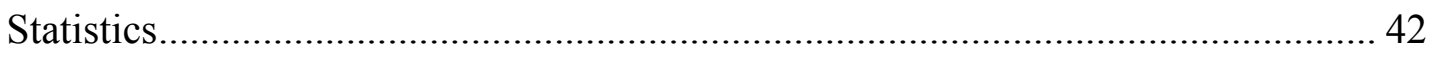

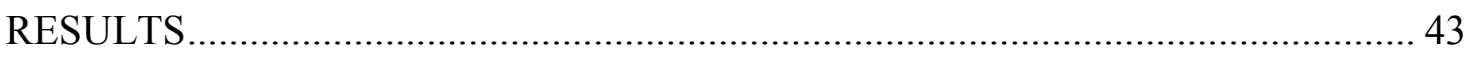

Effect of Formulation and Manufacturing Parameters on Particle Morphology and

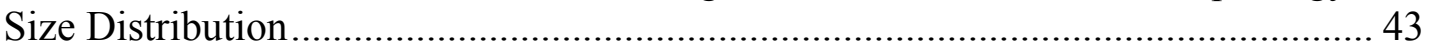

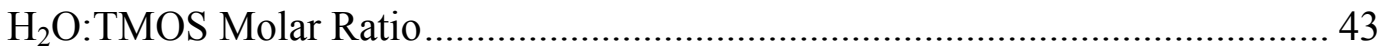

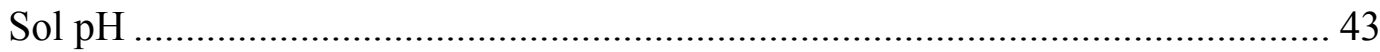

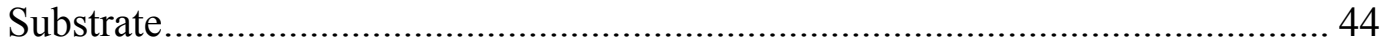

Effect of Formulation Parameters on Particle Degradation Behavior........................ 48

Effect of Particle Deposition on Substrate Surface Character.................................... 49

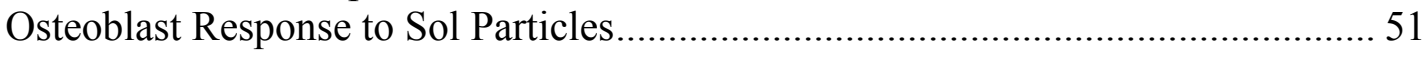

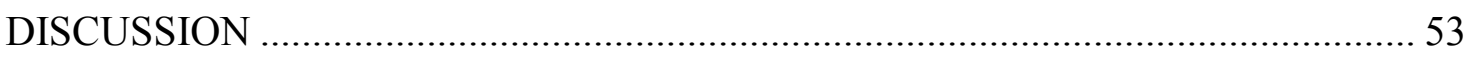

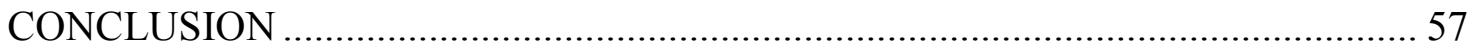

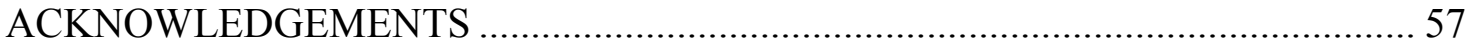

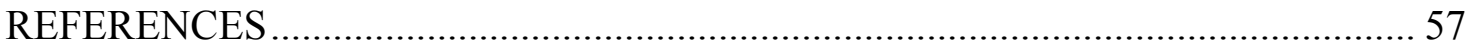

CHAPTER THREE: CALCIUM-PHOSPHATE SILICA SOL PARTICLES FOR BIOACTIVE SURFACE MODIFICATION ............................................................ 62

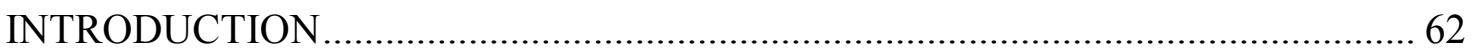

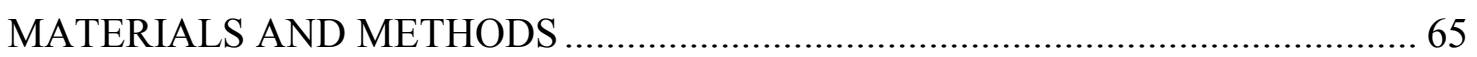

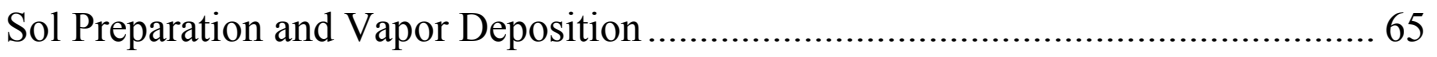

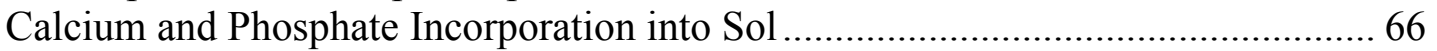

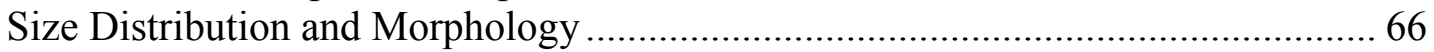

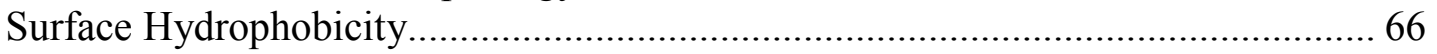

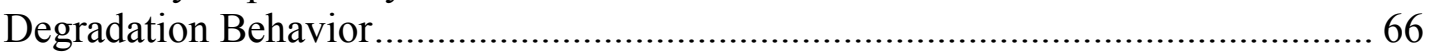

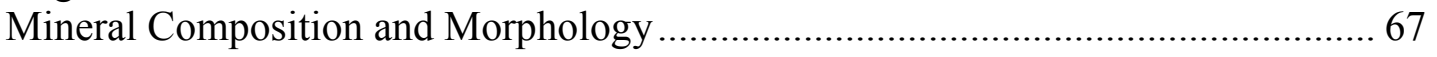

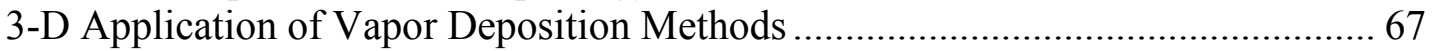

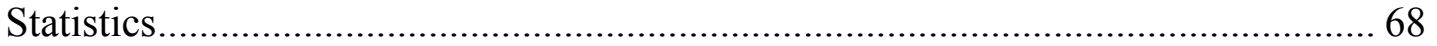

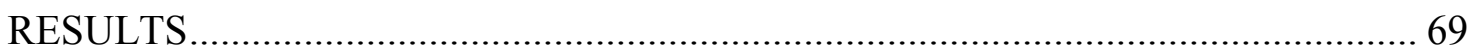

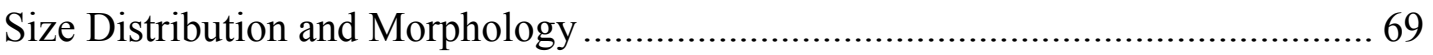

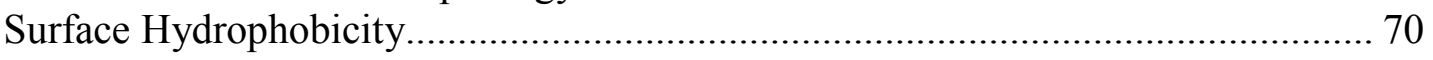




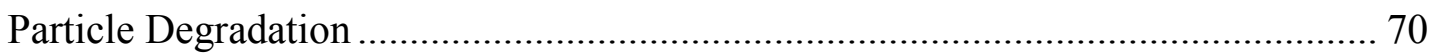

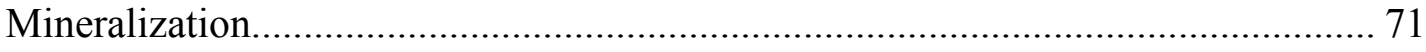

3-D Application of Vapor Deposition Methods ........................................................ 71

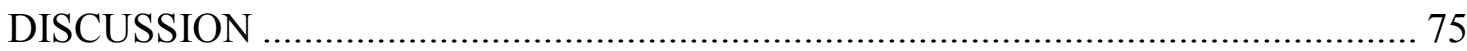

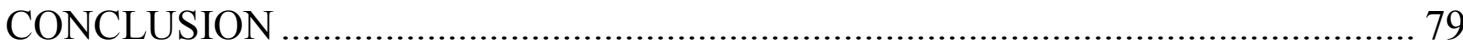

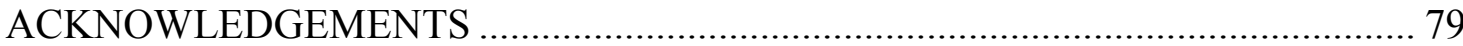

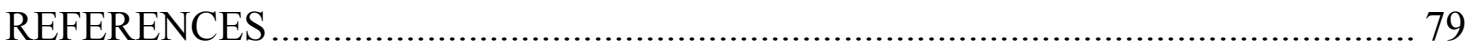

CHAPTER FOUR: OSTEOBLAST RESPONSE TO CALICIUM-PHOPHATE SOL PARTICLES........................................................................................................ 83

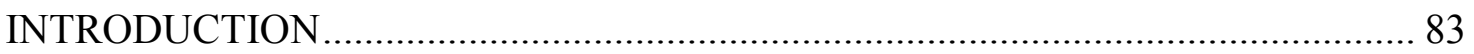

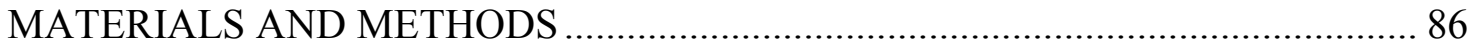

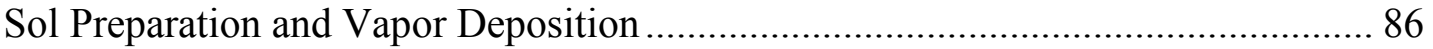

Calcium and Phosphate Incorporation into Sol ..................................................... 86

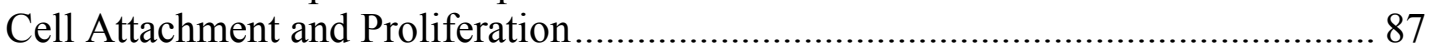

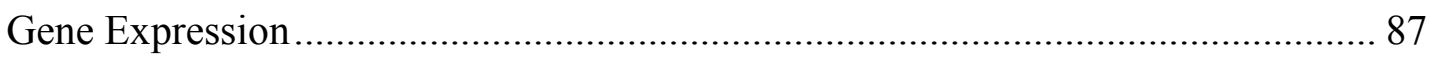

Mineralization- Alizarin Red and Alkaline Phosphatase ………............................. 88

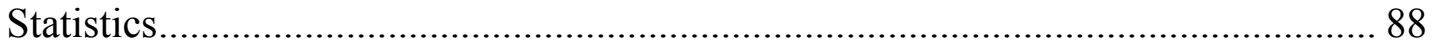

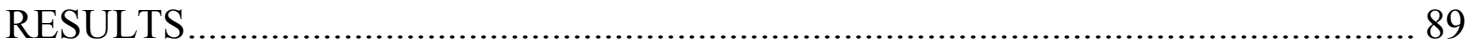

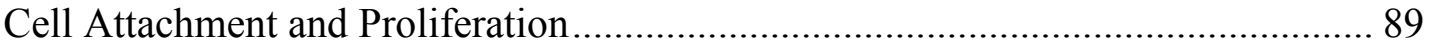

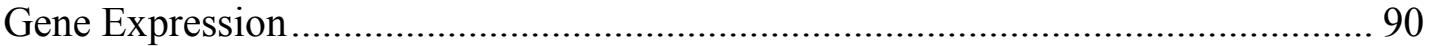

Mineralization Alizarin Red and ALP Staining …………..................................... 95

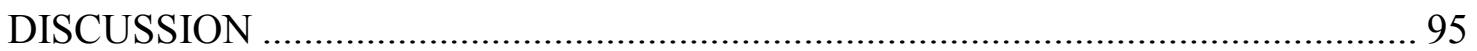

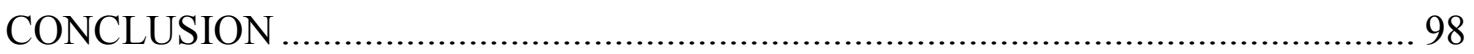

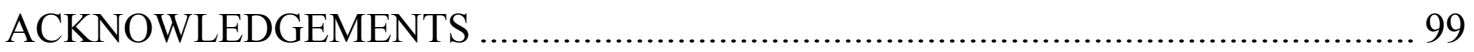

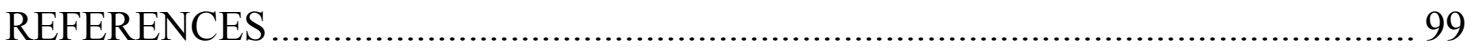

CHAPTER FIVE: CONCLUSIONS........................................................................ 107

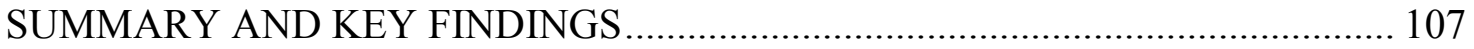

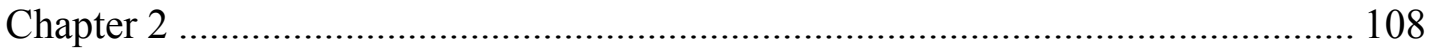

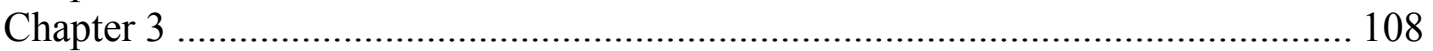

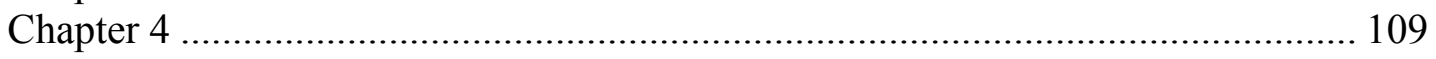

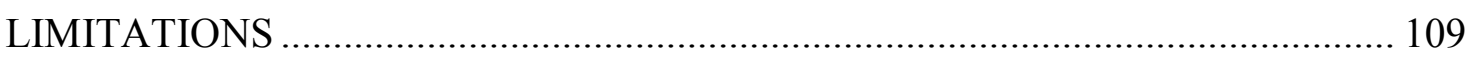

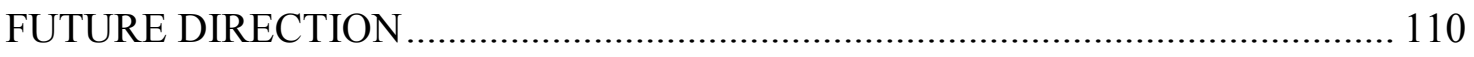

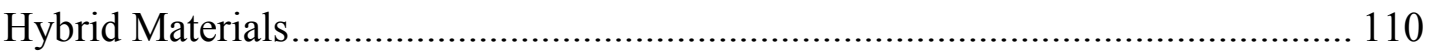

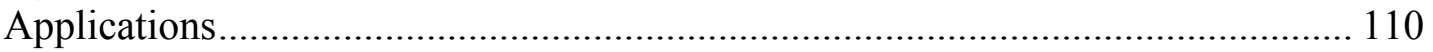

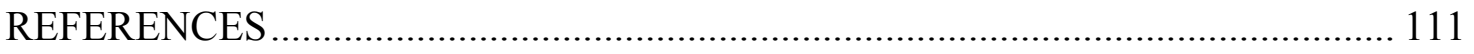

APPENDIX A: COPYRIGHT AGREEMENTS ........................................................ 115 
Figure 1.1 Structure of compact and spongy bone and apatite formation................4

Figure 1.2 Osteoblast differentiation................................................

Figure 1.3. Contact angle measurements.......................................... 10

Figure 1.4. Surface roughness measurements................................... 12

Figure 1.5. Stages involved in synthesis of TMOS-based silica sol-gel.................16

Figure 1.6. Overview of silica sol-gel bioglass bioactivity..........................18

Figure 1.7. Summary of biological effects due to ionic dissolution products of

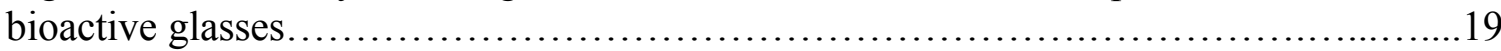

Figure 1.8. Schematic of vapor deposition system................................22

Figure 2.1. Schematic of vaporization chamber and formation of

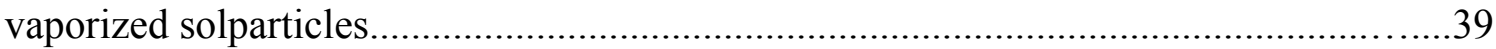

Figure 2.2. Effect of $\mathrm{H}_{2} \mathrm{O}$ :TMOS on particle morphology and size distribution.........45

Figure 2.3. Effect of solution $\mathrm{pH}$ on particle morphology and size distribution..........46

Figure 2.4. Effect of substrate on particle morphology and size distribution..............47

Figure 2.5. Effect of deposition time and $\mathrm{pH}$ on degradation of sol particles.............48

Figure 2.6. Effect of sol particles on surface wettability and roughness................50

Figure 2.7. Osteoblast response to sol particles................................52

Figure 3.1. Network modifiers.................................................65

Figure 3.2. Application of vapor deposition methods................................68

Figure 3.3. Morphology and size distribution of vapor deposited $\mathrm{Ca} / \mathrm{P}$ sol particles......69

Figure 3.4. Surface hydrophobicity of vapor deposited $\mathrm{Ca} / \mathrm{P}$ sol particles............... 70

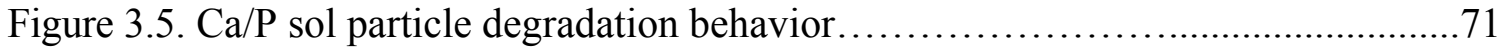

Figure 3.6. Apatite-like mineral growth with $\mathrm{Ca} / \mathrm{P}$ sol particles.........................73

Figure 3.7. Apatite-like mineral growth of 3-D porous fibrin scaffolds.................74

Figure 3.8. Size distribution and morphology of vapor deposited particles

containing no additional ions.............................................. 76

Figure 3.9. Examples of $\mathrm{Ca} / \mathrm{P}$ sol particles generated from higher

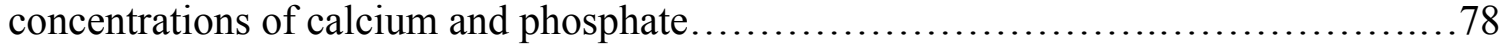

Figure 4.1, Diagram of interaction of bone tissue and cells with a material at

different topographical scales................................................. 86

Figure 4.2. Osteoblast attachment in response to $\mathrm{Ca} / \mathrm{P}$ sol particles...................91

Figure 4.3. Osteoblast Ki-67 expression in response to $\mathrm{Ca} / \mathrm{P}$ sol particles..............92

Figure 4.4. Osteoblast gene expression in response to $\mathrm{Ca} / \mathrm{P}$ sol particles................94

Figure 4.5, Mineralization of osteoblasts in response to $\mathrm{Ca} / \mathrm{P}$ sol particles.............95

Figure 4.6. Schematic of an inorganic-organic hybrid material......................98

Figure 5.1.Vapor deposition onto electrospun fibers...........................111 


\section{LIST OF TABLES}

Table 3.1. Overview of apatite formation on bioglass material upon exposure

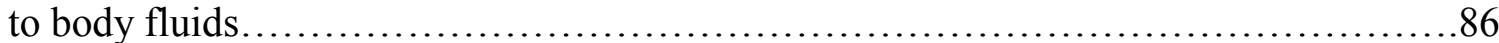

Table 4.1. Genes and primer sequences used in PCR reactions........................89

Table 4.2. Gene expression of MC3T3 osteoblasts cultured with $\mathrm{Ca} / \mathrm{P}$ sol particles.....93 
This dissertation describes the development of vapor deposited sol-gel particles for use in directing osteoblast behavior and their potential to be used in orthopedic tissue engineering constructs. Several chapters in this dissertation are in preparation for publication and/or are already published in scientific journals.

Chapter 1 is a literature review, with background information on bone biology and osteoblast differentiation, approaches to treating damaged bone tissue, the effect of biomaterial properties on osteoblast behavior, and the use of sol-gels as biomaterials. It also includes the rationale, hypotheses, and specific aims for this dissertation.

Chapter 2 covers the development and characterization of a silica sol-gel vapor deposition system that can be used to tailor the material properties of substrates. The data in this chapter is published in the Journal of Biomedical Research Part A (2012). I performed the majority of the research, with contributions by Hallie Holmes, Michael VanWagner, and Natalie Hartman on the degradation, contact angle and roughness analyses. Rupak Rajachar provided input and was a mentor on experimental design, analysis, and paper editing. However, the conclusions presented are my own, and I am the main author for this publication.

Chapter 3 covers the characterization of particle properties when calcium and phosphate ions are incorporated. The data in this chapter is being prepared for publication. I performed the majority of the research with contributions by Hallie Holmes the contact angle analysis. Rupak Rajachar provided input and was a mentor on experimental design, analysis, and paper editing. However, the conclusions presented are my own, and am the main author for this publication. The data in this chapter is being prepared for submission to the Journal of Biomedical Matierals Part A.

Chapter 4 assesses the response of osteoblasts to vapor deposited calciumphosphate sol-gel particles. The data in this chapter is being prepared for publication. I performed the research and am the main author for this publication. Rupak Rajachar provided input and was a mentor on experimental design, analysis, and paper editing The data in this chapter is being prepared for submission to the Journal of Biomedical Matierals Part A. 
Chapter 5 is a summary of all findings and conclusions reached in this dissertation. 
Alkaline Phosphatase

Collagen

Cyclophilin

Hydroxyapatite

in vitro

in vivo

MC3T3-E1

Osteoblast
Enzyme localized on cell membranes found in all tissues and in high concentration in bone, kidneys, intestines, biliary ducts, plasma, and teeth that hydrolyzes phosphate esters liberating inorganic phosphate. In bone, used as a marker of osteoblast differentiation and bone remodeling

Structural protein found in connective tissues. In bone tissues, it is the main organic constituent and is secreted by osteoblasts

Protein found in all cells exhibit peptidyl-prolyl cis-trans isomerase (PPIase) activity which facilitates protein folding

The main inorganic constitute of bone and tooth enamel $\left(\mathrm{Ca}_{10}\left(\mathrm{PO}_{4}\right)_{6}(\mathrm{OH})_{2}\right)$

Procedure that takes place in a controlled environment outside of a living organism (i.e., laboratory, test tube, culture dish)

Procedure that takes place inside a living organism

An immortalized cell line of osteoblast precursors derived from mice

Cell that secretes bone matrix and is responsible for the formation of bone 
Osteocalcin

Osteopontin

Runx2

Ubiquitin
Calcium-binding noncollagenous bone matrix protein secreted by osteoblasts that is involved in regulating mineralization in the bones and teeth and is used as an osteoblast differentiation marker

Calcium-binding noncollagenous bone matrix protein secreted by osteoblasts that plays a role in bone remodeling and various immunological functions and is used as an osteoblast differentiation marker (also known as bone sialoprotein 1, BSP-1)

Key transcription factor associated with differentiation of osteoblasts (also known as core-binding factor subunit alpha-1, Cbfa1)

Small regulatory protein present in almost all cells that attaches to proteins tags them for proteolysis 


\section{ABBREVIATIONS}

a-MEM

AFM

ALP

ANOVA

Ca

cDNA

COLI

DAPI

DMEM

DTT

ECM

EDS.

FBS

FE-SEM

FTIR

GOI

HA

HCl

HK

NBF

OCN

OPN

$\mathbf{P}$

$\mathbf{P} / \mathbf{S}$

PBS

PCR

PLLA

PS

RNA
Alpha-modified minimal essential medium

Atomic force microscopy

Alkaline phosphatase

Analysis of variance

Calcium

Complementary deoxyribonucleic acid

Type I collagen

4',6-diamidino-2-phenylindole

Dulbecco's modified eagle medium

Dithiothreitol

Extracellular matrix

Energy dispersive X-ray spectrometry

Fetal bovine serum

Field emission scanning electron spectroscopy

Fourier transform infrared spectroscopy

Genes of interest

Hydroxyapatite

Hydrochloric acid

Housekeeping genes

Neutral buffered formalin

Osteocalcin

Osteopontin

Phosphate

Penicillin-streptomycin

Phosphate buffered saline

Polymerase chain reaction

Poly-L-lactide acid

Polystyrene

Ribonucleic acid

xii 
Runx2

SEM

TCPS

TEP

TMOS

Tris-HCl

TRITC
Runt-related transcription factor 2

Standard error of the mean

Tissue-culture treated polystyrene

Triethyl phosphate

Tetramethyl orthosilicate

Tris(hydroxymethyl)aminomethane-hydrochloric acid

Tetramethyl rhodamine iso-thiocyanate 
Tissue engineering and regenerative medicine have emerged in an effort to generate replacement tissues capable of restoring native tissue structure and function, but because of the complexity of biologic system, this has proven to be much harder than originally anticipated. Silica based bioactive glasses are popular as biomaterials because of their ability to enhance osteogenesis and angiogenesis. Sol-gel processing methods are popular in generating these materials because it offers: 1) mild processing conditions; 2) easily controlled structure and composition; 3) the ability to incorporate biological molecules; and 4) inherent biocompatibility. The goal of this work was to develop a bioactive vaporization system for the deposition of silica sol-gel particles as a means to modify the material properties of a substrate at the nano- and micro- level to better mimic the instructive conditions of native bone tissue, promoting appropriate osteoblast attachment, proliferation, and differentiation as a means for supporting bone tissue regeneration. The size distribution, morphology and degradation behavior of the vapor deposited sol-gel particles developed here were found to be dependent upon formulation $\left(\mathrm{H}_{2} \mathrm{O}\right.$ :TMOS, $\mathrm{pH}, \mathrm{Ca} / \mathrm{P}$ incorporation) and manufacturing (substrate surface character, deposition time). Additionally, deposition of these particles onto substrates can be used to modify overall substrate properties including hydrophobicity, roughness, and topography. Deposition of $\mathrm{Ca} / \mathrm{P}$ sol particles induced apatite-like mineral formation on both two- and three-dimensional materials when exposed to body fluids. Gene expression analysis suggests that $\mathrm{Ca} / \mathrm{P}$ sol particles induce upregulation osteoblast gene expression (Runx2, OPN, OCN) in preosteoblasts during early culture time points. Upon further modification-specifically increasing particle stability-these $\mathrm{Ca} / \mathrm{P}$ sol particles possess the potential to serve as a simple and unique means to modify biomaterial surface properties as a means to direct osteoblast differentiation. 


\section{CHAPTER ONE: INTRODUCTION}

\section{BACKGROUND AND SIGNIFICANCE}

Each year millions of people suffer from tissue loss or failure making it one of the most frequent, devastating, and costly problems in human healthcare. Specifically, for bone, $5-10 \%$ of the six million bone fractures that occur annually in the U.S. result in nonunions or delayed unions indicating there is a growing need for the development of material substitutes and therapies to help overcome this problem [1]. Consequently, the fields of tissue engineering and regenerative medicine have emerged in an effort to incorporate the fundamentals of engineering (mechanics and materials) and biological functions (cell and gene products) to generate replacement tissues capable of restoring native tissue structure and function [2]. Because of the complexity of biologic systems, it has proved to be much harder to design substitute matrices for cells than originally anticipated. Cells are affected by the chemical and molecular composition of the implanted material, as well as by its physical (i.e. topography and mechanical) properties. Development of materials that utilize the relationships between cells and material chemical, physical, and mechanical properties may provide a better platform for tissue regeneration [3]. Silica sol-gel bioactive glasses have become increasingly popular for use in tissue engineering materials due to their simple processing methods into a variety of shapes, the ease of control over composition and structure, and inherent biocompatibility [4-7]. The goal of this work was to develop and characterize a bioactive silica sol-gel surface modification system that can be used to coat materials in order to tailor their material properties at the nano- and micro- level to better mimic the instructive conditions of native bone tissue, promoting appropriate osteoblast attachment, proliferation, and differentiation as a means for supporting bone tissue regeneration. 


\section{BONE BIOLOGY}

\section{Bone Composition}

Bone is a composite material composed of roughly $22-35 \%$ organic phase, 60$70 \%$ inorganic phase, and 5-8\% water (Figure 1.1A). The organic phase is made up of $90 \%$ type I collagen fibers with the other 5\% consisting of glycoproteins, and glycosaminoglycans (GAGs). The inorganic phase is composed primarily of hydroxyapatite (HA) crystals $\left(\mathrm{Ca}_{10}\left(\mathrm{PO}_{4}\right)_{6}(\mathrm{OH})_{2}\right)$. There are two theories of how this mineral is incorporated into the collagen fibers: (1) direct nucleation and (2) matrix vesicle (MV) mediated matrix mineralization [8-12]. In direct nucleation, stable mineral droplets of calcium phosphate cluster-bipolymer complexes bind to regions on collagen fibers and diffuse through the fibrils where they solidify into an amorphous mineral, which is then transformed into orientated apatite crystals in the direction of the collagen fibers (Figure 1.1B) [8]. MV mediated matrix mineralization is based on calcium phosphate crystals contained within matrix vesicles that are produced by osteoblasts. Suggested mechanisms for this include: (i) matrix vesicles regulate ion concentrations, leading to the formation of soluble molecular species that initiate mineral formation in the collagen fibrils, (ii) matrix vesicles regulate ion compositions leading to the formation of intravesicular apatite crystals that leave the vesicle and initiate mineralization; and (iii) matrix vesicles directly associate with the collagen to initiate mineralization (Figure 1.1C) $[8,13]$. The rigid HA crystals provide the compressive strength of bone, while the collagen fibers contribute to bone's high tensile properties. Embedded in this matrix are osteoblasts, osteocytes, and osteoclasts [14-17]. Cortical bone has a porosity of 5-10\% and its structural unit is the osteon (also called haversian systems), composed of concentric layers of bone (lamellae). Lacunae are small cavities within the bone matrix that contain osteocytes. Micro-scale canals called canaliculi radiate outward from a central canal (Haversian canal) and connect lacunae to one another, allowing for nutrient dispersal. Haversian canals are located in the center of each osteon and contain blood vessels and never fibers. At the periphery of each osteon is a cement line, an area of ground substance composed mostly of GAGs. Collagen fibers and canaliculi do not cross the cement line [18]. Osteons are arranged longitudinally, making the properties of 
cortical bone anisotropic. In the longitudinal direction, bone strength varies from 79$151 \mathrm{MPa}$ in tension and 131-224MPa in compression. The moduli ranges from 17-20GPa in both tension and compression [14]. Trabecular bone is more porous that cortical bone (50-90\%) and is made up of trabeculae, which are most often characterized as rod or plate like structures. Trabeculae consist of lamellae containing osteocytes in lacunae connected by canaliculi. However, unlike cortical bone, the lamellae are not concentrically arranged and do not contain central canals with blood vessels [18]. Trabecular bone also exhibits anisiotropy. Because of the increased porosity, trabecular bone has lower ultimate strength and modulus of elasticity, but can withstand greater strains than cortical bone [19]. 
Compact Bone \& Spongy (Cancellous Bone)

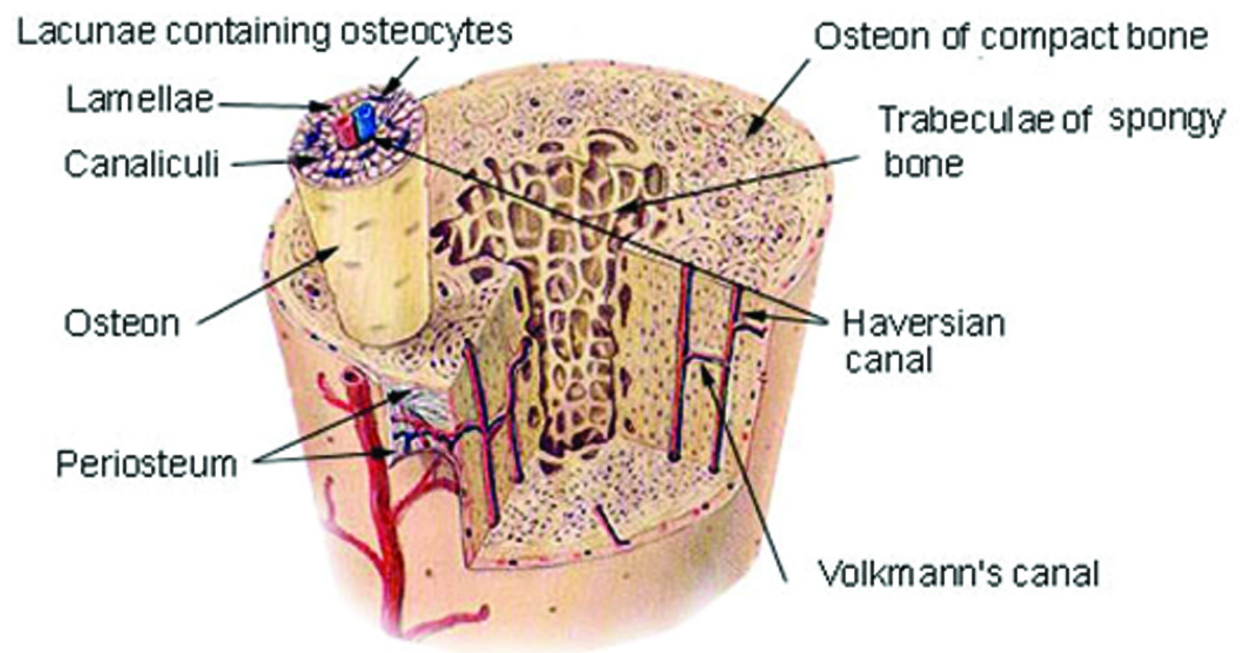

(B)
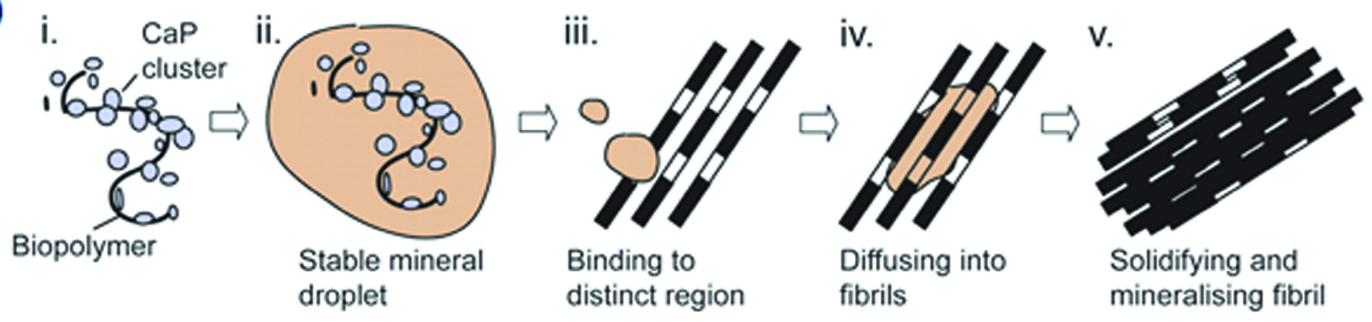

(C)

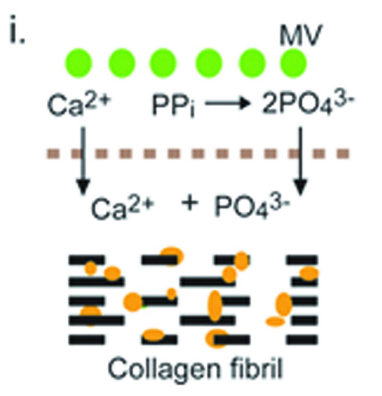

ii.

$\mathrm{Ca}^{2+} \mathrm{Ca}^{2+}$

iii.

$$
\mathrm{PPi}_{\mathrm{i}} \rightarrow 2 \mathrm{PO}_{4}{ }^{3-}
$$
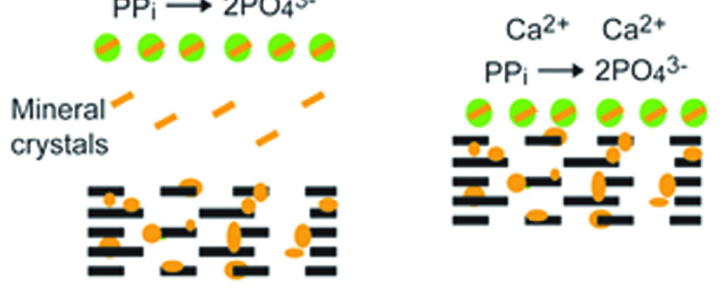

Figure 1.1 Structure of compact and spongy bone and apatite formation. (A) Cortical bone is organized into osteons composted of concentric lamellae around the Haversian canal with lacunae containing osteocytes connected by canaliculi. Cacellous bone is composed of more porous trabeculae. From SEER Training Module [20]. Theories of collagen mineralization in bone include: (B) direct nucleation of $\mathrm{CaP}$ crystals [(i) CaP clusters form complexes with biopolymer to form (ii) stable mineral droplets. (iii) The droplets bind to regions of collagen fibers and (iv) form an amorphous phase by diffusing through the fibrils. (iv) The amorphous phase becomes orientated apatite crystals in the direction of the collagen fibers] and (C) MV mediated matrix mineralization [(i) matrix vesicles regulate ion concentrations, leading to the formation of soluble molecular species that initiate mineral formation in the collagen fibrils, (ii) matrix vesicles regulate ion compositions leading to the formation of intravesicular apatite crystals that leave the vesicle and initiate mineralization; and (iii) matrix vesicles directly associate with the collagen to initiate mineralization]. From Chai et al. with permission (see Appendix A) [12]. 


\section{Osteoblast Differentiation}

Osteoblasts descend from mesenchymal stem cells, which can differentiate into many different cell types including adipocytes, myoblasts, fibroblasts, chondrocytes, and osteoblasts. The process of differentiation of these pluripotent cells into osteoblasts is complex and controlled by morphogens, hormones, growth factors cytokines, matrix proteins, and the expression of lineage-specific master transcription regulators and their co-regulatory proteins [21]. The differentiation of osteoblasts is regulated by the master transcription factor Runx2, with the help of other transcription factors including but not limited to osterix, ATF4, SMADs, NFATc1/calcineurin, Twist, AP-1, and TCF/LEF [22]. These transcription factors have many different signaling systems including the Wnt/ $\beta$ catenin, the BMP/TGF $\beta$, the Notch, the Hedgehog, and the FGF signaling pathways [21].

Following a lineage commitment, osteoprogentitor cells undergo a distinct temporal sequence of gene expression that has three distinct periods: (1) proliferation and ECM biosynthesis; (2) ECM development, maturation and organization; and (3) extracellular matrix mineralization [21-23] (Figure 1.2).

Proliferation and Extracellular Matrix Synthesis (Days 1-12 in isolated cell culture): During this stage, cells proliferate to form multilayers or focal nodules. This stage is characterized by mitotic activity where cell cycle (e.g. histones which help package newly replicated DNA) and cell growth (e.g. c-fos, c-jun, c-myc which act as

transactivation factors) genes are expressed. Genes for proteins associated with the extracellular matrix are also expressed including type I collagen and fibronectin (cell attachment ECM protein) [21-23]. The expression of these genes gradually decline, with type I collagen expression maintained at a basal level in future stages of osteoblast differentiation [23].

Extracellular Matrix Development, Maturation and Organization (Days 12-18 in isolated cell culture): As these cells exit mitosis they further differentiate into osteoblasts and begin expressing genes such as alkaline phosphatase (ALP), bone sialoprotein (BSP), and type I collagen [21-23]. ALP is a noncollagenous cell-linked polypeptide that is secreted by osteoblasts and promotes crystal formation in matrix vesicles by removing nucleation inhibitors and is often considered one of the earliest markers of the osteoblast 
phenotype. BSP is a noncollagenous ECM protein that is associated with cell attachment and is also thought to help direct apatite crystal growth along collagen fibers [24]. During this phase, signaling events occur, and a large cuboidal shaped osteoblast develops from the spindly shaped pre-osteoblast. These cells are responsible for causing the ECM to undergo a series of modifications in composition and organization so that it can begin mineralization. As mineralization increases, cellular expression of ALP (often considered one of the earliest markers of the osteoblast phenotype) will decrease [23].

Extracellular Matrix Mineralization (Days 16-20 in isolated cell culture): As osteoblast differentiation continues, the cells begin to express genes involved in ECM mineralization including osteocalcin, osteopontin, and collegenase. Osteocalcin, a vitamin $\mathrm{K}$ dependent calcium ion binding noncollagenous matrix protein, is thought to play a role in the body's metabolic regulation. It is also implicated in bone mineralization and calcium ion homeostasis as well as thought to play a role in bone resorption. Osteocalcin is only expressed post-proliferation with the onset of nodule formation. Osteopontin, also a calcium ion binding noncollagenous matrix protein associated with cell attachment and spreading within the matrix, is expressed during the proliferation stage, decreases during the ECM maturation stage and is induced at the onset of mineralization, where it reaches is maximum expression levels. Collagenase expression begins after the proliferation stage and increases with mineralization, most likely associated with the remodeling of the collagen ECM to support tissue organization and mineral deposition. Cell apoptosis also occurs during this phase, possibly as a way of regulating the number of osteoblasts that differentiate into osteocytes [21-23]. Mineralization of the matrix occurs in two steps: (1) Nucleation of calcium-phosphate crystals and (2) crystal growth. Nucleation usually occurs in matrix vesicles, [small membrane bound organelles containing alkaline phosphatase (cleaves phosphate groups)], secreted by osteoblasts undergoing apoptosis and from cell processes originating from the plasma membrane. Ion pumps are used to raise the levels of calcium and phosphate within the vesicles. When the levels are above supersaturation, nucleation occurs on the inner face of the membrane first. The vesicles then rupture and the crystals continue to grow in between the collagen fibers within the ECM [24]. A portion of 
osteoblasts that become embedded into the mineralized matrix can terminally differentiate to become osteocytes, which support bone structure and metabolic functions. Other osteoblasts are thought to become inactivated and elongated bone lining cells which line the surfaces of bone [21].

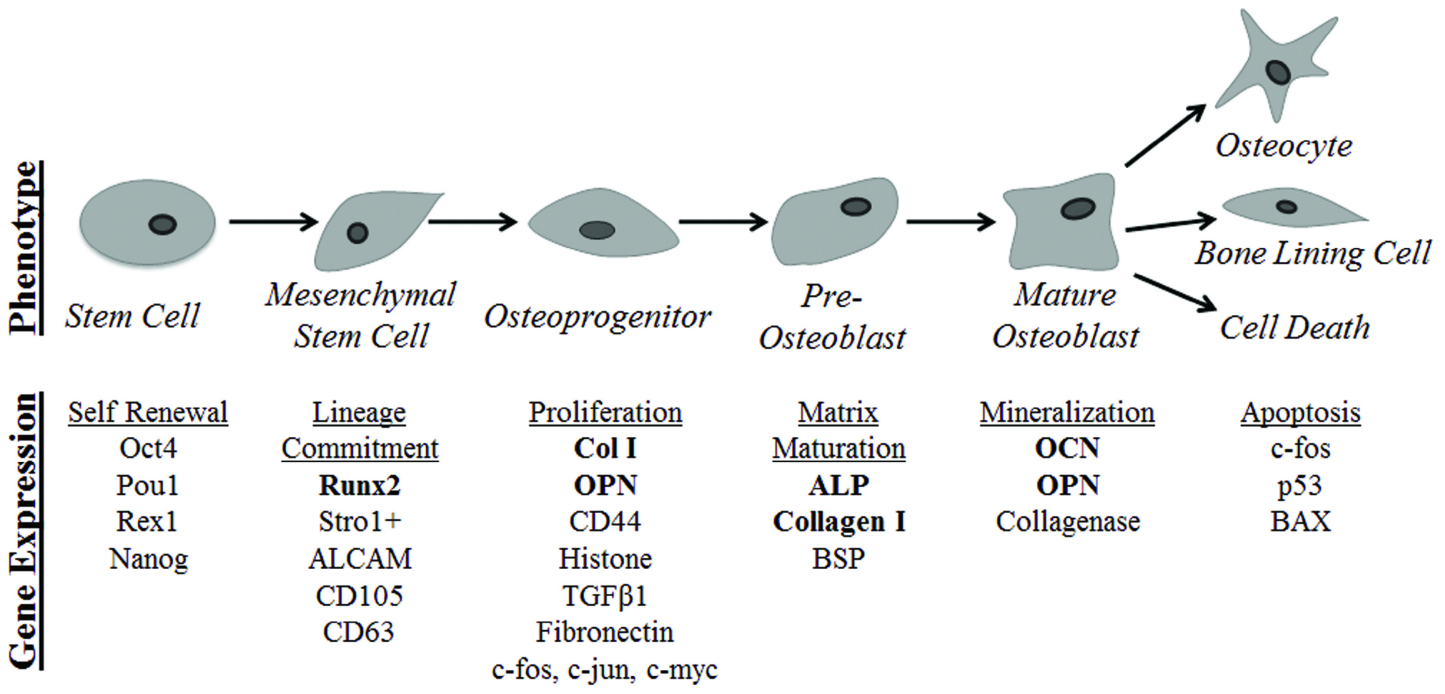

Figure 1.2 Osteoblast differentiation. Osteoblast phenotype and temporal protein sequence during differentiation from stem cell to mature osteobalast/ostocytes. Bold genes common markers chosen for osteoblastic differentiation.

\section{TREATMENT OF DAMAGED TISSUES}

\section{Biologic and Synthetic Grafts}

Traditional methods of surgical treatment of bone injuries include biologic grafts as well as permanent artificial prostheses. They can be classified as three types-autogenic, allogenic, and xenogenic. Autografts (taken from host) are limited by the amount of donor tissue available as well as the fact that a second surgical site must be created, often creating donor site morbidity and weakening of a second tissue. Allografts (taken from host of the same species) pose antigenicity problems and are in limited supply, especially in emergency situations. While xenografts (taken from a different species) may be readily available, they pose significant immunogenic problems [14, 25-27]. Synthetic prostheses are often made out of metals such as iron, cobalt, and titanium, and/or ceramic materials. Metal implants often have issues with fatigue, corrosion, tissue infection, while both metal and ceramic implants have issues mechanical property mismatches between the 
material and bone, often resulting in complete implant removal in the long term [14, 2831]. The most significant deficiency with any of the current grafting systems in both soft and hard tissue is the lack of integration of the graft to bone tissue. Additionally, there are often immunogenic and/or material property mismatches, leading to decreased integration of the implant with bone tissue [27, 32]. Current existing grafting systems, both biologic and synthetic, are not able to restore tissues to their native structural and functional characteristics, leading to compromised graft function and long-term outcome $[27,32]$.

\section{Tissue Engineering}

Tissue engineering is a promising approach to creating permanent solutions for damaged tissues that aims to develop biological substitutes capable of restoring natural structure and function to damaged tissue $[2,14,25,33]$. Currently, many materials are being used, either alone or in blends for bone reconstruction including but not limited to, natural polymers such as chitin, glycosaminoglycans (hyaluronic acid, heparin, chondroitin-6-sulphate), alginate, fibrin, collagen, and silk, as well as synthetic polymers like polyglycolic acid (PGA)/polylactic acid (PLA), poly-e-caprolactone, polyethylene terephthalate, and polypropylene [25, 34-42]. Many of these scaffolds often also incorporate additional materials including growth factors [bone morphogenic proteins (BMPs), vascular endothelial growth factor (VEGF), platelet derived growth factor (PDGF)], proteins [parathyroid hormone (PTH), alkaline phosphatase (ALP), fibronectin] and calcium/phosphate based ceramics [tricalcium phosphate (TCP), hydroxyapatite (HA), Bioglass ${ }^{\mathrm{TM}} \quad$ (45S5: $46.1 \mathrm{~mol} \% \mathrm{SiO}_{2}, \quad 26.9 \mathrm{~mol} \% \mathrm{CaO}, \quad 24.4 \mathrm{~mol} \% \mathrm{Na}_{2} \mathrm{O}$, $\left.2.5 \mathrm{~mol} \% \mathrm{P}_{2} \mathrm{O}_{5}\right)$ ] in effort to further enhance scaffold osteogenic potential [43-51].

\section{MATERIAL PROPERTIES INFLUENCE CELL BEHAVIOR}

In order to regenerate tissues successfully, the materials used in constructs should be chosen carefully. The chemical, physical, and mechanical properties of a material can affect cell behavior in multiple ways including attachment, morphology, proliferation, and gene expression. Specific cell behavior can be with property-cell interactions have been thoroughly characterized. Surface chemistry, hydrophobicity, roughness, 
topography, and mechanical properties all play a role in influencing cell behavior. Many studies have investigated the role of these parameters on cell behavior, but few have isolated individual properties, making it difficult to determine the extent a single property has in influencing cell behavior and also leading to sometimes conflicting conclusions. This interdependency of materials properties makes it important to fully characterize a material when examining cell-material interactions.

\section{Surface Chemistry}

Surface chemistry dictates at the outset the surface character of a material and can be one of the earliest and most influential material properties on cell behavior. However, it is difficult to make generalizations about the effect of surface chemistry on cell behavior due to the sheer number of material choices and surface modifications available. The chemistry of the exposed groups on a material's surface clearly affects cell behavior, though the mechanisms are not always understood [52]. Surface charge and released ions change how serum proteins and ions will interact and adsorb to the material, further altering the surface chemistry of the material and influencing cell behavior. Osteoblasts have been found to have increased attachment, proliferation, and differentiation on charged surfaces and/or surfaces that release ions, possibly due to increases in the concentration of ions and the ionic conditions needed for mineralization [53].

\section{Surface Hydrophobicity}

Surface hydrophobicity (wettability) refers to the interactions between a material's surface and water. Because water has a high capacity for bonding (i.e., Lewis acid-base interactions), materials with a high surface energy have more contacts for bonding, making them generally more hydrophilic. Contact angle measurement is the simplest way of measuring surface hydrophobicity, with the most common technique being the sessile drop method. The angle formed at the liquid-solid interface is the contact angle $(\theta)$, which can range from 0 to $180^{\circ}$. Depending on the material's hydrophobicity the droplet will take a different shape-for more hydrophobic surfaces the droplet will stay rounded (larger angle), while on more hydrophilic surfaces the droplet will spread out (smaller angle) (Figure 1.3). Relative surface hydrophobicity of a 
material is one of the first properties to influence cells when exposed to a material. Osteoblasts have been found to respond to surface hydrophobicity in a time dependant manner. Osteoblasts cultured on hydrophobic surfaces have delayed attachment and remain rounded for a longer period of time than on more hydrophilic surfaces. However, over time the surviving cells on the hydrophobic surface will eventually attach, flatten, and spread out across the surface, possibly due to the secretion of ECM proteins that remodel the substrate surface [54]. Many studies have found that fibroblasts attach, spread, and proliferate best on surfaces with hydrophilic character, with some studies determining the strongest affinity for moderately hydrophilic surfaces, also in a time dependent manner [55-58]. When determining the effect of surface hydrophobicity on cell attachment, spreading, and proliferation, it is important to measure the correct time points-measuring too early may give incorrect information about long-term cell survival on substrates, while measuring too late will give little information about initial cell interactions with the material [54]. More recently, evidence suggests that a cell's activation state and not just adhesion must be considered in evaluating cell response to materials [59].
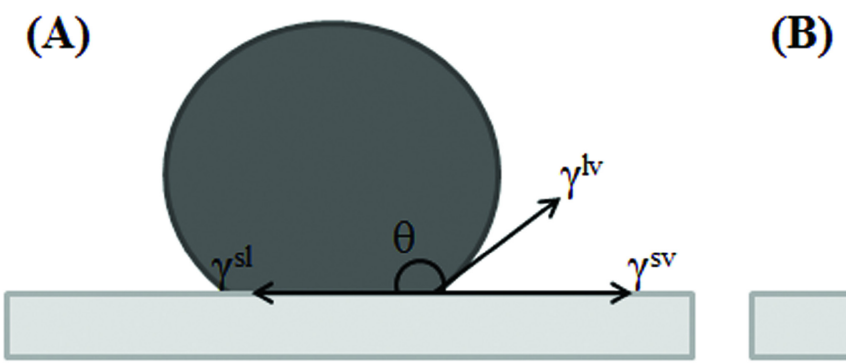

$$
\begin{gathered}
\begin{array}{c}
\text { Young's Equation } \\
\gamma^{\text {sv }}=\gamma^{\text {sl }}+\gamma^{\mathrm{kv}} \cos \theta
\end{array} \\
\gamma^{\text {sl }}=\text { the solid/liquid interfacial free energy } \\
\gamma^{\text {sv }}=\text { the solid surface free energy } \\
\gamma^{\mathrm{lv}}=\text { the liquid surface free energy }
\end{gathered}
$$

Figure 1.3. Contact angle measurements. Schematic of how contact angle would look on a (A) hydrophobic surface and (B) a hydrophilic surface. Young's equation relates the balance of forces of a liquid drop on a solid surface. 


\section{Surface Roughness}

Surface roughness is often quantified by the arithmetic mean roughness $\left(R_{a}\right)$ and the root mean square roughness $\left(R_{R M S}\right.$ or $\left.R_{q}\right) . R_{a}$ is defined as the average distance between surface peaks and valleys relative to the center plane of the surface and $R_{R M S}$ is defined as the root mean square average of the profile height deviations from the center plane, recorded within the evaluation length (Figure 1.4A) [60]. While these values describe the overall roughness of the material surface they do not describe the material topography and features. Therefore, two surfaces with similar $R_{a}$ and $R_{R M S}$ values can

appear very different macroscopically (Figure 1.4B) [61]. In general it has been found that osteoblasts attach better to rough surfaces while fibroblasts to smooth surfaces. Many studies show that surface roughened implants promote osseointegration better than their smooth counterparts, which tend to promote fibroblast adhesion [62-67]. Surface roughness increases material surface area, potentially resulting in more opportunities for cells to establish adhesive contact with a material [61]. Osteoblasts have better adhesion, larger cell spreading, higher proliferation, and enhanced differentiation on substrates with an increased surface roughness [68-72]. 
(A)

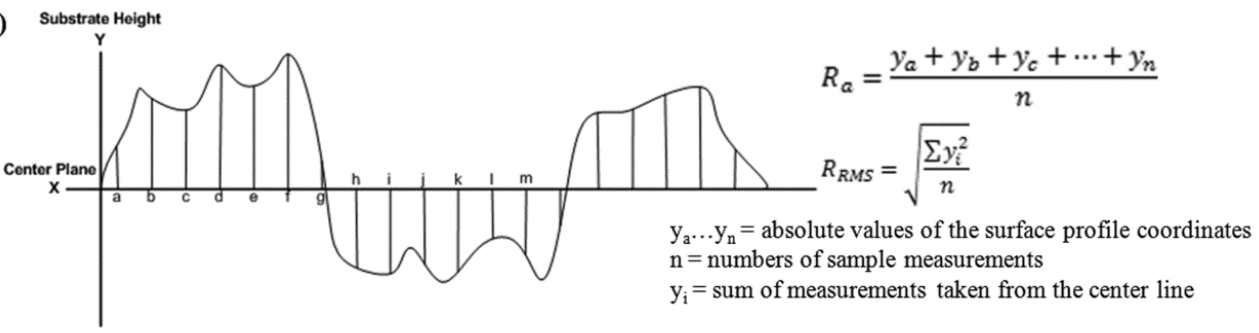

(B)
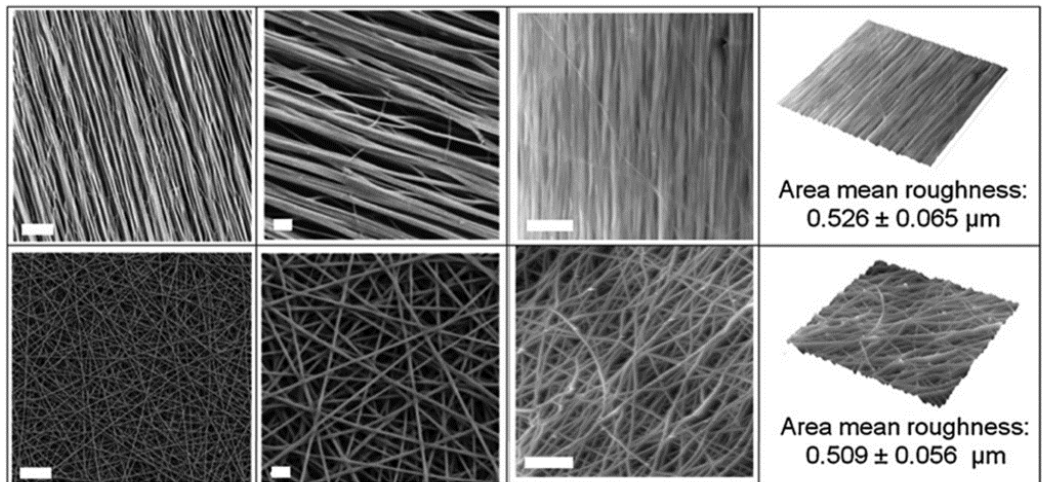

Figure 1.4. Surface roughness measurements. (A) Surface roughness is often expressed as arithmetic roughness $(R a)$ or root mean square roughness $\left(R_{R M S}\right.$ or $\left.R_{q}\right)$. (B) Electrospun fibers with similar $R_{R M S}$ values but distinctly different topographies (scale bar $=10 \mu \mathrm{m}$ ). Modified from Ricotti et al. with permission (see Appendix A) [73].

\section{Topography}

Many studies of have been done to investigate the effect of specific surface topography on cell behavior including groves/grates, posts/islands, and pits created on different metals and polymers. Cell attachment, morphology, proliferation and gene expression have been found to be influenced by substrate topography as small as $100 \mathrm{~nm}$ in width and $75 \mathrm{~nm}$ in depth, though cell response differs depending on cell type and feature size and geometry [74]. In general, nano- and micro- grates have been found to enhance cell attachment, elongate cell morphology, align cells with the nanogratings, and lower proliferation rates $[70,74]$. The effect of nanopost and nanopit on cell behavior is more varied, with different combinations of substrate material, feature geometries, and cell types producing differing effects on cell attachment and proliferation [74]. Both osteoblasts and fibroblasts cultured on substrates containing randomly sized and orientated nanoposts of varying heights had higher cell attachment, spreading, proliferation and differentiation on surfaces containing shorter nanoposts than on substrates containing taller structures [75, 76]. Mesenchymal stem cells cultured on 
substrates containing nanopits differentiate into either fibroblasts or osteoblast depending on the order or disorder of the nanopit arrays. Cells cultured on highly ordered arrays produce cells with fibroblastic appearances, while cells on arrays that were more irregular produced cells with an osteoblastic morphology and gene expression [77].

\section{Mechanical Properties}

Cells commonly attach to its surrounding extracellular matrix, which have an elastic moduli ranging from 10 to $10,000 \mathrm{~Pa}$ depending on the tissue. Therefore, cell morphology and function can be strongly influenced by substrate stiffness [78]. Fibroblasts grown on softer substrates, show few actin stress fibers and focal adhesions and diminished cell spreading than on stiffer surfaces [78-80]. Osteoblasts cultured on surfaces with higher elastic moduli had enhanced differentiation and mineralization [81]. Substrate mechanical properties can also affect cell proliferation and differentiationmesenchymal stem cells can be differentiated into neurogenic, myogenic, or osteogenic cell types by changing the stiffness of the material to mimic that of the native tissue [80]. In vivo, it is important to match the mechanical properties of a tissue engineering scaffold as closely to that of the tissue aiming to be regenerated so that there is not a compliance mismatch and to provide structural stability to the injury site [82].

\section{SOL-GEL METHODS FOR GENERATING BIOACTIVE GLASSES}

Bioactive glasses are silica-based materials whose matrices are porous gels obtained by the hydrolysis and condensation-polymerization of metallic alkoxides usually based on silicon dioxide $\left(\mathrm{SiO}_{2}\right)$ network materials [83]. These materials are attractive because of their ability, when exposed to body fluids, to generate a dynamic bio-reactive surface microenvironment that can act as a strong bonding interface between the glass and its hard or soft tissue environment, giving them an inherent biocompatibility [84].

The use of sol-gel processing methods is increasingly popular as a technique for generating bioactive glass-ceramic materials because of the mild processing conditions (ambient temperatures and biologically tolerated by-products) and simple methods for controlling composition and structure through synthesis parameters $[6,85]$. Additionally, 
these materials can be used as delivery vehicles for various inorganic and organic small molecules including ions, drugs, enzymes, antibodies, growth factors, DNA and even cells [7, 86-92]. Sol-gel materials can be generated in the form of fibers, powders, xerogels, aerogels, nanoparticles, and thin films [6, 93-98]. Potential biomedical uses of sol-gel materials include: nanoparticles used in magnetic resonance imaging (MRI), targeted drug delivery, and magnetic separation; surface coatings for metal surgical tools, implants, and optical and electrochemical biosensors; and scaffolds for tissue engineering [6]. Because of the attractive processing conditions and flexibility of their composition, bioactive glasses and ceramics are widely being explored to replace or augment both hard and soft tissues [99]. These materials further possess the capacity to exert an inherent active influence on cell behavior; modulated in part by surface chemistry, topography, and active agents incorporated in the sol-based material. However, the exact balance of these parameters that is most appropriate for directing cell function and gene expression is not fully understood and warrants further exploration [100, 101].

Sol-gel processing methods produce ceramic materials from a colloidal suspension of precursors (sol). The solvent is removed from the system in order to solidify the material (gel). Precursors are usually metallic alkoxide compounds $\left(\mathrm{Si}-(\mathrm{OR})_{\mathrm{n}}\right.$, where $\mathrm{R}$ is an organic group) such as tetraethyl- or tetramethyl-orthosilicate (TEOS and TMOS respectively) [102]. Reactions carried out with TMOS are more volatile and consequently more energetic, so preparation of less bulky higher $\mathrm{S} / \mathrm{V}$ ratio ceramics is much more amenable to the use of TMOS [103]. In the presence of water, the alkoxide groups are hydrolyzed, creating silanol groups and releasing alcohol. Condensation between silanol groups then occurs, creating $\mathrm{Si}-\mathrm{O}-\mathrm{Si}$ bonds. Extension of this reaction leads to a silica network with pores created through the removal of water and alcohol molecules. As the polycondensation reaction continues, colloidal mircro-particles are formed (Figure 1.5). This colloidal solution can then be cast into shapes or used as a coating. Over time the colloidal silica particles link together, increasing the viscosity of the solution, to form a solid three-dimensional network (gel). The size, growth rate, and amount of cross-linking within the particles are dependent upon several variables (e.g. sol $\mathrm{pH}$ and water-alkoxide ratio) that help determine the overall physical properties of the gel 
network $[83,85]$. Gels can then be cured with elevated temperatures, UV radiation, or "aged" by storing at room temperature to increase material density. Body temperature curing is also possible if the final material form has suitable physical properties (i.e. high $\mathrm{S} / \mathrm{V}$ in the form of particles or thin-film coatings) [102].

Additionally, inorganic-organic hybrid sol-gel materials can be formed by the additional of a polymer early on in the sol-gel process, during the condensation phase, in order to generate a composite material that interacts at the nano-scale and behave as a single phase material. These hybrid materials are beneficial because they improve the mechanical and degradation properties of the bioglass [104, 105]. Hybrid materials are classified into two categories: (1) class I hybrids that contain molecular entanglements, hydrogen bonding, and/or van der Waals forces; and (2) class II hybrids that also contain covalent bonding between components and are usually synthesized by functionalizing the polymer before introduction to the sol-gel. While these hybrids allow the generation of materials with highly tunable material properties, there are currently several disadvantages that must be considered when generating them $[104,106,107]$. The polymer chosen must be soluble in the sol-gel process (i.e., $\mathrm{H}_{2} \mathrm{O}$ ), and have a suitable degradation rate. Additionally, the polymer may degrade at lower pHs (the isolectric point of silicic acid in water is 2 , where the longest gelation time occurs) so the $\mathrm{pH}$ may need to be adjusted, resulting in quicker gelation times [104, 108]. Perhaps the biggest challenge of hybrid materials is the incorporation of calcium into the material. The calcium precursor for most sol-gel processing methods is calcium nitrate tetrahydrate $\left(\mathrm{Ca}\left(\mathrm{NO}_{3}\right)_{2} \cdot 4 \mathrm{H}_{2} \mathrm{O}\right)$ because it is highly soluble, but the nitrate byproducts are cytotoxic. This is usually addressed when the sol-gel materials are processed at high temperatures, which removes the nitrates, but the addition of polymers into the material does not allow for this $[104,109]$. Therefore it is necessary to find a new source of calcium that will effectively be incorporated into the silica network, when generating these hybrid materials [104]. 

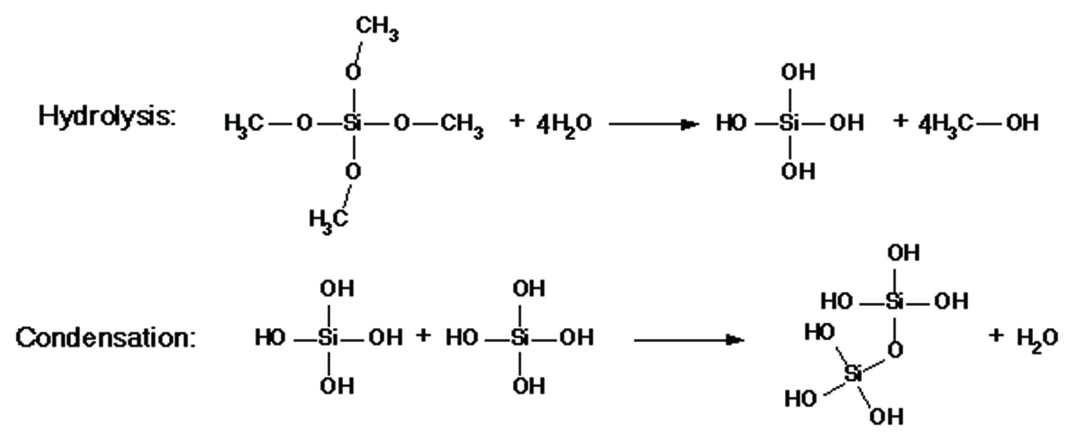

Polycondensation:
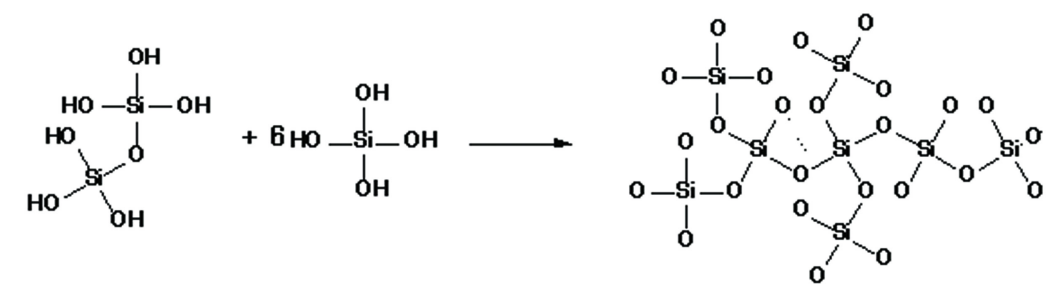

Figure 1.5. Stages involved in synthesis of TMOS-based silica sol-gel. Synthesis takes places in three distinct steps: hydrolysis, condensation, and poly-condensation. Post-synthesis processing can be used to further consolidate network structure.

\section{Silica Sol-Gel Bioactivity and Mineralization}

It is widely accepted that silica based bioglasses have osteogenic inducing properties. When the glass is exposed to body fluids or simulated body fluids, soluble silica is lost in the form of $\mathrm{Si}(\mathrm{OH})_{4}$ into the solution, breaking $\mathrm{Si}-\mathrm{O}-\mathrm{Si}$ bonds and creating $\mathrm{Si}-\mathrm{OH}$ (silanols) at the material-solution interface. $\mathrm{SiO}_{2}$ condensates and repolymerizes at this surface, causing the migration of $\mathrm{Ca}^{2+}$ and $\mathrm{PO}_{4}{ }^{3-}$ which forms a $\mathrm{CaO}-\mathrm{P}_{2} \mathrm{O}_{5}$ rich film on top of the $\mathrm{SiO}_{2}$ layer. This amorphous $\mathrm{CaO}-\mathrm{P}_{2} \mathrm{O}_{5}$ film continues to grow through the incorporation of calcium and phosphates from solution, and is then crystallized by incorporation of $\mathrm{OH}^{-}$and $\mathrm{CO}_{3}{ }^{2-}$ anions to form a mixed hydroxyapatite (HA) layer (Figure 1.6). At this point biological growth factors can adsorb into the HA layer, contributing to the active differentiation of stem cells into osteoblasts. This dynamic interaction creates a strong bonding interface between the glass and its hard or soft tissue environment. In hard tissues a bond is formed as a result of the biological equivalence of the mineral phase of bone and the growing HA layer of the bioglass material. Soft tissue bonding occurs when collagen fibrils are chemisorbed on the $\mathrm{SiO}_{2}$ layer by electrostatic, ionic, and/or hydrogen bonding and HA is precipitated and crystallized onto collagen 
fiber and material surfaces [84]. The character of the HA layer that is formed at the sol gel glass surface is dependent upon many factors including the composition of the sol material and the physical properties (i.e. roughness, topography, surface area) of the substrate surface. Previous work has shown that apatite formation on sol gel glasses composed of up to $90 \mathrm{~mol} \% \mathrm{SiO}_{2}$, is enhanced due to the large surface area available and the high concentration of silanol groups at the surface of the material. More recent work has been focused on determining the effect of additional elements to the composition of the bioglass including magnesium, potassium, aluminum, and iron on sol gel material's bioactivity, with the majority of the focus being on the addition of different amounts calcium and phosphate to the silica network. However, the composition of a sol gel glass that is optimum for mineral formation is not known $[110,111]$. 
(i) BIO-REACTIVE SURFACE EXPOSED TO BODY FLUID:

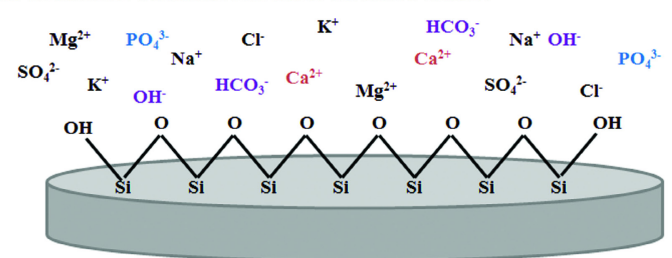

(ii) SILANOL FORMATION:
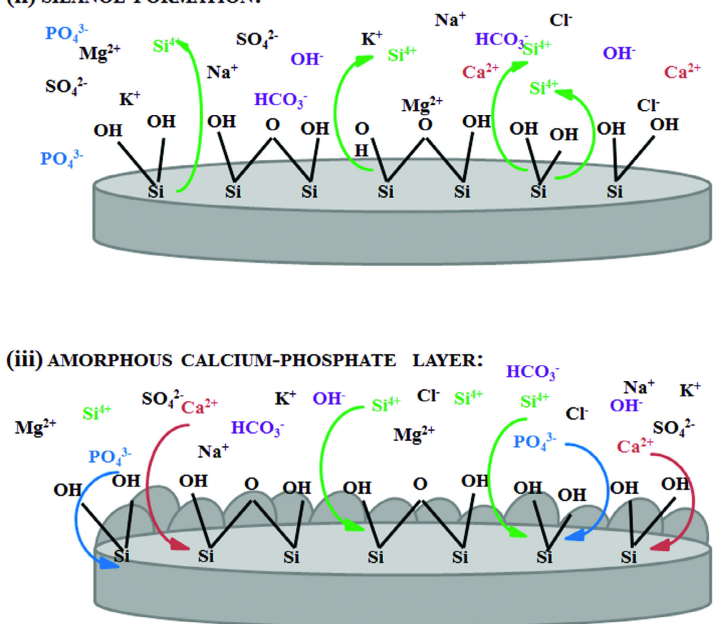

(iv) CRYSTALLIZATION TO FORM HYDROXYAPATITE:

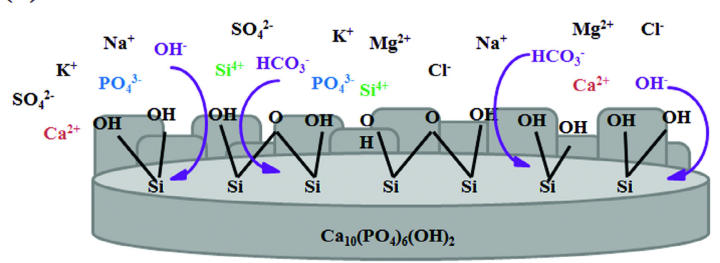

(v) BOND BETWEEN MATERIAL AND TISSUE:

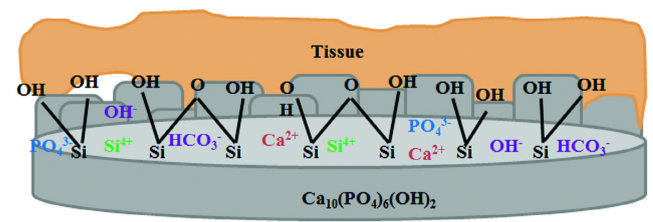

Figure 1.6. Overview of silica sol-gel bioglass bioactivity. (i) When silica based bioglasses are exposed to body fluids: (ii) soluble silica is lost in the form of $\mathrm{Si}(\mathrm{OH})_{4}$ into the solution, breaking Si-O-Si bonds and creating $\mathrm{Si}-\mathrm{OH}$ (silanols) at the material-solution interface. (iii) $\mathrm{SiO}_{2}$ condensates and repolymerizes at this surface, causing the migration of $\mathrm{Ca}^{2+}$ and $\mathrm{PO}_{4}{ }^{3-}$ which forms a $\mathrm{CaO}-\mathrm{P}_{2} \mathrm{O}_{5}$ rich film on top of the $\mathrm{SiO}_{2}$ layer. This amorphous $\mathrm{CaO}-\mathrm{P}_{2} \mathrm{O}_{5}$ film continues to grow through the incorporation of calcium and phosphates from solution. (iv) Hydroxyl $\left(\mathrm{OH}^{-}\right)$and carbonate $\left(\mathrm{CO}_{3}{ }^{2-}\right)$ anions are incorporated to form a mixed hydroxyapatite (HA) layer. At this point biological growth factors can adsorb into the HA layer, contributing to the activation of differentiation of stem cells into osteoblasts. (v) The bioglass material and tissue create a bond due to the biological equivalence of the mineral phase of bone and the growing HA layer. 


\section{ION INFLUENCE ON OSTEOBLAST BEHAVIOR}

In addition to the ability to enhance biomineralization, dissolution ions (e.g. Si, $\mathrm{Ca}, \mathrm{P})$ in the surrounding dissolution medium as the bioglass network degrades have been found to influence the behavior of many tissue-specific cell types including, mesenchymal stem cells, osteoblasts, osteoclasts, fibroblasts, and endothelial cells; as well as bacteria (Figure 1.7) [4]. How these ions affect cell behavior is often tested with simultaneously using multiple ions, making it difficult to isolate the mechanisms by which the ions work to affect cell functions.

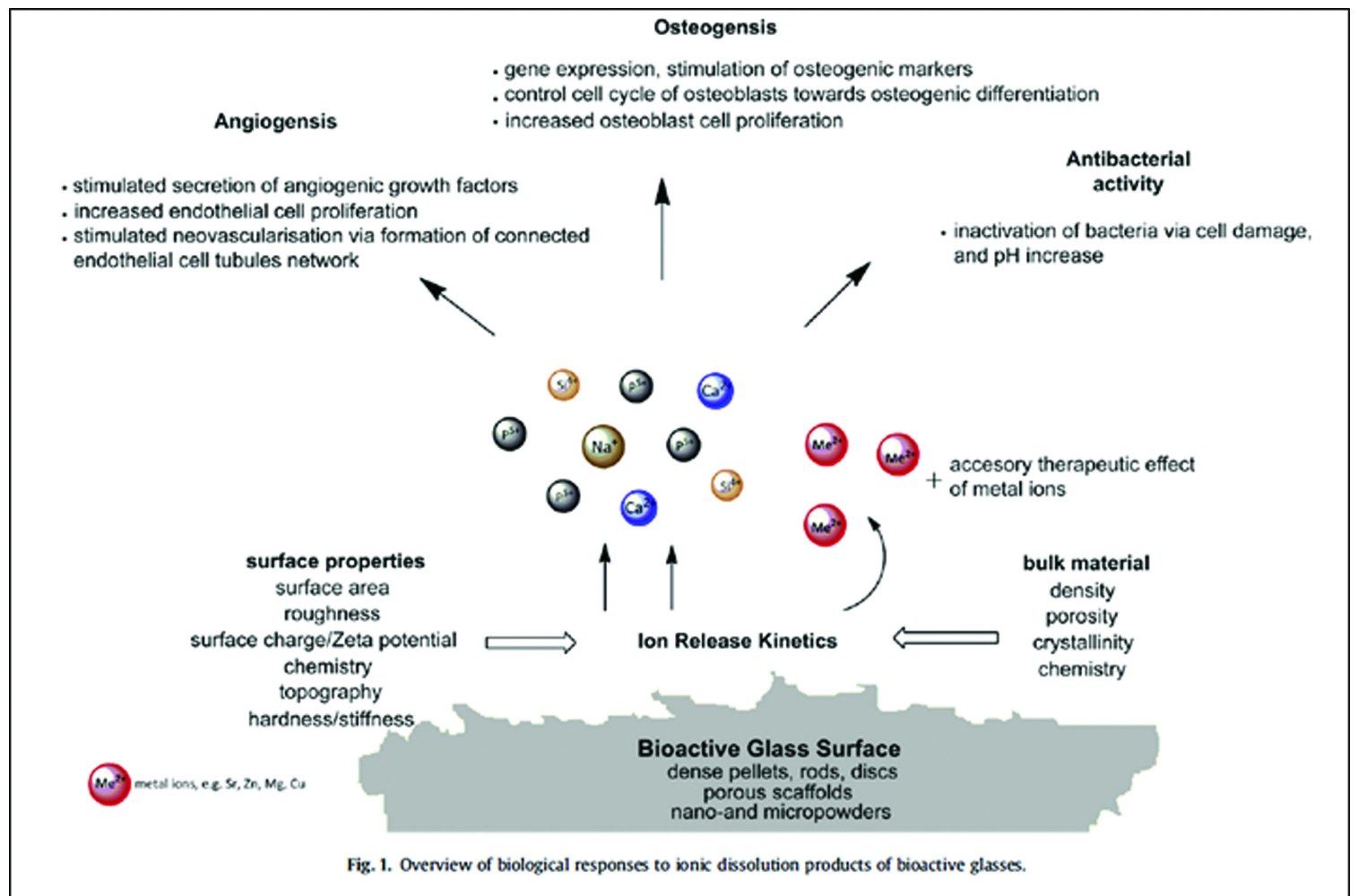

Figure 1.7. Summary of biological effects due to ionic dissolution products of bioactive glasses. From Hoppe et al. with permission (see Appendix A) [4].

\section{Silica $\left(\mathrm{SiO}_{2}\right)$}

Osteoblasts exposed to silicate ions have been found to have increased collagen I production possibly through the posttranscriptional regulation of transforming growth factor $\beta$ (TGF $\beta)[112,113]$. Silicon is also thought to play a role in collagen crosslinking through the regulation of prolyl-hydroxylase activity and the binding of 
glycosaminoglycans (GAGs) to collagen, aiding collagen stabilization and preventing degradation $[113,114]$. Osteoblast precursors cultured with silica ions have also been found to have increased adhesion, metabolic activity, and proliferation $[115,116]$. Silica ions have also been found to increase ALP activity and Runx2 and osteocalcin expression, indicating increased osteoblast differentiation [114, 117, 118]. Additionally, silica has been found to increase nodule formation (increased ECM mineralization) in osteoblast cultures due to its ability to facilitate nucleation of an apatite layer when exposed to body fluids [119].

\section{Calcium}

In bone, calcium not only is a main component of hydroxyapatite mineral, it acts as a signaling molecule to promote various osteoblast cell functions. During bone resorption osteoclasts direct calcium and phosphate release into the microenvironment, Increases in the local concentration of ions, specifically calcium, creates a gradient of chemical signals for preosteoblast migration and growth through a variety of mechanisms including the activation of calcium sensing receptors (CaSR/CaR), increasing intracellular calcium concentrations, and/or the extracellular signal-regulated kinase (ERK 1/2) pathway [120-122]. Calcium also plays a role in osteoblast proliferation and differentiation through calcium/calomodulin signaling [121]. However, the concentration range appropriate to ensure cell viability, while promoting cell differentiation and matrix maturation is still unclear. Several studies have found that treatment of preosteoblasts/osteoblasts with calcium ions at a concentration slightly higher than physiological increases cell proliferation, while at even higher levels cell differentiation and matrix mineralization is increased in both monolayer and three-dimensional culture. However, the elevated calcium levels also results in slight decreases in cell viability. Further, excessive calcium concentrations are known to be cytotoxic $[5,122,123]$.

\section{Phosphate}

Phosphate, in addition to be the other main constituent of hydroxyapatite, is an important signaling molecule that helps to regulate osteoblast proliferation, transcriptional factors [Nrf2, HMGA1 and 2], signal transduction pathways [Fos-related 
antigen-1 (Fra-1), extracellular signal-regulated kinase (ERK 1/2), calcyclin, A170)], plasma membrane and membrane transport factors [Pit-1, Annexin V], the secretion of bone-related proteins [matrix Gla protein (MGP)], and extracellular matrix cell adhesion protein [osteopontin] [124-128]. Additionally, cells treated with inorganic phosphate are found to exhibit decreased extracellular matrix protein gene expression [decorin, Tenascin C, periostin, thrombospondin, and collagens (I and III)] [125, 127]. However, the effects of phosphate are highly dose and time dependant, with high concentrations and exposure times increasing cell (osteoblast, chondrocyte, odontoblast) apoptosis in addition to ultimately contributing to these cells terminal differentiation $[129,130]$. The use of phosphate releasing biomaterials is rare in the literature, possibly due to the lack of effective phosphate dosing methods to balance cell differentiation and apoptosis [12].

\section{NEBULIZER BASED SOL DEPOSITION OF SOL PARTICLES}

The novel sol vaporization system developed for this project uses nebulizer technology to generate vaporized sol particles at ambient conditions. A jet typecompressed air nebulizer attached to a vaporization chamber (Figure 1.8A) aerosolizes the sol precursor solution, generating sol droplets with a large aggregate surface area that can easily be used to modify substrate surface topography and as a delivery vehicle for active molecules. This method allows for surfaces to be modified without the use extreme processing conditions, (i.e. temperature and harsh solvents), minimizing uncontrolled effects on substrate character as well as the functionality of inorganic and organic factors delivered via the sol-vapor.

The system developed here uses a nebulizer to vapor deposit nano- and microsized particles made of silica sol gel. In a jet-type nebulizer, compressed air flows through a narrow hole and collides with a colloidal solution from one or more inlets, generating vapor particles through momentum transfer (physical collision) (Figure 1.8B). The complex liquid break-up process is dependent upon the nozzle design and usually a combination of turbulent rupture of the instable liquid column and secondary droplet break-up [131, 132]. In its simplest form, the air flowing in to the nebulizer impinges

directly on a solid jet of liquid. Large droplets impact on the internal structure of the 
nebulizer effectively reducing the mean droplet size and distribution. Only smaller droplets with less inertia can follow the flow of the compressed air and pass through the spray nozzle $[133,134]$. Control over the size distribution of the particles produced is determined by the properties of the colloidal solution to a significant degree, with key variables including species concentration $\left(\mathrm{H}_{2} \mathrm{O}\right.$ : alkoxide $)$ and $\mathrm{pH}$. The method developed here allows for a layer of sol particles to be deposited onto substrates, providing a large surface area, and creating a unique nano-structured surface topography and controlled modification of substrate surface properties.
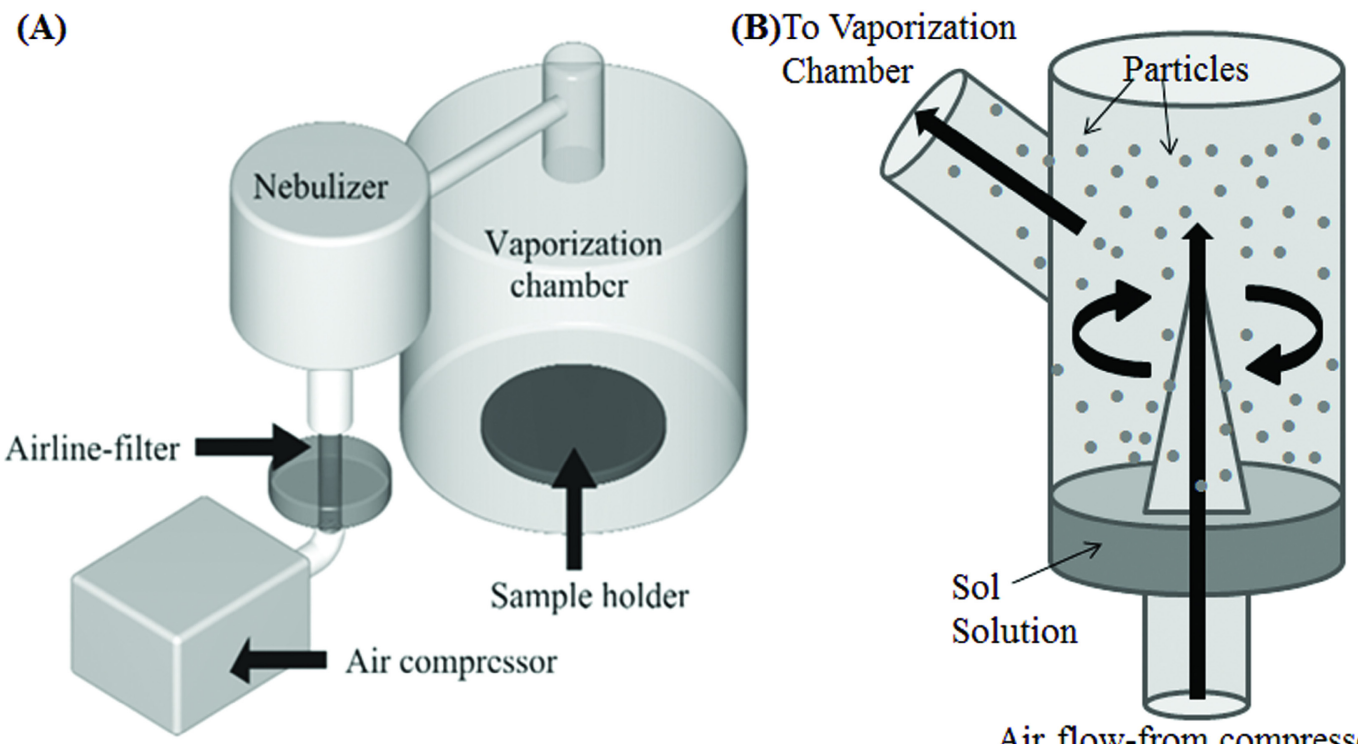

Air flow-from compressor

Figure 1.8. Schematic of vapor deposition system. (A) A jet-type nebulizer is attached to an air compressor and a vaporization chamber where sample is placed. (B) When air flow is applied it enters nebulizer causing turbulence, breaking apart the sol solution and generating particles, which exit the nebulizer and enter the vaporization chamber.

\section{HYPOTHESES AND SPECIFIC AIMS}

The ultimate goal of tissue engineering is to restore and/or regenerate tissue structure and function, with typical approaches using engineered materials scaffolds. However, designing materials that will lead to a practical degree of recovery are difficult to construct, due in large part to the complexity of the dynamic chemical and physical microenvironment of a the native extracellular matrix. Cell behavior is influenced by the 
chemical and its physical properties of a material. Therefore, development of biomaterials that utilize the relationship between material chemical and physical properties and cell response may provide a better platform for tissue regeneration. This project aims to develop vapor deposited silica sol gel particles as a novel cell instructive material system for use in composite bone and interfacial tissue engineering scaffolds. We hypothesize that these sol particles can be used as a means to: 1) deliver soluble bioactive factors to control cell behavior and mineral formation and 2) control chemical and physical properties of biomaterials to be used in orthopedic tissue engineering constructs. It is vital to understand how sol particle chemical and physical properties influence cell behavior in order to design material constructs that are capable of directing appropriate adhesion, proliferation, and differentiation of cells, with specific focus on osteoblasts. Understanding these relationships will allow us to develop a bioactive materials system to functionalize tissue engineering constructs, a focus of this research project, the specific aims of which are:

\section{Hypothesis 1- VAPOR DEPOSITED SOL PARTICLE CHEMICAL AND PHYSICAL PROPERTIES} CAN BE CONTROLLED THROUGH CHANGES IN THEIR FORMULATION AND MANUFACTURING PARAMETERS.

Specific Aim 1: Design sol formulations and fabrication methods for producing vapor deposited sol particles with controlled chemical and physical properties.

The chemical (composition, stability, hydrophobicity) and physical (size distribution-morphology, roughness-topography) properties of vapor deposited sol particles are dependent upon sol formulation $\left(\mathrm{pH}, \mathrm{H}_{2} \mathrm{O}: \mathrm{TMOS}\right)$ and manufacturing (deposition time, substrate composition) parameters. The goal of Aim 1 was to manufacture and characterize a series of particles whose chemical and physical properties are optimized to address controlling osteoblast behavior (bone formation).

Hypothesis 2- VAPOR DEPOSITED SOL PARTICLES CAN BE USED AS DELIVERY VEHICLES FOR BIOACTIVE FACTORS AND INDUCE APATITE-LIKE MINERAL GROWTH. 
Specific Aim 2: Generate sol particles capable of controlled release of inorganic molecules.

Sol particles were modified by incorporating calcium and phosphate ions into the formulation process. Release kinetics and the functionality (mineral formation) of the incorporated molecules were determined. Additionally, how the incorporation of these molecules influences particle properties was assessed. The goal of Aim 2 was to assess particle potential to serve as controlled delivery vehicles for incorporated inorganic molecules and determine a specific set of parameters that facilitates biomimetic $\underline{\text { mineralization. }}$

\section{Hypothesis 3- VAPOR DEPOSITED SOL PARTICLES CAN BE USED TO DIRECT BEHAVIOR OF OSTEOBLASTS THROUGH CELL-MATERIAL INTERACTIONS.}

Specific Aim 3: Determine the relationship between vapor deposited sol particle chemical-physical properties and osteoblast behavior.

Osteoblast response (adhesion, proliferation, differentiation, and ECM development) in response to sol particles was assessed. Full characterization of the particles used will aid in determining the relationship between the material chemicalphysical properties and cell behavior. The goal of Aim 3 was to determine the particle formulation that best directs osteoblast behavior and ultimately aids in bone formation.

\section{Summary of Dissertation Chapters}

These aims will be discussed in a series of chapters written in the form of journal articles for publication. Chapter 2 will characterize the development of the sol particle vapor deposition system as a means to tailor material properties and sol formulation and manufacturing parameters affects on the particles (AIM 1). Chapter 3 will determine the ability to incorporate calcium and phosphate ions into the sol particles as well as the affects of these ions on particle properties and bioactivity (AIM 2). Chapter 4 will assess the ability of calcium-phosphate particles characterized in Chapter 3 to direct osteoblast behavior (AIM 3). Finally, Chapter 5 will present an overall summary and conclusions of the work from this dissertation, including an outline of the limitations of this work and proposed future directions. 


\section{REFERENCES}

1. Brinker, M. and D. O'Connor, Nonunions: Evaluation and Treatment, in Skeletal Trauma, B. Browner, et al., Editors. 2009.

2. Langer, R. and J.P. Vacanti, Tissue engineering. Science, 1993. 260(5110): p. 920-6.

3. Lutolf, M.P. and J.A. Hubbell, Synthetic biomaterials as instructive extracellular microenvironments for morphogenesis in tissue engineering. Nature biotechnology, 2005. 23(1): p. 47-55.

4. Hoppe, A., N.S. Güldal, and A.R. Boccaccini, A review of the biological response to ionic dissolution products from bioactive glasses and glass-ceramics. Biomaterials, 2011. 32: p. 2757-2774.

5. Jung, G.-Y.P., Yoon-Jeong and J.-S. Han, Effects of HA released calcium ion on osteoblast differentiation. Journal of materials Science. Materials in Medicine, 2010. 21: p. 1649-1654.

6. Gupta, R. and A. Kumar, Bioactive materials for biomedical applications using sol-gel technology. Biomedical materials, 2008. 3: p. 034005.

7. Avnir, D., et al., Recent bio-applications of sol-gel materials. Journal of Materials Chemistry, 2006. 16(11): p. 1013-1030.

8. Chai, Y.C., et al., Current views on calcium phosphate osteogenicity and the translation into effective bone regeneration strategies. Acta Biomaterialia, 2012. 8(11): p. 3876-3887.

9. Colfen, H., Biomineralization: a crystal-clear view. Nature Materials, 2010. 9: p. 960-961.

10. Stewart, A., et al., The presence of PHOSPHO1 in matrix vesicles and its developmental expression prior to skeletal mineralization. Bone, 2006. 39: p. 1000-1007.

11. Anderson, H., R. Garimella, and S. Tague, The role of matrix vesicles in growth plate development and biomineralization. Frontiers in Biosciences, 2005. 10: p. 822-837.

12. Chai, Y., et al., Current views on calcium phosphate osteogenicity and the translation into effective bone regeneration strategies. Acta Biomaterialia, 2012. 8(11): p. 3876-3887. 
13. Golub, E., Role of matrix vesicles in biomineralization. Biochimica et Biophysica Acta, 2009. 1790: p. 1592-1598.

14. Mistry, A.S. and A.G. Mikos, Tissue engineering strategies for bone regeneration. Adv Biochem Eng Biotechnol, 2005. 94: p. 1-22.

15. Spalazzi, J.P., et al., Development of controlled matrix heterogeneity on a triphasic scaffold for orthopedic interface tissue engineering. Tissue engineering, 2006. 12(12): p. 3497-508.

16. Wang, I.N.E., et al., Role of osteoblast-fibroblast interactions in the formation of the ligament-to-bone interface. Journal of orthopaedic research, 2007. 25(12): p. 1609-20.

17. Nisbet, D.R., et al., Review Paper: A Review of the Cellular Response on Electrospun Nanofibers for Tissue Engineering. (0885-3282 (Print)).

18. Frankel, V.H. and M. Nordin, Biomechanics of Bone, in Basic Biomechanics of the Musculosketal System, M. Nordin and V.H. Frankel, Editors. 2001, Lippincott Williams and Wilkins.

19. Cullinane, D.M. and T.A. Einhorn, Biomechanics of Bone, in Principles of Bone Biology, J.P. Bilezikian, L.G. Raisz, and G.A. Rodan, Editors. 2002, Academic Press.

20. SEER Training Modules, Skeletal System. U. S. National Institutes of Health, National Cancer Institute. 10 November 2010]; Available from: http://training.seer.cancer.gov/anatomy/skeletal/.

21. Aubin, J.E., J.B. Lian, and G.S. Stein, Chapter 4. Bone Formation: Maturation and Functional Activities of Osteoblast Lineage Cells, in Primer on the Metabolic Bone Diseases and Disorders of Mineral Metabolism, M.J. Favus, Editor. 2006, The American Society for Bone and Mineral Research.

22. Jenson, E.D., R. Gopalakrishnan, and J.J. Westendorf, Regulation of gene expression in osteoblasts. BioFactors, 2010. 36(1): p. 25-32.

23. Lian, J.B. and G.S. Stein, Development of the Osteoblast Phenotype: Molecular Mechanisms Mediating Osteoblast Growth and Differentiation. The Iowa Orthopaedic Journal, 1995. 15: p. 118-140.

24. Sikavitsas, V.I., J.S. Temenoff, and A.G. Mikos, Biomaterials and bone mechanotransduction. Biomaterials, 2001. 22(19): p. 2581-93.

25. DeFranco, M.J., K. Derwin, and J.P. Iannotti, New therapies in tendon reconstruction. Journal of the American Academy of Orthopaedic Surgeons, 2004. 12(5): p. 298-304. 
26. Doroski, D.M., K.S. Brink, and J.S. Temenoff, Techniques for biological characterization of tissue-engineered tendon and ligament. Biomaterials, 2007. 28(2): p. 187-202.

27. $\mathrm{Lu} \mathrm{Hh}$ Fau - Jiang, J. and J. Jiang, Interface tissue engineering and the formulation of multiple-tissue systems. (0724-6145 (Print)).

28. Galluccio, G., Variability of the dental surface: effects on orthopedic treatment. Progress in Orthodontics 2008. 9(1): p. 18-.

29. Gil, F., et al., Influence of the height of the external hexagon and surface treatment on fatigue life of commercially pure titanium dental implants. The International Journal of Oral \& Maxillofacial Implants, 2009. 24(4): p. 583-590.

30. Kim, J., L. Kim, and C. Kim, Size control of silica nanoparticles and their surface treatment for fabrication of dental nanocomposites. Biomacromolecules, 2007. 8(1): p. 215-222.

31. Li, D., et al., Improvement of osseointegration of titanium dental implants by a modified sandblasting surface treatment: an in vivo interfacial mechanics study. Implant Dentistry, 1999. 8(3): p. 289-294.

32. Mikos, A.G., et al., Engineering complex tissues. Tissue engineering, 2006. 12(12): p. 3307-39.

33. Fuchs, J.R., B.A. Nasseri, and J.P. Vacanti, Tissue engineering: a 21st century solution to surgical reconstruction. The Annals of thoracic surgery, 2001. 72(2): p. 577-91.

34. Jayakumar, R., et al., Chitin Scaffolds in Tissue Engineering. International Journal of Molecular Sciences, 2011. 12(3): p. 1876-1887.

35. Mathews, S., et al., Glycosaminoglycans enhance osteoblast differentiation of bone marrow derived human mesenchymal stem cells. Journal of Tissue Engineering and Regenerative Medicine, 2012: p. n/a-n/a.

36. Florczyk, S.J., et al., Enhanced bone tissue formation by alginate gel-assisted cell seeding in porous ceramic scaffolds and sustained release of growth factor. Journal of Biomedical Materials Research Part A, 2012: p. n/a-n/a.

37. Osathanon, T., et al., Microporous nanofibrous fibrin-based scaffolds for bone tissue engineering. Biomaterials, 2008. 29(30): p. 4091-9.

38. Cunniffe, G., et al., Development and characterisation of a collagen nanohydroxyapatite composite scaffold for bone tissue engineering. Journal of Materials Science. Materials in Medicine, 2010. 21(8): p. 2293-8. 
39. Mandal, B., et al., High-strength silk protein scaffolds for bone repair. Proceedings of the National Academy of Sciences of the United States of America, 2012. 109(20): p. 7699-704.

40. Li, W.-J., et al., Electrospun nanofibrous structure: A novel scaffold for tissue engineering. Journal of biomedical materials research, 2002. 60(4): p. 613-621.

41. Lu, L., et al., Biocompatibility and biodegradation studies of PCL/ $\beta$-TCP bone tissue scaffold fabricated by structural porogen method. Journal of Materials Science: Materials In Medicine, 2012. 23(9): p. 2217-2226.

42. Mohajeri, S., et al., Proliferation and Differentiation of Mesenchymal Stem Cell on Collagen Sponge Reinforced with Polypropylene/Polyethylene Terephthalate Blend Fibers. 16, 2010. 12(3821-3830).

43. Rahman, C.V., et al., Controlled release of BMP-2 from a sintered polymer scaffold enhances bone repair in a mouse calvarial defect model. Journal of Tissue Engineering and Regenerative Medicine, 2012: p. n/a-n/a.

44. Jabbarzadeh, E., et al., VEGF-incorporated biomimetic poly(lactide-co-glycolide) sintered microsphere scaffolds for bone tissue engineering. Journal of Biomedical Materials Research Part B: Applied Biomaterials, 2012: p. n/a-n/a.

45. Phipps, M., Y. XU, and S. Bellis, Delivery of platelet-derived growth factor as a chemotactic factor for mesenchymal stem cells by bone-mimetic electrospun scaffolds. PLoS One, 2012. 7(7): p. e40831.

46. Jeon, J.H. and D.A. Puleo, Alternating release of different bioactive molecules from a complexation polymer system. Biomaterials, 2008. 29(26): p. 3591-3598.

47. Osathanon, T., C. Giachelli, and M. Somerman, Immobilization of alkaline phosphatase on microporous nanofibrous fibrin scaffolds for bone tissue engineering. Biomaterials, 2009. 30(27): p. 4513-4521.

48. Thein-Han, W., J. Liu, and H.H.K. Xu, Calcium phosphate cement with biofunctional agents and stem cell seeding for dental and craniofacial bone repair. Dental Materials, 2012. 28(10): p. 1059-1070.

49. Perez, R.A., et al., Calcium phosphate cements loaded with basic fibroblast growth factor: Delivery and in vitro cell response. Journal of Biomedical Materials Research Part A, 2012: p. n/a-n/a.

50. Zhou, H. and J. Lee, Nanoscale hydroxyapatite particles for bone tissue engineering. Acta Biomaterialia, 2011. 7(7): p. 2769-2781. 
51. Garcia-Garcia, J., et al., Novel poly(hydroxyalkanoates)-based composites containing Bioglass $\AA$ and calcium sulfate for bone tissue engineering. Biomedical Materials, 2012. 7(5): p. 054105.

52. Meyer, U. and H.P. Wiesmann, Cell/Surface Interactions, in Bone and Cartilage Engineering, G. Schroder, Editor. 2006, Springer.

53. Wilson, C., et al., Mediation of biomaterial-cell interactions by adsorbed proteins: a review. Tissue Engineering, 2005. 11(1-2): p. 1-18.

54. Liu, X., et al., Influence of substratum surface chemistry/energy and topography on the human fetal osteoblastic cell line hFOB 1.19: Phenotypic and genotypic responses observed in vitro. Biomaterials, 2007. 28(31): p. 4535-4550.

55. Khang, G., et al., Interaction of fibroblast cells on poly(lactide-co-glycolide) surface with wettability chemogradient Bio-Medical Materials and Engineering, 1999. 9(3): p. 179-87.

56. Webb, K., V. Hlady, and P. Tresco, Relative importance of surface wettability and charged functional groups on NIH 3 T3 fibroblast attachment, spreading, and cytoskeletal organization. Journal of Biomedical Materials Research 1998. 42(3): p. 422-30.

57. Jianhua, W., et al., Adhesion of mouse fibroblasts on hexamethyldisiloxane surfaces with wide range of wettability. Journal of Biomedical Materials Research Part B: Applied Biomaterials, 2007. 81B(1): p. 66-75.

58. Lee, J.H., et al., Interaction of Different Types of Cells on Polymer Surfaces with Wettability Gradient. Journal of colloid and interface science, 1998. 205(2): p. 323-330.

59. Chang, D.T., et al., Lymphocyte/macrophage interactions: Biomaterial surfacedependent cytokine, chemokine, and matrix protein production. Journal of Biomedical Materials Research Part A, 2008. 87A(3): p. 676-687.

60. Benbow, D.W., A.K. Elshennawy, and H.F. Walker, Chapter III: Metrology and Calibration, in The Certified Quality Technician Handbook. 2003, American Society for Quality.

61. Jell, G., C. Minelli, and M.M. Stevens, Biomaterial-Related Approaches: Surface Structuring, in Fundamentals of Tissue Engineering and Regenerative Medicine, U. Meyer, et al., Editors. 2009, Springer. p. 469-84.

62. Morra, M., Biochemical modification of titanium surfaces: peptides and ECM proteins. European Cells and Materials, 2006. 12: p. 1-15. 
63. Nishimoto, S., et al., The effect of titanium surface roughening on protein absorption, cell attachment, and cell spreading. The International Journal of Oral \& Maxillofacial Implants, 2008. 23: p. 675-680.

64. Puleo, D.A. and A. Nanci, Understanding and controlling the bone-implant interface. Biomaterials, 1999. 20(23-24): p. 2311-21.

65. Salido, M., et al., Actin cytoskeletal organization in human osteoblasts grown on different dental titanium implant surfaces. Histology and Histopathology, 2007. 7(241-256).

66. Shi, G., et al., $\mathrm{H} 2 \mathrm{O} 2 / \mathrm{HCl}$ and heat-treated Ti-6Al-4V stimulates pre-osteoblast proliferation and differentiation. Oral Surgery, Oral Medicine, Oral Pathology, Oral Radiology \& Endodontics 2009. 108(368-375).

67. Uggeri, J., et al., Adhesion of human osteoblasts to titanium: A morpho-functional analysis with confocal microscopy. Micron, 2010. 41: p. 210-219.

68. Das, K., S. Bose, and A. Bandyopadhyay, Surface modifications and cellmaterials interactions with anodized Ti. Acta biomaterialia, 2007. 3: p. 573-85.

69. Kunzler, T.P., et al., Systematic study of osteoblast and fibroblast response to roughness by means of surface-morphology gradients. Biomaterials, 2007. 28(13): p. 2175-2182.

70. Ricci, J.L., J.C. Grew, and H. Alexander, Connective-tissue responses to defined biomaterial surfaces. I. Growth of rat fibroblast and bone marrow cell colonies on microgrooved substrates. Journal of Biomedical Materials Research Part A, 2008. 85(2): p. 313-25.

71. Schwartz, Z. and B.D. Boyan, Underlying mechanisms at the bone-biomaterial interface. Journal of cellular biochemistry, 1994. 56(3): p. 340-347.

72. Wirth, C., et al., Nitinol surface roughness modulates in vitro cell response: a comparison between fibroblasts and osteoblasts. Materials Science and Engineering: C, 2005. 25(1): p. 51-60.

73. Ricotti, L., et al., Proliferation and skeletal myotube formation capability of $\mathrm{C} 2 \mathrm{C} 12$ and $\mathrm{H} 9 \mathrm{c} 2$ cells on isotropic and anisotropic electrospun PHB scaffolds. Biomedical Materials 2012. 7: p. 035010.

74. Bettinger, C., R. Langer, and J. Borenstein, Engineering substrate topography at the micro- and nanoscale to control cell function. Angewandte Chemie (International ed. in English), 2009. 48(30): p. 5406-5415. 
75. Lim, J.Y., et al., Human foetal osteoblastic cell response to polymer-demixed nanotopographic interfaces. Journal of The Royal Society Interface, 2005. 2(2): p. 97-108.

76. Dalby, M.J., et al., Polymer-Demixed Nanotopography: Control of Fibroblast Spreading and Proliferation. Tissue Engineering, 2002. 8(6): p. 1099-1108.

77. Dalby, M.J., et al., The control of human mesenchymal cell differentiation using nanoscale symmetry and disorder. Nature Materials, 2007. 6(12): p. 997-1003.

78. Yeung, T., et al., Effects of substrate stiffness on cell morphology, cytoskeletal structure, and adhesion. Cell motility and the cytoskeleton, 2005. 60(1): p. 24-34.

79. Georges, P.C. and P.A. Janmey, Cell type-specific resonse to growth on soft materials. Journal of Applied Physiology, 2005. 98: p. 1547-1553.

80. Solon, J., et al., Fibroblast Adaptation and Stiffness Matching to Soft Elastic Substrates. Biophysical Journal, 2007. 93(12): p. 4453-4461.

81. Chatterjee, K., et al., The effect of $3 D$ hydrogel scaffold modulus on osteoblast differentiation and mineralization revealed by combinatorial screening. Biomaterials. 31(19): p. 5051-5062.

82. Hutmacher, D.W., Scaffolds in tissue engineering bone and cartilage. Biomaterials, 2000. 21(24): p. 2529-2543.

83. Hench, L.L. and J.K. West, The Sol-Gel Process. Chemical Reviews, 1990. 90(1): p. 33-72.

84. Jones, J.R. and L.L. Hench, Biomedical materials for new millennium: perspective on the future. Materials Science and Technology, 2001. 17: p. 891900.

85. Coradin, T., M. Boissire, and J. Livage, Sol-gel chemistry in medicinal science. Current Medicinal Chemistry, 2006. 13(1): p. 99-108.

86. Hong, Z., R.L. Reis, and J.F. Mano, Preparation and in vitro characterization of novel bioactive glass ceramic nanoparticles. J Biomed Mater Res A, 2009. 88(2): p. 304-13.

87. Kortesuo, P., et al., Effect of synthesis parameters of the sol-gel-processed spraydried silica gel microparticles on the release rate of dexmedetomidine. Biomaterials, 2002. 23(13): p. 2795-2801.

88. Yang, S., et al., Simple approach for efficient encapsulation of enzyme in silica matrix with retained bioactivity. Analytical chemistry, 2009. 81(9): p. 3478-84. 
89. Chen, J., et al., A gold nanoparticles/sol-gel composite architecture for encapsulation of immunoconjugate for reagentless electrochemical immunoassay. Biomaterials, 2006. 27(10): p. 2313-21.

90. Nicoll, S.B., et al., In vitro release kinetics of biologically active transforming growth factor-beta 1 from a novel porous glass carrier. Biomaterials, 1997. 18(12): p. 853-9.

91. Pierre, A., et al., Encapsulation of deoxyribonucleic acid molecules in silica and hybrid organic-silica gels. Journal of materials science. Materials in medicine, 2001. 12(1): p. 51-5.

92. Nieto, A., et al., Cell viability in a wet silica gel. Acta Biomaterialia, 2009. 5(9): p. 3478-3487.

93. Yin, W., et al., Biocompatibility of surfactant-templated polyureananoencapsulated macroporous silica aerogels with plasma platelets and endothelial cells. J Biomed Mater Res A, 2009.

94. Domingues, R.Z., A.E. Clark, and A.B. Brennan, A sol-gel derived bioactive fibrous mesh. Journal of biomedical materials research, 2001. 55(4): p. 468-74.

95. Kawashita, M., et al., Antibacterial silver-containing silica glass prepared by solgel method. Biomaterials, 2000. 21(4): p. 393-8.

96. Czarnobaj, K. and J. Lukasiak, In vitro release of cisplatin from sol-gel processed organically modified silica xerogels. Journal of materials science. Materials in medicine, 2007. 18(10): p. 2041-4.

97. Kim, J.W., L.U. Kim, and C.K. Kim, Size control of silica nanoparticles and their surface treatment for fabrication of dental nanocomposites. Biomacromolecules, 2007. 8(1): p. 215-22.

98. MacCraith, B.D., et al., Sol-gel coatings for optical chemical sensors and biosensors. Sensors and Actuators B: Chemical, 1995. 29(1-3): p. 51-57.

99. Hench, L.L., Bioactive materials: the potential for tissue regeneration. Journal of biomedical materials research, 1998. 41(4): p. 511-8.

100. Hench, L.L., I.D. Xynos, and J.M. Polak, Bioactive glasses for in situ tissue regeneration. J Biomater Sci Polym Ed, 2004. 15(4): p. 543-62.

101. Jell, G. and M.M. Stevens, Gene activation by bioactive glasses. Journal of materials science. Materials in medicine, 2006. 17(11): p. 997-1002.

102. Brinker, C.J. and G.W. Scherer, Sol-Gel Science: The Physics and Chemistry of Sol-Gel Processing. 1990, San Diego, CA: Academic Press Inc. 
103. Soleimani Dorcheh, A. and M.H. Abbasi, Silica aerogel; synthesis, properties and characterization. Journal of Materials Processing Technology, 2008. 199(1-3): p. 10-26.

104. Jones, J., Review of bioactive glasses: From Hench to hybrids. Acta Biomaterialia, 2013. 9(1): p. 4457-4486.

105. Novak, B., Hybrid nanocomposite materials - between inorganic glasses and organic polymers. Advanced Materials, 1993. 5: p. 422-433.

106. Valliant, E. and J. Jones, Softening bioactive glass for bone regeneration: sol-gel hybrid materials. Soft Matter, 2011. 7: p. 5083-5095.

107. Jones, J., New trends in bioactive scaffolds: the importance of nanostructure. Journal of the European Ceramic Society, 2009. 29: p. 1275-1281.

108. Iler, R., The chemistry of silica: solubility, polymerization, colloid and surface properties and biochemistry of silica. 1979, New York: Wiley-Interscience.

109. Saravanapaan, P., et al., Bioactivity of gel-glass powders in the CaO-SiO2 system: a comparison with ternary (CaO-P2O5-SiO2) and quaternary glasses (SiO2CaO-P2O5-Na2O). Journal of Biomedical Materials Research Part A, 2003. 66A: p. 110-119.

110. Olmo, N., et al., Bioactive sol-gel glasses with and without hydrocarbonite apatite layer as substrates for osteoblast cell adhesion and proliferation. Biomaterials, 2003. 24: p. 3383-3393.

111. Salinas, A.J., M. Vallet-Regi, and I. Izquierdo-Barba, Biomimetic Apatite Deposition on Calcium Silicate Gel Glasses. Journal of Sol-Gel Science and Technology, 2001. 21: p. 13-25.

112. Keeting, P., et al., Zeolite a increases proliferation, differentiation, and transforming growth factor $\beta$ production in normal adult human osteoblast-like cells in vitro. Journal of Bone and Mineral Research, 1992. 7(11): p. 1281-1289.

113. Valerio, P., et al., The effect of ionic products from bioactive glass dissolution on osteoblast proliferation and collagen production. Biomaterials, 2004. 25(15): p. 2941-2948.

114. Reffitt, D.M., et al., Orthosilicic acid stimulates collagen type I synthesis and osteoblastic differentiation in human osteoblast-like cells in vitro. Bone, 2003. 32: p. 127-135.

115. Zou, S., et al., The Effects of Silicate Ions on Human Osteoblast Adhesion, Proliferation, and Differentiation. Journal of Biomedical Materials Research Part B: Applied Biomaterials, 2008: p. 123-130. 
116. Gibson, I., et al., Enhanced in vitro cell activity and surface apatite layer formation on novel silicon-substituted hydroxyapatite. Bioceramics, 1999. 12: p. 191-194.

117. Feng, J., et al., Stimulating effect of silica-containing nanospheres on proliferation of osteoblast-like cells. Journal of Materials Science: Materials in medicine, 2007. 18(2167-2172).

118. Varanasi, V., et al., Si and Ca Individually and Combinatorially Target Enhanced MC3T3 Subclone 4 Early Osteogenic Marker Expression. Journal of Oral Implantology, 2012. 38(4): p. 325-336.

119. Anderson, S.I., et al., Evaluation of the osteoblast response to a silica gel in vitro. Journal of Materials Science: Materials in medicine, 1998. 9: p. 731-735.

120. Dvorak, M. and D. Riccardi, Ca2+ as an extracellular signal in bone. Cell calcium, 2004. 35(3): p. 249-255.

121. Zayzafoon, M., Calcium/calmodulin signaling controls osteoblast growth and differentiation. Journal of cellular biochemistry, 2006. 97(1): p. 56-70.

122. Zhou, H., et al., The bio-functional role of calcium in mesoporous silica xerogels on the responses of osteoblasts in vitro. Journal of Materials Science. Materials in Medicine, 2010.

123. Maeno, S., et al., The effect of calcium ion concentration on osteoblast viability, proliferation and differentiation in monolayer and $3 D$ culture. Biomaterials, 2005. 26(23): p. 4847-4855.

124. Conrads, K., et al., A combined proteome and microarray investigation of inorganic phosphate induced pre-osteoblast cells. Molecular \& Cellular Proteomics 2005. 4(9): p. 1284-96.

125. Beck, G.R., Inorganic phosphate as a signaling molecule in osteoblast differentiation. Journal of cellular biochemistry, 2003. 90(2): p. 234-243.

126. Julien, M., et al., Phosphate-Dependent Regulation of MGP in Osteoblasts: Role of ERK1/2 and Fra-1. Journal of Bone and Mineral Research, 2009. 24(11): p. 1856-1868.

127. Beck, G.R., E. Moran, and N. Knecht, Inorganic phosphate regulates multiple genes during osteoblast differentiation, including Nrf2. Experimental cell research, 2003. 288: p. 288-300.

128. Beck, G.R., Osteopontin regulation by inorganic phosphate is ERK1/2-, protein kinase $C$-, and proteasome-dependent. The Journal of biological chemistry, 2003. 278(43): p. 41921-9. 
129. Meleti, Z., I.M. Shapiro, and C.S. Adams, Inorganic Phosphate Induces Apoptosis of Osteoblast-like Cells in Culture. Bone, 2000. 27(3): p. 359-366.

130. Bourgine, A., et al., Inorganic phosphate stimulates apoptosis in murine M06-G3 odontoblast-like cells. Archives of Oral Biology, 2011. 56: p. 977-983.

131. Newman, S., P. Pellow, and S. Clarke, Droplet size distribution of nebulised aerosols for inhalation therapy. Clinical Physics and Physiological Measuremen, 1986. 7(139-146).

132. O'Callaghan, C. and P. Barry, The science of nebulised drug delivery. Thorax, 1997. 52(Suppl 2): p. S31-S44.

133. Le Brun, P.P.H., et al., A review of the technical aspects of drug nebulization. Pharmacy World \& Science, 2000. 22(3): p. 75-81.

134. Newman, S., P. Pellow, and S. Clarke, Drop sizes from medical atomisers for drug solutions with different viscosites and surface tensions. Atomization and Spray Technology, 1987. 3(1-11). 


\section{CHAPTER TWO: DEVEOLOPMENT OF VAPOR DEPOSITED SOL-GEL PARTICLES ${ }^{1}$}

This chapter develops methods for generating vapor deposited sol particles as well as characterizing particle morphology, size distribution, and degradation and their affect on substrate surface hydrophobicity and roughness. Finally initial cell behavior in response to particles was assessed. The work in this chapter addresses Specific Aim 1.

\section{INTRODUCTION}

Surface modification and coatings for orthopedic and dental implants have been shown to promote osseointegration and mechanical fixation, increasing long-term implant effectiveness. In addition to surface roughening techniques, current methods of surface coating implants include plasma spraying, sputter deposition, electrophoretic deposition, biomimetic precipitation, and sol-gel coating [1-3]. Most established approaches have distinct shortcomings, especially those involving high energy plasma spraying or sputter coating [4-7]. These limitations include the introduction of surface porosity and residual stresses at the coating interface during processing, post-implantation concerns regarding delamination of applied coatings, and limitations in the size of treatable features [8-12]. For this reason, a significant research effort is aimed at improving the performance of implantable materials by better understanding and applying surface modification (e.g. chemistry, hydrophobicity, roughness, eluting coatings) to promote integration as well as resistance to infections. Many of these efforts include the surface modification of tissue engineering materials to make them bioactive in order to help restore and/or regenerate cell, tissue, and organ structure and function [13-15].

Bioactive glasses are silica-based materials most prominently associated with orthopedic applications in both traditional implants as well as hard and soft tissue

\footnotetext{
1 The material presented in this chapter was previously published in the Journal of Biomedical Materials Research Part A. [Snyder KL, Holmes HR, VanWagner MJ, Hartman NJ, Rajachar RM. Development of Vapor Deposited Silica Sol-Gel Particles for Use as a Bioactive Materials System. Journal of Biomedical Materials Part A 2012 (in press)] Reprinted with permission (see Appendix A).
} 
engineering materials [16]. These matrices are porous networks obtained by the hydrolysis and condensation-polymerization of metallic alkoxides, most commonly silicon dioxide $\left(\mathrm{SiO}_{2}\right)$ [17]. Sol-gel processing methods are becoming an increasingly popular approach for generating these glass materials because they offer simple methods to control composition and structure, making them suitable for a variety of biomedical applications [18, 19]. Sol-gel materials are produced when the solvent is removed from a colloidal suspension of precursors (sol) and the material is allowed to solidify (gel). In the presence of water, the alkoxide groups are hydrolyzed, creating silanol groups and releasing alcohol. Condensation (polymerization) between silanol groups then occurs, creating $\mathrm{Si}-\mathrm{O}-\mathrm{Si}$ bonds. Extension of this reaction leads to a silica network with pores resulting from the removal of water and alcohol molecules. As the polycondensation reaction continues, colloidal particles are formed in the solution. Over time the colloidal silica particles link together, increasing the viscosity of the solution, to form a solid threedimensional network. Due to their mild processing conditions, sol-gel materials can as also serve as controlled delivery vehicles for inorganic and organic small molecules (i.e. ions, drugs, proteins, antibodies, DNA) and even cells [20-25]. These materials have an inherently active influence on cell behavior modulated in part by ion release, surface chemistry, and topography. Dissolution products (e.g. Si, Ca, P ions) from these bioactive glasses can stimulate gene expression and promote osteogenesis and angiogenesis [26, 27]. The exact nature by which these materials influence gene expression and promote tissue regeneration is not fully understood and warrants further exploration $[28,29]$.

The aim of this work was to develop a novel nebulizer deposition system to generate vaporized sol-gel nanoparticles for the controlled surface modification of biomaterial substrates at ambient temperatures and pressures. More specifically, a jet type-compressed air nebulizer is used to aerosolize sol-based materials. In jet-type nebulizers, compressed air passes through a narrow hole and collides with a colloidal sol solution, generating vapor particles through momentum transfer (physical collision). The complex liquid break-up process is usually a combination of turbulent rupture of the instable liquid column and secondary droplet break-up [30, 31]. Large droplets impact on internal components of the nebulizer and only smaller droplets with less inertia can 
follow the flow of the compressed air and pass through the spray nozzle [32, 33]. Control over the vaporized particle size distribution is dictated by the formulation properties of the colloidal sol-gel solution to a significant degree, with key variables being species concentration $\left(\mathrm{H}_{2} \mathrm{O}\right.$ : alkoxide $)$ and $\mathrm{pH}[17,19]$. The method developed here allows for a layer of sol particles to be deposited onto substrates, providing a large surface area, and creating a unique nano-structured surface topography and controlled modification of substrate surface properties. Conversely, most other sol-gel application methods consisting of dip, spin or spray coating, generate uniform thin film sol-gels [18, 34-36]. Unlike other common bioglass processing methods, the nebulizer-based approach also allows surfaces to be coated without the use of high temperatures or other extreme processing conditions that may alter the substrate surface or the character of delivered factors. This approach has the potential for easily creating complex multi-layered biomimetic coatings-incorporating a variety of small molecules, cells, and bone-like mineral to functionalize both traditional orthopedic-dental implants and tissue engineering constructs. A series of vapor deposited silica particles was generated to determine how changes of key formulation and manufacturing parameters $\left(\mathrm{H}_{2} \mathrm{O}\right.$ : alkoxide, $\mathrm{pH}$, deposition time, and substrate character) affect morphology, size distribution, and degradation behavior of particles as well as the overall surface properties (hydrophobicity and roughness) of the substrate. Additionally, we assessed the cellular biocompatibility by evaluating cell attachment in response to particles.

\section{MATERIALS AND METHODS}

\section{Sol Preparation}

The base sol solution used in these experiments was a 16:1 molar ratio of deionized water and tetramethyl orthosilicate (TMOS; Sigma Aldrich). The solution was mixed in a $50 \mathrm{ml}$ centrifuge tube and catalyzed with $0.04 \mathrm{M}$ hydrochloric acid $(\mathrm{HCl}$; Sigma Aldrich) at $2 \mu 1$ per gram of $\mathrm{H}_{2} \mathrm{O}$ /TMOS. Catalyzed solutions were agitated for 20 minutes to ensure that the solution was completely mixed. The clear homogenous material was allowed to rest for 30 minutes at $25^{\circ} \mathrm{C}$ before vaporization. 


\section{Vaporization System and Deposition}

Nebulizer-based vaporization was carried out using a jet-type nebulizer (Pari LC Plus, Allegro Medical) attached to a $500 \mathrm{ml}$ vaporization chamber (Figure 2.1). Sol solution was added to the nebulizer and connected to a compressed air supply with a $0.2 \mu \mathrm{m}$ filter. Air pressure was maintained at 40psi during vaporization using an in-line pressure gauge. Samples were removed from chamber immediately after coating and allowed to fully polycondensate into a solid gel for 2 minutes. Samples were covered and stored for 3-7 days at $25^{\circ} \mathrm{C}$ until further use.

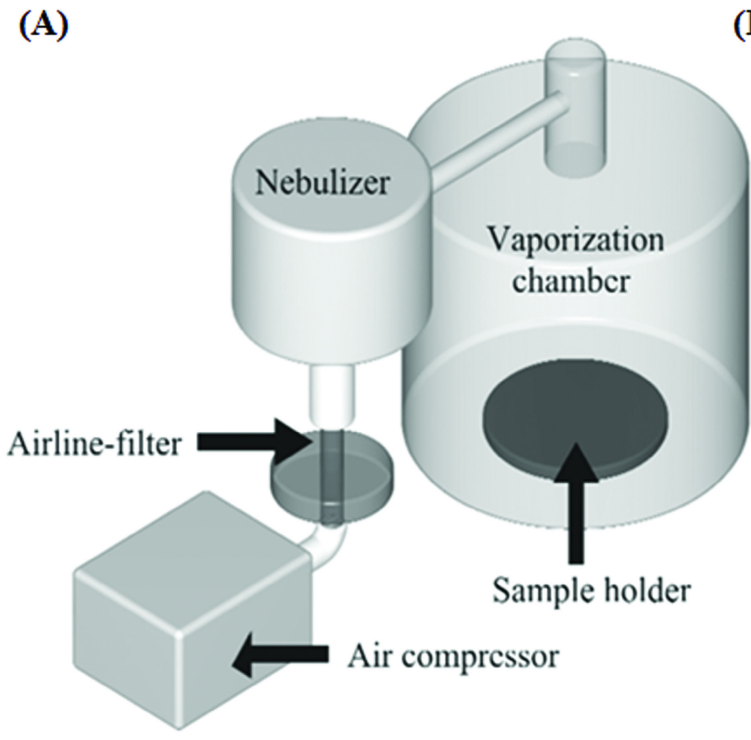

(B)To Vaporization

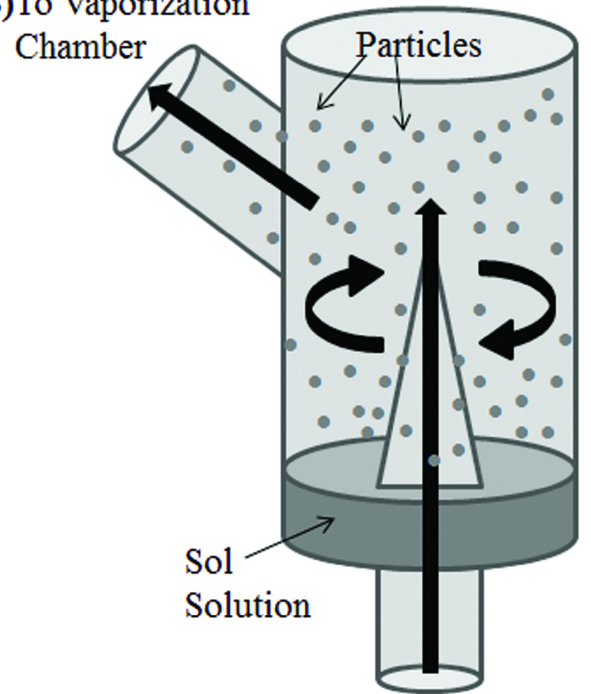

Air flow-from compressor

Figure 2.1. Schematic of vaporization chamber and formation of vaporized sol particles. Vapor deposited sol particles are generated using $\mathrm{H}_{2} \mathrm{O}$-tetramethyl orthosilicate (TMOS) catalyzed with $\mathrm{HCl}$. (A) A jet-type nebulizer is attached to an air compressor and feeds into a substrate chamber. (B) Applied air flow (40psi) enters nebulizer inducing turbulent rupture of the sol, generating particles that exit the nebulizer and deposit on to the substrate. 


\section{Compositional Analysis}

The chemical composition of the sol was determined using a series of five random energy dispersive X-ray spectrometry (EDS) measurements. Output peaks of interest include silicon and oxygen.

\section{Sol Formulation and Manufacturing Parameters}

The major sol formulation and manufacturing parameters affecting the vapor particle morphology, size distribution, and degradation behavior are: $\mathrm{H}_{2} \mathrm{O}$ :TMOS molar ratio, solution $\mathrm{pH}$, deposition time, and substrate character. Molar ratios $\left(\mathrm{H}_{2} \mathrm{O}: \mathrm{TMOS}\right)$ of 16:1 and 8:1 were used for analysis. For $\mathrm{pH}$ adjustments, sol solutions were adjusted to either 1 or 6 using $\mathrm{HCl}$ or $\mathrm{NaOH}$, respectively, before vapor deposition from an original $\mathrm{pH}$ of 3. Sol particles were deposited on to non-tissue culture polystyrene (PS; VWR) for 30, 60, and 90 seconds for both $\mathrm{H}_{2} \mathrm{O}$ :TMOS and $\mathrm{pH}$ experiments. To investigate the influence of substrate surface properties on particle morphology and size distribution, sol particles were deposited onto non-tissue culture treated polystyrene (PS), tissue culture treated polystyrene (TCPS; BD Bioscienes), and poly-L-lactide acid (PLLA; NatureWorks) films. TCPS and PLLA were chosen as substrates due to the differences in surface hydrophobicity (contact angle: untreated PS $=73.59 \pm 1.94^{\circ}, \mathrm{TCPS}=41.08 \pm 1.91^{\circ}$, $\operatorname{PLLA}=92.49 \pm 0.22^{\circ}$ ).

\section{Morphology and Size Distribution}

Scanning electron microscopy images were used to make all particle morphology and size distribution measurements. Samples were sputter coated with $\mathrm{Pt} / \mathrm{Pd}$ and imaged with a field emission scanning electron microscope (FE-SEM; Hitachi S-4700) under high vacuum conditions at an accelerating voltage of $1-5 \mathrm{kV}$. Quantitative measures of particle size distribution were made using a custom written MATLAB macro. All size distribution measurements were based on surface area measures for each individual particle.

\section{Degradation Behavior}

The degradation behavior of the sol particle formulations was determined by depositing particles onto non-tissue culture PS (16:1 pH 3 for 30, 60, and 90s, 16:1 pH 1 
for 60s). Silica matrix degradation over time (phenol-free Dulbecco's Modified Eagle Medium (DMEM; Gibco) at $37^{\circ} \mathrm{C}$ ) was assessed using a modified colorimetric molybdenum blue assay at $810 \mathrm{~nm}$. Percentage silica matrix degradation was determined as a function of total silica deposited.

\section{Surface Hydrophobicity and Roughness}

Sol was prepared as described above and labeled with Rhodamine B $(0.075 \mu \mathrm{g} / \mathrm{ml}$; Molecular Probes, Invitrogen) for image analysis. To evaluate the relationship that exists between the deposition time of particles and subsequent changes in surface properties, as well as demonstrate the ability to easily generate a single substrate that multiple regions of distinct surface character, a gradient was generated by vapor coating PLLA films ( $\mathrm{t}=$ $0.5,1,2,5$, and 15 minutes). PLLA was chosen as a model substrate because it would demonstrate the largest change in surface character with the deposition of sol particles due to its hydrophobic character. Samples were imaged using fluorescent microcopy, covered, and stored at room temperature until further analysis. The effect of vapor deposition on substrate surface hydrophobicity was determined using standard contact angle methods (sessile drop method). A Kruss G10 goniometer (Rame-Hart, Inc.) system was used to make all measurements. Droplets of di- $\mathrm{H}_{2} \mathrm{O}$ were added to the center of each sample; angle measurements at the liquid/substrate surface interface were taken and droplets were added until a plateau was reached (approximately $3-12 \mu 1$ total). All measurements were taken at $25^{\circ} \mathrm{C}$.

Comparative surface roughness of the PLLA film coated with a gradient of particles was determined using atomic force microscopy (AFM). A Nanoscope E (Digital Instruments) AFM system (constant deflection mode) with a micro-fabricated silicon nitride cantilever was used for imaging in air with a $5 \mu \mathrm{m}$ scanner. The surface topographical images of the PLLA film coated with vapor particles obtained by AFM were processed using Digital Instruments AFM software. RMS roughness $(R q)$ of the surface, defined as the standard deviation of the elevation ( $z$ values) within the given area, was determined within the image area $(2.5 \mu \mathrm{m})$. Images were taken at six different locations and the average RMS roughness was determined based on these images. 
Measurements were taken at regions corresponding to $0.5,1$, and 2 minute deposition times on a sol gradient.

\section{Cell Attachment}

Samples were generated by depositing sol solution (16:1 $\mathrm{H}_{2} \mathrm{O}$ :TMOS; $\mathrm{pH}$ 3) for 60 and 90 seconds on to non-tissue culture PS. Samples were sterilized using ethylene oxide and rinsed three times with sterile phosphate buffered saline (PBS). MC3T3-E1 Subclone 4 osteoblast progenitors (ATCC) were cultured directly on plates coated with particles or non-tissue culture PS as a control $\left(1 \times 10^{4}\right.$ cells $\left./ \mathrm{cm}^{2}\right)$ at $37^{\circ} \mathrm{C}$ and $5 \% \mathrm{CO}_{2}$ in Minimal Essential Media ( $\alpha$-MEM; Hyclone) supplemented with 1\% penicillinstreptomycin (Mediatech) and 10\% fetal bovine serum (FBS; Hyclone). Cells were also cultured on non-tissue culture PS using media that had been conditioned for 48 hours with particles deposited for 90 seconds at $37^{\circ} \mathrm{C}$ and $5 \% \mathrm{CO}_{2}$.

At 24 and 48 hours, cells were fixed (4\% paraformaldehyde), stained (TRITCconjugated Phalloidin and 4',6-diamidino-2-phenylindole, DAPI; Molecular Probes, Invitrogen), and imaged (Olympus BX51 microscope). Cell attachment was determined through direct cell counts and normalized to control samples with untreated media. To determine whether particle degradation affected culture media with time, $\mathrm{pH}$ measurements were made at both 24 and 48 hours.

\section{Statistics}

All experiments were performed in triplicate. Data was analyzed for significance using an analysis of variance (ANOVA) and a Tukey's post-hoc test for pairwise comparison. Statistical significance defined as a p-value less than $0.05(\mathrm{p}<0.05)$. Error bars in text and graphs represent standard error of the mean $( \pm \mathrm{SEM})$. 


\section{$\underline{\text { RESULTS }}$}

\section{Effect of Formulation and Manufacturing Parameters on Particle Morphology and Size Distribution}

\section{$\mathrm{H}_{2} \mathrm{O}$ :TMOS MOLAR RATIO}

Silica nano- and micro-particles were generated using the vaporization chamber. EDS analysis of the particles showed a percent atomic composition of $43.47 \pm 1.76$ silicon and $54.88 \pm 1.30$ oxygen with trace amounts of carbon registering from the underlying polystyrene plate. The effect of $\mathrm{H}_{2} \mathrm{O}$ :TMOS molar ratio on sol particle morphology and size distribution was determined. Particles were generated from solutions with

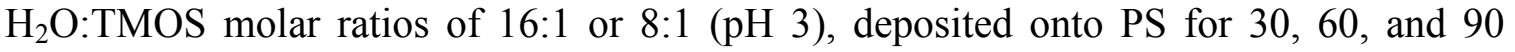
seconds, and imaged using FE-SEM (Figure 2.2A). At a molar ratio of 8:1 average particle area $\left(\mu \mathrm{m}^{2}\right)$ did not change significantly with deposition time $[0.136 \pm 0.01 \mathrm{t}=30 \mathrm{~s}$, $0.114 \pm 0.01 \mathrm{t}=60 \mathrm{~s}, 0.130 \pm 0.02 \mathrm{t}=90 \mathrm{~s} ; \mathrm{p} \geq 0.5]$ and the particle size distributions (Figure 2.2B) were also consistent for all deposition times. At a molar ratio of 16:1 the average particle area $\left(\mu \mathrm{m}^{2}\right)$ changed significantly with time $[0.620 \pm 0.13 \mathrm{t}=30 \mathrm{~s}, 0.076 \pm 0.01 \mathrm{t}=60 \mathrm{~s}$, $0.329 \pm 0.06 \mathrm{t}=90 \mathrm{~s} ; \mathrm{p}<0.0001]$ and the size distributions (Figure 2.2C) also varied with deposition time. At each deposition time the average particle area for the $8: 1$ and 16:1 particles was significantly different; the average area was larger for 16:1 particles at 30 and 90 seconds $(\mathrm{p}<0.0001)$ and 8:1 particles at 60 seconds $(\mathrm{p}<0.002$; Figure 2.2D).

\section{SOL PH}

To investigate the effect of $\mathrm{pH}$ on particle morphology and size distribution, the $\mathrm{pH}$ of sol solutions (16:1 $\mathrm{H}_{2} \mathrm{O}$ :TMOS) was adjusted from 3 to 1 or 6 before vapor deposition onto PS for 30, 60, and 90 seconds. FE-SEM images show particle morphologies at 30, 60, and 90 seconds (Figure 2.3A). Particles generated from solutions with an unadjusted pH 3 had average particle areas $\left(\mu \mathrm{m}^{2}\right)[0.620 \pm 0.13 \mathrm{t}=30 \mathrm{~s}, 0.076 \pm 0.01$ $\mathrm{t}=60 \mathrm{~s}, 0.329 \pm 0.06 \mathrm{t}=90 \mathrm{~s} ; \mathrm{p}<0.0001]$ and size distributions (Figure 2.3B) that varied at each deposition time. Particles generated from solutions with an adjusted $\mathrm{pH}$ of 1 had average particle areas $\left(\mu \mathrm{m}^{2}\right)$ and size distributions (Figure 2.3C) that were similar regardless of deposition time, with the average particle area being significantly smaller at 
90 seconds than the average area at 60 seconds $[0.052 \pm 0.01 \mathrm{t}=30 \mathrm{~s}, 0.058 \pm 0.004 \mathrm{t}=60 \mathrm{~s}$, $0.040 \pm 0.001 \mathrm{t}=90 \mathrm{~s} ; \mathrm{p}<0.0001]$. Though the average area $\left(\mu \mathrm{m}^{2}\right)$ of particles generated from $\mathrm{pH} 6$ solutions increased with deposition time, these changes were not statistically significant $[0.133 \pm 0.05 \mathrm{t}=30 \mathrm{~s}, 0.296 \pm 0.08 \mathrm{t}=60 \mathrm{~s}, 0.339 \pm 0.07 \mathrm{t}=90 \mathrm{~s} ; \mathrm{p}=0.1]$ and particles were much more irregular in shape than those generated from solutions with $\mathrm{pH}$ equal to 1 or 3 (Figure 2.3A). The size distributions of the $\mathrm{pH} 6$ particles also varied with deposition time (Figure 2.3D). At 30 seconds the average particle area was significantly different for all three particle formulations with $\mathrm{pH} 1$ particles being smallest and $\mathrm{pH} 3$ particles being largest $(\mathrm{p}<0.02)$. At 60 seconds, $\mathrm{pH} 1$ and 3 particles were significantly smaller than $\mathrm{pH} 6$ particles $(\mathrm{p}<0.0001)$, and at 90 seconds the average particle area of $\mathrm{pH}$ 1 particles was significantly smaller than $\mathrm{pH} 3$ and $\mathrm{pH} 6$ particles $(\mathrm{p}<0.0001$; Figure 2.3E).

\section{SUBSTRATE}

The effect of substrate surface properties on particle morphology and size distribution was also investigated (16:1 $\mathrm{H}_{2} \mathrm{O}$ :TMOS, $\left.\mathrm{pH} 3\right)$. In addition to PS, particles were deposited onto TCPS and PLLA (Figure 4A). Particles deposited onto TCPS had average particle areas $\left(\mu \mathrm{m}^{2}\right)$ that were significantly smaller at 60 seconds than 30 or 90 seconds $[0.123 \pm 0.02 \mathrm{t}=30 \mathrm{~s}, 0.044 \pm 0.01 \mathrm{t}=60 \mathrm{~s}, 0.104 \pm 0.02 \mathrm{t}=90 \mathrm{~s} ; \mathrm{p}<0.01]$. The size distribution of particles deposited onto TCPS also varied with deposition time (Figure 2.4C). Particles deposited onto PLLA maintained a similar size distributions regardless of deposition time (Figure 2.4D), though the average particle areas $\left(\mu \mathrm{m}^{2}\right)$ were significantly different from each other at each deposition time $[0.138 \pm 0.02 \mathrm{t}=30 \mathrm{~s}$, $0.049 \pm 0.002 \mathrm{t}=60 \mathrm{~s}, 0.083 \pm 0.01 \mathrm{t}=90 \mathrm{~s} ; \mathrm{p}<0.0001]$. Similar to particles deposited onto PS, particles on TCPS and PLLA had largest average particle areas at 30 seconds, a decrease in size at 60 seconds and a subsequent increase at 90 seconds. At 30 and 90 seconds the average area of particles deposited onto PS was significantly larger than that of particles deposited on to TCPS or PLLA $(\mathrm{p}<0.0001)$. At 60 seconds the average particle size was not significantly different on any of the substrates $(p=0.6$; Figure 2.4E). 
(A)
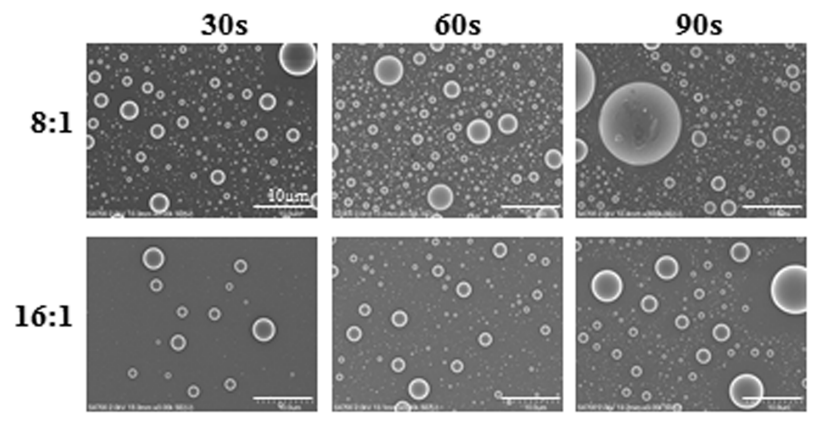

(C)

究

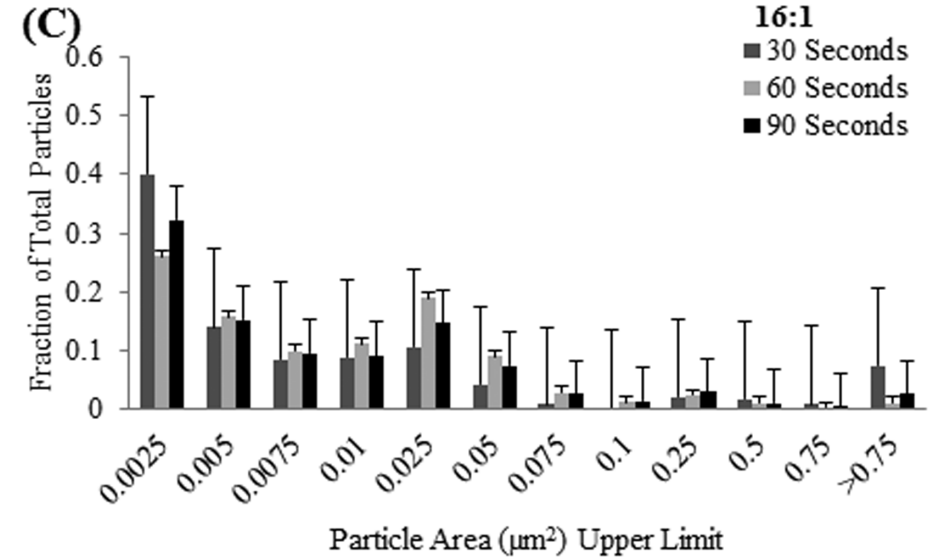

(B)

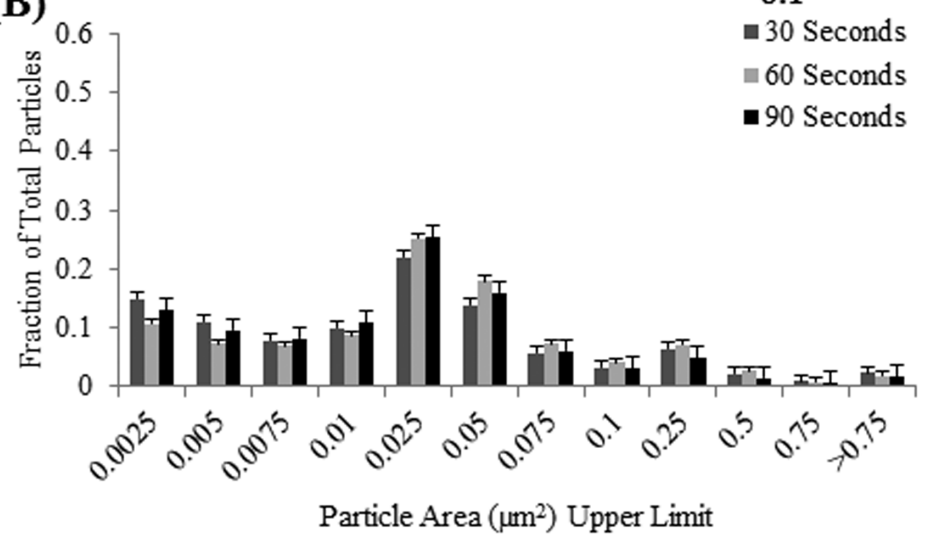

(D)

\begin{tabular}{|c|c|c|c|}
\hline \multirow{2}{*}{$\mathbf{H}_{2}$ O: TMOS } & \multicolumn{3}{|c|}{ Average Particle Area $\boldsymbol{\mu m}^{\mathbf{2}}( \pm$ SEM) } \\
\cline { 2 - 4 } & $\mathbf{3 0 ~ S e c}$ & $\mathbf{6 0 ~ S e c}$ & $\mathbf{9 0 ~ S e c}$ \\
\hline $\mathbf{8 : 1}$ & $0.136 \pm 0.01^{\mathrm{a}, 1}$ & $0.114 \pm 0.01^{\mathrm{a}, 3}$ & $0.130 \pm 0.02^{\mathrm{a}, 5}$ \\
\hline $\mathbf{1 6 : 1}$ & $0.620 \pm 0.13^{\mathrm{b}, 2}$ & $0.076 \pm 0.01^{\mathrm{c}, 4}$ & $0.329 \pm 0.06^{, \mathrm{d}, 6}$ \\
\hline
\end{tabular}

Figure 2.2. Effect of $\mathrm{H}_{2} \mathrm{O}: \mathrm{TMOS}$ on particle morphology and size distribution. Sol solutions ( $\mathrm{pH} 3$ ) with $\mathrm{H}_{2} \mathrm{O}: \mathrm{TMOS}$ of 8:1 and 16:1 were vapor deposited on to PS for 30,60, and 90 seconds, (A) imaged using FE-SEM (scale bar $=10 \mu \mathrm{m}$ ) and the area-based size distribution of particles was analyzed using a MATLAB macro [(B) 8:1 (C) 16:1]. (D) Average particle area did not change with increasing deposition time for 8:1 particles. Average area of 16:1 particles was initially largest, decreased at 60 seconds followed by an increase at 90 seconds. A molar ratio of 16:1 produced larger particles at 30 and 90 seconds while at 60 seconds a ratio of $8: 1$ yielded relatively larger particles. All comparisons were made using ANOVA, $p$-values $<0.05$ were considered significant. Values with different letters/numbers are significantly different-- letters compare different deposition times in same group (rows) and numbers compare different groups within same deposition time (columns). Error bars represent \pm SEM. 
(A)

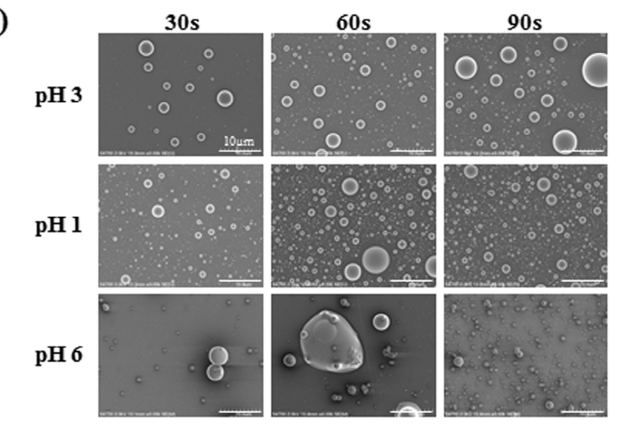

(C)

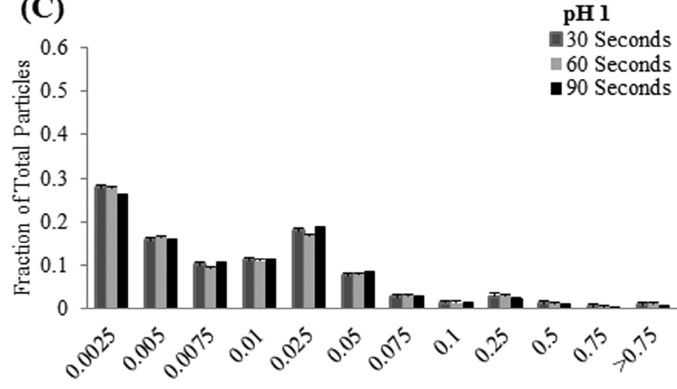

(B)

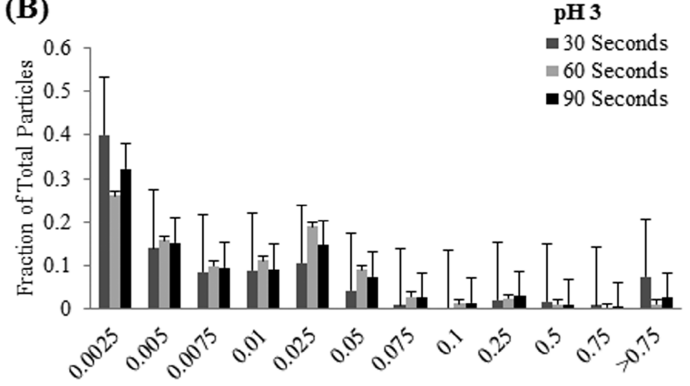

(D)

Particle Area $\left(\mu \mathrm{m}^{2}\right)$ Upper Limit

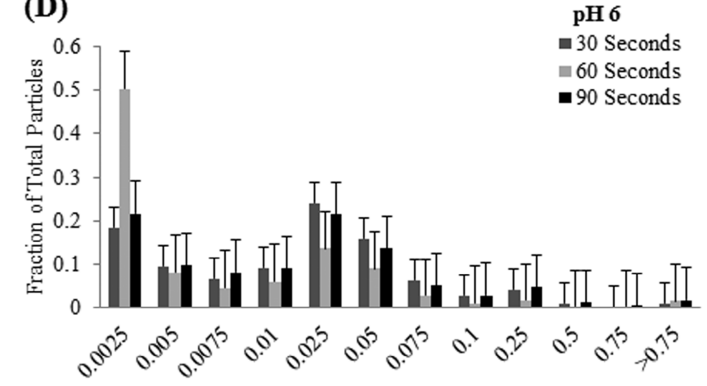

Particle Area $\left(\mu m^{2}\right)$ Upper Limit

(E)

\begin{tabular}{|c|c|c|c|}
\hline \multirow{2}{*}{$\mathbf{p H}$} & \multicolumn{3}{|c|}{ Average Particle Area $\boldsymbol{\mu m}^{\mathbf{2}}( \pm$ SEM) } \\
\cline { 2 - 4 } & $\mathbf{3 0 ~ S e c}$ & $\mathbf{6 0 ~ S e c}$ & $\mathbf{9 0 ~ S e c}$ \\
\hline pH 3 & $0.620 \pm 0.13^{\mathrm{a}, 1}$ & $0.076 \pm 0.01^{\mathrm{b}, 4}$ & $0.329 \pm 0.06^{\mathrm{c}, 6}$ \\
\hline pH 1 & $0.052 \pm 0.01^{\mathrm{d}, \mathrm{e}, 2}$, & $0.058 \pm 0.004^{\mathrm{d}, 4}$ & $0.040 \pm 0.001^{\mathrm{e}, 7}$ \\
\hline $\mathbf{p H} 6$ & $0.133 \pm 0.05^{\mathrm{f}, 3}$ & $0.296 \pm 0.08^{\mathrm{f}, 5}$ & $0.339 \pm 0.07^{\mathrm{f}, 6}$ \\
\hline
\end{tabular}

Figure 2.3. Effect of solution $\mathbf{p H}$ on particle morphology and size distribution. The $\mathrm{pH}$ of sol solutions $\left(16: 1 \mathrm{H}_{2} \mathrm{O}: \mathrm{TMOS}\right)$ was adjusted from 3 to 1 or 6 , deposited on to PS for 30, 60, and 90 seconds, (A) imaged using FE-SEM (scale bar $=10 \mu \mathrm{m}$ ), and the area-based size distribution was analyzed using a MATLAB macro [(B) pH 3, (C) pH 1, (D) pH 6]. (E) Particles generated from a solution with a pH of 3 produced the largest average particles at 30 seconds with a decrease in particle area at 60 seconds and an increase at 90 seconds. Solutions with a pH 1 generated particles with average areas that decreased at 90 seconds. Average particle area did not change in $\mathrm{pH} 6$ particles regardless of deposition time. At 30 seconds, $\mathrm{pH} 1$ particles generated the smallest average particles and $\mathrm{pH} 3$ the largest. At 60 seconds, $\mathrm{pH} 6$ particles were larger than $\mathrm{pH} 1$ and $\mathrm{pH} 3$ particles, and at 90 seconds the average area of $\mathrm{pH} 1 \mathrm{particles}$ is smaller than $\mathrm{pH} 3$ and $\mathrm{pH} 6$ particles. All comparisons were made using ANOVA, p-values < 0.05 were considered significant. Values with different letters/numbers are significantly different-- letters compare different deposition times in same group (rows) and numbers compare different groups within same debosition time (columns). Error bars rebresent \pm SEM. 

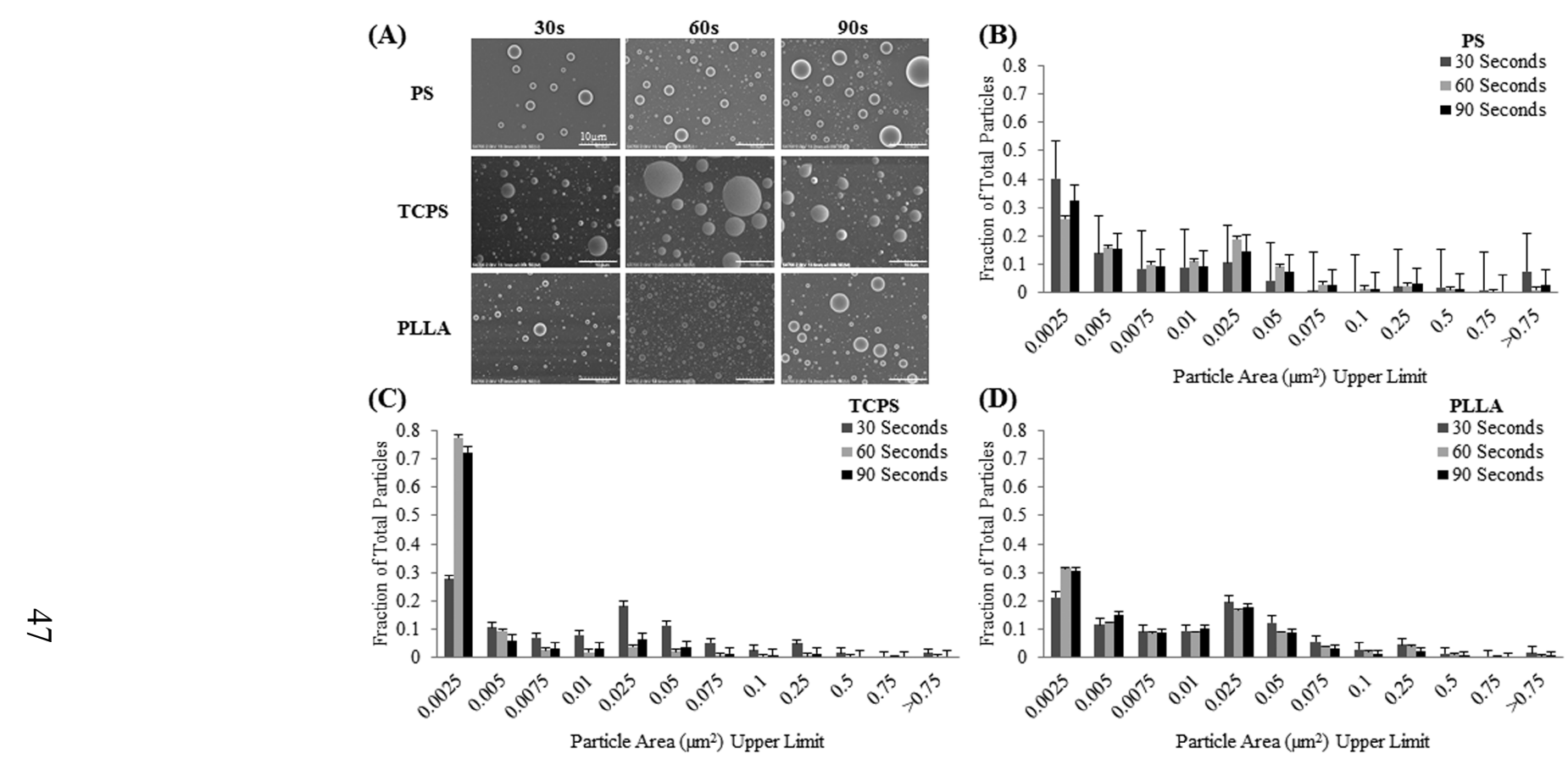

Particle Area $\left(\mu m^{2}\right)$ Upper Limit

Particle Area $\left(\mu \mathrm{m}^{2}\right)$ Upper Limi

\begin{tabular}{|c|c|c|c|}
\hline \multirow{2}{*}{ Substrate } & \multicolumn{3}{|c|}{ Average Particle Area $\boldsymbol{\mu m}^{\mathbf{2}}( \pm$ SEM) } \\
\cline { 2 - 4 } & $\mathbf{3 0 ~ S e c}$ & $\mathbf{6 0} \mathbf{~ S e c}$ & $\mathbf{9 0} \mathbf{~ S e c}$ \\
\hline PS & $0.620 \pm 0.13^{\mathrm{a}, 1}$ & $0.076 \pm 0.01^{\mathrm{b}, 3}$ & $0.329 \pm 0.06^{\mathrm{c}, 4}$ \\
\hline TCPS & $0.123 \pm 0.02^{\mathrm{d}, 2}$ & $0.044 \pm 0.01^{\mathrm{e}, 3}$ & $0.104 \pm 0.02^{\mathrm{d}, 5}$ \\
\hline PLLA & $0.138 \pm 0.02^{\mathrm{f}, 2}$ & $0.049 \pm 0.002^{\mathrm{g}, 3}$ & $0.083 \pm 0.01^{\mathrm{h}, 5}$ \\
\hline
\end{tabular}

Figure 2.4. Effect of substrate on particle morphology and size distribution. Sol solutions (16:1 $\mathrm{H}_{2} \mathrm{O}: \mathrm{TMOS}$; pH 3) were deposited on to PS, TCPS, and PLLA for 30,60, and 90 seconds, (A) imaged using FE-SEM (scale bar $=10 \mu \mathrm{m}$ ), and the area-based size distribution was analyzed using a MATLAB macro [(B) PS, (C) TCPS, (D) PLLA]. (E) Analysis of the average particle area showed that on all substrates at 30 seconds deposition time, the average particle area was largest, with a decrease in average particle area at 60 seconds and a subsequent increase in particle area at 90 seconds. The average particle area of particles deposited on to PS was larger than those deposited onto TCPS and PLLA at all deposition times. All comparisons were made using ANOVA, p-values $<0.05$ were considered significant. Values with different letters/numbers are significantly different-- letters compare different deposition times in same group (rnws) and nımhers c.nmnare different arnı ıns within same dennsition time (colımns) Frror hars renresent +SFM 


\section{Effect of Formulation Parameters on Particle Degradation Behavior}

The effect of deposition time and solution $\mathrm{pH}$ on particle degradation behavior was determined. Particles with a pH 3 (16:1 $\mathrm{H}_{2} \mathrm{O}$ :TMOS) were deposited onto PS 30, 60, and 90 seconds or an adjusted $\mathrm{pH}$ of 1 for 60 seconds. The amount of silica degraded over time in DMEM at $37^{\circ} \mathrm{C}$ was determined as a function of total silica deposited using a colorimetric silica assay. Though the amount of silica deposited $\left(\mathrm{mg} / \mathrm{cm}^{2}\right)$ onto the plate increases with deposition time the changes are not significant $(p=0.07$; Figure 2.5B). Particles deposited for 30 seconds ( $\mathrm{pH} 3$ ) were fully degraded by day 4 and $\mathrm{pH} 160 \mathrm{~s}$ particles by day 5, while $\mathrm{pH} 360 \mathrm{~s}$ and $\mathrm{pH} 390 \mathrm{~s}$ particles were $97.38 \pm 2.62 \%$ and $98.84 \pm 1.16 \%$ degraded, respectively by day 10 . The percent degradation for $\mathrm{pH} 330 \mathrm{~s}$ particles was significantly higher than $\mathrm{pH} 3$ 60s particles for days 1-3 and $\mathrm{pH} 390 \mathrm{~s}$ particles at days 1 and $2(\mathrm{p}<0.04)$. Particles with an adjusted $\mathrm{pH}$ of $1(60 \mathrm{~s})$ degraded significantly faster than $\mathrm{pH} 3$ 60s particles during the first two days only ( $\mathrm{p}=0.04$; Figure 2.5A).

(A)

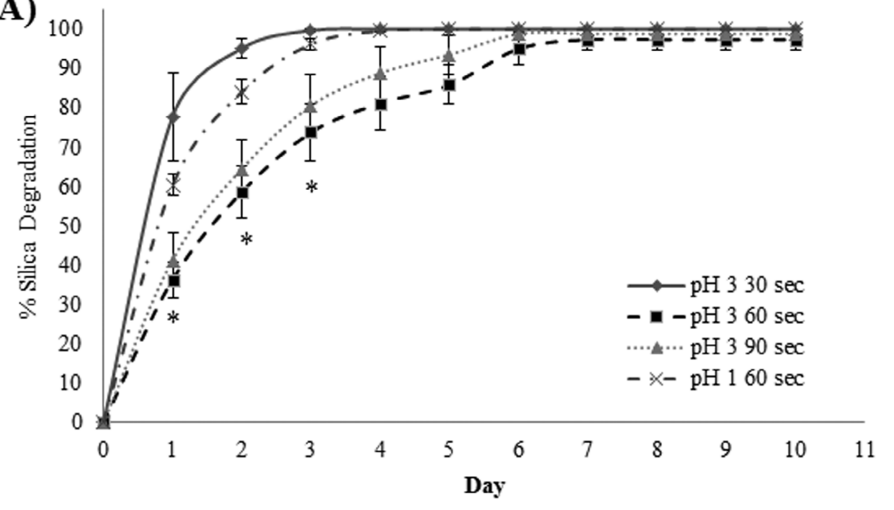

(B)

\begin{tabular}{cc}
\hline Formulation & mg silica $/ \mathbf{c m}^{2}$ \\
\hline pH330 Sec & $0.003 \pm 0.001$ \\
pH $360 \mathrm{Sec}$ & $0.015 \pm 0.005$ \\
$\mathrm{pH} 390 \mathrm{Sec}$ & $0.022 \pm 0.006$ \\
$\mathrm{pH} 160 \mathrm{Sec}$ & $0.013 \pm 0.001$ \\
\hline
\end{tabular}

Figure 2.5. Effect of deposition time and $\mathrm{pH}$ on degradation of sol particles. Sol solutions with $\mathrm{H}_{2} \mathrm{O}$ :TMOS of 16:1 were vapor deposited onto PS for 30,60 , and 90 seconds. Additionally particles with an adjusted $\mathrm{pH}$ of 1 were vapor deposited onto $\mathrm{PS}$ for 60 seconds. (A) Silica matrix degradation over time in phenol-free DMEM at $37^{\circ} \mathrm{C}$ was determined by measuring dissolved $\mathrm{Si}(\mathrm{OH})_{4}$ using a modified molybdenum blue assay at $810 \mathrm{~nm}$. pH 330 s particles were fully degraded by day 4 and $\mathrm{pH} 160 \mathrm{~s}$ particles were fully degraded by day 5 , while at day $10 \mathrm{pH} 360$ and 90 s particles were $97.38 \pm 2.62 \%$ and $98.84 \pm 1.16 \%$ degraded, respectively. Percent degradation of $\mathrm{pH} 330$ second and $\mathrm{pH} 160$ second particles was significantly different than $\mathrm{pH} 360$ s and 90 second particles during the first three days. (B) Total silica content on the plates $\left(\mathrm{mg} / \mathrm{cm}^{2}\right)$ shows an increase in silica deposited onto places increasing with deposition time. All comparisons were made using ANOVA, p-values < 0.05 were considered significant ( ${ }^{*}$ indicates statistical significance). Error bars represent \pm SEM. 


\section{Effect of Particle Deposition on Substrate Surface Character}

Contact angle analysis was used to determine changes in surface hydrophobicity with increasing sol deposition (Figure 2.6B). The average contact angle significantly decreased with increasing vapor deposition time $\left[92.49 \pm 0.22^{\circ}\right.$ at $\mathrm{t}=0$ to $73.92 \pm 1.33^{\circ}$ at $\mathrm{t}=15 \mathrm{~min} ; \mathrm{p}<0.0001]$. The overall trend showed that increasing vapor deposition caused a decrease in contact angle, indicating that the surface hydrophobicity decreases with vapor deposition time $\left[88.38 \pm 1.13^{\circ} \mathrm{t}=1 \mathrm{~min}, 81.11 \pm 0.82^{\circ} \mathrm{t}=2 \mathrm{~min}\right]$. However, the contact angle did increase at 5 minutes $\left(85.68 \pm 1.51^{\circ}\right)$ before decreasing again. Surface roughness measurements on sol gradient showed that average surface roughness (RMS roughness) increased with increased vapor deposition time $[0.22 \pm 0.05 \mathrm{~nm}$ at $\mathrm{t}=0$ to $303.4 \pm 42.83 \mathrm{~nm}$ at $\mathrm{t}=2 \mathrm{~min} ;$ Figure 2.6C]. There were significant increases in surface roughness at deposition times of 1 and 2 minutes when compared to the uncoated PLLA films $(\mathrm{p}<0.003)$. Roughness measurements at deposition times greater than 2 minutes were not feasible due to the resolution limits of AFM roughness measurements. 
(A)

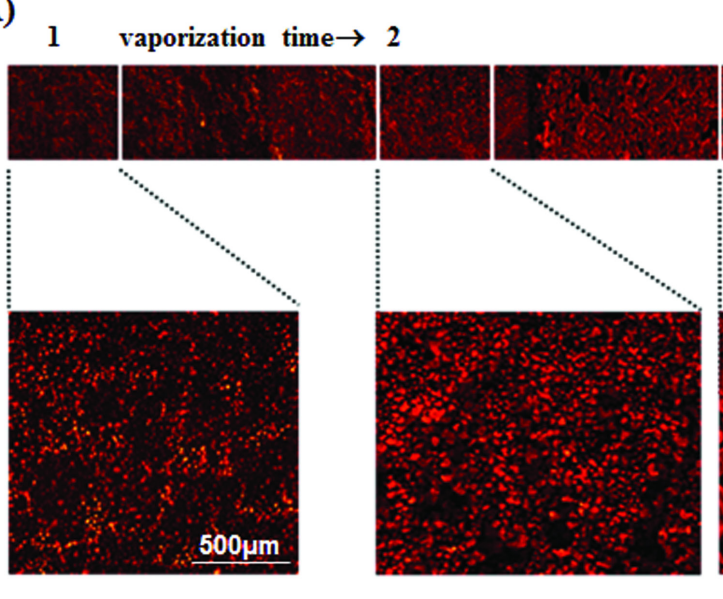

5

$15 \mathrm{~min}$

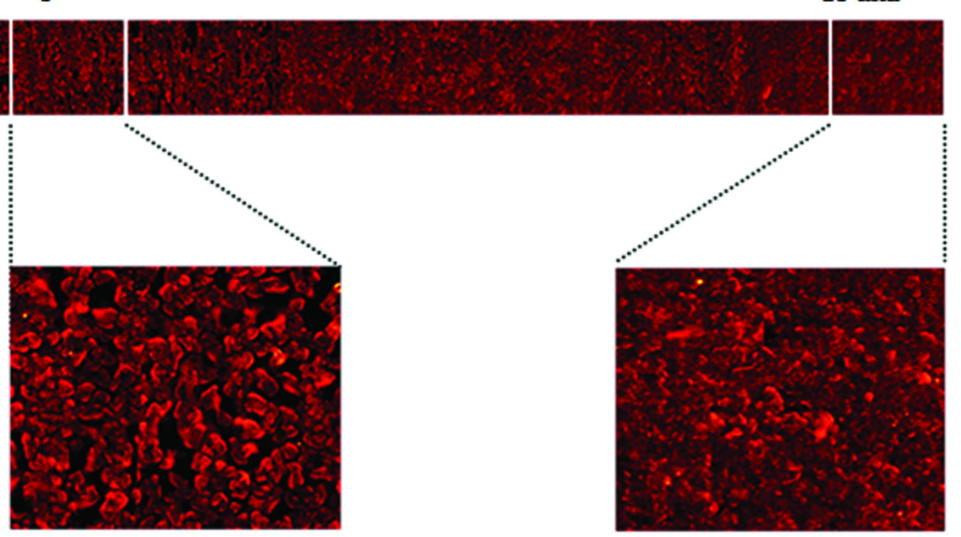

(B)

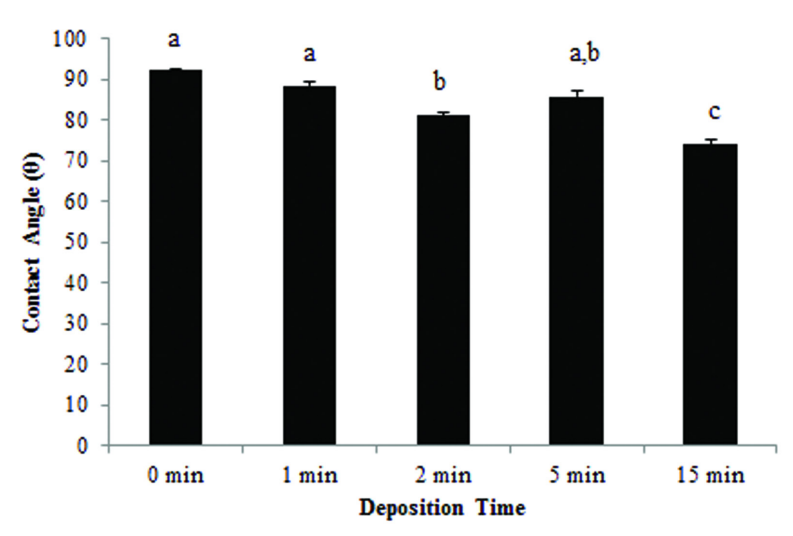

(C)

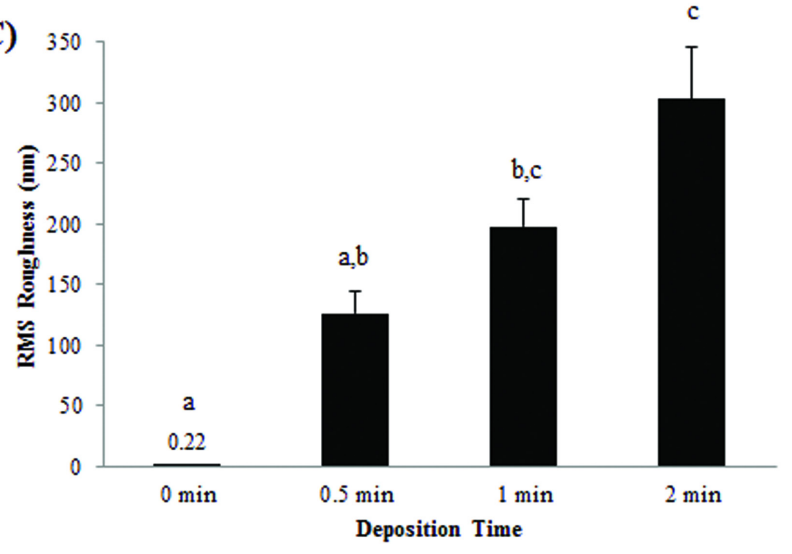

Figure 2.6. Effect of sol particles on surface wettability and roughness. (A) A sol gradient was generated on a PLLA film using a simple masking approach with vaporization time of Rhodamine B labeled sol ranging from 1-15 minutes and imaged using fluorescent microscopy. (B) Sessile drop contact angle analysis on a sol gradient was used to determine the relative hydrophobicity change on PLLA substrate with increasing particle deposition. The contact angle measures showed a general decrease with increasing vapor deposition indicating the surface hydrophobicity is decreasing. (C) Comparative surface roughness changes along gradient using AFM micrographs and analysis of $2.5 \mu \mathrm{m}$ area showed an increased surface roughness with increasing deposition time. Measurements over two minutes were not possible using AFM approach. All comparisons were made using ANOVA, p-values $<0.05$ were considered significant. Values with different letters are significantly different. Error bars represent \pm SEM. 


\section{Osteoblast Response to Sol Particles}

MC3T3 preosteoblasts were cultured on non-tissue culture PS dishes that were coated with particles (16:1 $\mathrm{H}_{2} \mathrm{O}$ :TMOS; pH 3) for 60 (Figure 2.7C,G), 90 seconds (Figure 2.7D,H), and on plain non-tissue culture PS dishes using either untreated culture media (Figure 2.7A,E) or culture media that had been conditioned for 48 hours with particles deposited for 90 seconds (Figure 2.7B,F) for 24 or 48 hours. At 24 hours, cell attachment on substrates cultured with conditioned media and those coated with sol particles for 60 and 90 seconds showed higher attachment compared to the control cultures, with significantly higher attachment on 90 s cultures [attachment $=1.00 \pm 0.16$ control, $1.57 \pm 0.24$ conditioned media, $1.59 \pm 0.22 \mathrm{t}=60 \mathrm{~s}, 1.97 \pm 0.29 \mathrm{t}=90 \mathrm{~s} ; \mathrm{p}=0.03]$. At 48 hours, cell attachment on substrates using conditioned media and those coated with sol particles for 60 and 90 seconds was still higher than control cultures with significantly higher attachment at $60 \mathrm{~s}$ [attachment $=1.00 \pm 0.11$ control, $1.34 \pm 0.11$ conditioned media, $1.88 \pm 0.24 \mathrm{t}=60 \mathrm{~s}, 1.37 \pm 0.15 \mathrm{t}=90 \mathrm{~s} ; \mathrm{p}=0.002$; Figure 2.7I $]$. To determine whether the sol particles affected media $\mathrm{pH}$ during culture as the particles degraded and released ions, media $\mathrm{pH}$ was recorded at each time point. No significant differences were found between the $\mathrm{pH}$ of control culture media and those of conditioned media or cultures containing particles ( $\mathrm{p}=0.2$; data not shown). 


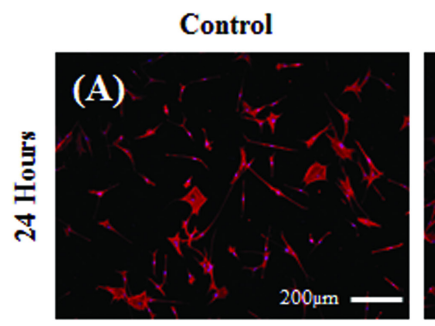

Conditioned Media
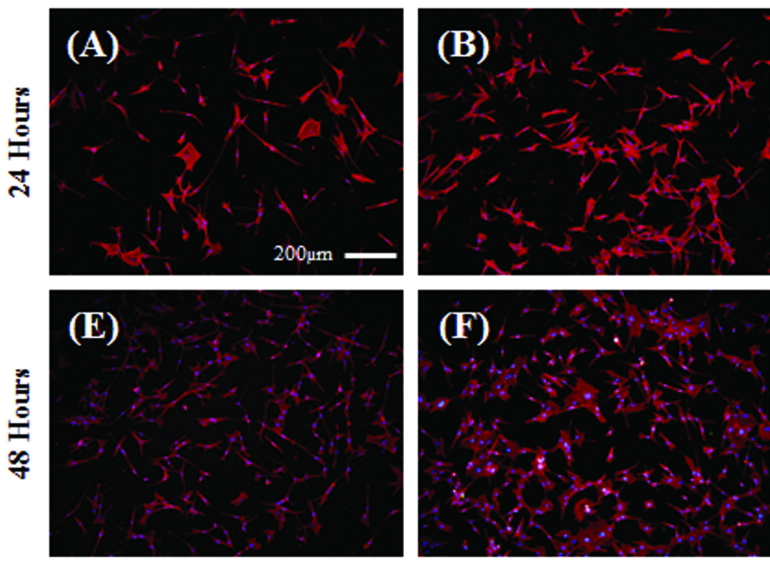

(I)

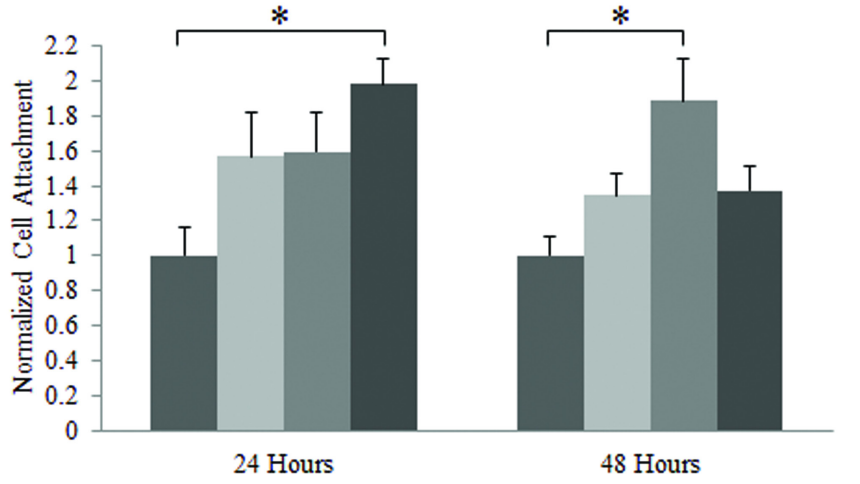

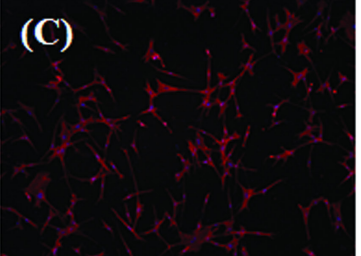
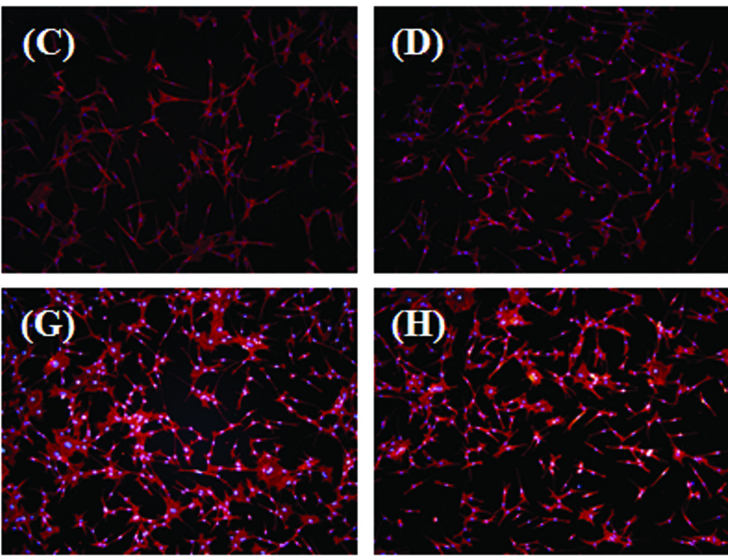

48 Hours

$\square$ Control $\backsim$ Conditioned Media $\square 60 \mathrm{~s} \backsim 90 \mathrm{~s}$

Figure 2.7. Osteoblast response to sol particles. MC3T3 preosteoblasts were cultured on non-tissue culture PS dishes that have been vapor coated with sol particles $\left(16: 1 \mathrm{H}_{2} \mathrm{O}\right.$ :TMOS; pH 3) for $(\mathrm{C}, \mathrm{G}) 60$ or $(\mathrm{D}, \mathrm{H}) 90$ seconds or on plain non-tissue culture PS dishes using either $(A, E)$ untreated culture media or $(B, F)$ culture media that had been conditioned with particles (deposited for 90 seconds) for 48 hours. At (A-D) 24 and (E-H) 48 hours the cells were stained using TRITC-conjugated Phalloidin and DAPI and cell attachment was assessed (scale bar $=200 \mu \mathrm{m}$ ). (I) Cell attachment on plates coated with sol particles had higher attachment at both 24 and 48 hours compared to control cultures that used untreated culture media (significant differences 60 seconds at 24 hours and 90 seconds at 48 hours). All comparisons were made using ANOVA, p-values $<0.05$ were considered significant ( ${ }^{*}$ indicates statistical significance). Error bars represent \pm SEM. 


\section{DISCUSSION}

There are inherent limitations in current techniques for the surface modification of biomaterials; this work focused on the development of a simple, rapid, and effective method to generate silica particles for the surface modification of biomaterials without extreme processing conditions (i.e. high temperatures and pressures and harsh solvents) used in other sol-gel manufacturing methods. Particle morphology, size distribution, and degradation behavior was characterized, and controlled by adjusting key manufacturing parameters including $\mathrm{H}_{2} \mathrm{O}$ :TMOS molar ratio, $\mathrm{pH}$, deposition time, and substrate. Changes in surface properties (hydrophobicity and roughness), the ability to incorporate apatite specific ions, and cell behavior in response to particles was also determined.

The amount of water available for the hydrolysis reaction has a dramatic influence on gelation time of a sol-gel solution. For lower water contents $\left(\mathrm{H}_{2} \mathrm{O}\right.$ :TMOS<7-8:1) an increase in the amount of water available decreases the gelation time. At $\mathrm{H}_{2} \mathrm{O}$ :TMOS>7$8: 1$, the increase in water creates a dilution effect, with the gelation time increasing with the quantity of water $[17,34]$. Molar ratios of $8: 1$ and 16:1 were used to determine the effect on particle morphology and size distribution. Solutions with an 8:1 ratio produced particles that were consistently the same size (size distributions and average particle size) regardless of deposition time. Solutions with a 16:1 ratio produced particles whose average area peaked at 30 seconds; decreased at a deposition time of 60 seconds and subsequently increased again at 90 seconds. The size distributions of the 16:1 particles showed similar trends at each deposition time. These differences may be attributed to gelation behavior. In 8:1 particles, deposition time was found to be irrelevant, whereas in the 16:1 particles, deposition time has an effect on the average particle size and distribution. Elevated relative water content may increase the gelation time of particles, causing deposition time to play a larger role in resultant particle size, with solutions containing a lower water content, whose gelation rates would be faster.

It is widely accepted that the polymerization of sol-gels is highly $\mathrm{pH}$ dependant. In the polymerization reaction the point of zero charge (where the surface charge is zero) and the isoelectric point (the point where the electrical mobility of the silica particles is zero) fall between $\mathrm{pH} 1$ and 3, producing slower gelation times. Between $\mathrm{pH} 2$ and 6 the 
gelation rate is proportional to the concentration of $\mathrm{OH}^{-}$, steadily decreasing the gelation time with increasing $\mathrm{pH}$. Solutions become most unstable (and therefore gelling most quickly) at $\mathrm{pH} 5-6$. Below $\mathrm{pH} \mathrm{2,} \mathrm{where} \mathrm{the} \mathrm{solubility} \mathrm{of} \mathrm{silica} \mathrm{is} \mathrm{low,} \mathrm{solutions} \mathrm{are}$ considered metastable resulting in gelation times that are relatively long and polymerization rates are proportional to the concentration of $\mathrm{H}^{+}[17,34]$. The original $\mathrm{pH}$ of the sol gel solutions was 3. Adjustments of the solution to $\mathrm{pH} 1$ and 6 were chosen due to the limitations of the system: at pHs lower than 1 solutions did not gel at all and at $\mathrm{pHs}$ higher than 6 solutions gelled too quickly to be used in the nebulizer. Solutions with a $\mathrm{pH}$ of 3 were stable enough to be used in the vaporization system but gelled quickly enough that deposition time influenced particle size. Particles generated from $\mathrm{pH} 1$ solutions produced particles with very small average particle sizes and similar size distributions at all times points. This is most likely due to the low viscosity and long gelation time of the colloidal solution. Solutions with a $\mathrm{pH}$ of 6 produced particles that had irregularly shaped morphologies and particles sizes that were inconsistent from sample to sample due the rapid gelling rate of the solution. The rate of polymerization of a sol solution is dependent upon the $\mathrm{pH}$ and therefore will have the largest impact on particles at $\mathrm{pH}$ values between 2 and 6 , where the gelation rate of the solution is the most suitable for use in the deposition system.

The underlying substrate will always play a role in dictating the outcome of any surface modification approach, due to substrate surface chemistry, hydrophobicity (wettability), and roughness. Particles were vapor deposited onto three distinct substrates (PS, TCPS, PLLA) to demonstrate this. On all substrates, particles show a trend with an average area largest, decreasing, and then subsequently increasing again at 30,60, and 90 seconds deposition time, respectively. However, at all three deposition times the average particle area was always significantly larger on PS than on TCPS or PLLA. A fraction of the particles deposited on to PS were able to aggregate and form larger particles before gelation, resulting in larger average particle areas. Plasma treatment of polystyrene (TCPS) decreases the hydrophobicity of the surface (contact angle of $41.08 \pm 1.91^{\circ}$ compared to $73.59 \pm 1.94^{\circ}$ of untreated PS), and generates a surface containing more exposed oxygen groups. This may allow for better adsorption of proteins such as 
vitronectin, providing a surface that is more conducive to cell attachment than untreated PS.[37-39] This change in surface chemistry interacts with the sol particles, which generates smaller particles than on PS. The highly hydrophobic nature of the PLLA surface (contact angle $92.49 \pm 0.22^{\circ}$ ) may essentially isolate the hydrophilic sol particles as they are deposited onto the PLLA surface preventing them from aggregating before they gel, resulting in many small particles at all deposition times [40]. The surface properties of a substrate will help dictate the particle size due to the interactions between the substrate and the particles.

The duration that cells are exposed to a material will determine to what extent it will influence their behavior. Therefore, the degradation rate of a material will significantly impact its overall effectiveness as an instrument to direct cell behavior. The degradation behavior of particles generated from 16:1 pH 3 (deposition time 30, 60, and 90s) and 16:1 pH 1 (deposition time 60s) solutions was determined over 10 days. Particles deposited for $30 \mathrm{~s}$ degraded most quickly, most likely due to the increased effective surface area available for degradation, compared to those deposited for 60 or 90s when particles have time to aggregate and thereby reducing the effective surface area. pH 1 60s particles also degraded more quickly than their $\mathrm{pH} 3$ counterparts even though the silica content on the plates was similar. This is could be due to the differences in the networking in the $\mathrm{pH} 1$ particles during the extended gelation time. The differences in degradation between particle groups are largest within the first three days, indicating that particles will have the greatest impact on cell behavior during this time period. Substrate surface character can impose a strong influence on initial protein adhesion, cell viability and attachment (nanoseconds to days), and consequently influence long-term cell behavior including cell spreading, proliferation, differentiation, and extracellular matrix production [41].

The surface properties of a material can be used to direct many aspects of cell behavior including attachment, proliferation, and differentiation depending on the cell type. Specifically, osteoblasts and osteoblast precursors have been found to respond to surface hydrophobicity in a time dependant manner. Initial cell attachment and spreading have been found to be higher on moderately hydrophilic surfaces than on hydrophobic 
surfaces [42]. In general, osteoblasts have better adhesion, larger cell spreading, higher proliferation, and enhanced differentiation on substrates with an increased surface roughness. Many studies have shown that surface roughened implants promote osseointegration better than their smooth counterparts [43, 44]. In this work it was demonstrated that increasing vapor deposition of particles onto substrates caused a decrease in contact angle, indicating that the surface became more hydrophilic. Vapor deposition of sol particles also showed the ability to increase the surface roughness of a material. Furthermore, a unique surface topography is created when sol is deposited onto substrates. This random surface topography generated by the deposition of sol particles onto substrates may further help to promote osteoblast differentiation. Dalby et al. showed that mesenchymal stem cells cultured on substrates containing nano-pit arrays differentiate into either fibroblasts or osteoblasts depending on the order/disorder of the arrays. Cells cultured on highly ordered arrays resulted in cells with fibroblastic appearances, while cells cultured on more irregular arrays resulted in cells with an osteoblastic morphology and gene expression [45]. Vapor deposited sol particles allow for the modification of a material's surface properties in a way that could aid in directing osteoblast behavior by increasing surface hydrophilicity and roughness, as well as generating a unique surface topography.

The ultimate goal of this work is to be able to use these particles in combination with other conventional biomaterials such as orthopedic and dental implants and tissue engineering scaffolds to better direct cell behavior including attachment, proliferation, and differentiation via cell-material interactions. Vapor deposition of sol particles onto non-tissue cultures PS substrates increased attachment of preosteoblasts in comparison to controls cultured on PS alone, potential indication their ability to increase cell proliferation. Cells cultured with no particles and media that had been conditioned with particles (containing silica sol dissolution products) also showed increased cell attachment, though the effect was not significant $(p=0.45)$. This indicates that increases in cell attachment can be attributed in part to both the modification of the physical properties of the PS (wettibility, roughness, topography) as well as the chemical composition, specifically silica. It is important to note that degradation products did not 
significantly change $\mathrm{pH}$ in culture. This surface modification method allows for the deposition of particles whose chemical and physical properties cause an increase in cell attachment onto substrates, indicating the potential of further directing osteoblast behavior.

\section{CONCLUSION}

This work demonstrates the use of a simple and novel system for the surface modification of materials through the vapor deposition of silica sol-gel particles. The morphology, size distribution, and degradation of these particles can easily be controlled through key formulation and manufacturing parameters including sol $\mathrm{H}_{2} \mathrm{O}$ :TMOS molar ratio and $\mathrm{pH}$, as well as deposition time and substrate character. These particles can be used to alter the overall surface properties of a material including surface hydrophobicity, roughness, and topography. Furthermore, these particles increase initial cell attachment of preosteoblasts compared to unmodified control substrates, demonstrating their potential to aid in promoting cell attachment. Current work is focused on how different formulations of particles can promote osteoblast attachment, proliferation, and differentiation using quantitative gene expression measures.

\section{ACKNOWLEDGEMENTS}

The authors would like to thank David Jaroch (Purdue), Nicholas Schaub (RPI), Owen Mills (ACMAL-MTU), Dr. Jaroslaw Drelich (MTU), Dr. Martyn Smith (MTU), and Melissa Roberts (MTU) for their help with portions of this work.

\section{REFERENCES}

1. $\quad$ Elias, C., et al., Relationship between surface properties (roughness, wettability and morphology) of titanium and dental implant removal torque. Journal of the mechanical behavior of biomedical materials, 2008. 1(3): p. 234-242.

2. Schuler, M., et al., Biomimetic modification of titanium dental implant model surfaces using the RGDSP-peptide sequence: a cell morphology study. biomaterials, 2006. 27(21): p. 4003-4015. 
3. Vasudev, D., et al., In vivo evaluation of a biomimetic apatitie coating grown on titanium surfaces. J Biomed Mater Res A, 2004. 69(4): p. 629-636.

4. Heimann, R. and R. Wirth, Formation and transformation of amorphous calcium phosphates on titatnium alloy surfaces during atmospheric plasma spraying and their subsequent in vitro performance. Biomaterials, 2006. 27(6): p. 823-831.

5. Park, E., et al., Characterization of hydroxyappatitie: before and after plasma spraying. Journal of materials science. Materials in medicine, 2002. 13(2): p. 211218.

6. Xiao, F., et al., Silicon-substituted hydroxyapatite composite coating by using vacuum-plasma spraying and its interaction with human serum albumin. Journal of materials science. Materials in medicine, 2009. 20(8): p. 1653-1658.

7. Yang, Y., K. Kim, and J. Ong, A review on calcium phosphate coatings produced using a sputtering process--an alternative to plasma spraying. Biomaterials, 2005. 26(3): p. 327-337.

8. Gil, F., et al., Influence of the height of the external hexagon and surface treatment on fatigue life of commercially pure titanium dental implants. The International Journal of Oral \& Maxillofacial Implants, 2009. 24(4): p. 583-590.

9. Galluccio, G., Variability of the dental surface: effects on orthopedic treatment. Progress in Orthodontics 2008. 9(1): p. 18-.

10. Kim, J., L. Kim, and C. Kim, Size control of silica nanoparticles and their surface treatment for fabrication of dental nanocomposites. Biomacromolecules, 2007. 8(1): p. 215-222.

11. Kadoma, Y., Surface treatment agent for dental metals using a thiirane monomer and a phosphoric acid monomer. Dental Materials Journal, 2002. 21(2): p. 156169.

12. Li, D., et al., Improvement of osseointegration of titanium dental implants by a modified sandblasting surface treatment: an in vivo interfacial mechanics study. Implant Dentistry, 1999. 8(3): p. 289-294.

13. Langer, R., et al., Tissue engineering: biomedical applications Tissue Engineering, 1995. 1(2): p. 151-161.

14. Putnam, A. and D. Mooney, Tissue engineering using synthetic extracellular matrices. Nat Mater, 1996. 2(7): p. 824-826.

15. Ratner, B. and S. Bryant, Biomaterials: where we have been and where we are going. Annual Review of Biomedical Engineering, 2004. 6: p. 41-75. 
16. Hench, L.L., Bioactive materials: the potential for tissue regeneration. Journal of biomedical materials research, 1998. 41(4): p. 511-8.

17. Hench, L.L. and J.K. West, The Sol-Gel Process. Chemical Reviews, 1990. 90(1): p. 33-72.

18. Gupta, R. and A. Kumar, Bioactive materials for biomedical applications using sol-gel technology. Biomedical materials, 2008. 3: p. 034005.

19. Coradin, T., M. Boissire, and J. Livage, Sol-gel chemistry in medicinal science. Current Medicinal Chemistry, 2006. 13(1): p. 99-108.

20. Hong, Z., R.L. Reis, and J.F. Mano, Preparation and in vitro characterization of novel bioactive glass ceramic nanoparticles. J Biomed Mater Res A, 2009. 88(2): p. 304-13.

21. Kortesuo, P., et al., Effect of synthesis parameters of the sol-gel-processed spraydried silica gel microparticles on the release rate of dexmedetomidine. Biomaterials, 2002. 23(13): p. 2795-2801.

22. Nicoll, S.B., et al., In vitro release kinetics of biologically active transforming growth factor-beta 1 from a novel porous glass carrier. Biomaterials, 1997. 18(12): p. 853-9.

23. Chen, J., et al., A gold nanoparticles/sol-gel composite architecture for encapsulation of immunoconjugate for reagentless electrochemical immunoassay. Biomaterials, 2006. 27(10): p. 2313-21.

24. Pierre, A., et al., Encapsulation of deoxyribonucleic acid molecules in silica and hybrid organic-silica gels. Journal of materials science. Materials in medicine, 2001. 12(1): p. 51-5.

25. Nieto, A., et al., Cell viability in a wet silica gel. Acta Biomaterialia, 2009. 5(9): p. 3478-3487.

26. Hoppe, A., N.S. Güldal, and A.R. Boccaccini, A review of the biological response to ionic dissolution products from bioactive glasses and glass-ceramics. Biomaterials, 2011. 32: p. 2757-2774.

27. Rahman, M.N., et al., Bioactive glass in tissue engineering. Acta Biomaterialia, 2011. 7: p. 2355-2373.

28. Hench, L.L., I.D. Xynos, and J.M. Polak, Bioactive glasses for in situ tissue regeneration. J Biomater Sci Polym Ed, 2004. 15(4): p. 543-62.

29. Jell, G. and M.M. Stevens, Gene activation by bioactive glasses. Journal of materials science. Materials in medicine, 2006. 17(11): p. 997-1002. 
30. Newman, S., P. Pellow, and S. Clarke, Droplet size distribution of nebulised aerosols for inhalation therapy. Clinical Physics and Physiological Measuremen, 1986. 7(139-146).

31. O'Callaghan, C. and P. Barry, The science of nebulised drug delivery. Thorax, 1997. 52(Suppl 2): p. S31-S44.

32. Le Brun, P.P.H., et al., A review of the technical aspects of drug nebulization. Pharmacy World \& Science, 2000. 22(3): p. 75-81.

33. Newman, S., P. Pellow, and S. Clarke, Drop sizes from medical atomisers for drug solutions with different viscosites and surface tensions. Atomization and Spray Technology, 1987. 3(1-11).

34. Brinker, C.J. and G.W. Scherer, Sol-Gel Science: The Physics and Chemistry of Sol-Gel Processing. 1990: Academic Press Inc.

35. Huang, Y.-Y. and K.-S. Chou, Studies on the spin coating process of silica films. Ceramics International, 2003. 29: p. 485-493.

36. Kobayashi, M., et al., Piezoelectric thick film ultrasonic transducers fabricated by a sol-gel spray technique. Ultrasonics, 2002. 39: p. 675-680.

37. Steele, J., et al., Polystyrene chemistry affects vitronectin activity: An explanation for cell attachment to tissue culture polystyrene but not to unmodified polystyrene. Journal of Biomedical Materials Research 1993. 27: p. 927-940.

38. Teare, D., et al., Cellular Attachment to Ultraviolet Ozone Modified Polystyrene Surfaces. Langmuir, 2000. 16(6): p. 2818-2824.

39. Curtis, A., et al., Adhesion of cells to polystyrene surfaces. The Journal of Cell Biology, 1983. 97(5): p. 1500-1506.

40. Vogler, E.A., Water and the acute biological response to surfaces. Journal of biomaterials science. Polymer edition, 1999. 10(10): p. 1015-1045.

41. Roach, P., et al., Modern biomaterials: a review-bulk properties and implications of surface modifications. Journal of Materials Science: Materials in Medicine, 2007. 18: p. 1263-1277.

42. Liu, X., et al., Influence of substratum surface chemistry/energy and topography on the human fetal osteoblastic cell line hFOB 1.19: Phenotypic and genotypic responses observed in vitro. Biomaterials, 2007. 28(31): p. 4535-4550.

43. Kunzler, T.P., et al., Systematic study of osteoblast and fibroblast response to roughness by means of surface-morphology gradients. Biomaterials, 2007. 28(13): p. 2175-2182. 
44. Ricci, J.L., J.C. Grew, and H. Alexander, Connective-tissue responses to defined biomaterial surfaces. I. Growth of rat fibroblast and bone marrow cell colonies on microgrooved substrates. Journal of Biomedical Materials Research Part A, 2008. 85(2): p. 313-25.

45. Dalby, M.J., et al., The control of human mesenchymal cell differentiation using nanoscale symmetry and disorder. Nat Mater, 2007. 6(12): p. 997-1 


\section{CHAPTER THREE: CALCIUM-PHOSPHATE SILICA SOL PARTICLES FOR BIOACTIVE SURFACE MODIFICATION ${ }^{2}$}

This chapter expands on the methods for generating vapor deposited particles developed in Chapter 2 by incorporating biologically active elements, calcium and phosphate ions, into the particles. The work in this chapter addresses Specific Aim 2.

\section{INTRODUCTION}

Bioactive glasses and other silica based materials are becoming increasingly popular for use in biomedical applications due to their inherent biocompatibility; ability to actively influence cell driven processes including osteogenesis and angiogenesis; and enhanced antimicrobial character [4]. These glasses can be generated using a variety of methods, with two of the most common being melt derived and sol-gel processing. Solgel approaches have an advantage over traditional melt methods because they allow for mild processing conditions (ambient temperature-pressure and biologically tolerated byproducts) and simple methods to control composition and structure of the material. Because of this sol-gel based materials have been used as delivery vehicles for various inorganic and organic small molecules including ions, drugs, enzymes, antibodies, growth factors, DNA, and even cells [7, 89-95].

The main disadvantage of sol-gel synthesis over the melt process is that it is difficult to obtain crack-free bioactive glass monoliths (diameters $>1 \mathrm{~cm}$ ) due to cracking during drying. The cracking can result in part from the large shrinkage that occurs during drying; and the evaporation of the liquid by-products of the condensation reaction. During drying, vapor must travel from within the gel to the surface via the interconnected pore network. This can cause capillary stresses within the pore network and therefore cracking. For small cross-sections, such as in particles, drying stresses are small, as the path of evaporation is short and the stresses are accommodated. For monolithic objects, the path from the center of the monolith to the surface is long and tortuous, and the

\footnotetext{
${ }^{1}$ The material presented in this chapter is in preparation for submission to the Journal of Biomedical Materials Research Part A. [Snyder KL, Holmes HR, Rajachar RM].
} 
drying stresses can introduce catastrophic fracture. Increasing pore size and obtaining pores with a narrow distribution reduce tortuosity [107].

When exposed to body fluids bioglass materials generate a dynamic bio-reactive surface microenvironment that can act as a strong bonding interface between the glass and a hard or soft tissue environment. Upon exposure, soluble silica in the form of $\mathrm{Si}(\mathrm{OH})_{4}$ is lost in solution, breaking Si-O-Si bonds and creating Si-OH (silanols) at the material-solution interface. $\mathrm{SiO}_{2}$ condensates and re-polymerizes at this surface, causing the migration of $\mathrm{Ca}^{2+}$ and $\mathrm{PO}_{4}{ }^{3-}-$-forming a $\mathrm{CaO}-\mathrm{P}_{2} \mathrm{O}_{5}$ rich film at the $\mathrm{SiO}_{2}$-aqueous interface. This amorphous $\mathrm{CaO}-\mathrm{P}_{2} \mathrm{O}_{5}$ film continues to grow incorporating calcium and phosphate from solution, which is then crystallized by incorporation of $\mathrm{OH}^{-}$and $\mathrm{CO}_{3}{ }^{2-}$ anions to form a mixed hydroxyapatite (HA) layer. At this point biological growth factors can adsorb into the HA layer, contributing to activate differentiation of stem cells into osteoblasts (Table 3.1-see also Figure 1.6). This dynamic interaction creates a strong bonding interface between the glass and its hard or soft tissue environment. In hard tissues a bond is formed due to the biological equivalence of the mineral phase of bone and the growing HA layer of the bioglass material. Soft tissue bonding occurs when collagen fibrils are chemisorbed on the $\mathrm{SiO}_{2}$ layer by electrostatic, ionic, and/or hydrogen bonding and $\mathrm{HA}$ is precipitated and crystallized onto collagen fibers and material surfaces [87].

Table 3.1. Overview of apatite formation on bioglass material upon exposure to body fluids.

1 Silanol formation: soluble silica is lost in the form of $\mathrm{Si}(\mathrm{OH})_{4}$ into the solution, breaking $\mathrm{Si}-\mathrm{O}-\mathrm{Si}$ bonds and creating $\mathrm{Si}-\mathrm{OH}$ (silanols) at the material-solution interface

2 Polycondensation: $\mathrm{Si}-\mathrm{OH}$ groups condensate at the surface causing the repolymerization of the silica layer

3 Amorphous $\mathbf{C a} / \mathbf{P}$ film formation: $\mathrm{Ca}^{2+}$ and $\mathrm{PO}_{4}{ }^{3-}$ migrates to the surface to form a CaO- $-\mathrm{P}_{2} \mathrm{O}_{5}$ rich film on top of the $\mathrm{SiO}_{2}$ layer. This layer continues to grow through the incorporation of calcium and phosphates from solution

4 Crystallization: incorporation of hydroxyl $\left(\mathrm{OH}^{-}\right)$and carbonate $\left(\mathrm{CO}_{3}{ }^{2-}\right)$ anions to form a mixed hydroxyapatite (HA) layer

5 Biological molecule adsorption: proteins and other biological molecules adsorb to HA layer, contributing to the activation of differentiation of stem cells into osteoblasts 
The HA layer that is formed at the sol-gel glass surface is dependent upon many factors including the ion concentration and $\mathrm{pH}$ of the solution medium as well as the composition of the sol material and its physical properties (i.e. roughness, topography, surface area, pore size) [138-142]. Recent work has been focused on determining the effect of additional elements (including calcium, phosphate, magnesium, potassium, aluminum, cobalt, boron, vanadium, zinc, strontium, iron and fluorine) to the composition of the bioglass and bioactivity, with the majority of the focus being on the addition of calcium and phosphate to the silica network. These elements are known network modifiers to the architecture of the silica network, and consequently the composition of mineral phase (Figure 3.1) [113, 114, 142, 143]. High calcium content in bioglass has been found to increase pore volume and decrease surface area of the material, thus increasing the amount of calcium released, which leads to increased apatite formation [141, 144-146]. While phosphate is not necessary in glasses for apatite formation, when the amount of $\mathrm{P}_{2} \mathrm{O}_{5}$ is added in less than $6 \mathrm{~mol} \%$, it increases the surface area and decreases pore diameter and pore volume, as well as induces mineral crystal growth more quickly than glasses without it [144, 147-149]. However, the composition of a sol-gel glass that is optimum for mineral formation is not known and remains a topic of exploration [4, 113, 114].

The goal of this work was to successfully incorporate calcium and phosphate ions into vapor deposited silica sol-gel particles (three different formulations). The morphology and size distribution of the calcium-phosphate sol particles was determined as well as how these particles affected overall substrate hydrophobicity. The silica matrix degradation and ion release character was also determined. Finally, the ability for these particles to induce apatite mineral formation was determined. 

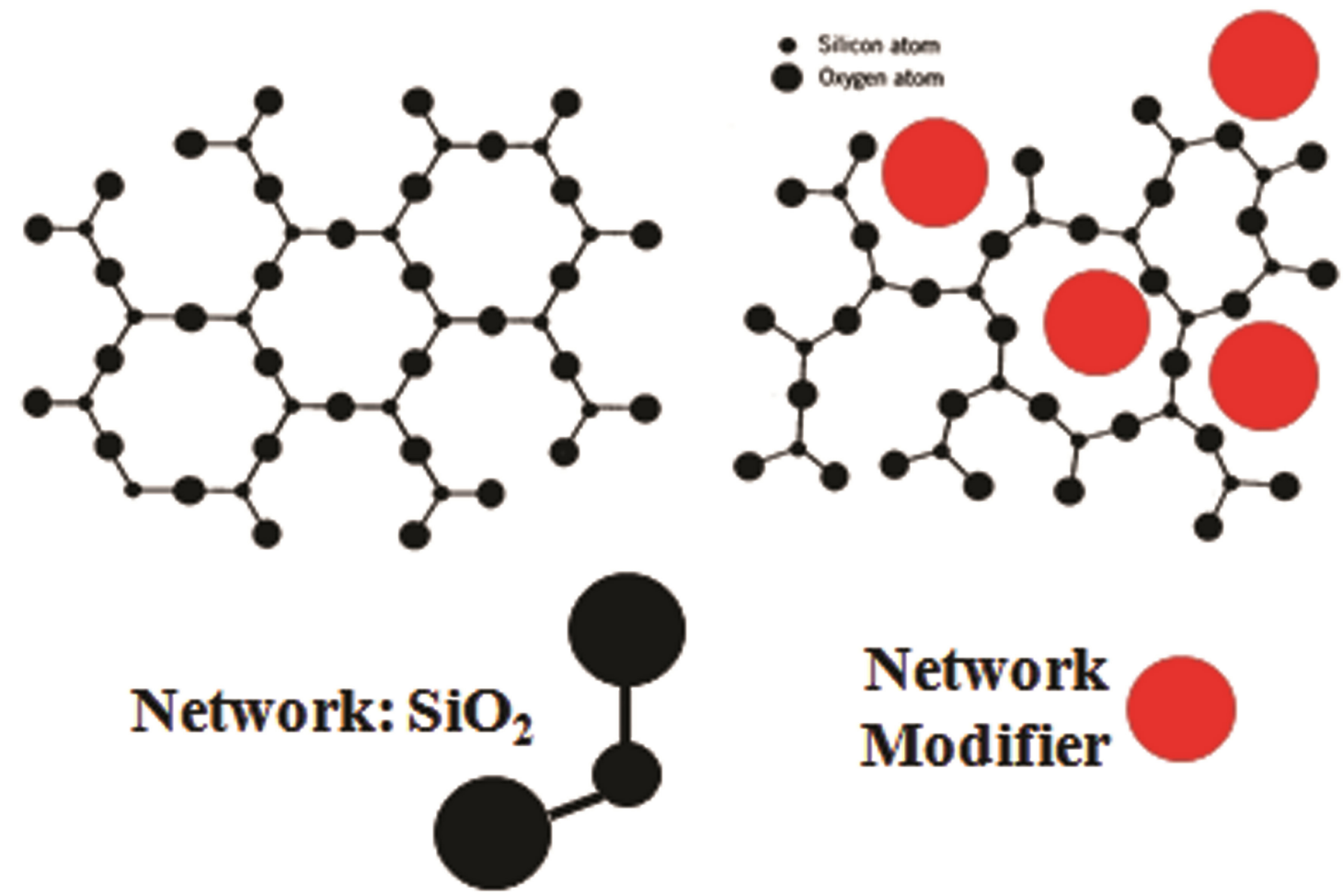

\section{Network Modifier}

Figure 3.1. Network modifiers. Incorporation of additional ions (i.e., calcium, phosphate magnesium, potassium) into a sol-gel will modify the silica network architecture and therefore have a resulting effect on the composition of the mineral formed.

\section{MATERIALS AND METHODS}

\section{Sol Preparation and Vapor Deposition}

The base compositions of the sol solutions used in these experiments was a 16:1 molar ratio of de-ionized water to tetramethyl orthosilicate (TMOS; Sigma Aldrich). The solution was catalyzed with $0.04 \mathrm{M}$ hydrochloric acid $(\mathrm{HCl}$; Sigma Aldrich) at $2 \mu \mathrm{l}$ per gram of TMOS/di- $\mathrm{H}_{2} \mathrm{O}$. Catalyzed solutions were agitated for 20 minutes to ensure that the solution was completely mixed. The clear homogenous solution was then allowed to rest for 30 minutes at $25^{\circ} \mathrm{C}$, where the solution was then stable for vaporization. Nebulizer-based vaporization was carried out using a jet-type nebulizer (Pari LC Plus, Allegro Medical) attached to a $500 \mathrm{ml}$ polycarbonate bottle whose bottom had been removed and served as the vaporization chamber. The nebulizer containing the sol was connected to a compressed air supply with a $0.2 \mu \mathrm{m}$ airline filter. Sol was vapor deposited onto non-tissue culture polystyrene (PS) for 60 seconds at 40psi, maintained using an in- 
line pressure gauge. Samples were removed immediately after deposition and the sol was allowed to fully polycondensate into a solid gel for 2 minutes. Samples were covered and stored at $25^{\circ} \mathrm{C}$ for 3-7 days until further use.

\section{Calcium and Phosphate Incorporation into Sol}

Calcium $(\mathrm{Ca})$ and phosphate $(\mathrm{P})$ ions were incorporated into solutions just before vapor deposition by adding $1 \mathrm{M}$ calcium chloride $\left(\mathrm{CaCl}_{2} ;\right.$ Sigma Aldrich) and $1 \mathrm{M}$ triethyl phosphate (TEP; Sigma Aldrich) in three different formulations (v/v\%): $5 \% \mathrm{Ca} / 5 \% \mathrm{P}$, $25 \% \mathrm{Ca} / 25 \% \mathrm{P}$, and $25 \% \mathrm{Ca} / 5 \% \mathrm{P}$.

\section{Size Distribution and Morphology}

Scanning electron microscopy was used to characterize the morphology and size distribution of the sol particles. All samples were sputter coated with Pt/Pd (5nm) and imaged with a field emission scanning electron microscope (FE-SEM; Hitachi S-4700) under high vacuum conditions at accelerating voltages of $1-5 \mathrm{kV}$. Quantitative measures of particle size distribution were made using a custom written MATLAB macro. All size distribution measurements were based on surface area measures for each individual particle.

\section{Surface Hydrophobicity}

The effect of vapor deposition of $\mathrm{Ca} / \mathrm{P}$ sol particles on substrate surface hydrophobicity was determined using standard contact angle methods (sessile drop analysis) at $25^{\circ} \mathrm{C}$. A Kruss G10 goniometer (Rame-Hart, Inc.) system was used to make all measurements. Droplets of di- $\mathrm{H}_{2} \mathrm{O}$ were added to the center of each sample in succession; angle measurements at the liquid/substrate surface interface were taken and droplets were added until a plateau was reached (approximately $3-12 \mu 1$ total).

\section{Degradation Behavior}

The degradation behavior of the silica matrix over 7 days in phenol-free media at $37^{\circ} \mathrm{C}$ was determined using a modified colorimetric tin chloride-molybdenum blue silica assay at $810 \mathrm{~nm}$. Percentage silica matrix degradation was determined as a function of total silica deposited. 


\section{Mineral Composition and Morphology}

$\mathrm{Ca} / \mathrm{P}$ particle ability to induce stabile mineral crystal formation was assessed by vapor depositing sol solutions onto PS plates for 60 seconds and incubating in simulated body fluid (SBF) at $37^{\circ} \mathrm{C}$ for 7 days. Control groups consisted of PS plates containing no particles and PS plates coated with sol particles containing no calcium or phosphate for 60 seconds. SBF solutions were changed every 2 days to replenish ions. Mineral crystal morphology and composition were analyzed with FE-SEM imaging and using energy dispersive X-ray spectrometry (EDS) compositional analysis, respectively. Output peaks of interest included calcium and phosphate and the calcium to phosphate ratio $(\mathrm{Ca}: \mathrm{P})$ of the mineral was determined.

\section{3-D Application of Vapor Deposition Methods}

To demonstrate the practical application of these particles for use in orthopedic tissue engineering applications, $5 \mathrm{Ca} / 5 \mathrm{P}$ particles were vapor deposited onto model 3-D porous fibrin scaffolds used for orthopedic tissue engineering [40, 50, 150] for 90 seconds Figure 3.2). Control groups consisted of fibrin scaffolds not coated with sol particles and fibrin scaffolds coated with particles containing no calcium or phosphate for 90 seconds. Fibrin scaffolds were generated by sintering $200 \mu \mathrm{m}$ diameter poly(methyl methacrylate) (PMMA; Polysciences Inc.) spheres at $145^{\circ} \mathrm{C}$ for 22 hours to generate molds. The molds were then immersed in a fibrinogen solution $(200 \mathrm{mg} / \mathrm{ml}$ in $0.9 \% \mathrm{NaCl}$; Sigma-Aldrich) and vacuum infiltrated overnight. The fibrinogen infiltrated molds were then cross-linked in a thrombin (Biopharm Laboratories) solution and the PMMA beads were dissolved from the scaffolds by soaking them in acetone for 72 hours. Mineral crystal formation was induced on the vapor coated scaffolds by incubating them in simulated body fluid (SBF) at $37^{\circ} \mathrm{C}$ for 7 days. SBF solutions were changed every 3 days to replenish ions. Mineral crystal morphology and composition were analyzed with FESEM imaging and EDS compositional analysis, respectively. 
(A)

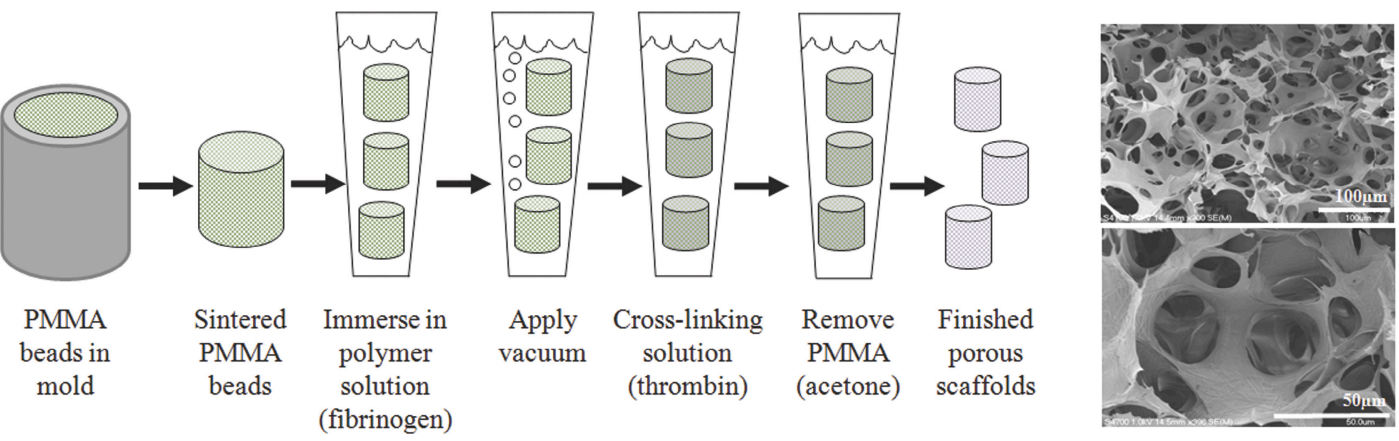

(B)
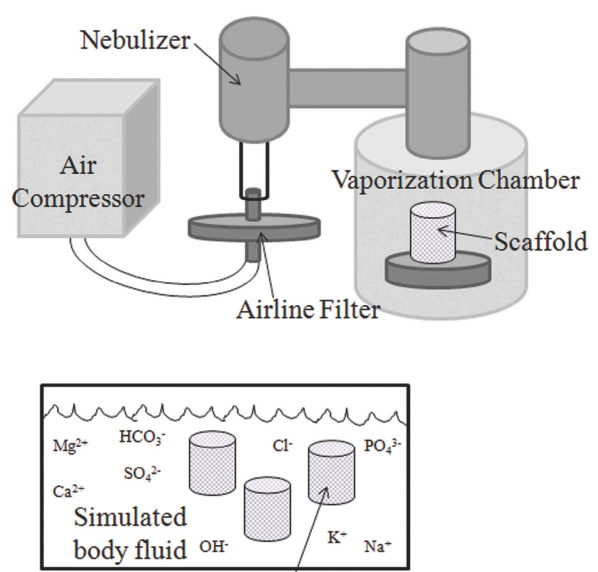

Vapor coated scaffolds

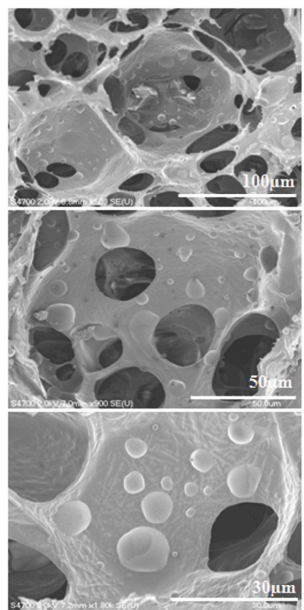

Figure 3.2. Application of vapor deposition methods. (A) Scaffold preparation: sphere-templated fibrin scaffolds were generated by vacuum infiltrating fibrinogen into a mold of sintered PMMA spheres, crosslinking the fibrinogen with a thrombin solution and removing the PMMA spheres in acetone to create porous scaffolds. (B) Vapor-directed mineralization: porous fibrin scaffolds were placed in vaporization chamber and vapor coated with $5 \mathrm{Ca} / 5 \mathrm{P}$ particles for 90 seconds. Vapor coated scaffolds were then immersed in SBF for 7 days. Methods for coating and inducing mineral growth on 2-D materials are similar to that seen in (B)

\section{Statistics}

All experiments were performed in triplicate $(n=3)$ unless otherwise stated. Data was analyzed for significance using an analysis of variance (ANOVA) and a Tukey's post-hoc test for pairwise comparison. Statistical significance defined as a $\mathrm{p}$ value less than $0.05(p<0.05)$. Error bars in text and on graphs represent standard error of the mean $( \pm \mathrm{SEM})$. 


\section{RESULTS}

\section{Size Distribution and Morphology}

The size distribution and morphology of particles loaded with calcium and phosphate and vapor deposited onto PS for 60 seconds was assessed. A deposition time point of 60 seconds was chosen because of the results seen in work up to this point showed similar effects to that of particles deposited for 90 seconds. The average area of $25 \mathrm{Ca} / 25 \mathrm{P}$ particles were significantly larger $\left(0.24 \pm 0.02 \mu \mathrm{m}^{2}\right)$ than both $5 \mathrm{Ca} / 5 \mathrm{P}$ $\left(0.12 \pm 0.02 \mu \mathrm{m}^{2}\right)$ and $25 \mathrm{Ca} / 5 \mathrm{P}\left(0.13 \pm 0.01 \mu \mathrm{m}^{2}\right)$ particles $(\mathrm{p}<0.001)$ and were much more irregularly shaped (Figure 3.3A). The size distributions of the particles is similar for $5 \mathrm{Ca} / 5 \mathrm{P}$ and $25 \mathrm{Ca} / 5 \mathrm{P}$ particles but $25 \mathrm{Ca} / 25 \mathrm{P}$ particles had a much larger fraction of particles that were $\leq 0.0025 \mu \mathrm{m}^{2}(5 \mathrm{Ca} / 5 \mathrm{P}=0.17 \pm 0.01 ; 25 \mathrm{Ca} / 25 \mathrm{P}=0.67 \pm 0.02 ; 25 \mathrm{Ca} / 5 \mathrm{P}=$ $0.18 \pm 0.01$; Figure 3.3B).

(A)

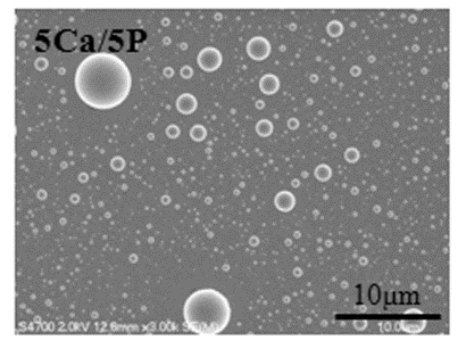

Average Particle Area $0.12 \pm 0.02 \mu \mathrm{m}^{2}$

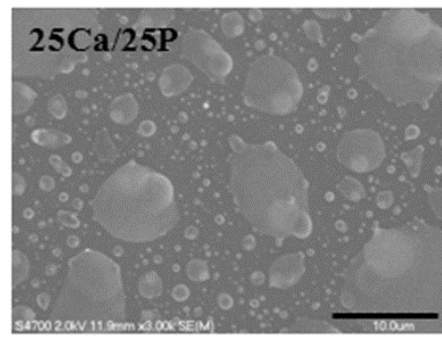

Average Particle Area $0.24 \pm 0.02 \mu \mathrm{m}^{2}$ *

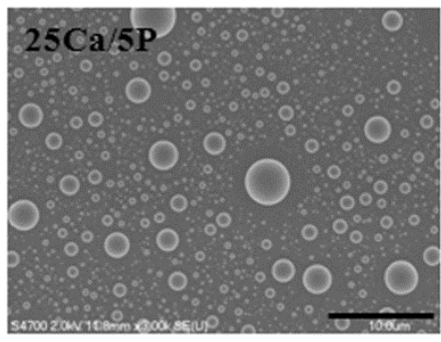

Average Particle Area $0.13 \pm 0.01 \mu \mathrm{m}^{2}$

(B)

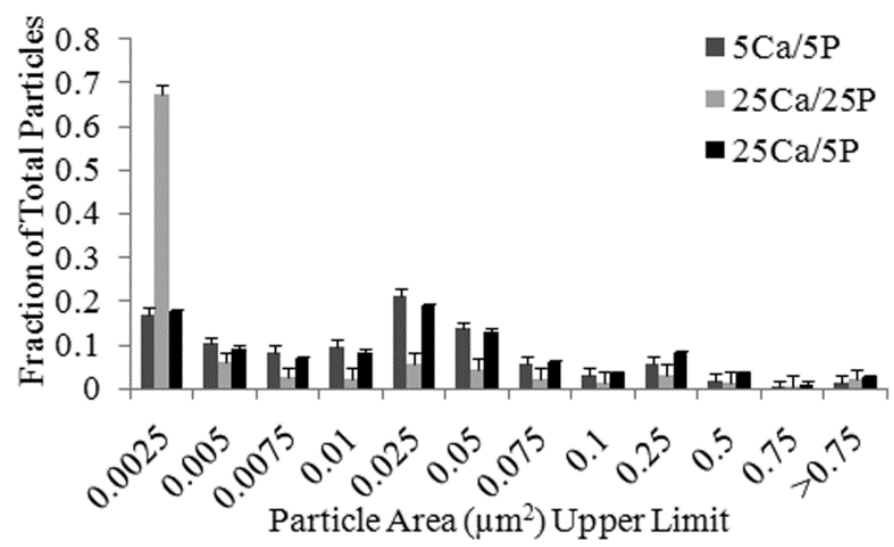

Figure 3.3. Morphology and size distribution of vapor deposited $\mathrm{Ca} / \mathrm{P}$ sol particles. (A) SEM images show morphology of $5 \mathrm{Ca} / 5 \mathrm{P}, 25 \mathrm{Ca} / 25 \mathrm{P}$, and $25 \mathrm{Ca} / 5 \mathrm{P}$ particles vapor deposited for 60 seconds onto polystyrene. (scale bar $=10 \mu \mathrm{m})$. Average area of particles was determined using an area-based MATLAB macro and $25 \mathrm{Ca} / 25 \mathrm{P}$ particles were found to be significantly larger than both $5 \mathrm{Ca} / 5 \mathrm{P}$ and $25 \mathrm{Ca} / 5 \mathrm{P}$ particles. All comparisons were made using ANOVA, $p$-values $<0.05$ were considered significant. Values expressed as \pm SEM. 


\section{Surface Hydrophobicity}

Deposition of $25 \mathrm{Ca} / 25 \mathrm{P}$ and $25 \mathrm{Ca} / 5 \mathrm{P}$ particles each significantly decreased the contact angle measurement $\left(50.5 \pm 1.2^{\circ}\right.$ and $66.3 \pm 1.4^{\circ}$ respectively) of the surface when compared to the PS plate controls $\left(79.7 \pm 1.9^{\circ}\right)$ and those coated with $5 \mathrm{Ca} / 5 \mathrm{P}$ particles $\left(74.4 \pm 1.1^{\circ}\right)$, indicating that deposition of these particles makes the overall surface character more hydrophilic $(\mathrm{p}<0.04$; Figure 3.4). Comparatively, the contact angle of TCPS, which has been plasma treated to allow for optimal cell attachment is $41.08 \pm 1.91^{\circ}$ and PLLA, which is a highly hydrophobic, has a contact angle of $92.49 \pm 0.22^{\circ}$. Deposition of $\mathrm{Ca} / \mathrm{P}$ sol particles lowers the contact angle to closer to that of TCPS.

(A)
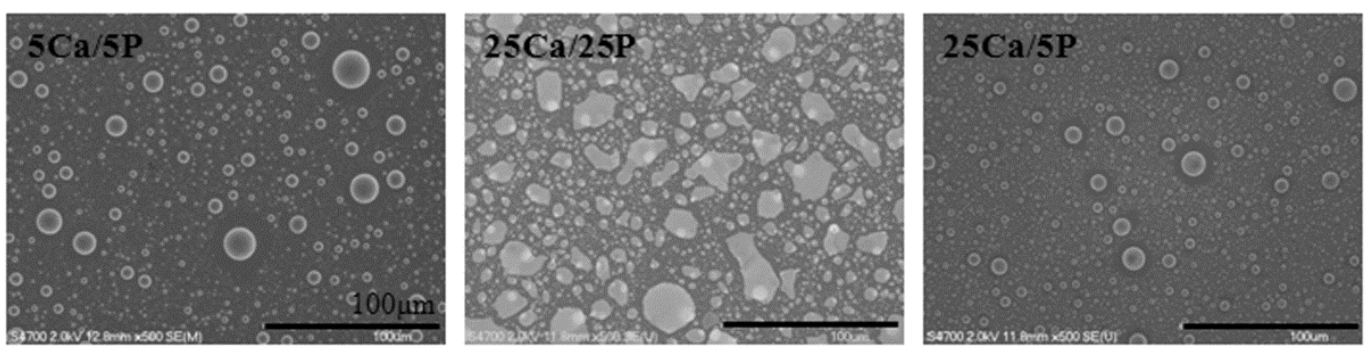

(B)

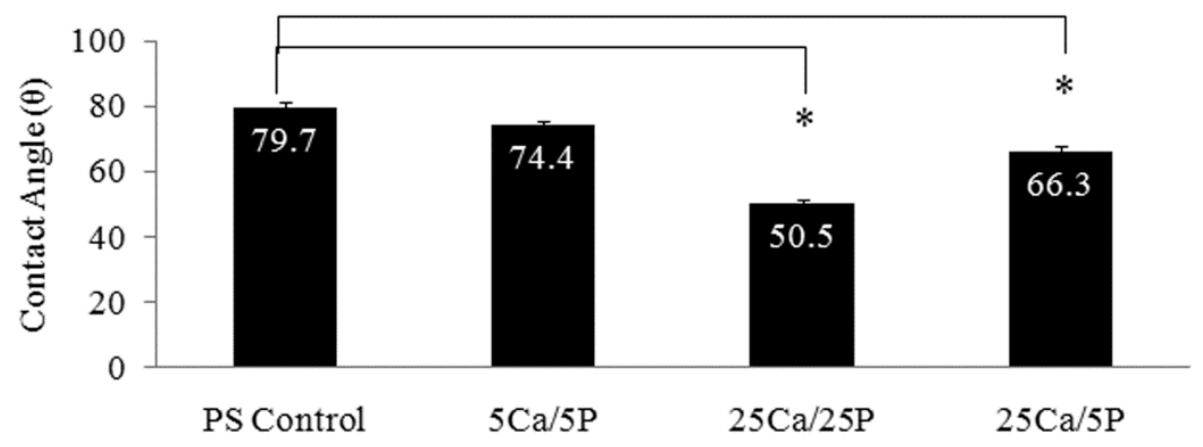

Figure 3.4. Surface hydrophobicity of vapor deposited Ca/P sol particles. (A) $25 \mathrm{Ca} / 25 \mathrm{P}$ particles have larger, more irregularly shaped particles that have a higher substrate surface coverage than $5 \mathrm{Ca} / 5 \mathrm{P}$ and $25 \mathrm{Ca} / 5 \mathrm{P}$ particles. (B) Contact angle analysis shows that depositing $\mathrm{Ca} / \mathrm{P}$ sol particles for 60 seconds decreases the contact angle of the substrate surface.

\section{Particle Degradation}

The degradation behavior of the $\mathrm{Ca} / \mathrm{P}$ sol particles in media at $37^{\circ} \mathrm{C}$ was found to be similar for all formulations except for at day 1 where Ca5/5P $(56.1 \pm 4.3 \%)$ particles were significantly less degraded than $25 \mathrm{Ca} / 25 \mathrm{P}(86.1 \pm 10.7 \% ; \mathrm{p}=0.03)$ and $25 \mathrm{Ca} / 5 \mathrm{P}$ 
$(90.1 \pm 4.2 \%$; $=0.048)$ particles, with all particles being over $90 \%$ degraded at day 7

(Figure 3.5A). Deposition of $25 \mathrm{Ca} / 25 \mathrm{P}$ particles for 60 seconds led to significantly more total silica $\left(0.014 \pm 0.003 \mathrm{mg} / \mathrm{cm}^{2}\right)$ being deposited onto the substrate than for $5 \mathrm{Ca} / 5 \mathrm{P}$ $\left(0.025 \pm 0.003 \mathrm{mg} / \mathrm{cm}^{2} ; \mathrm{p}=0.04\right)$ and $25 \mathrm{Ca} / 5 \mathrm{P}\left(0.010 \pm 0.001 \mathrm{mg} / \mathrm{cm}^{2} ; \mathrm{p}=0.01\right)$ particles (Figure 3.5B).

(A)

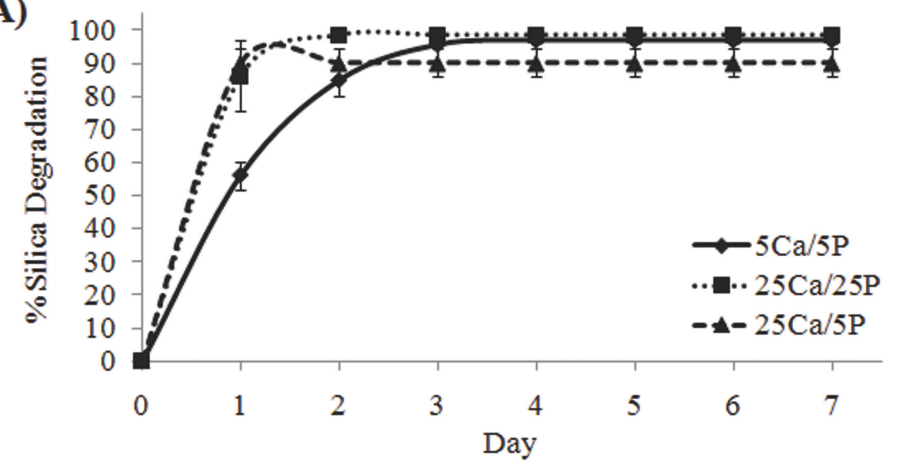

(B)

\begin{tabular}{lc}
\hline Particle Formulation & $\begin{array}{c}\text { Total Silica } \\
\left(\mathbf{m g} / \mathbf{c m}^{2}\right)\end{array}$ \\
\hline $5 \mathrm{Ca} / 5 \mathrm{P}$ & $0.014 \pm 0.003$ \\
$25 \mathrm{Ca} / 25 \mathrm{P}$ & $0.025 \pm 0.003^{*}$ \\
$25 \mathrm{Ca} / 5 \mathrm{P}$ & $0.010 \pm 0.001$ \\
\hline
\end{tabular}

Figure 3.5. $\mathrm{Ca} / \mathrm{P}$ sol particle degradation behavior. The degradation behavior of $5 \mathrm{Ca} / 5 \mathrm{P}, 25 \mathrm{Ca} / 25 \mathrm{P}$, and $25 \mathrm{Ca} / 5 \mathrm{P}$ particles is similar regardless of formulation, with over $90 \%$ of particles degrading in within 7 days. (B) Deposition of $25 \mathrm{Ca} / 25 \mathrm{P}$ particles resulted in significantly more total silica $\left(\mathrm{mg} / \mathrm{cm}^{2}\right)$ being deposited onto substrates than $5 \mathrm{Ca} / 5 \mathrm{P}$ or $25 \mathrm{Ca} / 5 \mathrm{P}$ particles. All comparisons were made using ANOVA, $\mathrm{p}$-values $<0.05$ were considered significant ( ${ }^{*}$ indicates statistical significance). Error bars and values expressed as \pm SEM.

\section{Mineralization}

$\mathrm{Ca} / \mathrm{P}$ sol particles were vapor deposited onto PS plates for 60 seconds, with uncoated PS and PS coated with $\mathrm{Ca} / \mathrm{P}$ free particles for 60 seconds to serve as controls, and after exposure to SBF for 7 days mineral growth was assessed. SEM images show that apatite-like mineral growth occurred in all groups, but mineral growth was much more advanced in samples coated with all $\mathrm{Ca} / \mathrm{P}$ particle formulations, though their morphologies vary (Figure 3.6). EDS analysis showed that the $\mathrm{Ca}: \mathrm{P}$ ratios for this mineral is similar for all $\mathrm{Ca} / \mathrm{P}$ formulations $(5 \mathrm{Ca} / 5 \mathrm{P}=1.29 \pm 0.08 ; 25 \mathrm{Ca} / 25 \mathrm{P}=1.32 \pm 0.02$; $25 \mathrm{Ca} / 5 \mathrm{P}=1.29 \pm 0.03 ; \mathrm{p}=0.8)$.

\section{3-D Application of Vapor Deposition Methods}

3-D porous scaffolds were either left uncoated (Figure 3.7A), coated with $\mathrm{Ca} / \mathrm{P}$ free particles for 90 seconds (Figure 3.7B), or coated with $5 \mathrm{Ca} / 5 \mathrm{P}$ particles for 90 seconds (Figure 3.7C) and exposed to SBF for 7 days all showed apatite-like mineral 
growth on the surface of the scaffolds. However, mineral growth was most significant on scaffolds coated with $\mathrm{Ca} / \mathrm{P}$ particles, with the mineral crystals uniformly covering the scaffold surface. EDS analysis or the mineral on scaffolds coated with $5 \mathrm{Ca} / 5 \mathrm{P}$ particles revealed a Ca:P ratio of $2.08 \pm 0.13$. 


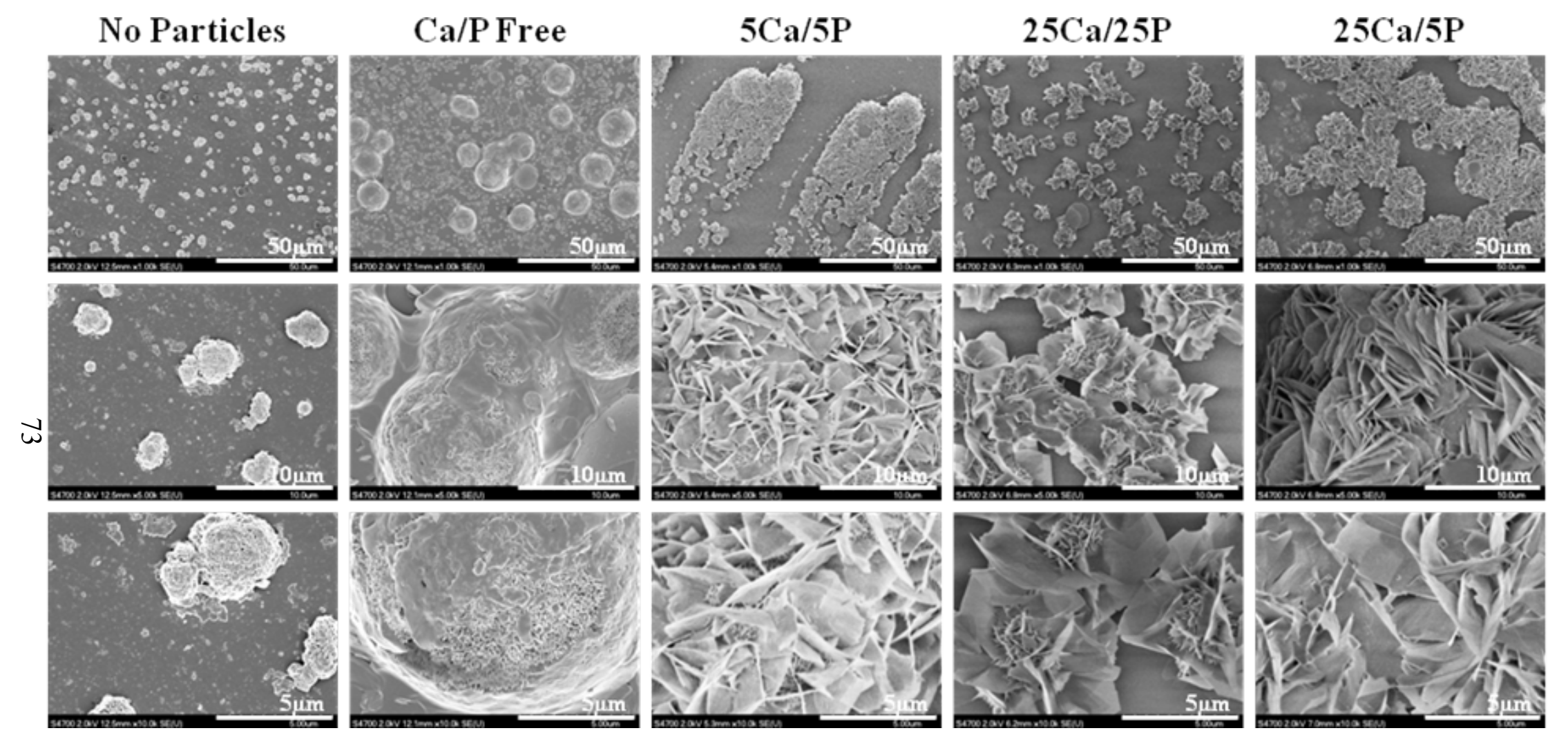

Figure 3.6. Apatite-like mineral growth with $\mathrm{Ca} / \mathrm{P}$ sol particles. SEM images of mineral growth induced by $\mathrm{PS}$ Controls, Ca/P free particles, $5 \mathrm{Ca} / 5 \mathrm{P}$, $25 \mathrm{Ca} / 25 \mathrm{P}$, and $25 \mathrm{Ca} / 5 \mathrm{P}$ particles deposited onto $\mathrm{PS}$ for 60 seconds after exposure to $\mathrm{SBF}$ for 7 days. All three $\mathrm{Ca} / \mathrm{P}$ particles formulations show more apatitelike mineral growth than either the PS controls or the $\mathrm{Ca} / \mathrm{P}$ free particles. 

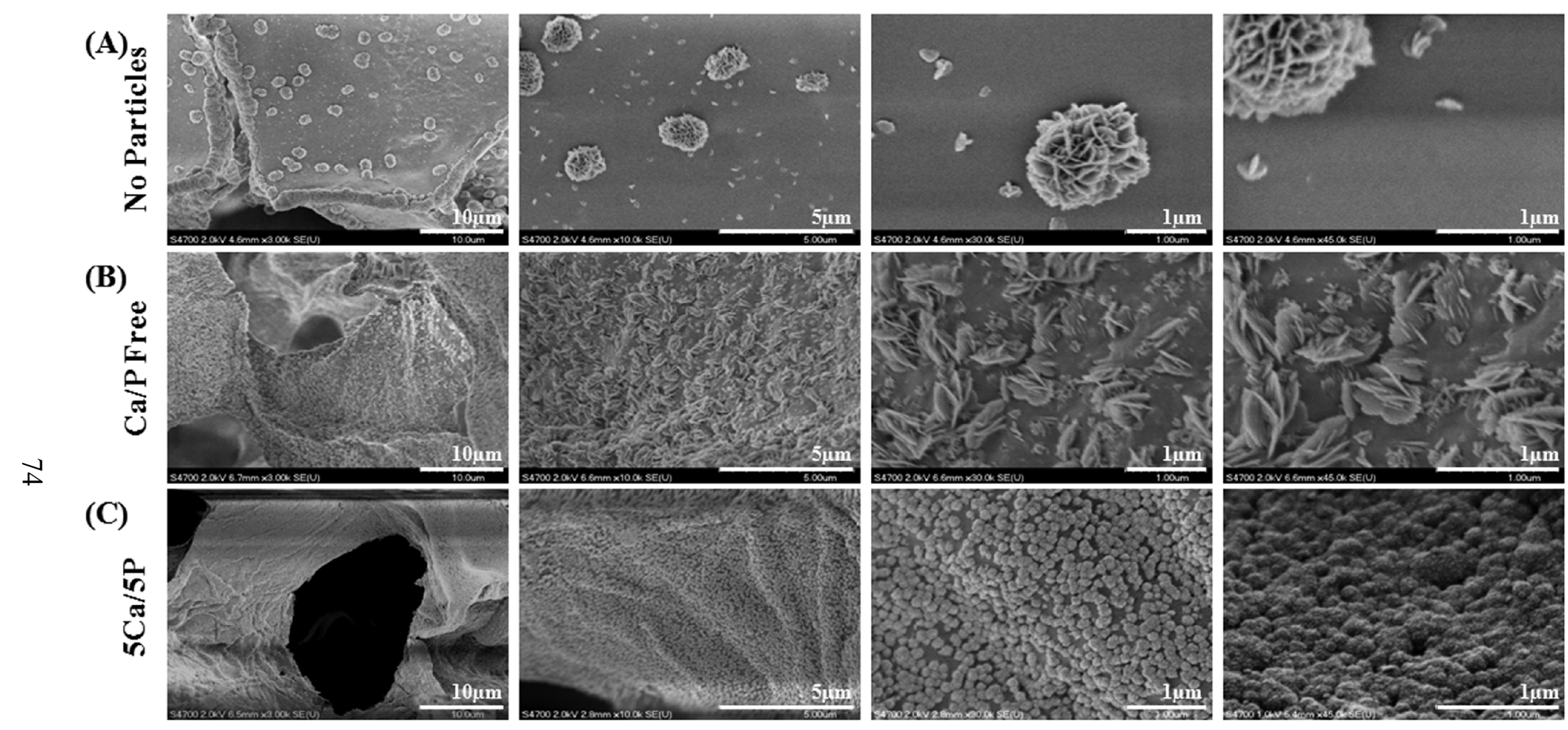

Figure 3.7. Apatite-like mineral growth on 3-D porous fibrin scaffolds. Sphere-templated fibrin scaffolds vapor coated with (A) no particles, (B) particles containing no calcium or phosphate for 90 seconds, or (C) $5 \mathrm{Ca} / 5 \mathrm{P}$ particles for 90 seconds and exposed to SBF for 7 days. Scaffolds with no particles show minimal mineral growth, while scaffolds coated with $\mathrm{Ca} / \mathrm{P}$ free particles show more apatite-like mineral growth. However, scaffolds coated with $5 \mathrm{Ca} / 5 \mathrm{P}$ particles show uniform apatite-like mineral growth on the entire scaffold surface (EDS analysis shows calcium to phosphate ratio (Ca:P) of 2.08 \pm 0.13 ). 


\section{DISCUSSION}

Sol-gels can be used as carriers for an abundance of molecules including ions, proteins, drugs, RNA, and DNA. This work aimed to incorporate calcium and phosphate into the developed vapor deposited particles to make them more bioactive. The addition of these ions will change how the internal silica network forms, so it was necessary to characterize the morphology and size distribution of the particles. Particles resulting from $5 \mathrm{Ca} / 5 \mathrm{P}$ and $25 \mathrm{Ca} / 5 \mathrm{P}$ solutions had regular rounded morphology similar to that of unloaded particles (Figure 3.3, Figure 3.8). However, $25 \mathrm{Ca} / 25 \mathrm{P}$ particles were more irregularly shaped. This may be due to the water that is added to the solution with the addition of the ions, but is unlikely because the particles did not crack as the excess water evaporated, leading to the conclusion that this change in morphology is due to the increased concentrations in calcium and phosphate. Additionally, the average particle area was larger for all three $\mathrm{Ca} / \mathrm{P}$ sol particle formulations, than for particles without the

ions $\left(0.076 \pm 0.01 \mu \mathrm{m}^{2}\right.$ at $\mathrm{t}=60$ seconds $)$. This could be due to the more disrupted silica network in the $\mathrm{Ca} / \mathrm{P}$ sol particles through the addition of ions. Phosphate is known to increase the surface area when incorporated into a bioactive glass [144, 147-149]. The fact that the $\mathrm{Ca} / \mathrm{P}$ sol particles generated have a relatively wide size range may be beneficial to bone formation. Bioglass particles with narrow $(300-360 \mu \mathrm{m})$ and wide (90$710 \mu \mathrm{m})$ size ranges were implanted into femur defects. At 4 and 12 weeks, the defects amount of bone generated in the grafts using the wide size range particles was larger and had biomechanical properties equivalent to native bone [151]. 


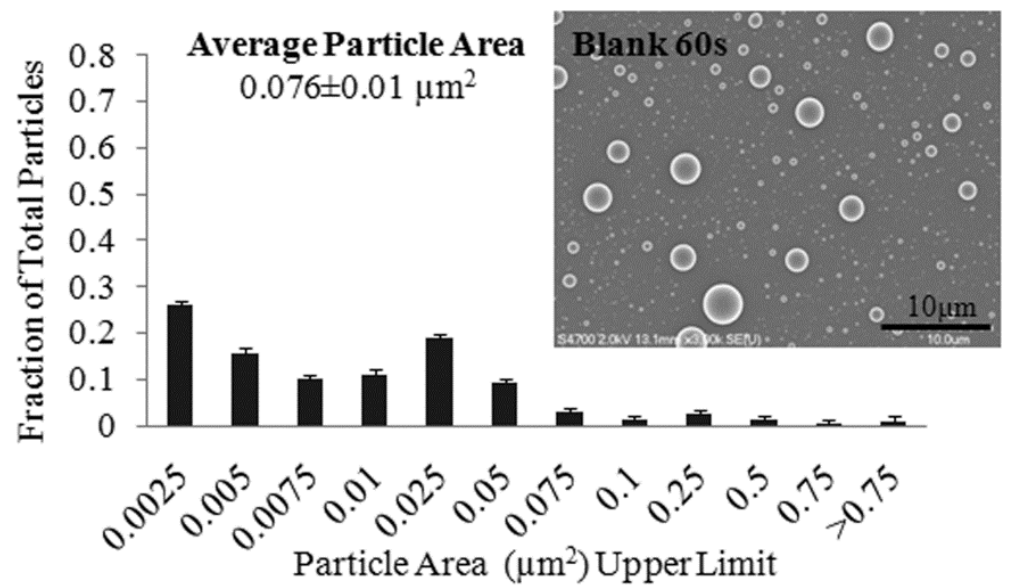

Figure 3.8. Size distribution and morphology of vapor deposited particles containing no additional ions. Sol-gel solutions containing no calcium or phosphate ions have similar size distributions and morphology to that of $5 \mathrm{Ca} / 5 \mathrm{P}$ and $25 \% \mathrm{Ca} / 5 \mathrm{P}$ particles.

Deposition of all three $\mathrm{Ca} / \mathrm{P}$ particles onto substrates decreased the contact angle of the overall surface, making them more hydrophilic, with the largest change resulting from the deposition of $25 \mathrm{Ca} / 25 \mathrm{P}$ particles. This may be due to the larger surface area that is covered by the larger $25 \mathrm{Ca} / 25 \mathrm{P}$ particles, allowing for more interaction between water and the particles as opposed to the other two formulations, which generated smaller particles (Figure 3.4A).

The sol particles degraded more quickly with the addition of calcium and phosphate ions (day 1: blank $=36.3 \pm 4.6 \%$ degraded; $5 \mathrm{Ca} / 5 \mathrm{P}=56.1 \pm 4.3 \% ; 25 \mathrm{Ca} / 25 \mathrm{P}=$ $86.1 \pm 10.7 \% ; 25 \mathrm{Ca} / 5 \mathrm{P}=90.1 \pm 4.2 \%)$. This is due to the effect that calcium and phosphate ions have on a bioglass network. The connectivity of a bioglass network is determined by the composition and synthesis method of the glass. When the content of silica is high, the network is highly connected and contains a large proportion of bridging oxygen bonds. Connectivity is lowered by adding network modifiers (e.g. calcium and sodium) that are known to disrupt the silica network through non-bridging oxygen bonds [107, 152, 153]. Conversely, phosphate that is added to a bioglass is found to be isolated from the silica network and can remove calcium ions from their network modifying role, leading to faster release into the aqueous environment and making the bioglass more soluble overall $[107,154,155]$. 
Though the particles successfully induced apatite-like mineral formation on 2-D substrates that was superior to the mineral growth on uncoated PS substrates and PS coated with $\mathrm{Ca} / \mathrm{P}$ free particles, the $\mathrm{Ca}: \mathrm{P}$ ratio was only around 1.3 for all $\mathrm{Ca} / \mathrm{P}$ particle formulations. Native bone $\mathrm{HA}$ is often defined of having a Ca:P ratio of 1.67 so most bioactive materials aim to induce mineral formation at this benchmark. However, the actual Ca:P ratio for bone mineral ranges from 1.57-1.71, and changes with the stage of mineral maturation-increasing from 1.35 in early calcification of nodules [156] Altering the amount of calcium and phosphate available for release within the particles to the aqueous environment may lead to changes in the composition of the apatite mineral formed on the substrate to achieve a $\mathrm{Ca}: \mathrm{P}$ ratio closer to mature bone $\mathrm{HA}$. It would also be beneficial to determine the mineral composition in vivo since this would more accurately determine particle ability to generate mineral that is close to that of native bone. The calcium and phosphate $\mathrm{Ca} / \mathrm{P}$ formulations that were used in this work were chosen because the addition of higher concentrations of calcium chloride and triethyl phosphate (i.e., $5 \mathrm{M}$ and $10 \mathrm{M}$ solutions) resulted in particles that were irregularly shaped and varied greatly from sample to sample (Figure 3.9). It has been noted that successful incorporation of calcium ions into silica nanoparticles makes it difficult to generate particles of a more regular morphology [107, 157]. A $25 \mathrm{v} / \mathrm{v} \%$ solution (1M) was chosen because the addition of higher concentrations was found to have a dilution effect on the solution. This resulted in a limit on the amount of calcium and phosphate that could be incorporated into the sol particles using this technique and led to a fairly low amount of calcium and phosphate in the overall composition of the particles, especially when compared to that of traditional melt bioglasses which can be composed of up to $50 \mathrm{~mol} \%$ calcium [158]. A possible solution to this is adding the calcium and phosphate solutions at the beginning of synthesis during hydrolysis, before the silica network has had a chance to form or through careful adjustment of sol pH $[107,159]$. 


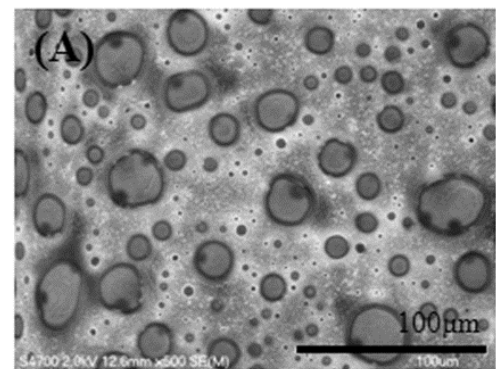

$5 \mathrm{v} / \mathrm{v} \% 10 \mathrm{M} \mathrm{CaCl}_{2}$

$5 \mathrm{v} / \mathrm{v} \% 5 \mathrm{M} \mathrm{TEP}$

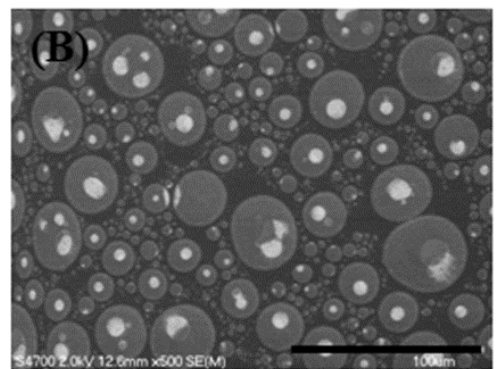

$25 \mathrm{v} / \mathrm{v} \% 5 \mathrm{M} \mathrm{CaCl}_{2}$ $5 \mathrm{v} / \mathrm{v} \% 5 \mathrm{M}$ TEP

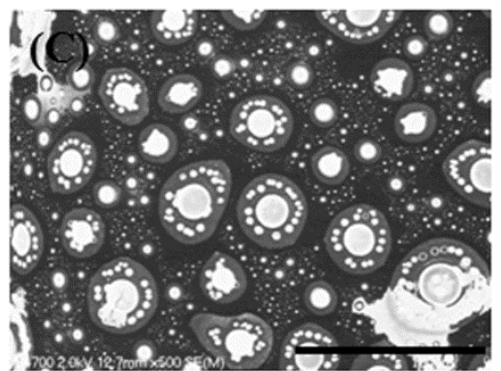

$25 \mathrm{v} / \mathrm{v} \% 5 \mathrm{M} \mathrm{CaCl}_{2}$ $25 \mathrm{v} / \mathrm{v} \% 5 \mathrm{M}$ TEP

Figure 3.9. Examples of $\mathrm{Ca} / \mathrm{P}$ sol particles generated from higher concentrations of calcium and phosphate. Solutions where higher concentration of $\mathrm{CaCl}_{2}$ and TEP were added [(A) $5 \mathrm{v} / \mathrm{v} \% 10 \mathrm{M} \mathrm{Ca} / 5 \mathrm{v} / \mathrm{v} \%$ $5 \mathrm{M} \mathrm{P}$, (B) $25 \mathrm{v} / \mathrm{v} \% 5 \mathrm{M} \mathrm{Ca} / 5 \mathrm{v} / \mathrm{v} \% 5 \mathrm{M} \mathrm{P}$, (C) $25 \mathrm{v} / \mathrm{v} \% 5 \mathrm{M} \mathrm{Ca} / 25 \mathrm{v} / \mathrm{v} \% 5 \mathrm{M}$ P] resulted in particles that were highly irregular in morphology, composed of multiple phases, and displayed significant variability between batch preparations, for this reason $1 \mathrm{M}$ solutions were chosen for generating $\mathrm{Ca} / \mathrm{P}$ sol particles.

Vapor deposition of $\mathrm{Ca} / \mathrm{P}$ sol particles and successful mineral growth on porous 3D scaffolds illustrates that these particles have the potential for application to structural biomaterials used in tissue engineering. The mineral growth on the 3-D scaffolds had a $\mathrm{Ca}: \mathrm{P}$ ratio that was higher $(2.08 \pm 0.13)$ than that of the mineral generated on 2-D substrates using the same $\mathrm{Ca} / \mathrm{P}$ formulation (1.29..0.08). This is because the generated mineral composition is dependent upon many factors including ion concentration, $\mathrm{pH}$ and movement of the body fluid, as well as the spatial organization of the surface $[114,160]$. Additionally, the presence of a polymer (in this case: fibrin) can alter the composition of the mineral due to the incorporation of the polymer into the mineral layer $[160,161]$. The high $\mathrm{Ca}: \mathrm{P}$ ratio of the 3-D mineral indicates that it is highly insoluble, as mineral solubility increases with decreasing Ca:P ratios. This system developed here is a simple and versatile platform for $\mathrm{Ca} / \mathrm{P}$ sol particle generation and upon further optimization, it could be possible to generate several different formulations of $\mathrm{Ca} / \mathrm{P}$ sol particles-some of which could be used promote interface stability and others that could be applied to tissue engineering constructs. However, more work will need to be done in order to overcome some limitations including the thickness of scaffold that the sol particles can penetrate into. Potential solutions to this problem could be the application of a low-level vacuum to the vaporization chamber to pull sol particles through the scaffolds as they are being 
generated and deposited or by incorporation of the sol particles into the fibrin structure itself to create a polymer-ceramic composite material.

\section{CONCLUSION}

This work establishes that vapor deposited particles with incorporated calcium and phosphate ions can successfully induce apatite-like mineral on both two- and threedimensional substrates superior to the mineral generated on untreated controls and samples coated with $\mathrm{Ca} / \mathrm{P}$ free particles, demonstrating their potential to be used as a surface modification technique for other biomaterials to increase their bioactivity. However, further work needs to be done to improve the properties of the particlesspecifically increasing particle stability in order to prolong the physical (generated topography and increased surface hydrophilicity) and chemical (ion release) properties that result from the vapor deposition of these particles onto surfaces, as well as optimization of calcium and phosphate content used, in an effort to further tailor the composition of the resultant mineral.

\section{ACKNOWLEDGEMENTS}

The authors would like to thank David Jaroch (Purdue), Patrick Bowen (MTU), Nicholas Schaub (RPI), Owen Mills (ACMAL-MTU), and Dr. Jaroslaw Drelich (MTU) for their help with portions of this work.

\section{REFERENCES}

1. Hoppe, A., N.S. Güldal, and A.R. Boccaccini, A review of the biological response to ionic dissolution products from bioactive glasses and glass-ceramics. Biomaterials, 2011. 32: p. 2757-2774.

2. Avnir, D., et al., Recent bio-applications of sol-gel materials. Journal of Materials Chemistry, 2006. 16(11): p. 1013-1030.

3. Hong, Z., R.L. Reis, and J.F. Mano, Preparation and in vitro characterization of novel bioactive glass ceramic nanoparticles. J Biomed Mater Res A, 2009. 88(2): p. 304-13. 
4. Kortesuo, P., et al., Effect of synthesis parameters of the sol-gel-processed spraydried silica gel microparticles on the release rate of dexmedetomidine. Biomaterials, 2002. 23(13): p. 2795-2801.

5. Yang, S., et al., Simple approach for efficient encapsulation of enzyme in silica matrix with retained bioactivity. Analytical chemistry, 2009. 81(9): p. 3478-84.

6. Chen, J., et al., A gold nanoparticles/sol-gel composite architecture for encapsulation of immunoconjugate for reagentless electrochemical immunoassay. Biomaterials, 2006. 27(10): p. 2313-21.

7. Nicoll, S.B., et al., In vitro release kinetics of biologically active transforming growth factor-beta 1 from a novel porous glass carrier. Biomaterials, 1997. 18(12): p. 853-9.

8. Pierre, A., et al., Encapsulation of deoxyribonucleic acid molecules in silica and hybrid organic-silica gels. Journal of materials science. Materials in medicine, 2001. 12(1): p. 51-5.

9. Nieto, A., et al., Cell viability in a wet silica gel. Acta Biomaterialia, 2009. 5(9): p. 3478-3487.

10. Jones, J., Review of bioactive glasses: From Hench to hybrids. Acta Biomaterialia, 2013. 9(1): p. 4457-4486.

11. Jones, J.R. and L.L. Hench, Biomedical materials for new millennium: perspective on the future. Materials Science and Technology, 2001. 17: p. 891900.

12. Li, P., et al., Induction and morphology of hydroxyapatite precipited from metastable simulated body fluids on sol-gel prepared silica. Biomaterials, 1993. 14: p. 963-968.

13. Ramila, A. and M. Vallet-Reg, Static and dynamic in vitro study of sol-gel glass bioactivity. Biomaterials, 2001. 22: p. 2301-2306.

14. Pereira, M. and L. Hench, Mechanisms of Hydroxyapatite Formation on Porous Gel-Silica Substrates. Journal of Sol-Gel Science and Technology, 1995. 7: p. 5968.

15. Vallet-Regí, M., D. Arcos, and J. Pérez-Pariente, Evolution of porosity during in vitro hydroxycarbonate apatite growth in sol-gel glasses. Journal of biomedical materials research, 2000. 51(1): p. 23-28.

16. Laczka, M., et al., Gel-derived materials of a CaO-P2O5-SiO2 system modified by boron, sodium, magnesium, aluminum, and fluorine compounds. Journal of biomedical materials research, 2000. 52(4): p. 601-612. 
17. Dietrich, E., et al., In vitro bioactivity of melt-derived glass 46 S6 doped with magnesium. Journal of Biomedical Materials Research Part A, 2009. 88A(4): p. 1087-1096.

18. Olmo, N., et al., Bioactive sol-gel glasses with and without hydrocarbonite apatite layer as substrates for osteoblast cell adhesion and proliferation. Biomaterials, 2003. 24: p. 3383-3393.

19. Salinas, A.J., M. Vallet-Regi, and I. Izquierdo-Barba, Biomimetic Apatite Deposition on Calcium Silicate Gel Glasses. Journal of Sol-Gel Science and Technology, 2001. 21: p. 13-25.

20. Salinas, A.J., A.I. Martin, and M. Vallet-Regí, Bioactivity of three $\mathrm{CaO}-\mathrm{P} 2 \mathrm{O} 5-$ $\mathrm{SiO} 2$ sol-gel glasses. Journal of biomedical materials research, 2002. 61(4): p. 524-532.

21. Vallet-Regí, M. and A. Ramila, New bioactive glass and changes in porosity during the growth of a carbonate hydroxyapatite layer on glass surfaces. Chemistry of Materials, 2000. 12: p. 961-965.

22. Perez-Pariente, J., et al., Influence of composition and surface characteristics on the in vitro bioactivity of $\mathrm{SiO} 2-\mathrm{CaO}-\mathrm{P} 2 \mathrm{O} 5-\mathrm{MgO}$ sol-gel glasses. Journal of Biomedical Materials Research 1999. 47(170-175).

23. Izquierdo-Barba, I., A. Salinas, and M. Vallet-Regí, In vitro calcium phosphate layer formation on sol-gel glasses of the $\mathrm{CaO}-\mathrm{SiO} 2$ system. Journal of Biomedical Materials Research, 1999. 47: p. 243-250.

24. Martinez, A., I. Izquierdo-Barba, and M. Vallet-Regí, Bioactivity of a CaO-SiO2 binary glass system. Chemistry of Materials, 2000. 12: p. 3080-3088.

25. Vallet-Regí, M., I. Izquierdo-Barba, and A.J. Salinas, Influence of P2O5 on crystallinity of apatite formed in vitro on surface of bioactive glasses. Journal of biomedical materials research, 1999. 46(4): p. 560-565.

26. Linnes, M.P., B.D. Ratner, and C.M. Giachelli, A fibrinogen-based precision microporous scaffold for tissue engineering. Biomaterials, 2007. 28(35): p. 5298306.

27. Osathanon, T., et al., Microporous nanofibrous fibrin-based scaffolds for bone tissue engineering. Biomaterials, 2008. 29(30): p. 4091-9.

28. Osathanon, T., C. Giachelli, and M. Somerman, Immobilization of alkaline phosphatase on microporous nanofibrous fibrin scaffolds for bone tissue engineering. Biomaterials, 2009. 30(27): p. 4513-4521. 
29. Thomas, M., D. Puleo, and M. Al-Sabbagh, Bioactive Glass Three Decades On. Journal of Long-Term Effects of Medical Implants, 2005. 15(6): p. 585-597.

30. Cormack, A., The structure of bioactive glasses and their surfaces, in Bioglasses: an introduction, J. Jones and A. Clare, Editors. 2012, Wiley: Chichester. p. 65-74.

31. Mercier, C., et al., Influence of P2O5 content on the structure of SiO2-Na2OCaO-P2O5 bioglasses by 29Si and 31P MASNMR. Journal of Non-Crystalline Solids, 2011. 357(3901-3909).

32. Abou Neel, E., et al., Bioactive functional materials: a perspective on phosphatebased glasses. Journal of Materials Chemistry, 2009. 19: p. 690-701.

33. Sepulveda, P., J. Jones, and L. Hench, In vitro dissolution of melt-derived 45S5 and sol-gel derived 585 bioactive glasses. Journal of Biomedical Materials Reserach 2002. 61(301-311).

34. Bonucci, E., Bone mineralization. Frontiers in Bioscience, 2012. 17: p. 100-128.

35. Labbaf, S., et al., Spherical bioactive glass particles and their interaction with human mesenchymal stem cells in vitro. Biomaterials, 2011. 32: p. 1010-1018.

36. Shi, D., Biomaterials and Tissue Engineering, ed. D. Shi. 2004, Heidelberg: Springer.

37. Luz, G. and J. Mano, Preparation and characterization of bioactive glass nanoparticles prepared by sol-gel for biomedical applications. Nanotechnology, 2011. 22: p. 494014.

38. Mann, S., Molecular recognition in biomineralization. Nature 1988. 332: p. 119124.

39. Bonucci, E., Calcification and silicification: a comparative survey of the early stages of biomineralization. Journal of Bone and Mineral Metabolism, 2009. 27(3): p. 255-264. 


\section{CHAPTER FOUR: OSTEOBLAST RESPONSE TO CALICIUM-PHOPHATE SOL PARTICLES ${ }^{3}$}

This chapter addresses Specific Aim 3-assessment of osteoblast behavior in response to the vapor deposited calcium-phosphate loaded sol particles characterized in Chapter 3 and evaluation of their of potential to be used to direct osteoblast attachment, proliferation, and differentiation in orthopedic tissue engineering applications.

\section{INTRODUCTION}

Native biological tissues are complex and composed of a variety biomolecules to create a heterogeneous environment whose structure is organized so that it creates a hierarchy ranging from nano- to micro- to macro-scale [162-165]. The physical and chemical properties of the tissue generate a particular set of cues for cells to promote proper cell behavior [164, 166-168]. Biomimetic materials aim to imitate the natural cellular micro-environment in order to promote tissue regeneration. More specifically, it is important to design materials with the minimal character to target desired cell behavior for tissue regeneration [168-175].

Surface roughness and topography, as examples, can significantly influence osteoblast behavior. It is widely accepted that implants with roughened surfaces display increased osseointegration [65-70]. Osteoblasts cultured on materials with high surface roughness (100-500nm) display increased attachment, compared to cells cultured on smoother substrates [176-183]. The coexistence of hierarchal nano- and micro-structures on a substrate surface (Figure 4.1) allows for greater interaction between the cell and the material and can induce both osteoblast proliferation and differentiation [183, 184]. Cells cultured on these materials have been found to have higher ALP activity, type I collagen and osteocalcin expression, prostaglandin E2 (PGE2) and transforming growth factor beta 1 (TGF- $\beta 1$ ) production, as well as calcium deposition [80, 163, 183-186]. Additionally, the organization of the nano- and micro-structure can have a significant effect on osteoblast behavior. Less ordered surface topography results in increased

\footnotetext{
${ }^{3}$ The material presented in this chapter is in preparation for submission to the Journal of Biomedical Materials Research Part A. [Snyder KL and Rajachar RM].
} 
osteoblast phenotypic character compared to that of highly ordered arrays in which cells develop a fibroblast phenotypic [80].

In addition to surface roughness and topography, surface hydrophobicity (wettability) can also play a significant role in protein adsorption and cell behavior [57, 187-189]. Hydrophilic surfaces $\left(\theta<65^{\circ}\right)$ allow for enhanced interaction between a substrate surface and its biologic environment, due to the ability to form covalent, ionic, hydrogen and charge-transfer bonds leading to increased cell adhesion and spreading [57, 190-195]. Osteoblasts exhibit elevated osteoblast specific gene expression (osteocalcin and osteoprotegrerin) as well as increased prostaglandin E2, transforming growth factor $\beta 1$, and vascular endothelial growth factor (VEGF) production, ultimately demonstrating increased differentiation on substrates that are more hydrophilic [182, 196-199]. Importantly, surface hydrophobicity effects on cell behavior are time dependent, guiding early activation and differentiation with effects that diminish over time (within 3 days) $[57,200]$.

Silica based bioactive glasses, including sol-gels, possess the ability to actively influence cell behavior including osteogenesis and angiogenesis, as well as enhance antibacterial activity (see Figure 1.7) [4]. In addition to roughness, topography, and hydrophobicity, dissolution ions $(\mathrm{Si}, \mathrm{Ca}, \mathrm{P})$ introduced to the surrounding medium have been found to influence the behavior many tissue specific cell types including mesenchymal stem cells, osteoblasts, osteoclasts, fibroblasts, and endothelial cells [4, 104].

Osteoblasts exposed to silicate ions show increased proliferation, collagen I production $(10-20 \mu \mathrm{M})$, ALP activity, osteocalcin expression, and ECM mineralization $(15-20 \mu \mathrm{g} / \mathrm{ml})$ depending on the concentration of silica ions and cell line used [117, 118, $120,122,201]$. Extracellular calcium and phosphate ions can have a significant impact on osteoblast proliferation, differentiation, and ECM production [12]. Calcium acts as a signaling molecule in many cell processes and pathways and can promote osteoblast migration, proliferation, and differentiation through the activation of calcium sensing receptors $(\mathrm{CaSR} / \mathrm{CaR})$, the extracellular signal-regulated kinase (ERK 1/2) pathway, and increases in intracellular calcium levels, with maximum effects being treatment dosages 
between $\sim 3-10 \mathrm{mM}$ [123-125, 202-204]. Phosphate ions (5-10mM) also play a role in bone remodeling and help to regulate osteoblast differentiation, increasing expression of transcriptional factors (e.g. Nrf2, HMGA1 and 2), signal transduction factors (e.g. calcyclin, A170), plasma membrane and membrane transport factors (e.g. Pit-1, Annexin $\mathrm{V})$, as well as the extracellular matrix protein, osteopontin $[128,130]$.

Again as with other material properties, the influence of dissolution ions is dose and time dependant in nature. Osteoblast precursors exposed to calcium ions at concentrations slightly higher than physiologic levels $(2-4 \mathrm{mM})$ show increased cell proliferation, while at even higher levels $(6-8 \mathrm{mM})$ differentiation and matrix mineralization are enhanced, but with a decrease in cell viability [126]. Excessive calcium levels $(>10 \mathrm{mM})$ are cytotoxic $[5,125,126,205]$. Similarly, treatment of cells with phosphate ions causes a dose and time dependant (high concentrations and exposure times) increase in chondrocyte and osteoblast apoptosis, while also contributing to terminal differentiation [128, 132, 133]. For example, treatment of osteoblast-like cells with $\mathrm{P}_{\mathrm{i}}$ for 48 hours at concentrations of $5 \mathrm{mM}$ and $7 \mathrm{mM}$ led to $75 \%$ and $40 \%$ cell viability respectively, while after 96 hours of treatment with $5 \mathrm{mM} \mathrm{P} \mathrm{P}_{\mathrm{i}}$ led to $30 \%$ viability and $7 \mathrm{mM}$ caused almost complete cell loss [132]. Ion concentrations that are appropriate to ensure viability, while promoting cell differentiation and matrix maturation remain unclear, and understanding the mechanisms controlling these relationships warrants further investigation.

The $\mathrm{Ca} / \mathrm{P}$ sol-particles developed and characterized in Chapter 3 allow for the modification of biomaterials by generating unique surface nano- and micro-topography and decreasing surface hydrophobicity. These particles also release calcium and phosphate ions as they degrade and induce apatite-like mineral formation. The goal of this work is to assess osteoblast behavior in response to these vapor deposited $\mathrm{Ca} / \mathrm{P}$ sol particles. Cell attachment, proliferation, and gene expression were evaluated. 


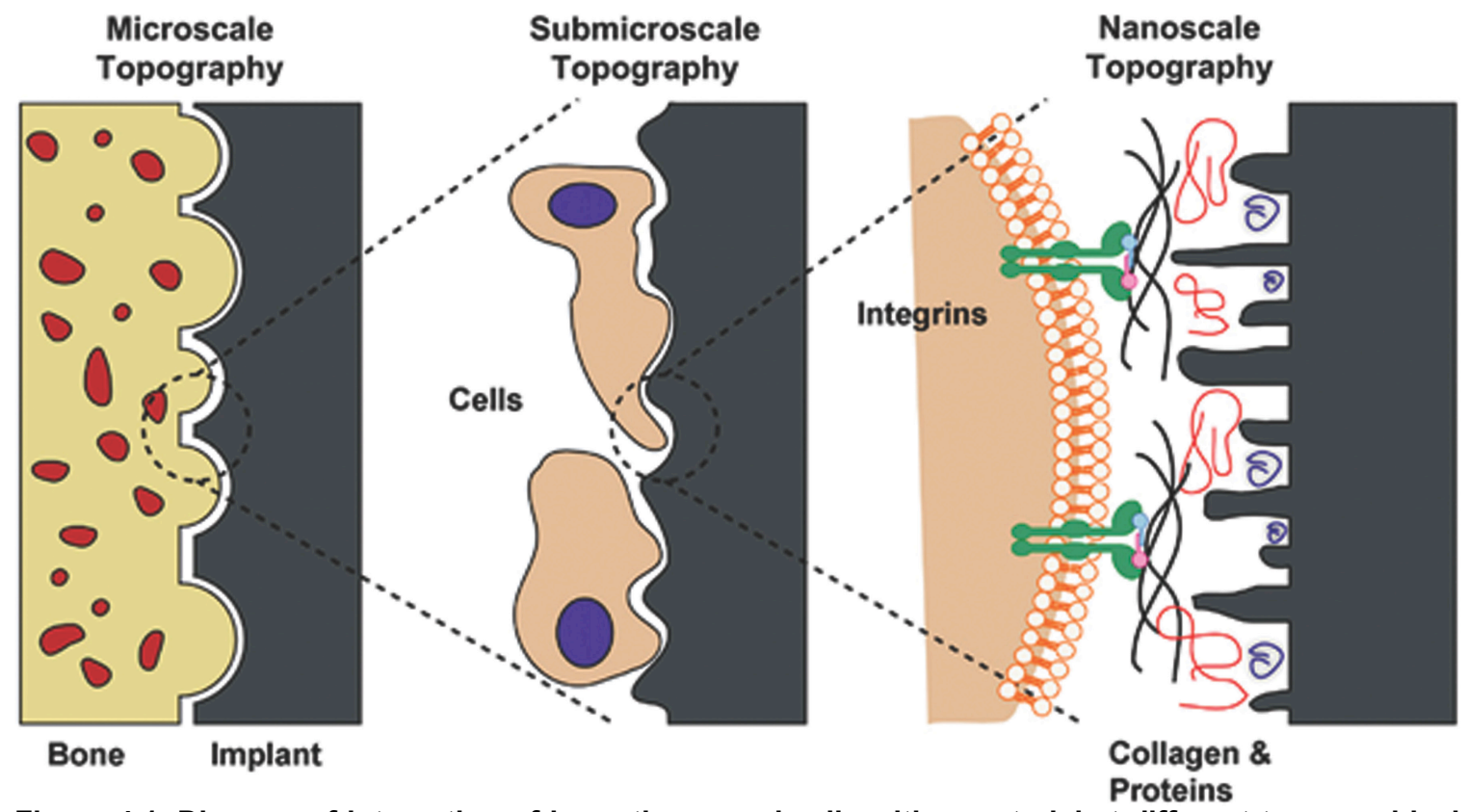

Figure 4.1, Diagram of interaction of bone tissue and cells with a material at different topographical scales. From Gittens et al. with permission (see Appendix A) [184].

\section{MATERIALS AND METHODS}

\section{Sol Preparation and Vapor Deposition}

The base compositions of the sol solutions used in these experiments was a 16:1 molar ratio of de-ionized water to tetramethyl orthosilicate (TMOS; Sigma Aldrich). Sol was vapor deposited using the developed vaporization chamber onto non-tissue culture polystyrene (PS) for 60 seconds at 40psi. Samples were removed immediately after deposition and the sol was allowed to fully polycondensate into a solid gel for 2 minutes. Samples were covered and stored at $25^{\circ} \mathrm{C}$ for 3-7 days until further use.

\section{Calcium and Phosphate Incorporation into Sol}

Calcium $(\mathrm{Ca})$ and phosphate $(\mathrm{P})$ ions were incorporated into solutions just before vapor deposition by adding $1 \mathrm{M}$ calcium chloride $\left(\mathrm{CaCl}_{2}\right.$; Sigma Aldrich) and $1 \mathrm{M}$ triethyl phosphate (TEP; Sigma Aldrich) in three different formulations (v/v\%): $5 \% \mathrm{Ca} / 5 \% \mathrm{P}$, $25 \% \mathrm{Ca} / 25 \% \mathrm{P}$, and $25 \% \mathrm{Ca} / 5 \% \mathrm{P}$. 


\section{Cell Attachment and Proliferation}

MC3T3-E1 Subclone 4 osteoblast progenitors (ATCC) were cultured directly on plates coated with particles $(5 \mathrm{Ca} / 5 \mathrm{P}, 25 \mathrm{Ca} / 25 \mathrm{P}, 25 \mathrm{Ca} / 5 \mathrm{P}$, and $\mathrm{Ca} / \mathrm{P}$ free $)$ or non-tissue culture PS as a control (seeding density: $1 \times 10^{4}$ cells $/ \mathrm{cm}^{2}$ ) at $37^{\circ} \mathrm{C}$ and $5 \% \mathrm{CO}_{2}$ in Minimal Essential Media ( $\alpha$-MEM; Hyclone) supplemented with $10 \%$ fetal bovine serum (FBS; Hyclone) and 1\% penicillin-streptomycin (P/S; Mediatech). All samples were sterilized using ethylene oxide and rinsed three times with sterile phosphate buffered saline (PBS) before cell seeding. At days 1 and 2, cells were fixed $(4 \%$ paraformaldehyde), stained (TRITC-conjugated Phalloidin and 4',6-diamidino-2phenylindole, DAPI; Molecular Probes, Invitrogen), and imaged (Olympus BX5 microscope). Cell attachment was quantified through direct cell counts and normalized to the cell seeding density.

To determine cell proliferation, at days 1 and 2 cells were fixed (4\% paraformaldehyde) and stained using the proliferation marker, Ki-67 (SP6) primary antibody (Abcam) with Alexafluor-488 conjugated secondary antibody (Abcam). Cell nuclei were stained using DAPI. Ki-67 positivity was quantified through direct cell counts and calculated by dividing the number of Ki-67 positive cells by the number of total cells [206].

\section{Gene Expression}

MC3T3-E1 Subclone 4 preosteoblasts were cultured directly on plates vapor coated with $\mathrm{Ca} / \mathrm{P}$ particles, $\mathrm{Ca} / \mathrm{P}$ free particles or PS as a control $(\mathrm{n}=6 / \mathrm{group})\left(1 \times 10^{4}\right.$ cells $/ \mathrm{cm}^{2}$ ) at $37^{\circ} \mathrm{C}$ and $5 \% \mathrm{CO}_{2}$ in $\alpha$-MEM supplemented with $10 \% \mathrm{FBS}$ and $1 \% \mathrm{P} / \mathrm{S}$. At days 1, 2, and 4 RNA was isolated using TRIzol ${ }^{\circledR}$ (Invitrogen) according to the manufacturer instructions and RNA concentration and quality was determined using spectrophotometer readings at 230, 260 and 280nm (Nanodrop ND-1000). RNA was reverse transcribed into cDNA using Superscript ${ }^{\circledR}$ II Reverse Transcriptase (Invitrogen), $1 \mathrm{X}$ first-strand buffer (Invitrogen), 48mM dithiothreitol (DTT; Invitrogen) $800 \mu \mathrm{M}$ dNTPs, (Promega), RNaseOUT ${ }^{\text {TM }}$ Recombinant Ribonuclease Inhibitor (Invitrogen), and 
$0.5 \mu \mathrm{g}$ Oligo(dT) $)_{12-18}$ Primer (Invitrogen) at $42^{\circ} \mathrm{C}$ for 20 minutes, $50^{\circ} \mathrm{C}$ for 10 minutes and $42^{\circ} \mathrm{C}$ for 60 minutes. cDNA was then used for real time PCR for genes of interest (GOI) and housekeeping genes (HK) (Table 4.1). All reactions were performed in the StepOnePlus ${ }^{\mathrm{TM}}$ real-time PCR system (Applied Biosystems) under the following parameters: hot start at $95^{\circ} \mathrm{C}$ for 15 minutes followed by 40 cycles at $95^{\circ} \mathrm{C}$ for 15 seconds, $60^{\circ} \mathrm{C}$ for 30 seconds and $72^{\circ} \mathrm{C}$ for 15 seconds. GOI expression levels relative to the geometric mean of housekeeping genes Ubiquitin and Cyclophilin were calculated using the $2^{(-\Delta \Delta C t)}$ method [207].

\section{Mineralization- Alizarin Red and Alkaline Phosphatase}

MC3T3 preosteoblasts were cultured directly on plates vapor coated with $\mathrm{Ca} / \mathrm{P}$ sol particles or PS as a control $\left(1 \times 10^{4}\right.$ cells $\left./ \mathrm{cm}^{2}\right)$ at $37^{\circ} \mathrm{C}$ and $5 \% \mathrm{CO}_{2}$ in $\alpha$-MEM supplemented with $10 \% \mathrm{FBS}, 1 \% \mathrm{P} / \mathrm{S}$ and $50 \mu \mathrm{g} / \mathrm{ml}$ ascorbic acid. Media was changed every 3 days. At days 4, 7, 10, and 14 cells were fixed with neutral buffered formalin (NBF) overnight.

Cultures were stained for either calcium content (alizarin red) or alkaline phosphatase (ALP). For alizarin red, cells were stained $\left(2 \mathrm{w} / \mathrm{v} \%\right.$ alizarin red in $\mathrm{dH}_{2} \mathrm{O}$ and $\mathrm{pH}$ adjusted to 4.1-4.3) for 30 minutes at room temperature, washed with $\mathrm{dH}_{2} \mathrm{O}$ and imaged. For ALP activity, cells were stained with Naphthol AS-MX phosphate $(0.1 \mathrm{mg} / \mathrm{ml}) /$ diazonium salt (fast red violet LB salt; $0.6 \mathrm{mg} / \mathrm{ml}$ ) in $50 \%$ Tris- $\mathrm{HCl}(\mathrm{pH}$ 8.74) $-50 \% \mathrm{dH}_{2} \mathrm{O}$ for 60 minutes at $37^{\circ} \mathrm{C}$, washed with $\mathrm{dH}_{2} \mathrm{O}$ and imaged.

\section{Statistics}

All experiments were performed in triplicate $(\mathrm{n}=3)$ unless otherwise stated. Data was analyzed for significance using an analysis of variance (ANOVA) and a Tukey's post-hoc test for pairwise comparison, except for gene expression data where each treatment group was compared to controls using a Student's t-test. Statistical significance defined as a p value less than $0.05(\mathrm{p}<0.05)$. Error bars in text and on graphs represent standard error of the mean $( \pm$ SEM). 


\begin{tabular}{ll}
\hline Gene & Primer Sequence \\
\hline HK: Ubiquitin & F: 5'- CGTCGAGCCCAGTGTTACCACCAAGAAGG -3 \\
& R: 5'- CCCCCATCACACCCAAGAACAAGCACAAG -3' \\
& F: 5'- TCATGTGCCAGGGTGGTGACTTTA-3' \\
HK: Cyclophilin & R: 5'-ATGCTTGCCATCCAGCCATTCAGT -3' \\
GOI: Runt-Related & F: 5'- AGAGTCAGATTACAGATCCCAGGC -3' \\
Transcription Factor 2 & R: 5'- GTCAGAGGTGGCAGTGTCATCAT -3' \\
(Runx2) & \\
& F: 5'- CAGCTGGATGAACCAAGTCTGGAA -3' \\
GOI: Osteopontin (OPN) & R: 5'-ACTAGCTTGTCCTTGTGGCTGTGA -3' \\
& F: 5'- TGGTTTGGAGAGAGCATGACCGAT -3' \\
GOI: Collagen I (COLI) & R: 5'- TGTAGGCTACGCTGTTCTTGCAGT -3' \\
& F: 5'- GAGTCTGACAAAGCCTTCATGTCC -3' \\
GOI: Osteocalcin (OCN) & R: 5'- TGATAGCTCGTCACAAGCAGGGTA -3' \\
\hline
\end{tabular}

\section{RESULTS}

\section{Cell Attachment and Proliferation}

MC3T3 preosteoblasts cultured on substrates coated with $\mathrm{Ca} / \mathrm{P}$ sol particles showed similar morphology to those cultured on polystyrene controls, with cells spread out on the substrate surface (Figure 4.2A). Relative cell attachment (normalized to uncoated PS) at day $1($ control $=1.00 \pm 0.15 ; \mathrm{Ca} / \mathrm{P}$ free $=1.59 \pm 0.22 ; 5 \mathrm{Ca} / 5 \mathrm{P}=0.97 \pm 0.07$; $25 \mathrm{Ca} / 25 \mathrm{P}=1.17 \pm 0.17 ; 25 \mathrm{Ca} / 5 \mathrm{P}=1.22 \pm 0.14$ ) showed significantly higher attachment on plates coated with $\mathrm{Ca} / \mathrm{P}$ free particles compared to plates coated with $5 \mathrm{Ca} / 5 \mathrm{P}$ particles $(\mathrm{p}=0.0049)$ and by day 2 (control $=1.00 \pm 0.12 ; \mathrm{Ca} / \mathrm{P}$ free $=1.88 \pm 0.24 ; 5 \mathrm{Ca} / 5 \mathrm{P}=$ $0.79 \pm 0.11 ; 25 \mathrm{Ca} / 25 \mathrm{P}=0.91 \pm 0.07 ; 25 \mathrm{Ca} / 5 \mathrm{P}=0.84 \pm 0.08)$ significantly higher attachment on plates coated with $\mathrm{Ca} / \mathrm{P}$ free particles compared to all groups (Figure 4.2B; $\mathrm{p}=0.0003$ ). This indicates that cell attachment during days 1 and 2 is enhanced when $\mathrm{Ca} / \mathrm{P}$ free particles are deposited onto PS substrate, while deposition of $\mathrm{Ca} / \mathrm{P}$ particles does not increase cell attachment compared to controls.

Cell proliferation, as indicated by the fraction of total cells positively expressing of the proliferation marker, Ki-67 was assessed (Figure 4.3A). At day 1, the fraction of 
Ki-67 positive cells (control $=0.53 \pm 0.03 ; \mathrm{Ca} / \mathrm{P}$ free $=0.74 \pm 0.04 ; 5 \mathrm{Ca} / 5 \mathrm{P}=0.45 \pm 0.02$; $25 \mathrm{Ca} / 25 \mathrm{P}=0.57 \pm 0.02 ; 25 \mathrm{Ca} / 5 \mathrm{P}=0.60 \pm 0.01)$, on $\mathrm{PS}$ coated with $\mathrm{Ca} / \mathrm{P}$ free particles was significantly higher compared to PS controls and all $\mathrm{Ca} / \mathrm{P}$ particle formulations $(\mathrm{p}=0.007)$. Additionally, the fraction of Ki-67 positive cells was significantly lower in $5 \mathrm{Ca} / 5 \mathrm{P}$ cultures compared to $25 \mathrm{Ca} / 5 \mathrm{P}$ cultures $(\mathrm{p}=0.006)$. At day 2 the fraction of $\mathrm{Ki}-67$ positive cells (control $=0.78 \pm 0.04 ; \mathrm{Ca} / \mathrm{P}$ free $=0.74 \pm 0.03 ; 5 \mathrm{Ca} / 5 \mathrm{P}=0.58 \pm 0.02$; $25 \mathrm{Ca} / 25 \mathrm{P}=0.77 \pm 0.05 ; 25 \mathrm{Ca} / 5 \mathrm{P}=0.78 \pm 0.02$ ) was significantly lower in $5 \mathrm{Ca} / 5 \mathrm{P}$ particle cultures compared to all other groups (Figure 4.3B; $\mathrm{p}<0.006$ ). This indicates that cell proliferation is initially enhanced in cells cultured with $\mathrm{Ca} / \mathrm{P}$ particles compared to controls while it is decreased in cells cultured with $5 \mathrm{Ca} / 5 \mathrm{P}$ particles.

\section{Gene Expression}

Gene expression of MC3T3 preosteoblasts cultured with $\mathrm{Ca} / \mathrm{P}$ free and $\mathrm{Ca} / \mathrm{P}$ sol particles was analyzed using quantitative PCR at days 1, 2, and 4. Osteoblast differentiation markers Runx2, osteopontin, (OPN), osteocalcin (OCN), and type I collagen were genes of interest and expression levels were normalized to housekeeping genes ubiquitin and cyclophilin (Table 4.2). There is a trend that is suggestive of an early up-regulation event of the master osteoblast differentiation regulator Runx 2 expression in cells cultured with all $\mathrm{Ca} / \mathrm{P}$ particle formulations at days 1 and 2 compared to controls (Figure 4.4A). Although the data did not reach the critical level for significance, these findings suggest that the presence of the particles themselves have the potential for accelerating commitment to an osteogenic phenotype. OPN expression was significantly increase in cells cultured with $\mathrm{Ca} / \mathrm{P}$ free particles at day $2(\mathrm{p}=0.02)$ and shows a trend of upregulation at days 2 and 4 in cells cultured with $\mathrm{Ca} / \mathrm{P}$ particles (Figure 4.4B). Similarly, OCN expression in osteoblasts cultured with $\mathrm{Ca} / \mathrm{P}$ particles was upregulated at days $1,2,4$ (statistical significance $25 \mathrm{Ca} / 5 \mathrm{P}$ at day $2 ; \mathrm{p}=0.001$ ) and downregulated in cells cultured with $\mathrm{Ca} / \mathrm{P}$ free particles at day $1(\mathrm{p}=0.02$; Figure 4.4C). ColI expression was down regulated in cells cultured with particles $(\mathrm{Ca} / \mathrm{P}$ free and $\mathrm{Ca} / \mathrm{P})$ at day 2 compared to controls (statistical significance in $25 \mathrm{Ca} / 25 \mathrm{P}$ cultures $\mathrm{p}=0.01$; Figure 4.4D). The upregulation of Runx2, OPN, and OCN expression in osteoblasts cultured with $\mathrm{Ca} / \mathrm{P}$ particles shows that they have to potential to induce early osteoblast differentiation. 

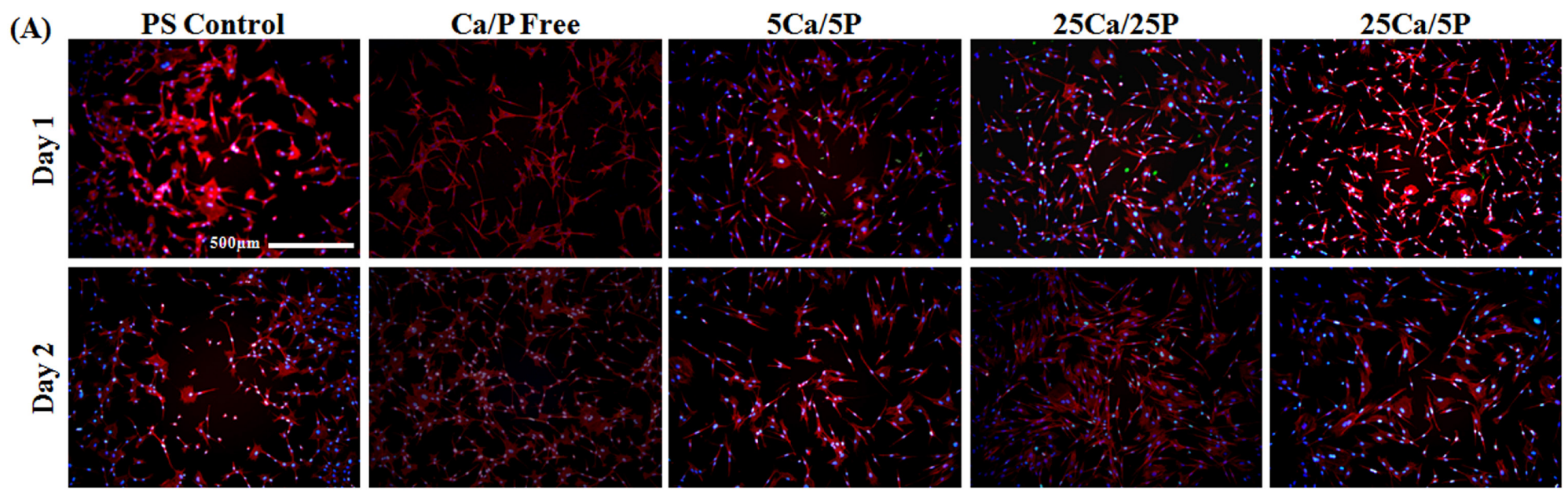

(B)

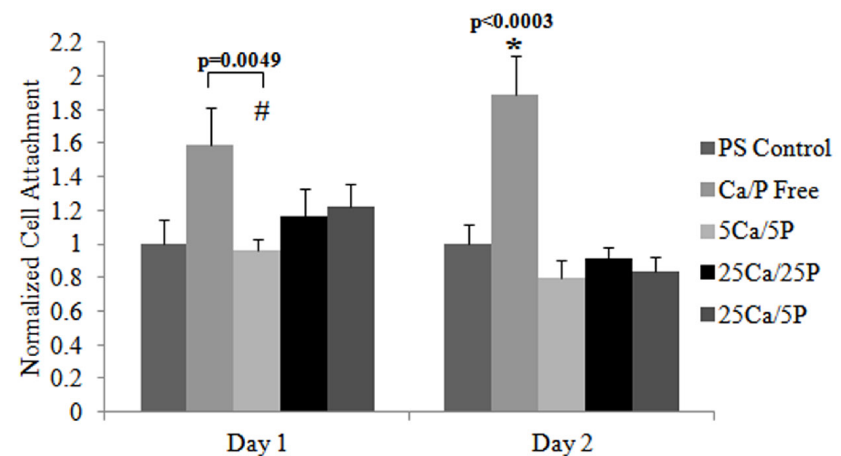

Figure 4.2. Osteoblast attachment in response to $\mathrm{Ca} / \mathrm{P}$ sol particles. МC3T3 preosteoblasts were cultured on non-tissue culture PS dishes that have been vapor coated with $\mathrm{Ca} / \mathrm{P}$ sol particles $(5 \mathrm{Ca} / 5 \mathrm{P}, 25 \mathrm{Ca} / 25 \mathrm{P}, 25 \mathrm{Ca} / 5 \mathrm{P})$ for 60 seconds, with uncoated PS plates and $\mathrm{PS}$ plates coated with $\mathrm{Ca} / \mathrm{P}$ free particles for 60 seconds serving as controls. (A) At days 1 and 2, cells were stained using TRITC-conjugated Phalloidin and DAPI and cell attachment was assessed (scale bar $=500 \mu \mathrm{m}$ ). (B) Relative cell attachment (normalized to uncoated PS) at day 1 showed a significantly higher attachment on plates coated with Ca/P free particles compared to plates coated with $5 \mathrm{Ca} / 5 \mathrm{P}$ particles and by day 2 significantly higher attachment on plates coated with Ca/P free particles compared to all groups. All comparisons were made using ANOVA, p-values $<0.05$ were considered significant. Error bars represent \pm SEM. (\# indicates statistical significance to a second group within time point. ${ }^{*}$ indicates statistical significance to all groups within time point). 
(A)

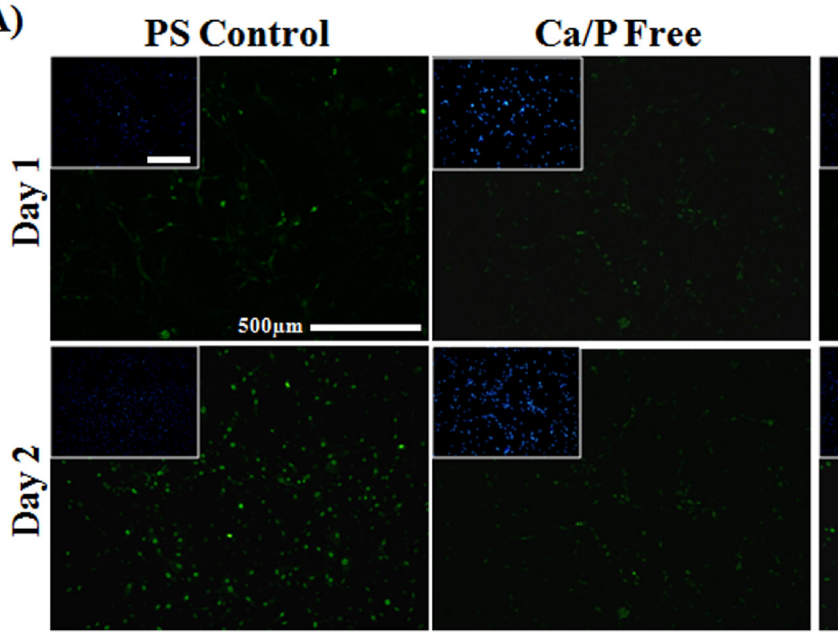

(B)

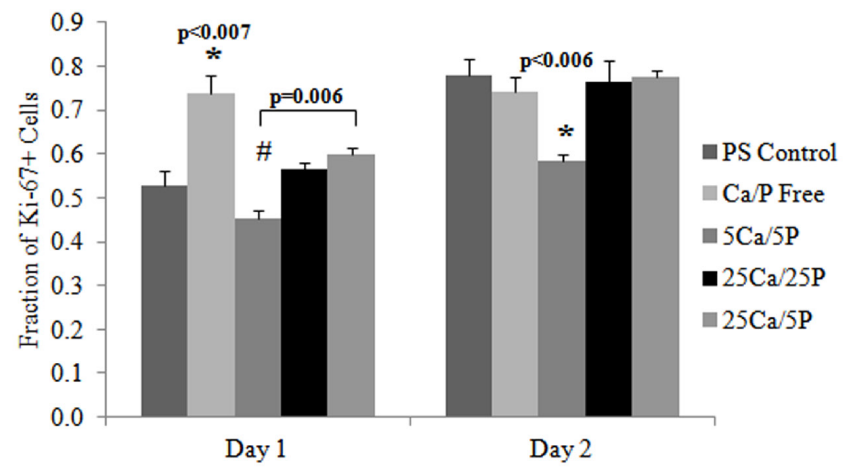

Figure 4.3. Osteoblast $\mathrm{Ki}-67$ expression in response to $\mathrm{Ca} / \mathrm{P}$ sol particles. MC3T3 preosteoblasts were cultured on non-tissue culture PS vapor coated with $\mathrm{Ca} / \mathrm{P}$ sol particles $(5 \mathrm{Ca} / 5 \mathrm{P}, 25 \mathrm{Ca} / 25 \mathrm{P}, 25 \mathrm{Ca} / 5 \mathrm{P})$ for 60 seconds, with uncoated $\mathrm{PS}$ and $\mathrm{PS}$ coated with $\mathrm{Ca} / \mathrm{P}$ free particles for 60 seconds as controls. (A) At days 1 and 2, Ki-67 expression was assessed. (Inset- corresponding DAPI image showing cell nuclei; scale bar $=500 \mu \mathrm{m}$ ). (B) At day 1 the fraction of Ki-67 positive cells on PS coated with Ca/P free particles was significantly higher compared to PS controls and all Ca/P particle formulations. Additionally, the fraction of Ki-67 positive cells was significantly lower in 5Ca/5P cultures compared to $25 \mathrm{Ca} / 5 \mathrm{P}$ cultures. At day 2 the fraction of Ki-67 positive cells was significantly lower in $5 \mathrm{Ca} / 5 \mathrm{P}$ particle cultures compared to all other groups. All comparisons were made using ANOVA, $\mathrm{p}$-values $<0.05$ were considered significant. Error bars represent \pm SEM. (\# indicates statistical significance to a second group within time point. * indicates statistical significance to all groups within time point). 
Table 4.2. Gene expression of MC3T3 osteoblasts cultured with $\mathrm{Ca} / \mathrm{P}$ sol particles

\begin{tabular}{|c|c|c|c|c|c|}
\hline Group & $\begin{array}{c}\text { Runx2 } \\
\text { Expression } \\
\pm \text { SEM }\end{array}$ & $\begin{array}{c}\text { p- } \\
\text { value }\end{array}$ & Group & $\begin{array}{c}\text { OPN } \\
\text { Expression } \\
\pm \text { SEM }\end{array}$ & $\begin{array}{c}\text { p- } \\
\text { value }\end{array}$ \\
\hline \multicolumn{3}{|c|}{ Day 1} & \multicolumn{3}{|c|}{ Day 1} \\
\hline PS Control & $1.00 \pm 0.05$ & & PS Control & $1.00 \pm 0.43$ & \\
\hline $\mathrm{Ca} / \mathrm{P}$ Free Particles & $0.70 \pm 0.26$ & 0.75 & $\mathrm{Ca} / \mathrm{P}$ Free Particles & $0.37 \pm 0.43$ & 0.20 \\
\hline $5 \mathrm{Ca} / 5 \mathrm{P}$ & $2.74 \pm 0.83$ & 0.35 & $5 \mathrm{Ca} / 5 \mathrm{P}$ & $0.31 \pm 0.11$ & 0.17 \\
\hline $25 \mathrm{Ca} / 25 \mathrm{P}$ & $4.09 \pm 1.77$ & 0.19 & $25 \mathrm{Ca} / 25 \mathrm{P}$ & $0.44 \pm 0.14$ & 0.26 \\
\hline $25 \mathrm{Ca} / 5 \mathrm{P}$ & $6.71 \pm 1.89$ & 0.07 & $25 \mathrm{Ca} / 5 \mathrm{P}$ & $0.67 \pm 0.19$ & 0.50 \\
\hline \multicolumn{3}{|c|}{ Day 2} & \multicolumn{3}{|c|}{ Day 2} \\
\hline PS Control & $1.00 \pm 0.59$ & & PS Control & $1.00 \pm 0.27$ & \\
\hline $\mathrm{Ca} / \mathrm{P}$ Free Particles & $0.45 \pm 0.27$ & 0.37 & Ca/P Free Particles & $7.89 \pm 1.21$ & $0.02 *$ \\
\hline $5 \mathrm{Ca} / 5 \mathrm{P}$ & $4.79 \pm 1.31$ & 0.05 & $5 \mathrm{Ca} / 5 \mathrm{P}$ & $1.69 \pm 0.56$ & 0.31 \\
\hline $25 \mathrm{Ca} / 25 \mathrm{P}$ & $7.89 \pm 3.09$ & 0.11 & $25 \mathrm{Ca} / 25 \mathrm{P}$ & $1.01 \pm 0.27$ & 0.97 \\
\hline $25 \mathrm{Ca} / 5 \mathrm{P}$ & $3.56 \pm 1.30$ & 0.18 & $25 \mathrm{Ca} / 5 \mathrm{P}$ & $1.89 \pm 0.44$ & 0.13 \\
\hline \multicolumn{3}{|c|}{ Day 4} & \multicolumn{3}{|c|}{ Day 4} \\
\hline PS Control & $1.00 \pm 0.38$ & & PS Control & $1.00 \pm 0.11$ & \\
\hline $\mathrm{Ca} / \mathrm{P}$ Free Particles & $0.90 \pm 0.27$ & 0.84 & Ca/P Free Particles & $2.12 \pm 0.11$ & 0.16 \\
\hline $5 \mathrm{Ca} / 5 \mathrm{P}$ & $1.04 \pm 0.26$ & 0.93 & $5 \mathrm{Ca} / 5 \mathrm{P}$ & $3.11 \pm 1.19$ & 0.15 \\
\hline $25 \mathrm{Ca} / 25 \mathrm{P}$ & $0.92 \pm 0.14$ & 0.86 & $25 \mathrm{Ca} / 25 \mathrm{P}$ & $1.42 \pm 0.27$ & 0.56 \\
\hline $25 \mathrm{Ca} / 5 \mathrm{P}$ & $1.48 \pm 0.74$ & 0.59 & $25 \mathrm{Ca} / 5 \mathrm{P}$ & $1.47 \pm 0.48$ & 0.43 \\
\hline Group & $\begin{array}{c}\text { OCN } \\
\text { Expression } \\
\pm \text { SEM }\end{array}$ & $\begin{array}{c}\text { p- } \\
\text { value }\end{array}$ & Group & $\begin{array}{c}\text { COLI } \\
\text { Expression } \\
\pm \text { SEM }\end{array}$ & $\begin{array}{c}\mathbf{p}- \\
\text { value }\end{array}$ \\
\hline \multicolumn{3}{|c|}{ Day 1} & \multicolumn{3}{|c|}{ Day 1} \\
\hline PS Control & $1.00 \pm 0.21$ & & PS Control & $1.00 \pm 0.19$ & \\
\hline Ca/P Free Particles & $0.24 \pm 0.02$ & $0.02 *$ & $\mathrm{Ca} / \mathrm{P}$ Free Particles & $0.24 \pm 0.02$ & 0.35 \\
\hline $5 \mathrm{Ca} / 5 \mathrm{P}$ & $3.11 \pm 1.22$ & 0.18 & $5 \mathrm{Ca} / 5 \mathrm{P}$ & $0.75 \pm 0.07$ & 0.24 \\
\hline $25 \mathrm{Ca} / 25 \mathrm{P}$ & $4.04 \pm 2.07$ & 0.24 & $25 \mathrm{Ca} / 25 \mathrm{P}$ & $1.27 \pm 0.17$ & 0.29 \\
\hline $25 \mathrm{Ca} / 5 \mathrm{P}$ & $7.22 \pm 3.98$ & 0.19 & $25 \mathrm{Ca} / 5 \mathrm{P}$ & $1.26 \pm 0.24$ & 0.41 \\
\hline \multicolumn{3}{|c|}{ Day 2} & \multicolumn{3}{|c|}{ Day 2} \\
\hline PS Control & $1.00 \pm 0.14$ & & PS Control & $1.00 \pm 0.15$ & \\
\hline $\mathrm{Ca} / \mathrm{P}$ Free Particles & $1.24 \pm 0.33$ & 0.56 & Ca/P Free Particles & $1.24 \pm 0.34$ & 0.11 \\
\hline $5 \mathrm{Ca} / 5 \mathrm{P}$ & $7.24 \pm 2.34$ & 0.05 & $5 \mathrm{Ca} / 5 \mathrm{P}$ & $0.62 \pm 0.16$ & 0.11 \\
\hline $25 \mathrm{Ca} / 25 \mathrm{P}$ & $3.39 \pm 2.34$ & 0.35 & $25 \mathrm{Ca} / 25 \mathrm{P}$ & $0.40 \pm 0.10$ & $0.01 *$ \\
\hline $25 \mathrm{Ca} / 5 \mathrm{P}$ & $5.70 \pm 0.42$ & $0.001^{*}$ & $25 \mathrm{Ca} / 5 \mathrm{P}$ & $0.64 \pm 0.12$ & 0.09 \\
\hline \multicolumn{3}{|c|}{ Day 4} & \multicolumn{3}{|c|}{ Day 4} \\
\hline PS Control & $1.00 \pm 0.13$ & & PS Control & $1.00 \pm 0.17$ & \\
\hline $\mathrm{Ca} / \mathrm{P}$ Free Particles & $0.51 \pm 0.13$ & 0.49 & Ca/P Free Particles & $0.77 \pm 0.26$ & 0.08 \\
\hline $5 \mathrm{Ca} / 5 \mathrm{P}$ & $2.94 \pm 0.60$ & 0.05 & $5 \mathrm{Ca} / 5 \mathrm{P}$ & $1.27 \pm 0.58$ & 0.68 \\
\hline $25 \mathrm{Ca} / 25 \mathrm{P}$ & $0.68 \pm 0.26$ & 0.35 & $25 \mathrm{Ca} / 25 \mathrm{P}$ & $0.80 \pm 0.32$ & 0.60 \\
\hline $25 \mathrm{Ca} / 5 \mathrm{P}$ & $1.36 \pm 0.32$ & 0.33 & $25 \mathrm{Ca} / 5 \mathrm{P}$ & $1.03 \pm 0.58$ & 0.97 \\
\hline
\end{tabular}


(A)

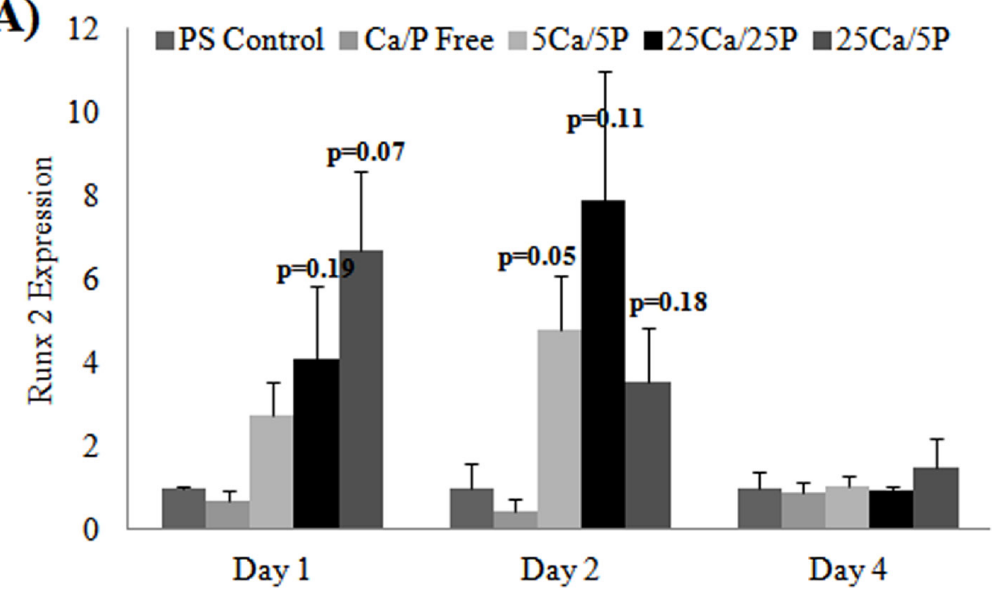

$\stackrel{\circ}{\perp}$

(C)

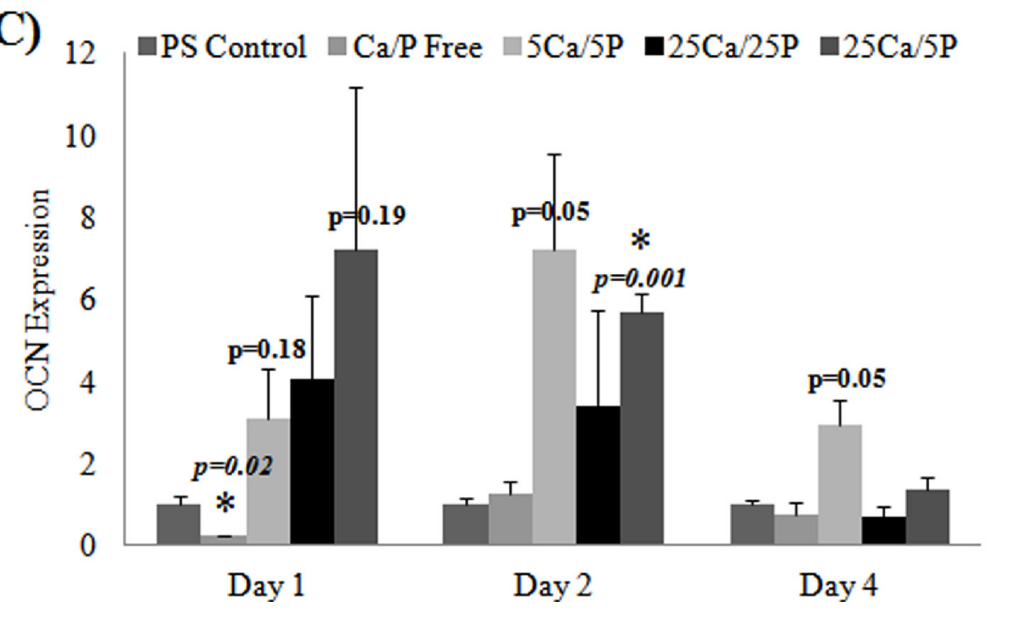

(B)

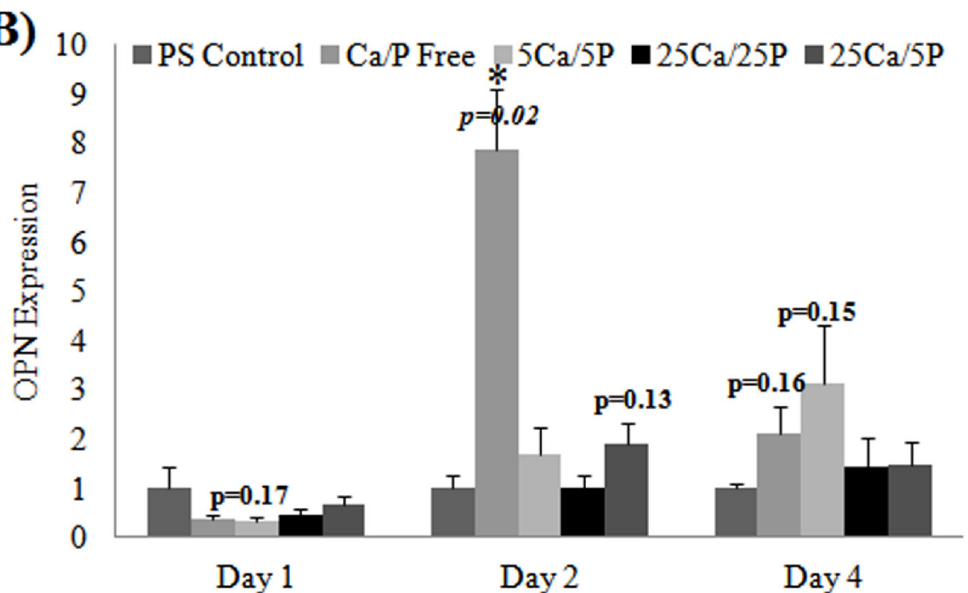

(D)

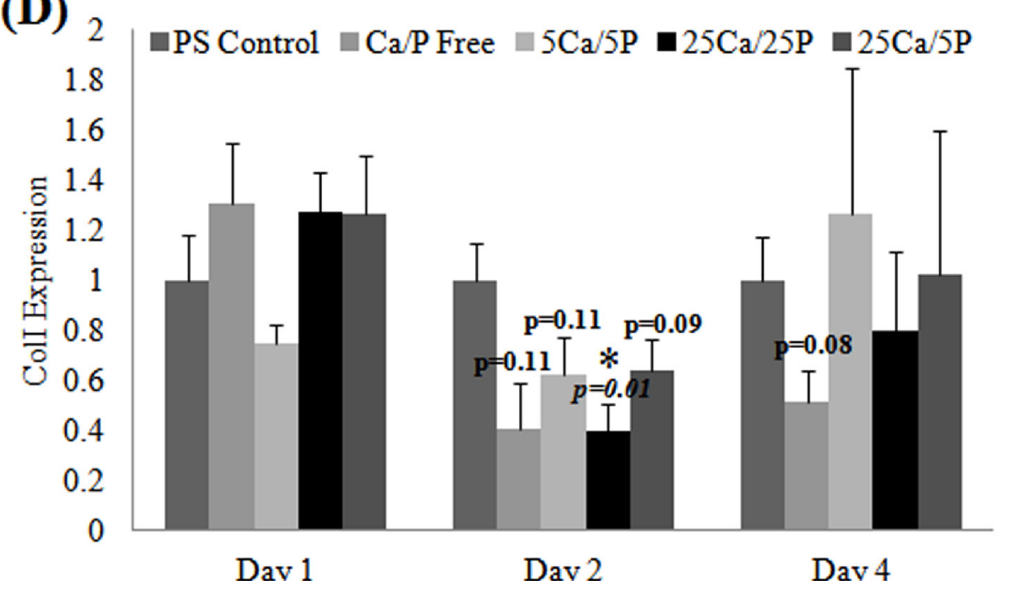

Figure 4.4. Osteoblast gene expression in response to Ca/P sol particles. Quantitative PCR expression of osteoblastic differentiation markers (A) Runx2, (B) osteopontin (OPN), (C) osteocalcin (OCN) and (D) collagen type I (COLI) show relative gene expression levels of MC3T3 preosteoblasts cultured with Ca/P free, $5 \mathrm{Ca} / 5 \mathrm{P}, 25 \mathrm{Ca} / 25 \mathrm{P}$, or $25 \mathrm{Ca} / 5 \mathrm{P}$ particles deposited for 60 seconds normalized to cells cultured on untreated polystyrene (PS control) at days 1,2 , and 4 . All comparisons between treatment groups and control were made t-test, $p$-values $<0.05$ were considered significant $\left({ }^{*}\right.$ indicates statistical significance compared to control) Error bars represent \pm SEM. 


\section{Mineralization Alizarin Red and ALP Staining}

Cells cultured with Ca-P particles and stained for alizarin red after 14 days of culture show increased calcium deposition compared to controls especially in $5 \mathrm{Ca} / 5 \mathrm{P}$ cultures, indicating a higher degree of mineralization in these cultures (Figure 4.5). ALP staining of cultures at day 14 was inconclusive (data not shown).

Day 14

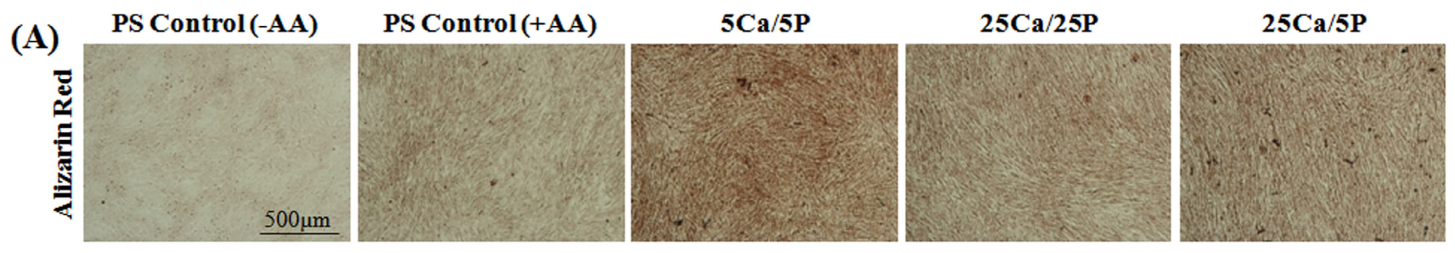

Figure 4.5. Mineralization of osteoblasts in response to $\mathrm{Ca} / \mathrm{P}$ sol particles. MC3T3 preosteoblasts were cultured on non-tissue culture PS dishes that have been vapor coated with $\mathrm{Ca} / \mathrm{P}$ sol particles $(5 \mathrm{Ca} / 5 \mathrm{P}$, $25 \mathrm{Ca} / 25 \mathrm{P}, 25 \mathrm{Ca} / 5 \mathrm{P}$ ) for 60 seconds, with non-coated PS plates serving as controls (with and without media containing $50 \mu \mathrm{g} / \mathrm{ml}$ ascorbic acid; AA). At day 14 cultures, were stained to assess calcium deposition (alizarin red) (scale bar $=500 \mu \mathrm{m})$.

\section{DISCUSSION}

Osteoblast attachment and proliferation in cultures treated with $\mathrm{Ca} / \mathrm{P}$ sol particles showed no significant differences when compared to control cultures, with the exception of $5 \mathrm{Ca} / 5 \mathrm{P}$ cultures at day 2 , where those cells showed significantly less proliferation. When cells begin to differentiate, their proliferation rate slows [25]. This, in conjunction with the increased Runx2, OPN and OCN expression at day 1 and the increased calcium deposition (i.e. alizarin red staining) suggest that particles containing calcium and phosphate may enhance osteoblast differentiation.

The gene expression data suggests that the there is a trend of upregulation in osteoblasts cultured with $\mathrm{Ca} / \mathrm{P}$ sol particles when compared to control cultures. Runx 2 is often considered the master transcription factor for commitment of cells to the osteoblast lineage in both endochondral and intramembranous ossification. Additionally, Runx2 is needed to ensure mature osteoblasts function properly by triggering their synthesis of many extracellular matrix genes, including type I collagen. Runx2 gene expression and protein function is regulated at various levels including transcription, translation, and 
post-translational modification through a variety of pathways [208-210]. The data in this work is promising because without the upregulation of Runx2 expression, cells will not differentiate into osteoblasts. Additionally, the trend for up-regulated collagen expression in cells cultured with $\mathrm{Ca} / \mathrm{P}$ sol particles further implies that these particles hold the potential to direct osteoblast differentiation with further modification of the system.

When designing a silica based material for drug/molecule delivery there are many aspects that need to be taken into account including: the particle size, shape, and structure (pore network size, connectivity and volume). These properties can all be influenced by the synthesis parameters as well as any post-generation treatments such as thermal treatment or surface functionalization. Changing any of these features can dramatically influence the incorporated agents are released. Additionally, how the molecule interacts with the silica network will influence its ability to be incorporated as well as its release kinetics [211-214]. The influence of all of these factors is why developing a successful material system to deliver bioactive factors can be extremely difficult.

The borderline significant differences in gene expression between control cultures and $\mathrm{Ca} / \mathrm{P}$ sol particle cultures, indicates that the formulation of calcium and phosphate will need further optimization--possibly by increasing the deposition time of particles in order to increase the number of particles cells are exposed to and/or using a particle formulation with slower degradation characteristics in order to prolong the exposure particle material chemical (i.e. ion release) and physical (i.e. topography, surface hydrophobicity) properties to the osteoblast cells. Currently, the $\mathrm{Ca} / \mathrm{P}$ sol particles designed in this work degrade within the first 3 days of culture, so any effects they induce are at the early time points. In order to fully induce osteoblast differentiation a threshold that was not reached with these particle formulations and/or sustained ion release may be required.

Particle stability could be increased by aging particles using temperature curing for example. Increasing the drying time and temperature will promote the densification (decrease in pore size) of the silica network, thus controlling the degradation rate, which is especially important in systems designed for drug/molecule release [86, 105, 215, 216]. 
Many sol-gel applications currently being developed involve a step where the material is heated to $400-600^{\circ} \mathrm{C}$, which aids in incorporating calcium into the silica network as well as dramatically improving the stability of the material [217-220]. Though this step can help to improve the properties of the sol-gel material, it prevents the addition of any temperature sensitive polymers and/or biological molecules, thus limiting its use.

Perhaps a better solution to increasing the stability of the $\mathrm{Ca} / \mathrm{P}$ sol particles is to generate an inorganic-organic hybrid material. These materials incorporate a polymer into the silica network at the beginning stages of sol-gel synthesis, so that the silica network forms around the polymer molecules (Figure 4.6). The two materials interact on the nano-level, allowing them to behave as a single phase material. Hybrid materials take advantage of the properties of both the inorganic (e.g. hardness, strength, thermal stability, density, etc.) and the organic (e.g. elasticity, hydrophobic character, chemical reactivity) components to generate materials that have improved mechanical and degradation properties that would not be possible otherwise [221]. For example collagensilica hybrid films (thickness $=100-200 \mu \mathrm{m}$ ) degraded only about $50 \%$ of its mass in 14 days in $\mathrm{PBS}$ at $37^{\circ} \mathrm{C}$ [222] In hybrid synthesis, the polymer is added to the sol-gel during condensation, where the chain-like structure of the silicate can entangle with the polymer chains [107-109]. Though hybrid materials have improved properties, there are several challenges that must be considered: 1) the chosen polymer must soluble in the sol-gel solution and have suitable degradation characteristics; and 2) the conditions in which solgel is produced under can degrade the polymer so the $\mathrm{pH}$ must be carefully controlled to balance degradation and gelling time $[107,109,110]$. Currently polymers that are used in hybrid materials include poly(methyl methacrylate)-PMMA, poly(diemthylsiloxane)PDMS, poly(tetramethylene oxide)-PTMO, poly(2-hydroxyethyl methacrylate)-pHEMA ,and polycaprolactone-PCL, as well as the natural polymers gelatin, collagen, chitosan, alginate, and poly $(\gamma$-glutamic acid)- $\gamma$ PGA [7, 107, 221]. 


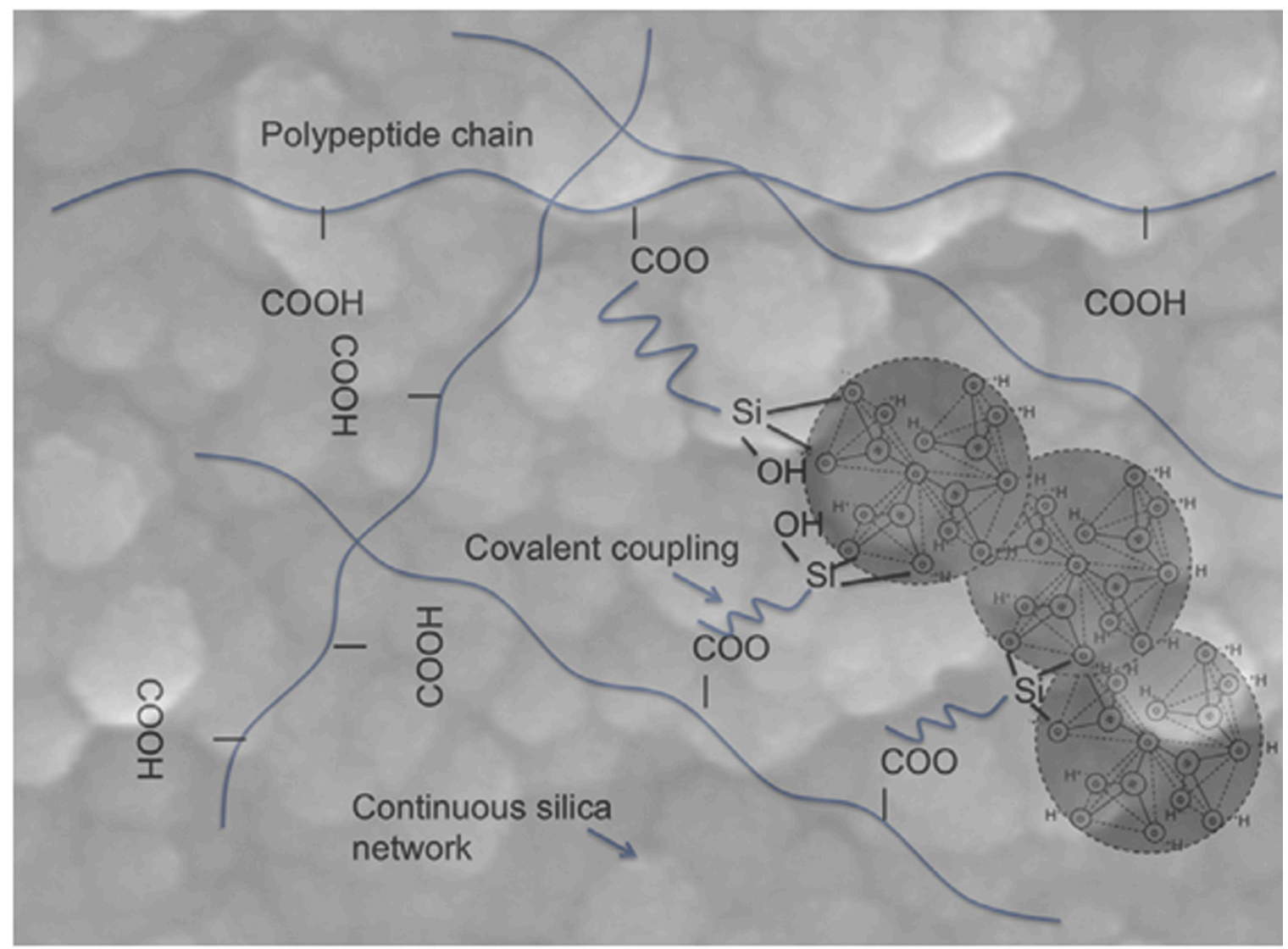

Figure 4.6. Schematic of an inorganic-organic hybrid material. The silica network is linked to the polymer chains by a coupling agent-the carboxylic acid groups on the polymer act as nuclophiles to form a bond. From Jones with permission (See Appendix A)[107].

\section{CONCLUSION}

The vapor deposition method established here allows for simple means of generating silica sol particles where calcium and phosphate ions can be incorporated. These $\mathrm{Ca} / \mathrm{P}$ sol particles have been shown to hold the potential to direct osteoblast behavior. This system can now be optimized to address issues regarding particle stability. To address this, the development of an inorganic-organic hybrid material for the sol particles is an attractive approach. 


\section{ACKNOWLEDGEMENTS}

The authors would like to thank David Jaroch (Purdue), Meghan McGeeLawrence (Mayo), Jennifer Sanders (MTU), and Hallie Holmes (MTU) for their help with portions of this work.

\section{REFERENCES}

1. Buehler, M.J. and T. Ackbarow, Nanomechanical strength mechanisms of hierarchical biological materials and tissues. Computer Methods in Biomechanics and Biomedical Engineering, 2008. 11(6): p. 595-607.

2. Martins, A., et al., Hierarchical starch-based fibrous scaffold for bone tissue engineering applications. Journal of Tissue Engineering and Regenerative Medicine, 2009. 3(1): p. 37-42.

3. Sanchez, C., H. Arribart, and M. Guille, Biomimetism and bioinspiration as tools for the design of innovative materials and systems. Nature Materials, 2005. 4: p. 277-288.

4. Soler-Illia, G.J.d.A.A., et al., Chemical Strategies To Design Textured Materials: from Microporous and Mesoporous Oxides to Nanonetworks and Hierarchical Structures. Chemical Reviews, 2002. 102(11): p. 4093-4138.

5. Fantner, G., et al., Sacrificial bonds and hidden length dissipate energy as mineralized fibrils separate during bone fracture. Nature Materials, 2005. 4: p. 612-616.

6. Tai, K., et al., Nanoscale heterogeneity promotes dissipation in bone. Nature Materials, 2007. 9(454-462).

7. Tamerler, C. and M. Sarikaya, Molecular biomimetics: Utilizing nature's molecular ways in practical engineering. Acta Biomaterialia, 2007. 3(3): p. 289299.

8. Agrawal, C. and R. Ray, Biodegradable polymeric scaffolds for musculoskeletal tissue engineering. Journal of Biomedical Materials Research, 2001. 55: p. 141150.

9. Norman, J. and T. Desai, Methods for fabrication of nanoscale topography for tissue engineering scaffolds. Annals of Biomedical Engineering, 2006. 34: p. 89101. 
10. Variola, F., et al., Tailoring the surface properties of Ti6Al4V by controlled chemical oxidation. Biomaterials 2008. 29: p. 1285-1298.

11. Sarikaya, M., et al., Molecular biomimetics: nanotechnology through biology. Nature Materials, 2003. 2: p. 577-585.

12. Ikkala, O. and G. ten Brinke, Hierarchical self-assembly in polymeric complexes: towards functional materials. Chemical Communications, 2004: p. 2131-2137.

13. Seunarine, K., et al., A hierarchical response of cells to perpendicular micro- and nanometric textural cues. IEEE Transactions on Nanobioscience, 2009.

14. Spatz, J., Nano- and micropatterning by organic-inorganic templating of hierarchical self-assembled structures. Angewandte Chemie International Edition, 2002. 41: p. 3359-3362.

15. Puleo, D.A. and A. Nanci, Understanding and controlling the bone-implant interface. Biomaterials, 1999. 20(23-24): p. 2311-21.

16. Morra, M., Biochemical modification of titanium surfaces: peptides and ECM proteins. European Cells and Materials, 2006. 12: p. 1-15.

17. Nishimoto, S., et al., The effect of titanium surface roughening on protein absorption, cell attachment, and cell spreading. The International Journal of Oral \& Maxillofacial Implants, 2008. 23: p. 675-680.

18. Uggeri, J., et al., Adhesion of human osteoblasts to titanium: A morpho-functional analysis with confocal microscopy. Micron, 2010. 41: p. 210-219.

19. Shi, G., et al., $\mathrm{H} 2 \mathrm{O} 2 / \mathrm{HCl}$ and heat-treated Ti-6Al-4V stimulates pre-osteoblast proliferation and differentiation. Oral Surgery, Oral Medicine, Oral Pathology, Oral Radiology \& Endodontics 2009. 108(368-375).

20. Salido, M., et al., Actin cytoskeletal organization in human osteoblasts grown on different dental titanium implant surfaces. Histology and Histopathology, 2007. 7(241-256).

21. Bowers, K., et al., Optimization of surface micromorphology for enhanced osteoblast responses in vitro. International Journal of Oral \& Maxillofacial Implants, 1992. 7: p. 302-310.

22. Degasne, I., et al., Effects of roughness, fibronectin and vitronectin on attachment, spreading, and proliferation of human osteoblast-like cells (Saos-2) on titanium surfaces. Calcified Tissue International, 1999. 64(499-507).

23. Jayaraman, M., et al., Influence of titanium surfaces on attachment of osteoblastlike cells in vitro. Biomaterials, 2004. 25: p. 625-631. 
24. Bächle, M. and R.J. Kohal, A systematic review of the influence of different titanium surfaces on proliferation, differentiation and protein synthesis of osteoblast-like MG63 cells. Clinical Oral Implants Research, 2004. 15(6): p. 683692.

25. Boyan, B.D., et al., Osteoblast-Mediated Mineral Deposition in Culture is Dependent on Surface Microtopography. Calcified Tissue International, 2002. 71(6): p. 519-529.

26. Takeuchi, K., et al., Enhanced intrinsic biomechanical properties of osteoblastic mineralized tissue on roughened titanium surface. Journal of Biomedical Materials Research Part A, 2005. 72A(3): p. 296-305.

27. Zhao, G., et al., High surface energy enhances cell response to titanium substrate microstructure. Journal of Biomedical Materials Research Part A, 2005. 74A(1): p. $49-58$.

28. Kubo, K., et al., Cellular behavior on TiO2 nanonodular structures in a micro-tonanoscale hierarchy model. Biomaterials, 2009. 30(29): p. 5319-5329.

29. Gittens, R.A., et al., The effects of combined micron-/submicron-scale surface roughness and nanoscale features on cell proliferation and differentiation. Biomaterials, 2011. 32(13): p. 3395-3403.

30. Dalby, M.J., et al., The control of human mesenchymal cell differentiation using nanoscale symmetry and disorder. Nature Materials, 2007. 6(12): p. 997-1003.

31. Kieswetter, K., et al., Surface roughness modulates the local production of growth factors and cytokines by osteoblast-like MG-63 cells. Journal of Biomedical Materials Research, 1996. 32: p. 55-63.

32. Jeon, H. and G. Kim, Effects of a Cell-Imprinted Poly(dimethylsiloxane) Surface on the Cellular Activities of MG63 Osteoblast-like Cells: Preparation of a Patterned Surface, Surface Characterization, and Bone Mineralization. Langmuir, 2012. 28(37): p. 13423-13430.

33. Liu, X., et al., Influence of substratum surface chemistry/energy and topography on the human fetal osteoblastic cell line hFOB 1.19: Phenotypic and genotypic responses observed in vitro. Biomaterials, 2007. 28(31): p. 4535-4550.

34. Balaur, E., et al., Tailoring the wettability of TiO2 nanotube layers. Electrochemical Communications, 2005. 7: p. 1066-1070.

35. Suchea, M., et al., Pure and Nb2O5-doped TiO2 amorphous thin films grown by dc magnetron sputtering at room temperature: Surface and photo-induced hydrophilic conversion studies. Materials Science and Engineering: B, 2007. 144(1-3): p. 54-59. 
36. Vijayanand, K., et al., Interpreting Blood-Biomaterial Interactions from Surface Free Energy and Work of Adhesion. Trends in Biomaterials and Artifical Organs, 2005. 18(2): p. 73-83.

37. Baier, R., et al., Surface properties determine bioadhesive outcomes: methods and results. Journal of Biomedical Materials Research, 1984. 18: p. 327-355.

38. Hurburtt, T., et al., Some background concepts, in Biomaterials science: An introduction to materials in medicine, B. Ratner, et al., Editors. 1996, Academic Press: New York. p. 133-164.

39. Kilpadi, D. and J. Lemons, Surface energy characterization of unalloyed titanium implants. Journal of Biomedical Materials Research, 1994. 28: p. 1419-1425.

40. Schakenraad, J., et al., The influence of substratum surface free energy on growth and spreading of human fibroblasts in the presence and absence of serum proteins. Journal of Biomedical Materials Research, 1986. 20(6): p. 773-784.

41. Schrader, M., On adhesion of biological substances to low energy solid-surfaces. Journal of Colloid and Interface Science, 1982. 88: p. 296-297.

42. Anselme, K., Osteoblast adhesion on biomaterials. Biomaterials, 2000. 21: p. 667-681.

43. García, A. and B. Keselowsky, Biomimetic surfaces for control of cell adhesion to facilitate bone formation. Critical Reviews in Eukaryotic Gene Expression, 2002. 12(2): p. 151-162.

44. Park, J.H., et al., The responses to surface wettability gradients induced by chitosan nanofilms on microtextured titanium mediated by specific integrin receptors. Biomaterials, 2012. 33(30): p. 7386-7393.

45. Rausch-fan, X., et al., Differentiation and cytokine synthesis of human alveolar osteoblasts compared to osteoblast-like cells (MG63) in response to titanium surfaces. Dental Materials, 2008. 24(1): p. 102-110.

46. Zhao, G., et al., Requirement for both micron- and submicron scale structure for synergistic responses of osteoblasts to substrate surface energy and topography. Biomaterials, 2007. 28(18): p. 2821-2829.

47. Eriksson, C., H. Nygren, and K. Ohlson, Implantation of hydrophilic and hydrophobic titanium discs in rat tibia: cellular reactions on the surfaces during the first 3 weeks in bone. Biomaterials, 2004. 25(19): p. 4759-4766.

48. Hoppe, A., N.S. Güldal, and A.R. Boccaccini, A review of the biological response to ionic dissolution products from bioactive glasses and glass-ceramics. Biomaterials, 2011. 32: p. 2757-2774. 
49. Jell, G. and M.M. Stevens, Gene activation by bioactive glasses. Journal of materials science. Materials in medicine, 2006. 17(11): p. 997-1002.

50. Anderson, S.I., et al., Evaluation of the osteoblast response to a silica gel in vitro. Journal of Materials Science: Materials in medicine, 1998. 9: p. 731-735.

51. Feng, J., et al., Stimulating effect of silica-containing nanospheres on proliferation of osteoblast-like cells. Journal of Materials Science: Materials in medicine, 2007. 18(2167-2172).

52. Reffitt, D.M., et al., Orthosilicic acid stimulates collagen type I synthesis and osteoblastic differentiation in human osteoblast-like cells in vitro. Bone, 2003. 32: p. 127-135.

53. Zou, S., et al., The Effects of Silicate Ions on Human Osteoblast Adhesion, Proliferation, and Differentiation. Journal of Biomedical Materials Research Part B: Applied Biomaterials, 2008: p. 123-130.

54. Tsigkou, O., et al., Differentiation of fetal osteoblasts and formation of mineralized bone nodules by 45S5 Bioglass conditioned medium in the absence of osteogenic supplements. Biomaterials, 2009. 30: p. 3542-3550.

55. Chai, Y., et al., Current views on calcium phosphate osteogenicity and the translation into effective bone regeneration strategies. Acta Biomaterialia, 2012. 8(11): p. 3876-3887.

56. Dvorak, M. and D. Riccardi, Ca2+ as an extracellular signal in bone. Cell calcium, 2004. 35(3): p. 249-255.

57. Zayzafoon, M., Calcium/calmodulin signaling controls osteoblast growth and differentiation. Journal of cellular biochemistry, 2006. 97(1): p. 56-70.

58. Zhou, H., et al., The bio-functional role of calcium in mesoporous silica xerogels on the responses of osteoblasts in vitro. Journal of Materials Science. Materials in Medicine, 2010.

59. Aguirre, A., et al., Extracellular calcium modulates in vitro bone marrow-derived Flk1 + CD34+ progenitor cell chemotaxis and differentiation through a calciumsensing receptor. Biochemical and Biophysical Research Communications, 2010. 393: p. 156-161.

60. Dvorak, M.M., et al., Constitutive Activity of the Osteoblast Ca2+-Sensing Receptor Promotes Loss of Cancellous Bone. Endocrinology, 2007. 148(7): p. 3156-3163.

61. Dvorak, M.M., et al., Physiological changes in extracellular calcium concentration directly control osteoblast function in the absence of calciotropic 
hormones. Proceedings of the National Academy of Sciences of the United States of America, 2004. 101(14): p. 5140-5145.

62. Beck, G.R., Inorganic phosphate as a signaling molecule in osteoblast differentiation. Journal of cellular biochemistry, 2003. 90(2): p. 234-243.

63. Beck, G.R., E. Moran, and N. Knecht, Inorganic phosphate regulates multiple genes during osteoblast differentiation, including Nrf2. Experimental cell research, 2003. 288: p. 288-300.

64. Maeno, S., et al., The effect of calcium ion concentration on osteoblast viability, proliferation and differentiation in monolayer and $3 D$ culture. Biomaterials, 2005. 26(23): p. 4847-4855.

65. Jung, G.-Y.P., Yoon-Jeong and J.-S. Han, Effects of HA released calcium ion on osteoblast differentiation. Journal of materials Science. Materials in Medicine, 2010. 21: p. 1649-1654.

66. Hench, L.L., Genetic design of bioactive glass. Journal of the European Ceramic Society, 2009. 29: p. 1257-1265.

67. Meleti, Z., I.M. Shapiro, and C.S. Adams, Inorganic Phosphate Induces Apoptosis of Osteoblast-like Cells in Culture. Bone, 2000. 27(3): p. 359-366.

68. Bourgine, A., et al., Inorganic phosphate stimulates apoptosis in murine M06-G3 odontoblast-like cells. Archives of Oral Biology, 2011. 56: p. 977-983.

69. Scholzen, T. and J. Gerdes, The Ki-67 protein: From the known and the unknown. Journal of Cellular Physiology, 2000. 182(3): p. 311-322.

70. Pfaffl, M., A new mathematical model for relative quantification in real-time RTPCR. Nucleic Acids Research, 2001. 29(9): p. e45.

71. Aubin, J.E., Advances in the osteoblast lineage. Biochemistry and Cell Biology, 1998. 76(6): p. 899-910.

72. Komori, T., Regulation of bone development and extracellular matrix protein genes by RUNX2. Cell and Tissue Research, 2010. 339(1): p. 189-195.

73. Long, F., Building strong bones: molecular regulation of the osteoblast lineage. Nature Reviews Molecular Cell Biology, 2012. 13: p. 27-38.

74. Jonason, J.H., et al., Post-translational Regulation of Runx2 in Bone and Cartilage. Journal of Dental Research, 2009. 88(8): p. 693-703.

75. Wu, S.-H., Y. Hung, and C.-Y. Mou, Mesoporous silica nanoparticles as nanocarriers. Chemical Communications, 2011. 47(36): p. 9972-9985. 
76. Jin, W. and J. Brennan, Properties and applications of proteins encapsulated within sol-gel derived materials. Analytica Chimica Acta, 2002. 461: p. 1-36.

77. Tang, F., L. Li, and D. Chen, Mesoporous Silica Nanoparticles: Synthesis, Biocampatibility and Drug Delivery. Advanced Materials, 2012. 24: p. 15041534.

78. Vallet-Regi, M., F. Balas, and D. Arcos, Mesoporous Materials for Drug Dlivery. Angewandte Chemie International Edition, 2007. 46(7548-7558).

79. Barbe, C., et al., Silica Particles: A Novel Drug-Delivery System. Advanced Materials, 2004. 16(20).

80. Brinker, C.J. and G.W. Scherer, Sol-Gel Science: The Physics and Chemistry of Sol-Gel Processing. 1990, San Diego, CA: Academic Press Inc.

81. Hench, L.L. and J.K. West, The Sol-Gel Process. Chemical Reviews, 1990. 90(1): p. 33-72.

82. Bass, J., et al., Stability of mesoporous oxide and mixed metal oxide materials under biologically relevant conditions. Chemistry of Materials, 2007. 19: p. 43494356.

83. Saravanapavan, P., et al., Bioactivity of gel-glass powders in the CaO-SiO2 system: a comparison with ternary (CaO-P2O5-SiO2) and quaternary glasses (SiO2-CaO-P2O5-Na2O). Journal of Biomedical Materials Research Part A, 2003. 66A: p. 110-119.

84. Lin, S., et al., Nanostructure evolution and calcium distribution in sol-gel derived bioactive glass. Journal of Materials Chemistry, 2009. 19: p. 1276-1282.

85. Skipper, L., et al., The structure of a bioactive calcia-silica sol-gel glass. Journal of Materials Chemistry, 2005. 15: p. 2369-2374.

86. Martin, R., et al., Characterizing the hierarchical structures of bioactive sol-gel silicate glass and hybrid scaffolds for bone regeneration. Philosophical Transactions. Series A, Mathematical, Physical, and Engineering Sciences, 2012. 370: p. 1422-1443.

87. Arcos, D. and M. Vallet-Regi, Sol-gel silica-based biomaterials and bone tissue regeneration. Acta Biomaterialia, 2010. 6: p. 2874-2888.

88. Lee, E.-J., et al., Collagen-silica xerogel nanohybrid membrane for guided bone regeneration. Journal of Biomedical Materials Research Part A, 2012. 100A(4): p. 841-847. 
89. Jones, J., Review of bioactive glasses: From Hench to hybrids. Acta Biomaterialia, 2013. 9(1): p. 4457-4486.

90. Valliant, E. and J. Jones, Softening bioactive glass for bone regeneration: sol-gel hybrid materials. Soft Matter, 2011. 7: p. 5083-5095.

91. Novak, B., Hybrid nanocomposite materials - between inorganic glasses and organic polymers. Advanced Materials, 1993. 5: p. 422-433.

92. Jones, J., New trends in bioactive scaffolds: the importance of nanostructure. Journal of the European Ceramic Society, 2009. 29: p. 1275-1281.

93. Avnir, D., et al., Recent bio-applications of sol-gel materials. Journal of Materials Chemistry, 2006. 16(11): p. 1013-1030. 


\section{CHAPTER FIVE: CONCLUSIONS}

\section{SUMMARY AND KEY FINDINGS}

Six million bone fractures occur annually in the U.S., 5-10\% of which result in non-unions or delayed unions indicating there is a growing need for the development of material substitutes and therapies to address this problem [1]. Tissue engineering and regenerative medicine have emerged in an effort to generate replacement tissues capable of restoring native tissue structure and function [2]. Because of the complexity of biologic systems, it has proved to be much harder to design substitute matrices for cells than originally anticipated. Cells are affected by the chemical and molecular composition of the implanted material, as well as by its physical properties. Development of materials that utilize the relationships between cells and material chemical, physical, and mechanical properties may provide a better platform for tissue regeneration [3]. Silica based bioactive glasses are most prominently associated with orthopedic applications in both traditional implants as well as hard and soft tissue engineering materials [102]. These materials have been known to enhance osteogenesis and angiogenesis as well as promote antibacterial activity [4, 223]. Sol-gels are attractive as a bioglass generation method because of their mild processing conditions, the ability to control structure and composition through their synthesis parameters, the ability to incorporate a variety of biological molecules, and their inherent biocompatibility [6, 7, 87, 88, 105]. Further, they possess the capacity to exert an inherent active influence on cell behavior; modulated in part by surface chemistry, topography, and active agents incorporated in the sol-based material. However, the exact balance of these parameters that is most appropriate for directing cell function and gene expression is not fully understood and warrants further exploration $[104,205,224]$. The goal of this work was to develop and characterize a bioactive silica sol-gel surface modification system that can be used to tailor their material properties at the nano- and micro- level to better mimic the instructive conditions of native bone tissue, promoting appropriate osteoblast attachment, proliferation, and differentiation as a means for supporting bone tissue regeneration. The findings of this work are summarized below: 


\section{Chapter 2}

Vapor deposited silica sol-gel particle size distribution, morphology and degradation are dependent upon various formulation and manufacturing parameters including: $\mathrm{H}_{2} \mathrm{O}$ :TMOS, solution $\mathrm{pH}$, underlying substrate character, and deposition time.

- The $\mathrm{H}_{2} \mathrm{O}$ :TMOS affects particle size distribution through changes in the amount of $\mathrm{H}_{2} \mathrm{O}$ available for hydrolysis, which effects gelation time. At a ratio below approximately 8:1, increasing $\mathrm{H}_{2} \mathrm{O}$ content, decreases the gelation time, while at ratios above 8:1 the increased $\mathrm{H}_{2} \mathrm{O}$ acts as a diluent, causing a decreasing in gelation time $[86,105]$.

- Solution $\mathrm{pH}$ will significantly affect particle properties. Solutions near the silica isolectric point $(\mathrm{pH}=2-3)$ will have the longest gelation times and as $\mathrm{pH}$ increases gelation time decreases. Solutions with $\mathrm{pH} 5-6$ have the greatest instability and quickest gelation time. Below the isolectric point the solubility of silica decreases and leads to metastable solutions, and a silica network has trouble forming [86, 105].

- Substrate surface character plays a role in particle size distribution due to the interaction of substrate chemistry, hydrophobicity and roughness on the sol-gel as it is deposited.

- Deposition time has a larger effect on particle properties when the sol formulation has a longer gelation time.

- Deposition of sol particles changes the overall surface properties of a material, decreasing surface hydrophobicity and increasing surface roughness with increasing deposition time, as well as generating a unique surface topography.

- Osteoblast attachment increases on substrates coated with silica sol particles during the first 48 hours of culture due to both changes in the surface properties as well as silica ions release into the surrounding culture media.

\section{Chapter 3}

Calcium and phosphate ions can be incorporated into the vapor deposited sol-gel particles, and their size distribution and morphology is dependent upon the concentration of ions added, with higher concentrations of calcium and phosphate yielding larger, less rounded particles.

- The degradation rate of $\mathrm{Ca} / \mathrm{P}$ sol particles is largely independent of added ion concentration, with an average, effective mass loss of $90 \%$ within 7 days. 
- $\mathrm{Ca} / \mathrm{P}$ sol particles decrease overall substrate surface hydrophobicity, with increasing calcium and phosphate ion concentration.

- Exposure to simulated body fluids generated apatite like mineral formation within 7 days for all particle formulations.

- $\mathrm{Ca} / \mathrm{P}$ sol particles can be vapor deposited onto three-dimensional porous scaffolds and induce uniform surface apatite-like mineral nucleation and growth, demonstrating potential use as a surface modification technique for bone tissue engineering.

\section{Chapter 4}

Osteoblasts cultured on $\mathrm{Ca} / \mathrm{P}$ sol particles showed no significant differences in cell attachment within 48 hours compared to controls. Cell proliferation in these cultures was also similar to controls with the exception of cells cultured with $5 \mathrm{Ca} / 5 \mathrm{P}$ particles, which showed decreased cell proliferation. This is promising, because differentiating osteoblasts have decreased proliferation rates [225].

Gene expression in osteoblasts cultured with $\mathrm{Ca} / \mathrm{P}$ sol particles shows a trend of up-regulated Runx2 expression. Runx2 is the master transcription factor in the commitment of cells to the osteoblast lineage [208, 210, 226]. Up-regulation of this gene shows the potential for $\mathrm{Ca} / \mathrm{P}$ sol particles to aid in osteoblast differentiation.

\section{LIMITATIONS}

This work is limited by several factors including that many of the conclusions drawn regarding particle promotion of osteoblast differentiation are drawn from RTqPCR data. While this provides evidence of gene transcription, it does not necessarily show that the gene was translated into protein expression. Alizarin red and ALP staining attempted to demonstrate the calcium deposition (i.e., mineralization) and expression on ALP in longer-term cultures, but the ALP stain was inconclusive. A more reliable and quantitative method to assess protein expression would be western blotting. Additionally,

gene expression was only assessed at early time points. This may not have captured the whole picture of how $\mathrm{Ca} / \mathrm{P}$ sol particles influence cell behavior at later time points.

Perhaps the biggest limitation of this work is the stability of the generated particles. Both unloaded silica and $\mathrm{Ca} / \mathrm{P}$ sol particles degraded quickly when in culture 
(within 7 days), with the majority of degradation occurring within the first 3 days. This limited the time that the particles were able to influence cell behavior, specifically full differentiation of preosteoblasts and bone matrix production. If the degradation rate of the particles could be slowed, their effects-induced both through changes in substrate physical properties as well as chemically through the release of calcium and phosphate ions could be sustained and have a greater impact.

\section{FUTURE DIRECTION}

\section{Hybrid Materials}

Incorporation of an organic material into the sol-gel formulation could greatly improve the degradation properties of the particles. Polymers added to the solution early in the sol-gel process allow the organic and inorganic portions to mix and interact very closely with one another so that they behave as a single phase material [107, 108, 220].

The polymer chosen must be soluble in the sol-gel solution and the solution $\mathrm{pH}$ must be carefully controlled to prevent polymer degradation as well as control the gelation time [107]. Additionally, a hybrid material may alter the release characteristics of the $\mathrm{Ca} / \mathrm{P}$ sol particles, allowing for the incorporation of different concentrations of calcium and phosphate and sustaining their release during culture.

\section{Applications}

The particles developed in this work could be used in a variety of applications. They can be used to coat a variety of biomaterials, from three-dimensional scaffolds (see Figures 3.1 and 3.6) to electrospun fiber mats (Figure 5.1), generating unique composite composition and architecture. Many other biomolecules could be incorporated into these sol particles in addition to calcium and phosphate ions in order to further enhance osteoblast differentiation including but not limited to bone morphogenic protein (BMP), transforming growth factor-beta (TGF- $\beta$ ), fibroblast growth factor (FGF), vascular endothelial growth factor $(V E G F)$, insulin-like growth factor (IGF), and parathyroid hormone (PTH) [227-229]. A potential clinical application for these particles is with bone allografts. Allografts are limited in their osteogenic and remodeling potential, with 
approximately $25-35 \%$ failing within 3 years due to fracture and nonunion. At 10 years, the failure rate has been reported to be as high as 60\% [230]. Coating these materials with vapor deposited sol particles containing osteogenic factors may aid in integration of the graft with native bone tissue and potentially reduce local immunogenicity.

In addition to orthopedic applications, the particles developed in this the work have the potential to be used in a variety of other applications. Bioactive glasses have recently been used in both soft tissue repair and angiogenesis [4, 223, 231]. Fibroblasts and endothelial cells treated with bioactive glass particles have been found have enhanced proliferation as well as produce high concentrations of VEGF, which stimulates angiogenesis [232-234]. Vapor deposition of sol particles onto biomaterials designed for soft tissue or cardiovascular applications may enhance effectiveness of these materials. Further, these particles may be used to enhance the antimicrobial character of biomaterials, by damaging bacterial cell structures, preventing biofilm formation through increases in local $\mathrm{pH}$. Incorporation of known antibacterial agents such as silver $\left(\mathrm{Ag}^{+}\right)$ ions and NO donor groups into the particles may further enhance these properties $[4,6]$.

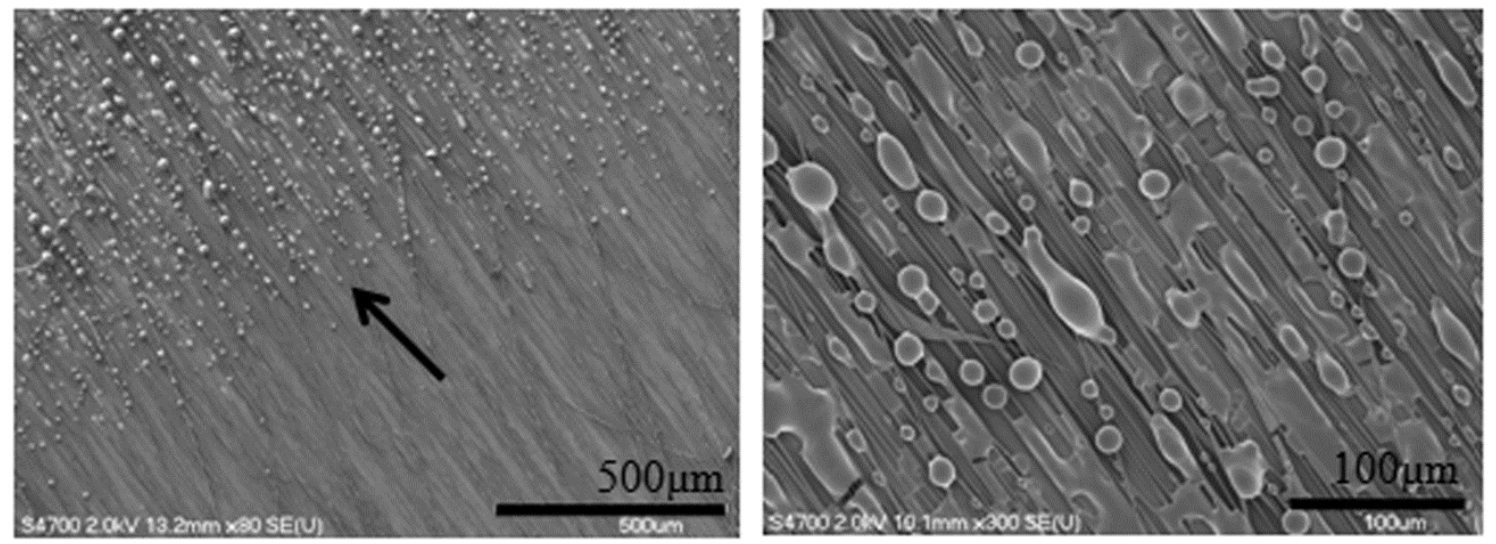

Figure 5.1. Vapor deposition onto electrospun fibers. Particles were vapor deposited onto electrospun PLLA fibers (arrow indicates vapor line created by masking) to demonstrate a potential application of particles on a relevant biomaterial surface.

\section{REFERENCES}

1. Brinker, M. and D. O'Connor, Nonunions: Evaluation and Treatment, in Skeletal Trauma, B. Browner, et al., Editors. 2009. 
2. Langer, R. and J.P. Vacanti, Tissue engineering. Science, 1993. 260(5110): p. 920-6.

3. Lutolf, M.P. and J.A. Hubbell, Synthetic biomaterials as instructive extracellular microenvironments for morphogenesis in tissue engineering. Nature biotechnology, 2005. 23(1): p. 47-55.

4. Hench, L.L., Bioactive materials: the potential for tissue regeneration. Journal of biomedical materials research, 1998. 41(4): p. 511-8.

5. Hoppe, A., N.S. Güldal, and A.R. Boccaccini, A review of the biological response to ionic dissolution products from bioactive glasses and glass-ceramics. Biomaterials, 2011. 32: p. 2757-2774.

6. Rahman, M.N., et al., Bioactive glass in tissue engineering. Acta Biomaterialia, 2011. 7: p. 2355-2373.

7. Avnir, D., et al., Recent bio-applications of sol-gel materials. Journal of Materials Chemistry, 2006. 16(11): p. 1013-1030.

8. Brinker, C.J. and G.W. Scherer, Sol-Gel Science: The Physics and Chemistry of Sol-Gel Processing. 1990, San Diego, CA: Academic Press Inc.

9. Coradin, T., M. Boissire, and J. Livage, Sol-gel chemistry in medicinal science. Current Medicinal Chemistry, 2006. 13(1): p. 99-108.

10. Gupta, R. and A. Kumar, Bioactive materials for biomedical applications using sol-gel technology. Biomedical materials, 2008. 3: p. 034005.

11. Jones, J.R. and L.L. Hench, Biomedical materials for new millennium: perspective on the future. Materials Science and Technology, 2001. 17: p. 891900.

12. Hench, L., I. Xynos, and J. Polak, Bioactive glasses for in situ tissue regeneration. Journal of biomaterials science. Polymer edition, 2004. 15(4): p. 543-562.

13. Hench, L.L., Genetic design of bioactive glass. Journal of the European Ceramic Society, 2009. 29: p. 1257-1265.

14. Jell, G. and M.M. Stevens, Gene activation by bioactive glasses. Journal of materials science. Materials in medicine, 2006. 17(11): p. 997-1002.

15. Hench, L.L. and J.K. West, The Sol-Gel Process. Chemical Reviews, 1990. 90(1): p. 33-72. 
16. Aubin, J.E., J.B. Lian, and G.S. Stein, Chapter 4. Bone Formation: Maturation and Functional Activities of Osteoclast Lineage Cells, in Primer on the Metabolic Bone Diseases and Disorders of Mineral Metabolism, M.J. Favus, Editor. 2006, American Society for Bone and Mineral Research. p. 20-29.

17. Jonason, J.H., et al., Post-translational Regulation of Runx2 in Bone and Cartilage. Journal of Dental Research, 2009. 88(8): p. 693-703.

18. Komori, T., Requisite roles of Runx2 and Cbfb in skeletal development. Journal of bone and mineral metabolism, 2003. 21(4): p. 193-197.

19. Komori, T., Regulation of bone development and extracellular matrix protein genes by RUNX2. Cell and Tissue Research, 2010. 339(1): p. 189-195.

20. Jones, J., Review of bioactive glasses: From Hench to hybrids. Acta Biomaterialia, 2013. 9(1): p. 4457-4486.

21. Martin, R., et al., Characterizing the hierarchical structures of bioactive sol-gel silicate glass and hybrid scaffolds for bone regeneration. Philosophical Transactions. Series A, Mathematical, Physical, and Engineering Sciences, 2012. 370: p. 1422-1443.

22. Novak, B., Hybrid nanocomposite materials - between inorganic glasses and organic polymers. Advanced Materials, 1993. 5: p. 422-433.

23. Yun, Y.-R., et al., Administration of growth factors for bone regeneration. Regenerative Medicine, 2012. 7(3): p. 369-385.

24. Lombartdi, G., et al., The roles of parathyroid hormone in bone remodeling. Prospects for novel therapeutics. Journal of Endocrinological Investigation, 2011. 34(7 Suppl): p. 18-22.

25. Chen, G., C. Deng, and Y. Li, TGF- $\beta$ and BMP Signaling in Osteoblast Differentiation and Bone Formation. International Journal of Biological Sciences, 2012. 8(2): p. 272-288.

26. Yazici, C., et al., The effect of surface demineralizaton of cortical bone allograft on the properties of recombinant adeno-associated virus coatings. Biomaterials, 2008. 29: p. 3882-3887.

27. Gorustovich, A., et al., Effect of Bioactive Glasses on Angiogenesis: A Review of In Vitro and In Vivo Evidences. Tissue Engineering: Part B, 2010. 16: p. 199-207.

28. Day, R., et al., Assessment of poly(glycolic acid) mesh and bioctive glass for soft tissue engineering scaffolds. Biomaterials, 2004. 25: p. 5857-5866. 
29. Keshaw, H., A. Forbes, and R. Day, Release of angiogenic growth factors from cells encapsulated in alginate beads within bioactive glass. Biomaterials, 2005. 26: p. 4171-4179.

30. Leu, A. and J. Leach, Proangiogenic potential of a collegen bioactive glass substrate. Pharmaceutical Research, 2008. 25: p. 1122-1129. 


\title{
APPENDIX A: COPYRIGHT AGREEMENTS
}

\author{
$11 / 24 / 12$ \\ Rightslink Printable License \\ FIGURE 1.1B AND 1.1 C ELSEVIER LICENSE \\ TERMS AND CONDITIONS
}

Nov 24, 2012

This is a License Agreement between Katherine L Snyder ("You") and Elsevier ("Elsevier") provided by Copyright Clearance Center ("CCC"). The license consists of your order details, the terms and conditions provided by Elsevier, and the payment terms and conditions.

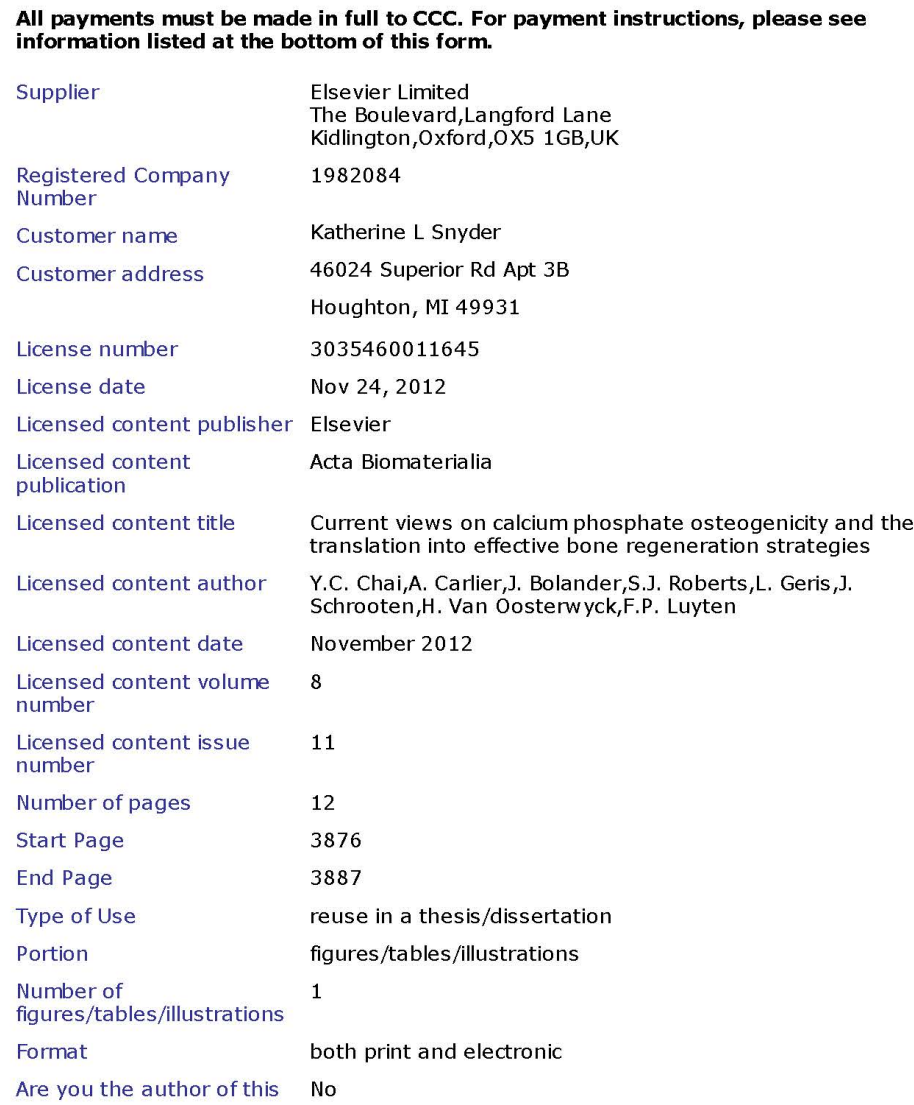




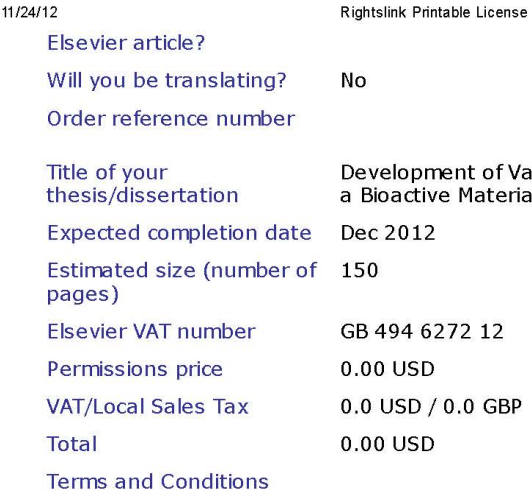

\section{INTRODUCTION}

1. The publisher for this copyrighted material is Elsevier. By clicking "accept" in connection with completing this licensing transaction, you agree that the following terms and conditions apply to this transaction (along with the Billing and Payment terms and conditions established by Copyright Clearance Center, Inc. ("CCC"), at the time that you opened your Rightslink account and that are available at any time at http//myaccount.copyright.com).

\section{GENERAL TERMS}

2. Elsevier hereby grants you permission to reproduce the aforementioned material subject to the terms and conditions indicated.

3. Acknowledgement: If any part of the material to be used (for example, figures) has appeared in our publication with credit or acknowledgement to another source, permission must also be sought from that source. If such permission is not obtained then that material may not be inchided in your publication/copies. Suitable acknowledgement to the source must be made, either as a footnote or in a reference list at the end of your publication, as follows:

"Reprinted from Publication title, Vol/edition number, Author(s), Title of article / title of chapter, Pages No., Copyright (Year), with permission from Elsevier [OR APPLICABLE SOCIETY COPYRIGHT OWNER]." Also Lancet special credit - "Reprinted from The Lancet, Vol. number, Author(s), Title of article, Pages No., Copyright (Year), with permission from Elsevier."

4. Reproduction of this material is confined to the purpose and/or media for which permission is hereby given.

5. Altering/Modifying Material: Not Permitted. However figures and illustrations may be altered/adapted minimally to serve your work. Any other abbreviations, additions, deletions and/or any other alterations shall be made only with prior written authorization of Elsevier Ltd. (Please contact Elsevier at permissions@elsevier.com) 
11/24/12 Rightslink Printable License

6. If the permission fee for the requested use of our material is waived in this instance, please be advised that your future requests for Elsevier materials may attract a fee.

7. Reservation of Rights: Publisher reserves all rights not specifically granted in the combination of (i) the license details provided by you and accepted in the course of this licensing transaction, (ii) these terms and conditions and (iii) CCC's Billing and Payment terms and conditions.

8. License Contingent Upon Payment: While you may exercise the rights licensed immediately upon issuance of the license at the end of the licensing process for the transaction, provided that you have disclosed complete and accurate details of your proposed use, no license is fmally effective unless and until full payment is received from you (either by publisher or by $\mathrm{CCC}$ ) as provided in $\mathrm{CCC}^{\prime} \mathrm{s}$ Billing and Payment terms and conditions. If full payment is not received on a timely basis, then any license preliminarily granted shall be deemed automatically revoked and shall be void as if never granted. Further, in the event that you breach any of these terms and conditions or any of CCC's Billing and Payment terms and conditions, the license is automatically revoked and shall be void as if never granted. Use of materials as described in a revoked license, as well as any use of the materials beyond the scope of an unrevoked license, may constitute copyright infringement and publisher reserves the right to take any and all action to protect its copyright in the materials.

9. Warranties: Publisher makes no representations or warranties with respect to the licensed material.

10. Indemnity: You hereby indemnify and agree to hold harmless publisher and $\mathrm{CCC}$, and their respective officers, directors, employees and agents, from and against any and all claims arising out of your use of the licensed material other than as specifically authorized pursuant to this license.

11. No Transfer of License: This license is personal to you and may not be sublicensed, assigned, or transferred by you to any other person without publisher's written permission.

12. No Amendment Except in Writing: This license may not be amended except in a writing signed by both parties (or, in the case of publisher, by CCC on publisher's behalf).

13. Objection to Contrary Terms: Publisher hereby objects to any terms contained in any purchase order, acknowledgment, check endorsement or other writing prepared by you, which terms are inconsistent with these terms and conditions or CCC's Billing and Payment terms and conditions. These terms and conditions, together with CCC's Billing and Payment terms and conditions (which are incorporated herein), comprise the entire agreement between you and publisher (and CCC) concerning this licensing transaction. In the event of any conflict between your obligations established by these terms and conditions and those established by CCC's Billing and Payment terms and conditions, these terms and conditions shall control.

14. Revocation: Elsevier or Copyright Clearance Center may deny the permissions described in this License at their sole discretion, for any reason or no reason, with a full refund payable to you. Notice of such denial will be made using the contact information provided by you. Failure to receive such notice will not alter or invalidate the denial. In no event will Elsevier or Copyright Clearance Center be responsible or liable for any costs, expenses or damage incurred by you as a result of a denial of your permission request, other than a refund of the amount(s) paid by you to 
Elsevier and/or Copyright Clearance Center for denied permissions.

\section{LIMITED LICENSE}

The following terms and conditions apply only to specific license types:

15. Translation: This permission is granted for non-exclusive world English rights only unless your license was granted for translation rights. If you licensed translation rights you may only translate this content into the languages you requested. A professional translator must perform all translations and reproduce the content word for word preserving the integrity of the article. If this license is to re-use 1 or 2 figures then permission is granted for non-exclusive world rights in all languages.

16. Website: The following terms and conditions apply to electronic reserve and author websites: Electronic reserve: If licensed material is to be posted to website, the web site is to be password-protected and made available only to bona fide students registered on a relevant course if:

This license was made in connection with a course,

This permission is granted for 1 year only. You may obtain a license for future website posting, All content posted to the web site must maintain the copyright information line on the bottom of each image,

A hyper-text must be included to the Homepage of the journal from which you are licensing at http:/www.sciencedirect.com/science/journal/xxxxx or the Elsevier homepage for books at http://www.elsevier.com, and

Central Storage: This license does not include permission for a scanned version of the material to be stored in a central repository such as that provided by Heron/XanEdu.

17. Author website for journals with the following additional clauses:

All content posted to the web site must maintain the copyright information line on the bottom of each image, and the permission granted is limited to the personal version of your paper. You are not allowed to download and post the published electronic version of your article (whether PDF or HTML, proof or final version), nor may you scan the printed edition to create an electronic version. A hyper-text must be included to the Homepage of the journal from which you are licensing at

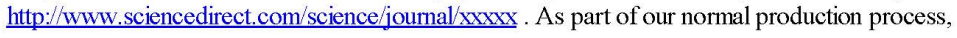
you will receive an e-mail notice when your article appears on Elsevier's online service ScienceDirect (www.sciencedirect.com). That e-mail will include the article's Digital Object Identifier (DOI). This number provides the electronic link to the published article and should be included in the posting of your personal version. We ask that you wait until you receive this e-mail and have the DOI to do any posting.

Central Storage: This license does not include permission for a scanned version of the material to be stored in a central repository such as that provided by Heron/XanEdu.

18. Author website for books with the following additional clauses:

Authors are permitted to place a brief summary of their work online only.

A hyper-text must be included to the Elsevier homepage at http:/www.elsevier.com . All content 
posted to the web site must maintain the copyright information line on the bottom of each image. You are not allowed to download and post the published electronic version of your chapter, nor may you scan the printed edition to create an electronic version.

Central Storage: This license does not include permission for a scanned version of the material to be stored in a central repository such as that provided by Heron/XanEdu.

19. Website (regular and for author): A hyper-text must be included to the Homepage of the journal from which you are licensing at http://www.sciencedirect.com/science/journal $/ \mathrm{xxxxx}$. or for books to the Elsevier homepage at http//www.elsevier.com

20. Thesis/Dissertation: If your license is for use in a thesis/dissertation your thesis may be submitted to your institution in either print or electronic form. Should your thesis be published commercially, please reapply for permission. These requirements include permission for the Library and Archives of Canada to supply single copies, on demand, of the complete thesis and include permission for UMI to supply single copies, on demand, of the complete thesis. Should your thesis be published commercially, please reapply for permission.

\section{Other Conditions :}

v1.6

If you would like to pay for this license now, please remit this license along with your payment made payable to "COPYRIGHT CLEARANCE CENTER" otherwise you will be invoiced within 48 hours of the license date. Payment should be in the form of a check or Once you receive your invoice for this order, you may pay your invoice by credit card. Please follow instructions provided at that time.

Make Payment To:

Copyright Clearance Center

Dept 001

P.O. Box 84300

Boston, MA 02284-3006

For suggestions or comments regarding this order, contact RightsLink Customer Support: customercare@copyright.com or +1-877-622-5543 (toll free in the US) or +1-978-6462777.

Gratis licenses (referencing $\$ 0$ in the Total field) are free. Please retain this printable license for your reference. No payment is required. 
FIGURE 1.4B

을

To: permissions@iop.org,

Bcc:

Subject: Figure Reuse Permsission

From: Katherine Snyder <klsnyder@mtu.edu> - Friday 3d/11/2012 16:58

To whom it may concern

I am preparing a work entitled

DEVELOPMENT OF VAPOR DEPOSITED SILICA SOL GEL PARTICLES FOR A BIOACTIVE MATERIALS SYSTEM TO DIRECT OSTEOBLAST BEHAVIOR

to be published as a dissertation at Michigan Technological University.

I would appreciate permission to reproduce the following item(s) in both print and electronic editions of my

dissertation and in all subsequent future editions, any derivative products and in publisher authorized

distribution by third party distributors, aggregators and other licensees such as abstracting and indexing

services. I should be grateful for nonexclusive perpetual world rights in all languages and media. Unless you

indicate otherwise, I will use the complete reference given below as the credit line.

In case you do not control these rights, I would appreciate it if you could let me know to whom I should apply for permissions.

1. Figure 1 in Proliferation and skeletal myotube formation capability of $\mathrm{C} 2 \mathrm{C} 12$ and $\mathrm{H} 9 \mathrm{c} 2 \mathrm{cells}$ on isotropic and anisotropic electrospun nanofibrous PHB scaffolds. Leonardo Ricotti, Alessandro Polini, Giada G Genchi, Gianni Ciofani, Donata landolo, Helena Vazao, Virgilio Mattoli, Lino Ferreira Arianna Menciassi and Dario Pisignano. Biomedical Materials. 7 (2012)035010. IOP PUBLISHING.

For material being published electronically a link to the version of record will be provided back to the origina article via DOI.

For your information, Institute of Physics Publishing is a not-for-profit subsidiary of the UK Institute of Physics and is a signatory to the STM guidelines on use and republication of figures/tables in science publishing. For your convenience a copy of this letter may serve as a release form: the duplicate copy may be retained for your files.

Thank you for your prompt attention to this request. Permission is being requested of the authors and the

publisher separately.

Yours sincerely

Whe grant permission for the use of the work as set out above.

Signed:

On behalf of Publisher:

PERMISSION TO REPRODUCE AS REQUESTED IS GIVEN PROVIDED THAT:

(a) the consent of the author(s) is obtained

(b) the source of the material including author, title of article, title of journal, volume number, issue number (if relevant), page range (or first page if this is the only information available), date and publisher is acknowledged.

(c) for material being published electronically, a link back to the original article should be provided (via DOI).

IOP Publishing Ltd

Temple Circus

Temple Way

BRISTOL

$.03 .1 .21 .20 x$

BS1 6BE

Date

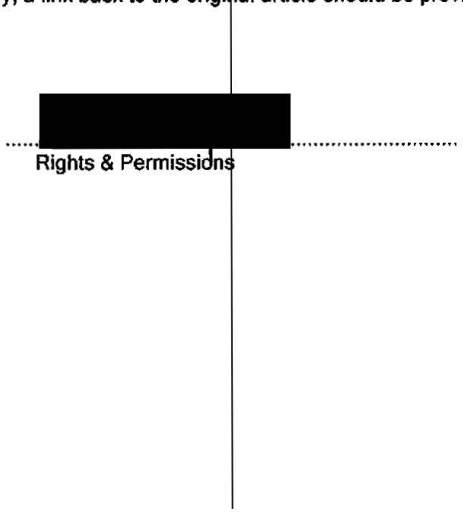


11/24/12

Rightslink Printable License

FIGURE 1.7

ELSEVIER LICENSE

TERMS AND CONDITIONS

Nov 24, 2012

This is a License Agreement between Katherine L Snyder ("You") and Elsevier ("Elsevier") provided by Copyright Clearance Center ("CCC"). The license consists of your order details, the terms and conditions provided by Elsevier, and the payment terms and conditions.

\begin{tabular}{|c|c|}
\hline Supplier & $\begin{array}{l}\text { Elsevier Limited } \\
\text { The Boulevard,Langford Lane } \\
\text { Kidlington, Oxford, OX5 1GB,UK }\end{array}$ \\
\hline $\begin{array}{l}\text { Registered Company } \\
\text { Number }\end{array}$ & 1982084 \\
\hline Customer name & Katherine L Snyder 46024 \\
\hline \multirow[t]{2}{*}{ Customer address } & Superior Rd Apt 3B \\
\hline & Houghton, MI 49931 \\
\hline License number & 3035460197513 \\
\hline License date & Nov 24, 2012 \\
\hline Licensed content publisher & Elsevier \\
\hline $\begin{array}{l}\text { Licensed content } \\
\text { publication }\end{array}$ & Biomaterials \\
\hline Licensed content title & $\begin{array}{l}\text { A review of the biological response to ionic dissolution products } \\
\text { from bioactive glasses and glass-ceramics }\end{array}$ \\
\hline Licensed content author & Alexander Hoppe,Nusret S. Güldal,Aldo R. Boccaccini \\
\hline Licensed content date & April 2011 \\
\hline $\begin{array}{l}\text { Licensed content volume } \\
\text { number }\end{array}$ & 32 \\
\hline $\begin{array}{l}\text { Licensed content issue } \\
\text { number }\end{array}$ & 11 \\
\hline Number of pages & 18 \\
\hline Start Page & 2757 \\
\hline End Page & 2774 \\
\hline Type of Use & reuse in a thesis/dissertation \\
\hline $\begin{array}{l}\text { Intended publisher of new } \\
\text { work }\end{array}$ & other \\
\hline Portion & figures/tables/illustrations \\
\hline $\begin{array}{l}\text { Number of } \\
\text { figures/tables/illustrations }\end{array}$ & 1 \\
\hline Format & both print and electronic \\
\hline
\end{tabular}

hitps://s 100. copyright.com/AppDispatchServlet 


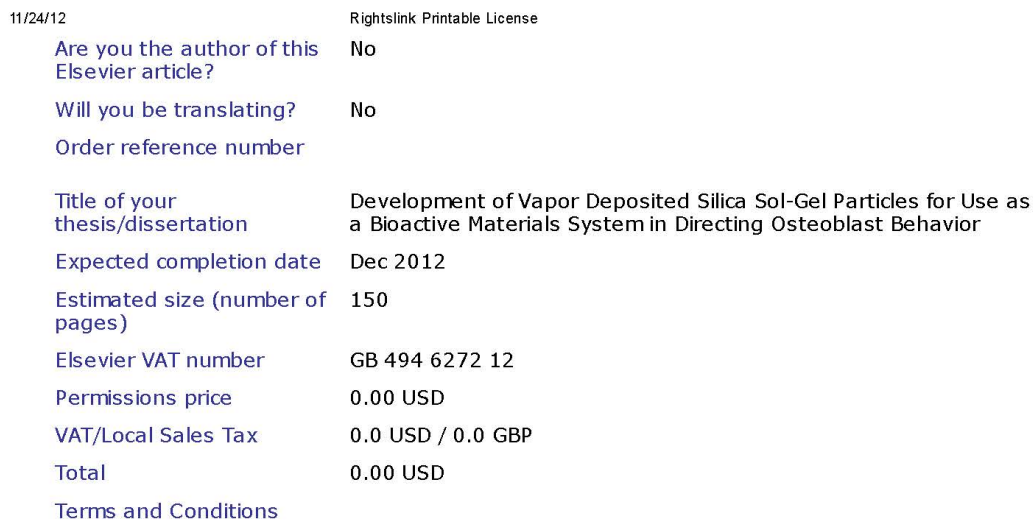

INTRODUCTION

1. The publisher for this copyrighted material is Elsevier. By clicking "accept" in connection with completing this licensing transaction, you agree that the following terms and conditions apply to this transaction (along with the Billing and Payment terms and conditions established by Copyright Clearance Center, Inc. ("CCC"), at the time that you opened your Rightslink account and that are available at any time at http:/myaccount.copyright.com).

\section{GENERAL TERMS}

2. Elsevier hereby grants you permission to reproduce the aforementioned material subject to the terms and conditions indicated.

3. Acknowledgement: If any part of the material to be used (for example, figures) has appeared in our publication with credit or acknowledgement to another source, permission must also be sought from that source. If such permission is not obtained then that material may not be included in your publication/copies. Suitable acknowledgement to the source must be made, either as a footnote or in a reference list at the end of your publication, as follows:

"Reprinted from Publication title, Vol/edition number, Author(s), Title of article / title of chapter, Pages No., Copyright (Year), with permission from Elsevier [OR APPLICABLE SOCIETY COPYRIGHT OWNER]." Also Lancet special credit - "Reprinted from The Lancet, Vol. number, Author(s), Title of article, Pages No., Copyright (Year), with permission from Elsevier."

4. Reproduction of this material is confined to the purpose and/or media for which permission is hereby given.

5. Altering/Modifying Material: Not Permitted. However figures and illustrations may be altered/adapted minimally to serve your work. Any other abbreviations, additions, deletions and/or any other alterations shall be made only with prior written authorization of Elsevier Ltd. (Please contact Elsevier at permissions@elsevier.com) 
11/24/12 Rightslink Printable Lic ense

6. If the permission fee for the requested use of our material is waived in this instance, please be advised that your future requests for Elsevier materials may attract a fee.

7. Reservation of Rights: Publisher reserves all rights not specifically granted in the combination of (i) the license details provided by you and accepted in the course of this licensing transaction, (ii) these terms and conditions and (iii) CCC's Billing and Payment terms and conditions.

8. License Contingent Upon Payment: While you may exercise the rights licensed immediately upon issuance of the license at the end of the licensing process for the transaction, provided that you have disclosed complete and accurate details of your proposed use, no license is fimally effective unless and until full payment is received from you (either by publisher or by $\mathrm{CCC}$ ) as provided in CCC's Billing and Payment terms and conditions. If full payment is not received on a timely basis, then any license preliminarily granted shall be deemed automatically revoked and shall be void as if never granted. Further, in the event that you breach any of these terms and conditions or any of CCC's Billing and Payment terms and conditions, the license is automatically revoked and shall be void as if never granted. Use of materials as described in a revoked license, as well as any use of the materials beyond the scope of an unrevoked license, may constitute copyright infringement and publisher reserves the right to take any and all action to protect its copyright in the materials.

9. Warranties: Publisher makes no representations or warranties with respect to the licensed material.

10. Indemnity: You hereby indemnify and agree to hold harmless publisher and CCC, and their respective officers, directors, employees and agents, from and against any and all claims arising out of your use of the licensed material other than as specifically authorized pursuant to this license.

11. No Transfer of License: This license is personal to you and may not be sublicensed, assigned, or transferred by you to any other person without publisher's written permission.

12. No Amendment Except in Writing: This license may not be amended except in a writing signed by both parties (or, in the case of publisher, by CCC on publisher's behalf).

13. Objection to Contrary Terms: Publisher hereby objects to any terms contained in any purchase order, acknowledgment, check endorsement or other writing prepared by you, which terms are inconsistent with these terms and conditions or CCC's Billing and Payment terms and conditions. These terms and conditions, together with CCC's Billing and Payment terms and conditions (which are incorporated herein), comprise the entire agreement between you and publisher (and $\mathrm{CCC}$ ) concerning this licensing transaction. In the event of any conflict between your obligations established by these terms and conditions and those established by CCC's Billing and Payment terms and conditions, these terms and conditions shall control.

14. Revocation: Elsevier or Copyright Clearance Center may deny the permissions described in this License at their sole discretion, for any reason or no reason, with a full refund payable to you. Notice of such denial will be made using the contact information provided by you. Failure to receive such notice will not alter or invalidate the denial. In no event will Elsevier or Copyright Clearance Center be responsible or liable for any costs, expenses or damage incurred by you as a result of a denial of your permission request, other than a refund of the amount(s) paid by you to 
11/24/12 Rightslink Printable License

Elsevier and/or Copyright Clearance Center for denied permissions.

\section{LIMITED LICENSE}

The following terms and conditions apply only to specific license types:

15. Translation: This permission is granted for non-exclusive world English rights only unless your license was granted for translation rights. If you licensed translation rights you may only translate this content into the languages you requested. A professional translator must perform all translations and reproduce the content word for word preserving the integrity of the article. If this license is to re-use 1 or 2 figures then permission is granted for non-exclusive world rights in all languages.

16. Website: The following terms and conditions apply to electronic reserve and author websites: Electronic reserve: If licensed material is to be posted to website, the web site is to be password-protected and made available only to bona fide students registered on a relevant course if:

This license was made in connection with a course,

This permission is granted for 1 year only. You may obtain a license for future website posting, All content posted to the web site must maintain the copyright information line on the bottom of each image,

A hyper-text must be included to the Homepage of the journal from which you are licensing at

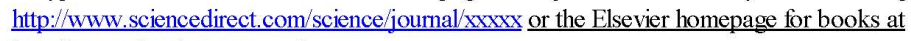
http://www.elsevier.com, and

Central Storage: This license does not include permission for a scanned version of the material to be stored in a central repository such as that provided by Heron/XanEdu.

17. Author website for journals with the following additional clauses:

All content posted to the web site must maintain the copyright information line on the bottom of each image, and the permission granted is limited to the personal version of your paper. You are not allowed to download and post the published electronic version of your article (whether PDF or HTML, proof or final version), nor may you scan the printed edition to create an electronic version. A hyper-text must be included to the Homepage of the journal from which you are licensing at http://www.sciencedirect.com/science/journal/xxxxx . As part of our normal production process, you will receive an e-mail notice when your article appears on Elsevier's online service ScienceDirect (www.sciencedirect.com). That e-mail will include the article's Digital Object Identifier (DOI). This number provides the electronic link to the published article and should be included in the posting of your personal version. We ask that you wait until you receive this e-mail and have the DOI to do any posting.

Central Storage: This license does not include permission for a scanned version of the material to be stored in a central repository such as that provided by Heron/XanEdu.

18. Author website for books with the following additional clauses: Authors are permitted to place a brief summary of their work online only. A hyper-text must be included to the Elsevier homepage at http:/www.elsevier.com . All content 
posted to the web site must maintain the copyright information line on the bottom of each image. You are not allowed to download and post the published electronic version of your chapter, nor may you scan the printed edition to create an electronic version.

Central Storage: This license does not include permission for a scanned version of the material to be stored in a central repository such as that provided by Heron/XanEdu.

19. Website (regular and for author): A hyper-text must be included to the Homepage of the journal from which you are licensing at http://www.sciencedirect.com/science/journal $/ \mathrm{xxxxx}$. or for books to the Elsevier homepage at http//www.elsevier.com

20. Thesis/Dissertation: If your license is for use in a thesis/dissertation your thesis may be submitted to your institution in either print or electronic form. Should your thesis be published commercially, please reapply for permission. These requirements include permission for the Library and Archives of Canada to supply single copies, on demand, of the complete thesis and include permission for UMI to supply single copies, on demand, of the complete thesis. Should your thesis be published commercially, please reapply for permission.

\section{Other Conditions}

$\vee 1.6$

If you would like to pay for this license now, please remit this license along with your payment made payable to "COPYRIGHT CLEARANCE CENTER" otherwise you will be invoiced within 48 hours of the license date. Payment should be in the form of a check or money order referencing your account number and this invoice number RLNK50090350 Once you receive your invoice for this order, you may pay your invoice by credit card. Please follow instructions provided at that time.

Make Payment To:

Copyright Clearance Center

.O. Box 84300

Boston, MA 02284-3006

For suggestions or comments regarding this order, contact RightsLink Customer Support: customercare@copyright.com or +1-877-622-5543 (toll free in the US) or +1-978-6462777.

Gratis licenses (referencing $\$ 0$ in the Total field) are free. Please retain this printable license for your reference. No payment is required. 
Date: $10 / 2 / 12$

Contributor name: Rupak Rajachar, PhD

Contributor address: 1400 Townsend Drive Houghton, MI 49931

Manuscript number (Editorial office only): JBMR-A-12-0367-RI

Re: Manuscript entitled Development of Vapor Deposited Sitica Soi-Gel Particus for Use as a Bioactive Materials System

(the "Contribution")

for publication in Journal of Biomedical Materials Reseanch Part A (the "Journal")

published by Wiley - Blackwel

("Wiley-Blackwell"),

Dear Contributor(s):

Thank you for submitting your Contribution for publication. In order to expedite the editing and publishing process and enable Wiley-Blackwell to dissem Agreement shall be null and void. Publication cannot proceed without a signed copy of this Agreement.

\section{A. COPYRIGHT}

1. The Contributor assigns to Wiley-Blackwell, during the full term of copy-

right and any extensions of renewals, all copyright in and to the Contribution

and all rights therein, including but not limited to the right to publish, reput-

part in electronic and print editions of the Journal and in derivative worts

throughout the world, in all languages and in all media of expression now

known or later developed, and to license or permit thers to do so.

2. Reproduction, posting, transmission or other distribution or use of the final

Contribution in whole or in part in any medum by the Contributor as permitit

ced by this Agreement to Wiley

in form and content as follows: (Titite of Article, Author, Journal Title and

Volume/ssue, Copyright 0 [yearl, copyright owner as specified in the Journal).
Links to the final article on Wiley-Blackwells website are encouraged where

Links to the

B. RETAINED Rights

Notwithstanding the above, the Contributor or, if applicable, the Contributor's
Employer, retains all propietary rights other, than copyright, such as paten Employer, retains all proprietary rights other than copyright, such as patent
rights, in any process, procedure or article of manufacture described in the

C. PERMITTED USES BY CONTRIBUTOR

1. Submitted Version. Wiley-8lackwell licenses back the following rights to
the Contributor in the version of the Contribution as originally submitted for the Contributor in the version of the Contribution as originally submitted for
publication:

a. After publication of the final article, the right to self-archive on the Coninstitutional repositong of archive. This right extends to both intranets and the Internet. The Contributor may not update the submission version of
replace it with the published Contribution. The version posted must contain a legend as follows: This is the pre-peer reviewed version of the tollowing
article: fUUL CIIT, which has been published in final form at llink to fina articice
article!

b. The right to transmit, print and share copies with colleagues.

2. Accepted Version. Re-use of the accepted and peer-reviewed (but not final) version of the Contribution shall be by separate agreement with Wiley-
Blackwell. Wiley-Blackwell has agreements with certain funding agencies Blackwell. Wiley-Blackwell has agreements with certain funding agencies
governing reuse of this version. The details of those relationships, and other offerings allowing open web use, are set forth at the following website. http://mmw.wiley.com/goffunderstatement. NIH grantees should check the box at the bottom of this document
3. Final Published Version. Wiley-Blackwell hereby licenses back to the Contributor the following rights with respect to the final published version of

a. Copies for colleagues. The personal right of the Contributor only to send colleagues upon their specific request provided no fee is charged. and further-provided that there is no systematic distribution of the Contribution, e.g. posting on a listseve, website or automated delivery. b. Re-use in other publications. The right to re-use the final Contribution or

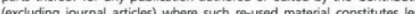
than half of the total material in such publication. In such case, any modifi-
the cations should be accurately noted.

c. Teaching duties. The right to include the Contribution in teaching or training duties at the Contributors institutionplace of employment including in course packs, e-reserves, presentation at professional conferences,
in h-house training, or distance learning. The Contribution may not be used in seminars outside of normal teaching obligations (e.g. commercial semnars). Electronic posting of the final pubished version in connection with permitted subiect to the implementation of reasonable apcoss controd mechanisms, such as user name and password. Posting the final published version on the open Internet is not permitted.

d. Oral presentations. The right to make oral presentations based on the Contribution.

4. Article Abstracts, Figures, Tables, Data Sets, Artwork and Selected xt (up to 250 words.

a. Contributors may re-use unmodified abstracts for any non-commercial does not requie inking back to the finas published versions

b. Contributors may re-use figures, tables, data sets, artwork, and selected text up to 250 words
conditions are me:

(i) Full and accurate credit must be given to the Contribution.
(ii) Modifications to the figures, tables and data must be noted. Otherwise, no changes may be made. financial consideration to the Contributor (iv) Nothing herein shall permit dual publication in violation of journal
ethical practices. 
D. CONTRIBUTIONS OWNED BY EMPLOYER

1. If the Contribution was written by the Contributor in the course of the
Contributor's employment (as a "work-made-for-hire" in the course of

Contributor's employment (as a "work-made-for-hire" in the course
employment), the Contribution is owned by the company/employer which

must sign this Agreement (in addition to the Contributor's signature) in the

space provided betow. In such case, the company/employer hereby assigns to

Wiley-Blackwell, during the full term of copyright, all copyright in and to the

Contribution for the
paragraph $A$ above.

2. In addition to the rights specified as retained in paragraph $B$ above and the rights granted back to the Contributor pursuant to paragraph C above, Wile

blackwell hereby grants back, without charge, lo such company/employer,

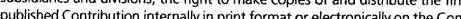
pany's internal network. Copies so used may not be resold or distributed externally However the company/employer may include information and text from the Contribution as part of an information package included with software or postingof the fini pulor sale or license or included in patent applications. website may only be donewith Wity of any applicable fee(s). Also, upon payment of Wiley-Blackwell's reprint fee, the institution may distribute printcopies of the published Contribution externally.

E. GOVERNMENT CONTRACTS

In the case of a Contribution prepared under U.S. Government contract or grant, he.S. Government may reproduce, without charge, all or portions of ment purposes only, if the U.S. Government contract or grant so requires. (U.S.

F. COPYRIGHT NOTICE

The Contributor and the company/employer agree that any and all copies of he final published version of the Contribution or any part thereof distributed or posted by them in print or electronic format as permitted herein will include the notice of copyright as stipulated in the Journal and a full citation to the

\section{G. CONTRIBUTOR'S REPRESENTATIONS}

The Contributor represents that the Contribution is the Contributors original work, all individuals identifified as Contributors actually contributed to the Conwas prepared jointly, the Contributor agrees to inform the co-Contributors of the terms of this Agreement and to obtain their signature to this Agreement or their written permission to sign on their behalf. The Contribution is submitted righted works owned by third parties are included, the Contributs from copywritten permission from the copyright owners for all uses as set forth in WileyBlackwell's permissions form or in the Journal's Instructions for Contributors, and show credit to the sources in the Contribution.) The Contributor also warrants that the Contribution contains no libelous or unlawful statements,

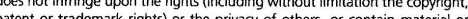
instructions that might cause harm or injur.

\section{CHECK ONE BOX: \\ X/ Contributor-owned work ATTACH ADDITIONAL SIGNATUR}

Contributor's signatur Date $10 / 2 / 12$ Type or print name and title Katherine Snyder, PhD Student Co-contributor's signature Date $10 / 2 / 2$

Type or print nameand title Hallie Holmes, Undergrasuate Stodent

\begin{tabular}{|c|c|c|}
\hline $\begin{array}{l}\square \text { Company/nstitution-owned work } \\
\text { (made-for-hire in the } \\
\text { course of employment) }\end{array}$ & Company or Institution (Employer-for-Hire) & Date \\
\hline & Authorized signature of Employer & Date \\
\hline$\square$ U.S. Government work & 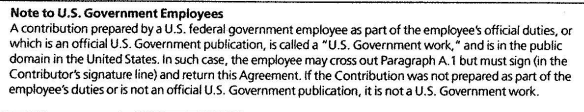 & \\
\hline $\begin{array}{l}\text { DU.K. Government work } \\
\text { (Crown Copyright) }\end{array}$ & 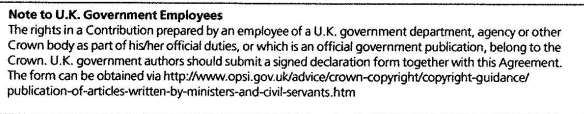 & \\
\hline$\square$ Other Government work & $\begin{array}{l}\text { Note to Non-U.S. Non-U.K. Government Employees } \\
\text { If your statsus a g govermment employee legally prevents you from signing this Agreement, please contact } \\
\text { the editorial office. }\end{array}$ & \\
\hline$\square$ NiH Grantees & 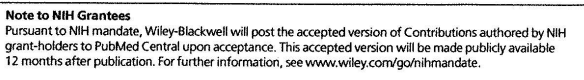 & \\
\hline
\end{tabular}


D. CONTRIBUTIONS OWNED BY EMPLOYER

1. If the Contribution was written by the Contributor in the course of the Contributor's employment (as a "work-made-for-hire" in the course of employment), the Contribution is owned by the company/employer which
must sign this Agreement (in addition to the Contributor's signature) in the must sign this Agreement (in addition to the Contributor's signature) in the wiley-Blackwell, during the full term of compright alloyer hereby assigns Contribution for the full term of copyright throughout the world as specified paragraph A above.

2. In addition to the rights specified as retained in paragraph $B$ above and the rights granted back to the Contributor pursuant to paragraph C above, Wile Blackwell hereby grants back, without charge, to such company/employer, it subsidiaries and divisions, the right to make copies of and distribute the fina

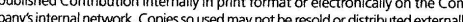
However the company/employer may include information and text from the Contribution as part of an information package included with software or other products offered for sale or license or included in patent applications. posting of the final published Contribution by the institution on a public access ef any applicalye fore Also, up the institution may distribute printcopies of the published Contribution externally

E. GOVERNMENT CONTRACTS

In the case of a Contribution prepared under U.S. Government contract or grant, the U.S. Government may reproduce, without charge, all or portions of ment purposes only, if the U.S. Government contract or grant so requires. (U.S.S Government, U.K. Government, and other government employees: see notes at end

\section{F. COPYRIGHT NOTICE}

The Contributor and the company/employer agree that any and all copies of the final published version of the Contribution or any part thereof distributed the notice of copyright as stipuated in the Journal and a full citation to the Journal as published by Wiley-Blackwell.

\section{G. CONTRIBUTOR'S REPRESENTATIONS}

The Contributor represents that the Contribution is the Contributor's original work, all individuals identified as Contributors actually contributed to the Conwas pren and ind the terms of this Agreement and to obtain their signature to this Agreement or their written permission to sign on their behalf. The Contribution is submitted only to this Journal and has not been published before. (If excerpts from copyrighted works owned by third parties are included, the Contributor will obtain written permission from the copyright owners for all uses as set forth in Wileyand show credit to the sources in the Contribution.) The Contributor also warrants that the Contribution contains no libelous or unlawful statements, does not infringe upon the rights (including without limitation the copyright. patent or trademark rights) or the privacy

\section{CHECK ONE BOX: \\ Contributor-owned work ATTACH ADDITIONAL SIGMATURE
PAGES AS NECESSARY \\ Contributor's signatur Date $10 \cdot 2 \cdot 12$ \\ Type or print name and title Michael ven Wagner Lab Technicion \\ Co-contributor's signature $\quad$ Date $10-2-12$ \\ Type or print name and title Natalle Hart man Undergraduotr Student

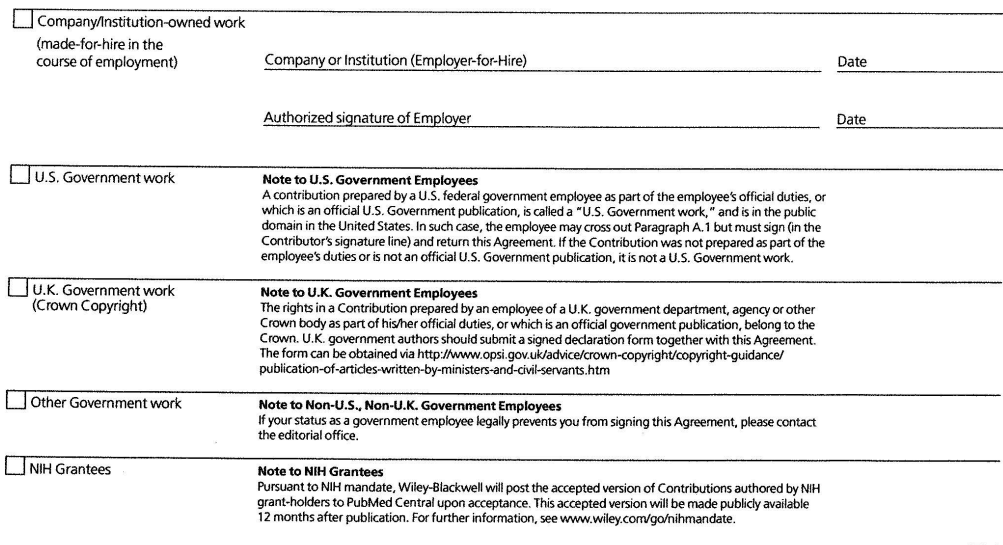


D. CONTRIBUTIONS OWNED BY EMPLOYER

1. If the Contribution was witten by the Contributor in the course of the
Contributor's employment (as a "work-made-for-hire" in the course of employment?, the Wiley-Blackwell, during the full term of copyright, all copyright in and to the Contribution for the full term of copyright throughout the world as specified in paragraph A above.

2. In addition to the rights specified as retained in paragraph $B$ above and the rights granted back to the Contributor pursuant to paragraph $C$ above, Wile Blackwell hereby grants back, whout charge, to such company/employer, published Contribution internally in print format or electronically on the Con pany's internal network. Copies so used may not be resold or distributed externaly However the company/employer may include information and text from the Contribution as part of an information package included with software or Posting oduct of thered for sale or ikense or incladed in patent applications. website may onlybe done with Wiley-Blackwell's written pernission and acters of any applicable fee(s). Also, upon payment of Wiley-Blackwell's reprint fee, the institution may distribute print copies of the published Contribution externally.

E. GOVERNMENT CONTRACTS In the case of a Contribution prepared under U.S. Government contract or
grant, the U.S. Government may reproduce, without charge, all or portions of ment purposes only, if the U.S. Government contract or grant so requires. (U.S.
Government, U.K. Government, and other government employees: see notes

\section{F. COPYRIGHT NOTICE}

The Contributor and the company/employer agree that any and all copies of 作 or posted by them in print the notice of copyright as stipulated in the Journal and a full citation to the

\section{G. CONTRIBUTOR'S REPRESENTATIONS}

The Contributor represents that the Contribution is the Contributor's origina tribution, and all individuals who contributed are included if the Contribution was prepared jointiy, the Contributor agrees to inform the co-Contributors of the terms of this Agreement and to obtain their signature to this Agreement or heir written permission to sign on their behalf. The Contribution is submitted ighted works owned by third partien published before. (If excerpts from copywritten permission from the copyright owners for all uses as set forth in Wileyllackwell's permissions form or in the Journal's Instructions for Contributors, and show credit to the sources in the Contribution.) The Contributor also warrants that the Contribution contains no libelous or unlawful statements, patent or trademark rights) or the privacy of others, or contan mapyright, instructions that might cause harm or injun.

CHECK ONE BOX:

邓 Contributor-owned work ATTACH ADDITIONAL SIG MATURE
PAGES AS NECESSARY Date $10 / 2 / 2012$ Typeor print name and titie RUpak Rajachar, AssISZIN PloFEsSon

Co-contributor's signature Type or print name and title

\begin{tabular}{|c|c|c|}
\hline \multirow[t]{2}{*}{$\begin{array}{l}\square \text { Company/nstitution-owned work } \\
\text { (made-for-hire in the } \\
\text { course of employment) }\end{array}$} & Company or Institution (Employer-for-Hire) & Date \\
\hline & Authorized signature of Employer & Date \\
\hline$\square$ U.S. Government work & 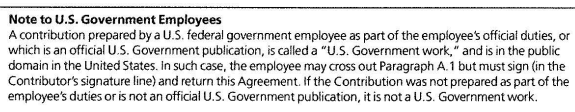 & \\
\hline $\begin{array}{l}\text { D.K. Government work } \\
\text { (Crown Copyright) }\end{array}$ & 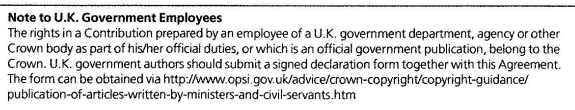 & \\
\hline$\square$ Other Government work & $\begin{array}{l}\text { Note to Non-U.S.S. Non-U.K. Government Employees } \\
\text { If your status as a gover-mment employee legally prevents you from signing this Agreement, please contact } \\
\text { the editorial office. }\end{array}$ & \\
\hline$\square$ NiH Grantees & 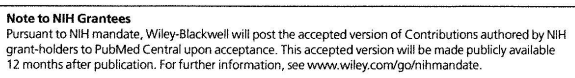 & \\
\hline
\end{tabular}


FIGURE 4.1

This is a License Agreement between Katherine L Snyder ("You") and Elsevier ("Elsevier") provided by Copyright Clearance Center ("CCC"). The license consists of your order details, the terms and conditions provided by Elsevier, and the payment terms and conditions.

\author{
All payments must be made in full to CCC. For payment instructions, please see \\ information listed at the bottom of this form. \\ Supplier \\ Elsevier Limited \\ The Boulevard, Langford Lane \\ Kidlington, Oxford, $0 \times 5$ 1GB, UK \\ Registered Company $\quad 1982084$ \\ Numbe \\ Katherine L Snyder \\ $\begin{array}{ll}\text { Customer name } & \text { Katherine L Snyder } \\ \text { Customer address } & \text { 46024 Superior Rd Apt }\end{array}$ \\ Houghton, MI 49931 \\ License number $\quad 3038221472065$ \\ License date Nov 29, 2012 \\ Licensed content publisher Elsevier \\ Licensed content Biomaterials \\ publication \\ Licensed content title \\ The effects of combined micron-/submicron-scale surface \\ roughness and nanoscale features on cell proliferation and \\ differentiation \\ Licensed content author Rolando A. Gittens, Taylor McLachlan, Rene Olivares-Navarrete, Ye \\ Cai,Simon Berner, Rina Tannenbaum,Zvi Schwartz,Kenneth H. \\ Sandhage,Barbara D. Boyan \\ Licensed content date May 2011 \\ Licensed content volume 32 \\ number \\ Licensed content issue $\quad 13$ \\ number \\ Number of pages 9 \\ Start Page 3395

End Page 3403 \\ Type of Use reuse in a thesis/dissertation \\ Intended publisher of new other \\ work \\ Portion figures/tables/illustrations \\ Number of
}

hitps://s100.copyright.com/AppDispatchServlet 


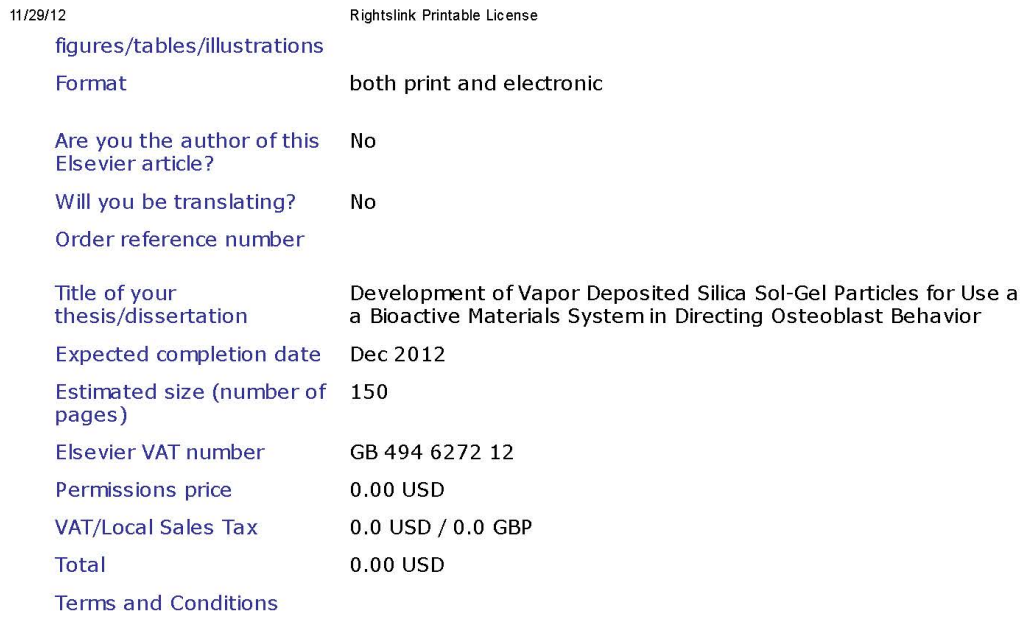

\section{INTRODUCTION}

1. The publisher for this copyrighted material is Elsevier. By clicking "accept" in connection with completing this licensing transaction, you agree that the following terms and conditions apply to this transaction (along with the Billing and Payment terms and conditions established by Copyright Clearance Center, Inc. ("CCC"), at the time that you opened your Rightslink account and that are available at any time at http:/mvaccount.copvright.com)

\section{GENERAL TERMS}

2. Elsevier hereby grants you permission to reproduce the aforementioned material subject to the terms and conditions indicated.

3. Acknowledgement: If any part of the material to be used (for example, figures) has appeared in our publication with credit or acknowledgement to another source, permission must also be sought from that source. If such permission is not obtained then that material may not be included in your publication/copies. Suitable acknowledgement to the source must be made, either as a footnote or in a reference list at the end of your publication, as follows:

"Reprinted from Publication title, Vol /edition number, Author(s), Title of article / title of chapter, Pages No., Copyright (Year), with permission from Elsevier [OR APPLICABLE SOCIETY COPYRIGHT OWNER]." Also Lancet special credit - "Reprinted from The Lancet, Vol. number, Author(s), Title of article, Pages No., Copyright (Year), with permission from Elsevier."

4. Reproduction of this material is confined to the purpose and/or media for which permission is hereby given.

5. Altering/Modifying Material: Not Permitted. However figures and illustrations may be altered/adapted minimally to serve your work. Any other abbreviations, additions, deletions and/or 
11/29/12 Rightslink Printable License

any other alterations shall be made only with prior written authorization of Elsevier Ltd. (Please contact Elsevier at permissions@elsevier.com)

6. If the permission fee for the requested use of our material is waived in this instance, please be advised that your future requests for Elsevier materials may attract a fee.

7. Reservation of Rights: Publisher reserves all rights not specifically granted in the combination of (i) the license details provided by you and accepted in the course of this licensing transaction, (ii) these terms and conditions and (iii) CCC's Billing and Payment terms and conditions.

8. License Contingent Upon Payment: While you may exercise the rights licensed immediately upon issuance of the license at the end of the licensing process for the transaction, provided that you have disclosed complete and accurate details of your proposed use, no license is finally effective unless and until full payment is received from you (either by publisher or by $\mathrm{CCC}$ ) as provided in $\mathrm{CCC}^{\prime} \mathrm{s}$ Billing and Payment terms and conditions. If full payment is not received on a timely basis, then any license preliminarily granted shall be deemed automatically revoked and shall be void as if never granted. Further, in the event that you breach any of these terms and conditions or any of CCC's Billing and Payment terms and conditions, the license is automatically revoked and shall be void as if never granted. Use of materials as described in a revoked license, as well as any use of the materials beyond the scope of an unrevoked license, may constitute copyright infringement and publisher reserves the right to take any and all action to protect its copyright in the materials.

9. Warranties: Publisher makes no representations or warranties with respect to the licensed material.

10. Indemnity: You hereby indemnify and agree to hold harmless publisher and $\mathrm{CCC}$, and their respective officers, directors, employees and agents, from and against any and all claims arising out of your use of the licensed material other than as specifically authorized pursuant to this license.

11. No Transfer of License: This license is personal to you and may not be sublicensed, assigned, or transferred by you to any other person without publisher's written permission.

12. No Amendment Except in Writing: This license may not be amended except in a writing signed by both parties (or, in the case of publisher, by CCC on publisher's behalf).

13. Objection to Contrary Terms: Publisher hereby objects to any terms contained in any purchase order, acknowledgment, check endorsement or other writing prepared by you, which terms are inconsistent with these terms and conditions or CCC's Billing and Payment terms and conditions. These terms and conditions, together with CCC's Billing and Payment terms and conditions (which are incorporated herein), comprise the entire agreement between you and publisher (and CCC) concerning this licensing transaction. In the event of any conflict between your obligations established by these terms and conditions and those established by CCC's Billing and Payment terms and conditions, these terms and conditions shall control.

14. Revocation: Elsevier or Copyright Clearance Center may deny the permissions described in this License at their sole discretion, for any reason or no reason, with a full refund payable to you. Notice of such denial will be made using the contact information provided by you. Failure to 
$11 / 29 / 12$

receive such notice will not alter or invalidate the denial. In no event will Elsevier or Copyright Clearance Center be responsible or liable for any costs, expenses or damage incurred by you as a result of a denial of your permission request, other than a refiund of the amount(s) paid by you to Elsevier and/or Copyright Clearance Center for denied permissions.

\section{LIMITED LICENSE}

The following terms and conditions apply only to specific license types:

15. Translation: This permission is granted for non-exclusive world English rights only unless your license was granted for translation rights. If you licensed translation rights you may only translate this content into the languages you requested. A professional translator must perform all translations and reproduce the content word for word preserving the integrity of the article. If this license is to re-use 1 or 2 figures then permission is granted for non-exclusive world rights in all languages.

16. Website: The following terms and conditions apply to electronic reserve and author websites: Electronic reserve: If licensed material is to be posted to website, the web site is to be password-protected and made available only to bona fide students registered on a relevant course if:

This license was made in connection with a course,

This permission is granted for 1 year only. You may obtain a license for future website posting, All content posted to the web site must maintain the copyright information line on the bottom of each image,

A hyper-text must be included to the Homepage of the joumal from which you are licensing at http:/www.sciencedirect.com/science/joumal/xxxxx or the Elsevier homepage for books at

http://www.elsevier.com , and

Central Storage: This license does not inchude permission for a scanned version of the material to be stored in a central repository such as that provided by Heron/XanEdu.

17. Author website for journals with the following additional clauses:

All content posted to the web site must maintain the copyright information line on the bottom of each image, and the permission granted is limited to the personal version of your paper. You are not allowed to download and post the published electronic version of your article (whether PDF or HTML, proof or final version), nor may you scan the printed edition to create an electronic version. A hyper-text must be included to the Homepage of the journal from which you are licensing at http://www.sciencedirect.com/science/joumal/xxxxx . As part of our normal production process, you will receive an e-mail notice when your article appears on Elsevier's online service ScienceDirect (www.sciencedirect.com). That e-mail will inchude the article's Digital Object Identifier (DOI). This number provides the electronic link to the published article and should be included in the posting of your personal version. We ask that you wait until you receive this e-mail and have the DOI to do any posting

Central Storage: This license does not include permission for a scanned version of the material to be stored in a central repository such as that provided by Heron/XanEdu. 
18. Author website for books with the following additional clauses: Authors are permitted to place a brief summary of their work online only.

A hyper-text must be included to the Elsevier homepage at http//www.elsevier.com . All content posted to the web site must maintain the copyright information line on the bottom of each image. You are not allowed to download and post the published electronic version of your chapter, nor may you scan the printed edition to create an electronic version.

Central Storage: This license does not inchude permission for a scanned version of the material to be stored in a central repository such as that provided by Heron/XanEdu.

19. Website (regular and for author): A hyper-text must be included to the Homepage of the journal from which you are licensing at http//www sciencedirect.com/science/joumal/xxxxx or for books to the Elsevier homepage at http://www.elsevier.com

20. Thesis/Dissertation: If your license is for use in a thesis/dissertation your thesis may be submitted to your institution in either print or electronic form. Should your thesis be published commercially, please reapply for permission. These requirements include permission for the Library and Archives of Canada to supply single copies, on demand, of the complete thesis and include permission for UMI to supply single copies, on demand, of the complete thesis. Should your thesis be published commercially, please reapply for permission.

\section{Other Conditions:}

v1.6

If you would like to pay for this license now, please remit this license along with your payment made payable to "COPYRIGHT CLEARANCE CENTER" otherwise you will be invoiced within 48 hours of the license date. Payment should be in the form of a check or money order referencing your account number and this invoice number RLNK500907325. Once you recer this order, you may pay your invoice by credit card. Please follow instructions provided at that time.

Make Payment To:

Copyright Clearance Cente

Dept 001

P.o. Box 843006

Boston, MA 02284-3006

For suggestions or comments regarding this order, contact RightsLink Customer Support: customercare@copyright.com or +1-877-622-5543 (toll free in the US) or +1-978-6462777.

Gratis licenses (referencing $\$ 0$ in the Total field) are free. Please retain this printable license for your reference. No payment is required. 
$11 / 29 / 12$ FIGURE 4.6 $\quad$ ELSEVIER LICENSE

Nov 29, 2012

This is a License Agreement between Katherine L Snyder ("You") and Elsevier ("Elsevier") provided by Copyright Clearance Center ("CCC"). The license consists of your order details, the terms and conditions provided by Elsevier, and the payment terms and conditions.

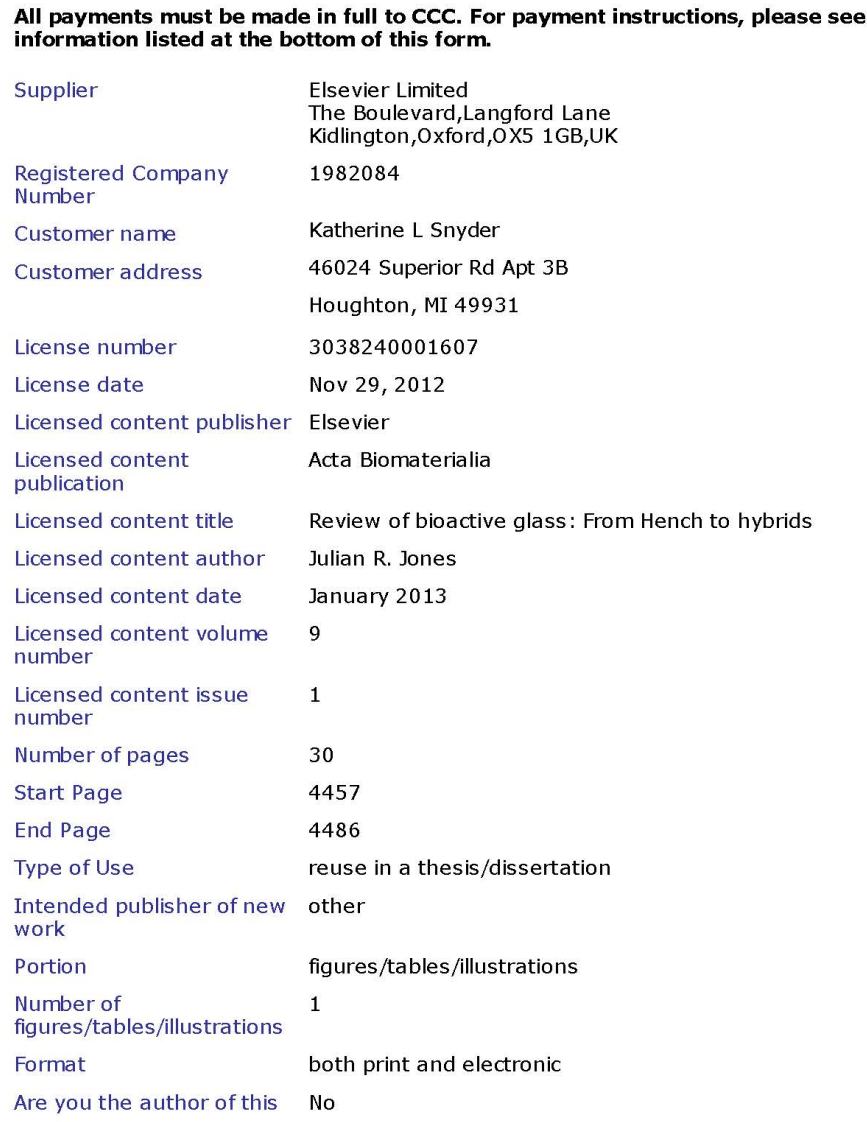




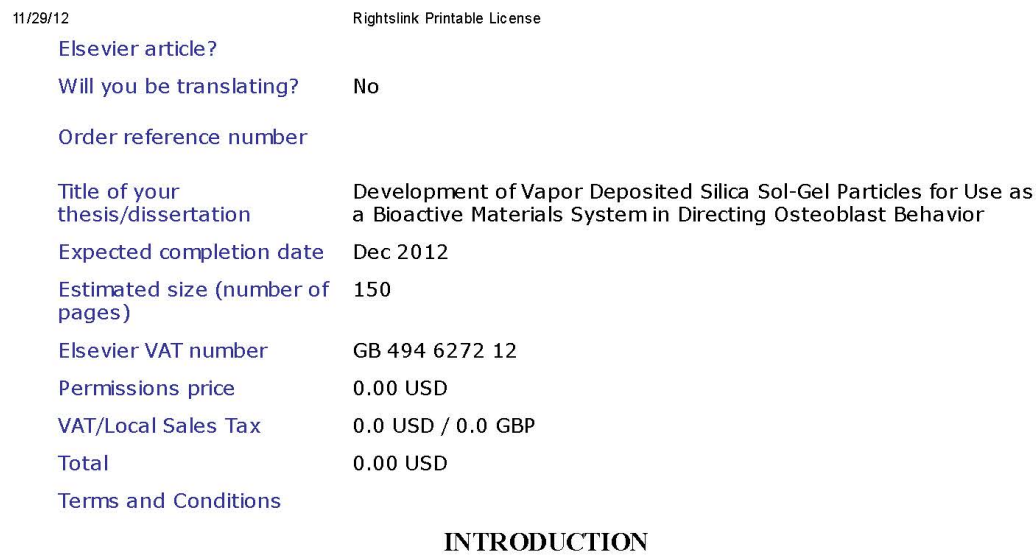

\section{INTRODUCTION}

1. The publisher for this copyrighted material is Elsevier. By clicking "accept" in connection with completing this licensing transaction, you agree that the following terms and conditions apply to this transaction (along with the Billing and Payment terms and conditions established by Copyright Clearance Center, Inc. ("CCC"), at the time that you opened your Rightslink account and that are available at any time at $\underline{\mathrm{htp}} \mathrm{p} / \mathrm{mvaccount.copyright.com})$.

\section{GENERAL TERMS}

2. Elsevier hereby grants you permission to reproduce the aforementioned material subject to the terms and conditions indicated.

3. Acknowledgement: If any part of the material to be used (for example, figures) has appeared in our publication with credit or acknowledgement to another source, permission must also be sought from that source. If such permission is not obtained then that material may not be included in your publication/copies. Suitable acknowledgement to the source must be made, either as a footnote or in a reference list at the end of your publication, as follows:

"Reprinted from Publication title, Vol /edition number, Author(s), Title of article / title of chapter, Pages No., Copyright (Year), with permission from Elsevier [OR APPLICABLE SOCIETY COPYRIGHT OWNER]." Also Lancet special credit - "Reprinted from The Lancet, Vol. number, Author(s), Title of article, Pages No., Copyright (Year), with permission from Elsevier."

4. Reproduction of this material is confined to the purpose and/or media for which permission is hereby given.

5. Altering/Modifying Material: Not Permitted. However figures and illustrations may be altered/adapted minimally to serve your work. Any other abbreviations, additions, deletions and/or any other alterations shall be made only with prior written authorization of Elsevier Ltd. (Please contact Elsevier at permissions(a) elsevier.com) 
11/29/12 Rightslink Printable Lic ense

6. If the permission fee for the requested use of our material is waived in this instance, please be advised that your future requests for Elsevier materials may attract a fee.

7. Reservation of Rights: Publisher reserves all rights not specifically granted in the combination of (i) the license details provided by you and accepted in the course of this licensing transaction, (ii) these terms and conditions and (iii) CCC's Billing and Payment terms and conditions.

8. License Contingent Upon Payment: While you may exercise the rights licensed immediately upon issuance of the license at the end of the licensing process for the transaction, provided that you have disclosed complete and accurate details of your proposed use, no license is finally effective unless and until full payment is received from you (either by publisher or by $\mathrm{CCC}$ ) as provided in $\mathrm{CCC}^{\prime} \mathrm{s}$ Billing and Payment terms and conditions. If full payment is not received on a timely basis, then any license preliminarily granted shall be deemed automatically revoked and shall be void as if never granted. Further, in the event that you breach any of these terms and conditions or any of CCC's Billing and Payment terms and conditions, the license is automatically revoked and shall be void as if never granted. Use of materials as described in a revoked license, as well as any use of the materials beyond the scope of an unrevoked license, may constitute copyright infringement and publisher reserves the right to take any and all action to protect its copyright in the materials.

9. Warranties: Publisher makes no representations or warranties with respect to the licensed material.

10. Indemnity: You hereby indemnify and agree to hold harmless publisher and $\mathrm{CCC}$, and their respective officers, directors, employees and agents, from and against any and all claims arising out of your use of the licensed material other than as specifically authorized pursuant to this license.

11. No Transfer of License: This license is personal to you and may not be sublicensed, assigned, or transferred by you to any other person without publisher's written permission.

12. No Amendment Except in Writing: This license may not be amended except in a writing signed by both parties (or, in the case of publisher, by CCC on publisher's behalf).

13. Objection to Contrary Terms: Publisher hereby objects to any terms contained in any purchase order, acknowledgment, check endorsement or other writing prepared by you, which terms are inconsistent with these terms and conditions or CCC's Billing and Payment terms and conditions These terms and conditions, together with CCC's Billing and Payment terms and conditions (which are incorporated herein), comprise the entire agreement between you and publisher (and $\mathrm{CCC}$ ) concerning this licensing transaction. In the event of any conflict between your obligations established by these terms and conditions and those established by CCC's Billing and Payment terms and conditions, these terms and conditions shall control.

14. Revocation: Elsevier or Copyright Clearance Center may deny the permissions described in this License at their sole discretion, for any reason or no reason, with a full refund payable to you. Notice of such denial will be made using the contact information provided by you. Failure to receive such notice will not alter or invalidate the denial. In no event will Elsevier or Copyright Clearance Center be responsible or liable for any costs, expenses or damage incurred by you as a result of a denial of your permission request, other than a refund of the amount(s) paid by you to

https://s 100 . copyright.com/AppDispatchServlet 
Elsevier and/or Copyright Clearance Center for denied permissions.

\section{LIMITED LICENSE}

The following terms and conditions apply only to specific license types:

15. Translation: This permission is granted for non-exclusive world English rights only unless your license was granted for translation rights. If you licensed translation rights you may only translate this content into the languages you requested. A professional translator must perform all translations and reproduce the content word for word preserving the integrity of the article. If this license is to re-use 1 or 2 figures then permission is granted for non-exclusive world rights in all languages.

16. Website: The following terms and conditions apply to electronic reserve and author websites: Electronic reserve: If licensed material is to be posted to website, the web site is to be password-protected and made available only to bona fide students registered on a relevant course if:

This license was made in connection with a course,

This permission is granted for 1 year only. You may obtain a license for future website posting, All content posted to the web site must maintain the copyright information line on the bottom of each image,

A hyper-text must be included to the Homepage of the journal from which you are licensing at http://www.sciencedirect.com/science/joumal/xxxxx or the Elsevier homepage for books at http://www.elsevier.com, and

Central Storage: This license does not include permission for a scanned version of the material to be stored in a central repository such as that provided by Heron/XanEdu.

17. Author website for journals with the following additional clauses:

All content posted to the web site must maintain the copyright information line on the bottom of each image, and the permission granted is limited to the personal version of your paper. You are not allowed to download and post the published electronic version of your article (whether PDF or HTML, proof or final version), nor may you scan the printed edition to create an electronic version. A hyper-text must be included to the Homepage of the journal from which you are licensing at http:/www.sciencedirect.com/science/journal/xxxxx . As part of our normal production process, you will receive an e-mail notice when your article appears on Elsevier's online service ScienceDirect (www.sciencedirect.com). That e-mail will include the article's Digital Object Identifier (DOI). This number provides the electronic link to the published article and should be included in the posting of your personal version. We ask that you wait until you receive this e-mail and have the DOI to do any posting.

Central Storage: This license does not include permission for a scanned version of the material to be stored in a central repository such as that provided by Heron/XanEdu.

18. Author website for books with the following additional clauses: Authors are permitted to place a brief summary of their work online only.

A hyper-text must be included to the Elsevier homepage at http://www.elsevier.com . All content 
posted to the web site must maintain the copyright information line on the bottom of each image. You are not allowed to download and post the published electronic version of your chapter, nor may you scan the printed edition to create an electronic version.

Central Storage: This license does not include permission for a scanned version of the material to be stored in a central repository such as that provided by Heron/XanEdu.

19. Website (regular and for author): A hyper-text must be included to the Homepage of the journal from which you are licensing at http://www.sciencedirect.com $/$ science/joumal $/ \mathrm{xxxxx}$. or for books to the Elsevier homepage at http:/www.elsevier.com

20. Thesis/Dissertation: If your license is for use in a thesis/dissertation your thesis may be submitted to your institution in either print or electronic form. Should your thesis be published commercially, please reapply for permission. These requirements include permission for the Library and Archives of Canada to supply single copies, on demand, of the complete thesis and include permission for UMI to supply single copies, on demand, of the complete thesis. Should your thesis be published commercially, please reapply for permission.

\section{Other Conditions:}

v1.6

If you would like to pay for this license now, please remit this license along with your payment made payable to "COPYRIGHT CLEARANCE CENTER" otherwise you will be invoiced within 48 hours of the license date. Payment should be in the form of a check or money order referencing your account number and this invoice number RLNK500907360. Once you receive your invoice for this order, you may pay your invoice by credit card. Please follow instructions provided at that time.

Make Payment To:

Copyright Clearance Center

Dept 001

P.O. Box 843006

Boston, MA 02284-3006

For suggestions or comments regarding this order, contact RightsLink Customer Support: customercare@copyright.com or +1-877-622-5543 (toll free in the US) or +1-978-6462777.

Gratis licenses (referencing $\$ 0$ in the Total field) are free. Please retain this printable license for your reference. No payment is required. 